\title{
Dietary advice for reducing cardiovascular risk (Review)
}

\author{
Brunner E, Rees K, Ward K, Burke M, Thorogood M
}

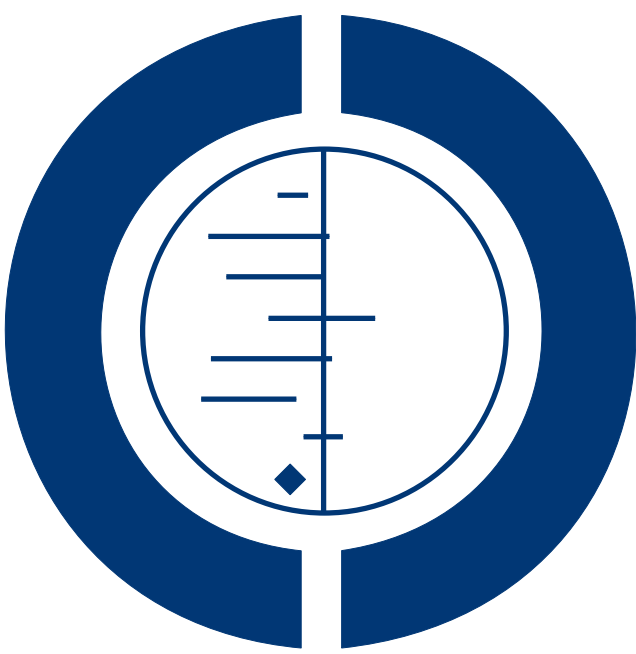

THE COCHRANE COLLABORATION $^{\circledR}$

This is a reprint of a Cochrane review, prepared and maintained by The Cochrane Collaboration and published in The Cochrane Library 2007, Issue 4

http://www.thecochranelibrary.com

\section{WILEY}


TABLE OF CONTENTS

HEADER . . . . . . . . . . . . . . . . . . . . . . . . . . . . . . . . . . . . . . . 1

ABSTRACT . . . . . . . . . . . . . . . . . . . . . . . . . . . . . . . . . . . . . . . . . . . . . . . . 1

PLAIN LANGUAGE SUMMARY . . . . . . . . . . . . . . . . . . . . . . . . . . . . . . . . . . . . . 2

BACKGROUND . . . . . . . . . . . . . . . . . . . . . . . . . . . . . . . . . . . . . . . . . . . .

OBJECTIVES . . . . . . . . . . . . . . . . . . . . . . . . . . . . . . . . . . . . . . . . . . . . . . .

METHODS . . . . . . . . . . . . . . . . . . . . . . . . . . . . . . . . . . . . . .

RESULTS . . . . . . . . . . . . . . . . . . . . . . . . . . . . . . . . . . . . . . . . . . .

DISCUSSION . . . . . . . . . . . . . . . . . . . . . . . . . . . . . . . . . . . . . . . . . . . . . . . . .

AUTHORS' CONCLUSIONS . . . . . . . . . . . . . . . . . . . . . . . . . . . . . . . . 12

ACKNOWLEDGEMENTS . . . . . . . . . . . . . . . . . . . . . . . . . . . . . . . . . . 13

REFERENCES . . . . . . . . . . . . . . . . . . . . . . . . . . . . . . . . . . . . . . 13

CHARACTERISTICS OF STUDIES . . . . . . . . . . . . . . . . . . . . . . . . . . . . . . . . . . . . . . .

DATA AND ANALYSES . . . . . . . . . . . . . . . . . . . . . . . . . . . . . . . . . . . . . . . . . . . . . . $\quad . \quad 51$

Analysis 1.1. Comparison 1 Any dietary intervention versus no intervention, Outcome 1 Systolic blood pressure, change from baseline $(\mathrm{mmHg})$.

Analysis 1.2. Comparison 1 Any dietary intervention versus no intervention, Outcome 2 Diastolic blood pressure, change from baseline $(\mathrm{mmHg})$.

Analysis 1.3. Comparison 1 Any dietary intervention versus no intervention, Outcome 3 Urinary sodium output (mmol/24 hr), change from baseline.

Analysis 1.4. Comparison 1 Any dietary intervention versus no intervention, Outcome 4 Total cholesterol ( $\mathrm{mmol} / \mathrm{l})$, change from baseline.

Analysis 1.5. Comparison 1 Any dietary intervention versus no intervention, Outcome $5 \mathrm{LDL}$ cholesterol (mmol/l), change from baseline.

Analysis 1.6. Comparison 1 Any dietary intervention versus no intervention, Outcome $6 \mathrm{HDL}$ cholesterol (mmol/l), change from baseline.

Analysis 1.7. Comparison 1 Any dietary intervention versus no intervention, Outcome 7 Triglycerides (mmol/l), change from baseline.

Analysis 1.8. Comparison 1 Any dietary intervention versus no intervention, Outcome 8 Plasma alpha-carotene (nanomol/L), change from baseline. . . . . . . . . . . . . . . . . . . . . . . . . . .

Analysis 1.9. Comparison 1 Any dietary intervention versus no intervention, Outcome 9 Plasma $B$-carotene (nanomol/L), change from baseline.

Analysis 1.10. Comparison 1 Any dietary intervention versus no intervention, Outcome 10 Plasma alpha-tocopherol (micromol/L), change from baseline.

Analysis 1.11. Comparison 1 Any dietary intervention versus no intervention, Outcome 11 Plasma gamma-tocopherol (micromol/L), change from baseline.

Analysis 1.12. Comparison 1 Any dietary intervention versus no intervention, Outcome 12 Plasma lycopene (micromol/L), change from baseline. . . . . . . . . . . . . . . . . . . . . . . . . . . . . . . . . . . . . .

Analysis 1.13. Comparison 1 Any dietary intervention versus no intervention, Outcome 13 Plasma lutein (micromol/L), change from baseline. . . . . . . . . . . . . . . . . . . . . . . . . . . . . . . . . . . . . . . .

Analysis 1.14. Comparison 1 Any dietary intervention versus no intervention, Outcome 14 Plasma beta-cryptoxanthin (micromol/L), change from baseline.

Analysis 1.15. Comparison 1 Any dietary intervention versus no intervention, Outcome 15 Plasma total carotenoids (micromol/L), change from baseline.

Analysis 1.16. Comparison 1 Any dietary intervention versus no intervention, Outcome 16 Plasma ascorbic acid (micromol/L), change from baseline. . . . . . . . . . . . . . . . . . . . . . . . . . .

Analysis 1.17. Comparison 1 Any dietary intervention versus no intervention, Outcome 17 Red cell folate (nanomol/L), change from baseline.

Analysis 1.18. Comparison 1 Any dietary intervention versus no intervention, Outcome 18 Total dietary fat (\% Kcal).

Analysis 1.19. Comparison 1 Any dietary intervention versus no intervention, Outcome 19 Dietary saturated fatty acids (\% Kcal).

Dietary advice for reducing cardiovascular risk (Review)

Copyright @ 2009 The Cochrane Collaboration. Published by John Wiley \& Sons, Ltd. 
Analysis 1.20. Comparison 1 Any dietary intervention versus no intervention, Outcome 20 Fruit and vegetable (servings per day), change from baseline.

Analysis 1.21. Comparison 1 Any dietary intervention versus no intervention, Outcome 21 Fruit (servings per day), change from baseline.

Analysis 1.22. Comparison 1 Any dietary intervention versus no intervention, Outcome 22 Vegetable (servings per day), change from baseline. . . . . . . . . . . . . . . . . . . . . . . . . . . . . . . . . . . . . .

Analysis 1.23. Comparison 1 Any dietary intervention versus no intervention, Outcome 23 Dietary fibre (grams per day), change from baseline. . . . . . . . . . . . . . . . . . . . . . . . . . . . . . . . . . . .

Analysis 1.24. Comparison 1 Any dietary intervention versus no intervention, Outcome 24 Dietary intake of ascorbic acid (mg/day), change from baseline.

Analysis 1.25. Comparison 1 Any dietary intervention versus no intervention, Outcome 25 Dietary intake of beta-carotene (mg/day), change from baseline. . . . . . . . . . . . . . . . . . . . . . . . . . . . 76

Analysis 2.1. Comparison 2 Subgroup analyses, Outcome 1 Total cholesterol (gender). . . . . . . . . . . . . . 77

Analysis 2.2. Comparison 2 Subgroup analyses, Outcome 2 Total dietary fat (gender). . . . . . . . . . . . . . . . 78

Analysis 2.3. Comparison 2 Subgroup analyses, Outcome 3 Fruit \& vegetable servings/day (gender). . . . . . . . 80

Analysis 2.4. Comparison 2 Subgroup analyses, Outcome 4 Total cholesterol (risk group). . . . . . . . . . . . . . . 81

Analysis 2.5. Comparison 2 Subgroup analyses, Outcome 5 Total dietary fat (risk group). . . . . . . . . . . . . . $\quad$. 83

Analysis 2.6. Comparison 2 Subgroup analyses, Outcome 6 Fruit \& vegetable servings/day (risk group). . . . . . . 84

Analysis 2.7. Comparison 2 Subgroup analyses, Outcome 7 SBP mmHg (risk group). . . . . . . . . . . . . . . 86

Analysis 2.8. Comparison 2 Subgroup analyses, Outcome 8 DBP mmHg (risk group). . . . . . . . . . . . . . . . 87

Analysis 2.9. Comparison 2 Subgroup analyses, Outcome 9 Total cholesterol (setting). . . . . . . . . . . . . . . . . 88

Analysis 2.10. Comparison 2 Subgroup analyses, Outcome 10 Total dietary fat (setting). . . . . . . . . . . . . . .89

Analysis 2.11. Comparison 2 Subgroup analyses, Outcome 11 Fruit $\&$ vegetable servings/day (setting). . . . . . . $\quad 90$

Analysis 2.12. Comparison 2 Subgroup analyses, Outcome 12 Total cholesterol (intensity). . . . . . . . . . . . 992

Analysis 2.13. Comparison 2 Subgroup analyses, Outcome 13 Total dietary fat (intensity). . . . . . . . . . . . . . 93

Analysis 2.14. Comparison 2 Subgroup analyses, Outcome 14 Fruit \& vegetable servings/day (intensity). $\quad . \quad$. . . 94

Analysis 2.15. Comparison 2 Subgroup analyses, Outcome $15 \mathrm{SBP}$ mmHg (intensity). . . . . . . . . . . . . . . 96

Analysis 2.16. Comparison 2 Subgroup analyses, Outcome 16 DBP mmHg (intensity). . . . . . . . . . . . . . 97

Analysis 2.17. Comparison 2 Subgroup analyses, Outcome 17 Total cholesterol (duration). . . . . . . . . . . . . . 98

Analysis 2.18. Comparison 2 Subgroup analyses, Outcome 18 Total dietary fat (duration). . . . . . . . . . . . . . 99

Analysis 2.19. Comparison 2 Subgroup analyses, Outcome 19 Fruit \& vegetable servings/day (duration). $\quad . \quad$. . $\quad 100$

Analysis 2.20. Comparison 2 Subgroup analyses, Outcome 20 SBP mmHg (duration). . . . . . . . . . . . . . . 102

Analysis 2.21. Comparison 2 Subgroup analyses, Outcome $21 \mathrm{DBP} m m H g$ (duration). . . . . . . . . . . . . . . . 103

ADDITIONAL TABLES . . . . . . . . . . . . . . . . . . . . . . . . . . . . . . . . . . . 103

WHAT'S NEW . . . . . . . . . . . . . . . . . . . . . . . . . . . . . . . . . . . . . 111

HISTORY . . . . . . . . . . . . . . . . . . . . . . . . . . . . . . . . . . . . . . . . . 112

CONTRIBUTIONS OF AUTHORS . . . . . . . . . . . . . . . . . . . . . . . . . . . . . . . . . . 112

DECLARATIONS OF INTEREST . . . . . . . . . . . . . . . . . . . . . . . . . . . . . . . . . . . . . 112

SOURCES OF SUPPORT . . . . . . . . . . . . . . . . . . . . . . . . . . . . . . . . . . . . . . . . . 112

INDEX TERMS . . . . . . . . . . . . . . . . . . . . . . . . . . . . . . . . . . . . 113

Dietary advice for reducing cardiovascular risk (Review) 


\title{
[Intervention Review] \\ Dietary advice for reducing cardiovascular risk
}

\author{
Eric Brunner ${ }^{1}$, Karen Rees ${ }^{2}$, Kirsten Ward ${ }^{3}$, Margaret Burke ${ }^{3}$, Margaret Thorogood ${ }^{4}$ \\ ${ }^{1}$ Department of Epidemiology and Public Health, University College London Medical School, London, UK. ${ }^{2}$ Department of Social \\ Medicine, Universiry of Bristol, Bristol, UK. ${ }^{3}$ Department of Epidemiology \& Population Health, London School of Hygiene \& \\ Tropical Medicine, London, UK. ${ }^{4}$ Public Health and Epidemiology, University of Warwick, Coventry, UK \\ Contact address: Eric Brunner, Department of Epidemiology and Public Health, University College London Medical School, 1-19 \\ Torrington Place, London, WC1E 6BT, UK. e.brunner@ucl.ac.uk.
}

Editorial group: Cochrane Heart Group.

Publication status and date: Edited (no change to conclusions), published in Issue 1, 2009.

Review content assessed as up-to-date: 29 July 2007.

Citation: Brunner E, Rees K, Ward K, Burke M, Thorogood M. Dietary advice for reducing cardiovascular risk. Cochrane Database of Systematic Reviews 2007, Issue 4. Art. No.: CD002128. DOI: 10.1002/14651858.CD002128.pub3.

Copyright (C) 2009 The Cochrane Collaboration. Published by John Wiley \& Sons, Ltd.

\begin{abstract}
A B S T R A C T
Background

Changes in population diet are likely to reduce cardiovascular disease and cancer, but the effect of dietary advice is uncertain.
\end{abstract}

Objectives

To assess the effects of providing dietary advice to achieve sustained dietary changes or improved cardiovascular risk profile among healthy adults.

\section{Search methods}

We searched the Cochrane Central Register of Controlled Trials, DARE and HTA databases on The Cochrane Library (Issue 4 2006), MEDLINE (1966 to December 2000, 2004 to November 2006) and EMBASE (1985 to December 2000, 2005 to November 2006). Additional searches were done on CAB Health (1972 to December 1999), CVRCT registry (2000), CCT (2000) and SIGLE (1980 to 2000). Dissertation abstracts and reference lists of articles were checked and researchers were contacted.

\section{Selection criteria}

Randomised studies with no more than $20 \%$ loss to follow-up, lasting at least 3 months involving healthy adults comparing dietary advice with no advice or minimal advice. Trials involving children, trials to reduce weight or those involving supplementation were excluded.

\section{Data collection and analysis}

Two reviewers independently assessed trial quality and extracted data. Study authors were contacted for additional information.

\section{Main results}

Thirty-eight trials with 46 intervention arms (comparisons) comparing dietary advice with no advice were included in the review. 17,871 participants/clusters were randomised. Twenty-six of the 38 included trials were conducted in the USA. Dietary advice reduced total serum cholesterol by $0.16 \mathrm{mmol} / \mathrm{L}$ (95\% CI 0.06 to 0.25$)$ and LDL cholesterol by $0.18 \mathrm{mmol} / \mathrm{L}$ (95\% CI 0.1 to 0.27 ) after 3-24 months. Mean HDL cholesterol levels and triglyceride levels were unchanged. Dietary advice reduced blood pressure by $2.07 \mathrm{mmHg}$ systolic (95\% CI 0.95 to 3.19$)$ and $1.15 \mathrm{mmHg}$ diastolic (95\% CI 0.48 to 1.85 ) and 24-hour urinary sodium excretion by $44.2 \mathrm{mmol}$ (95\% CI 33.6 to 54.7) after 3-36 months. Three trials reported plasma antioxidants where small increases were seen in lutein and $\beta$ -

Dietary advice for reducing cardiovascular risk (Review)

Copyright $\odot 2009$ The Cochrane Collaboration. Published by John Wiley \& Sons, Ltd. 
cryptoxanthin, but there was heterogeneity in the trial effects. Self-reported dietary intake may be subject to reporting bias, and there was significant heterogeneity in all the following analyses. Compared to no advice, dietary advice increased fruit and vegetable intake by 1.25 servings/day (95\% CI 0.7 to 1.81). Dietary fibre intake increased with advice by $5.99 \mathrm{~g} /$ day (95\% CI 1.12 to 10.86 ), while total dietary fat as a percentage of total energy intake fell by $4.49 \%$ (95\% CI 2.31 to 6.66) with dietary advice and saturated fat intake fell by $2.36 \%$ (95\% CI 1.32 to 3.39$)$.

\section{Authors' conclusions}

Dietary advice appears to be effective in bringing about modest beneficial changes in diet and cardiovascular risk factors over approximately 10 months but longer term effects are not known.

\section{PLAIN LANGUAGE SUMMARY}

\section{Dietary advice for reducing cardiovascular risk}

Diet is an important determinant of chronic disease risk, particularly heart disease. This review assessed the effects of providing dietary advice to healthy adults in order to produce sustained improvements in their diets. Whether dietary improvement would reduce the risk factors associated with heart disease was also examined. We found 38 trials in which healthy adults were randomly assigned to receive dietary advice or no dietary advice. The dietary improvements recommended to the people in the intervention groups centred largely on the reduction of salt and fat intake and an increase in the intake of fruit, vegetables, and fibre. Advice was delivered in a variety of ways, including one-to-one contact, group sessions, and written materials. There were variations in intensity of intervention, ranging from one contact per study participant to 50 hours of counselling over 4 years. The duration of the trials ranged from 3 months to 4 years, with a median follow-up period of 10 months. There was some evidence of greater effectiveness in people told that they were at risk of heart disease or cancer. Modest improvements were shown in cardiovascular risk factors, such as blood pressure and total and LDL-cholesterol levels. In the trials that separated effects by gender, women tended to make larger reductions in fat intake, but there was insufficient evidence to show whether this translated to a larger reduction in total cholesterol levels. The trials did not last long enough to answer the question of whether the beneficial changes in cardiovascular risk factors resulted in a reduced incidence of heart disease, stroke, or heart attack.

\section{B A C K G R O U N D}

\section{Why this review is important}

Public health policy in the UK and elsewhere advocates dietary change as a means to improve population health (DOH 2004). There remains some uncertainty about whether dietary advice given to healthy individuals is effective in achieving change (FHSG 1994; Hooper 2004a; Hooper 2004b; Kelly 2004; Ramsay 1991). In this review we aim to quantify the impact of dietary advice given to healthy free living adults and to identify factors that influence the effectiveness of dietary advice. We have excluded weight reduction trials because although obesity is a risk factor for cardiovascular disease and a major public health problem, other systematic reviews which address obesity are registered with the Cochrane Heart Group (Campbell 2002; Campbell 2003; Pirozzo 2002) and other health technology research organisations (Avenell 2004). We have also excluded trials involving supplementation, free foods or drinks, or financial inducements, because we are interested in the effects of advice rather than other interventions.

\section{Dietary factors in risk of cardiovascular disease}

Dietary pattern is an important determinant of chronic disease risk and overall mortality (Knoops 2004; Trichopoulou 2005). Although drug treatment, such as lipid-lowering with statins, may be appropriate among individuals at high risk of cardiovascular disease (CVD) (Hunninghake 1993), adoption of a healthy diet is preferable to long-term medication in the general population in order to prevent or delay the onset of disease and to reduce the burden on health services.

\section{Dietary advice to reduce risk of cardiovascular disease}

Advice that encourages consumption of a diet relatively lower in any one or more of: fat, saturated fatty acids, cholesterol, sodium; or relatively higher in any one of: fruit, vegetables, polyunsaturated fatty acids, monounsaturated fatty acids, fish, fibre, potassium is 
likely to reduce the risk of cardiovascular disease and certain cancers (COMA 1994; DOH 2004; HSS 2005; WHO 2003). Dietary advice can take many forms: verbal or written, single or multiple contacts with individuals or groups, and may be delivered by health professionals or other agencies such as fitness consultants, trade unions or commercial organisations. The present review is concerned with trials of the effect of such advice in healthy European, North American, Australasian and Japanese populations.

\section{How dietary advice might work}

Dietary change has been shown to modify risk. For example, changes in the quantity and quality of dietary fat improve the lipid profile (Mensink 1992), and blood pressure is lowered by reducing sodium intake (Hooper 2004a) and increasing potassium intake (Cappuccio 1991). These findings are based on trials involving well-motivated individuals, often in metabolic wards (Mensink 1992), living in institutions (Dayton 1969; Frantz 1989; Turpeinen 1979), or receiving treatment in a hospital clinic (Watts 1992).

\section{O B JECT IVES}

To assess the effects of providing dietary advice for obtaining sustained desirable dietary changes or improvement in cardiovascular risk profile among healthy adults.

\section{METHODS}

\section{Criteria for considering studies for this review}

\section{Types of studies}

We have included randomised controlled trials (RCTs) involving parallel group design, with allocation at either individual or group level. All trials involved dietary advice designed to reduce chronic disease risk and had at least 3 months of follow up from recruitment. Trials were excluded if there was more than $20 \%$ loss to follow up, unless there was an intention-to-treat analysis.

\section{Types of participants}

Participants were healthy community-dwelling adults aged 18 years or older. Less than $25 \%$ of the participants in any trial had diagnosed cardiovascular disease at recruitment. Reported use of pharmacological therapy (e.g. statins or diuretics), during the trial was no greater then $10 \%$ of participants in any arm of the trial. Trials involving pregnant women or children, trials to reduce weight or those involving supplementation were excluded.

\section{Types of interventions}

Dietary interventions involve verbal or written advice delivered in person or over the phone to individuals or small groups. The advice could include a combination of such approaches, and be given by health professionals or other personnel. Trials could include additional interventions such as posters in a works canteen. We considered trials involving advice to decrease consumption of one or more of fat, saturated fatty acids, cholesterol, salt, and/or increase consumption of one or more of fruit, vegetables, polyunsaturated fatty acids, monounsaturated fatty acids, fish, fibre, and potassium. We have restricted this review to interventions involving only advice on diet, to minimise confounding. Multiple interventions, such as those involving advice on physical activity, are excluded. Trials of weight reducing diets are excluded. The control group received no or minimal dietary advice.

\section{Types of outcome measures}

For all outcome measures the preferred measure of effect was the estimated mean net change in the outcome variable over the duration of the trial. The net change is the change in the outcome measure in the intervention group minus the change in the control group.

\section{Primary outcomes}

1. Cardiovascular risk factors: resting blood pressure, blood lipids and lipoproteins (cholesterol), and blood or red cell folate and/or homocysteine.

2. Bio-markers of dietary intake: urinary sodium, urinary potassium and blood diet-derived antioxidants such as $\beta$-carotene.

\section{Secondary outcomes}

Self-reported measures of dietary intake, including fat, fat fractions, dietary fibre, fish, fruit and vegetables, vitamin $\mathrm{C}$ (ascorbic acid), vitamin E (tocopherols), carotenoids, flavonoids, and folic acid.

\section{Follow up}

Trials were included if they had at least 3 months follow up from baseline. The longest follow-up duration was used provided loss to follow up was less than $20 \%$ for the outcome measure of interest, unless there was an intention-to-treat analysis.

\section{Search methods for identification of studies}

\section{Electronic searches}

We searched the Cochrane Central Register of Controlled Trials, the Database of Abstracts of Reviews of Effects (DARE) and the HTA database on The Cochrane Library (Issue 4 2006). We searched MEDLINE (January 1966 to December 2000, 2004 to November 2006) and EMBASE (January 1985 to December 2000, 2005 to November 2006). The updated searches were run from the years 2004 (MEDLINE) and 2005 (EMBASE) as central searches of these databases mean that identified RCTs have previously been added to CENTRAL. 
Additional searches were done on CAB Health (January 1972 to December 1999), CVRCT Registry (December 2000), INST ED-Bibliomap and INST ED-EPPI-Centre (December 2000), Current Controlled Trials (December 2000) and SIGLE (January 1980 to June 2000).

The search strategy used for The Cochrane Library is below, see additional Table 1 and Table 2 for details of MEDLINE and EMBASE searches. A filter for finding RCTs was used on MEDLINE (Dickersin 1994) and EMBASE (Lefebvre 1996).

\#1 MeSH descriptor Diet, Atherogenic explode all trees \#2 MeSH descriptor Diet, Fat-Restricted this term only \#3 MeSH descriptor Diet, Sodium-Restricted this term only \#4 MeSH descriptor Dietary Fats explode all trees \#5 MeSH descriptor Dietary Fiber this term only \#6 MeSH descriptor Potassium, Dietary this term only \#7 MeSH descriptor Sodium, Dietary explode all trees \#8 MeSH descriptor Ascorbic Acid explode all trees \#9 MeSH descriptor beta Carotene this term only \#10 MeSH descriptor FOLIC ACID explode all trees \#11 MeSH descriptor VITAMIN E explode all trees \#12 MeSH descriptor FISH OILS explode all trees \#13 MeSH descriptor PLANT OILS explode all trees \#14 MeSH descriptor DAIRY PRODUCTS explode all trees \#15 MeSH descriptor FRUIT explode all trees \#16 MeSH descriptor MEAT explode all trees \#17 MeSH descriptor VEGETABLES explode all trees \#18 MeSH descriptor Fats, Unsaturated explode all trees \#19 MeSH descriptor Fatty Acids, Unsaturated explode all trees $\# 20$ (\#1 or $\# 2$ or $\# 3$ or $\# 4$ or $\# 5$ or $\# 6$ or $\# 7$ or $\# 8$ or $\# 9$ or $\# 10$ ) $\# 21$ (\#11 or \#12 or \#13 or \#14 or \#15 or \#16 or \#17 or \#18 or \# 19)

\#22 diet* $^{*}$

\#23 food*

\#24 (lipid near/6 modifi*)

\#25 (lipid* near/6 low*)

\#26 (lipid* near/6 reduc*)

\#27 (fat* near/6 low*)

\#28 (fat* near/6 modifi*)

\#29 (fat* near/6 animal )

\#30 (fat* near/6 acid*)

\#31 (fat* near/6 saturat*)

\#32 (fat* near/6 unsaturat*)

\#33 (oil* near/6 olive )

\#34 (oil* near/6 rape*)

\#35 (oil* near/6 sunflower*)

\#36 (oil* near/6 linseed*)

\#37 (oil* near/6 saturat*)

\#38 (oil* near/6 unsaturat*)

\#39 polyunsaturate*

\#40 monounsaturate*

\#41 omega*

\#42 (fat or fats or oil* )
\#43 omega3*

\#44 omega- $3^{*}$

\#45 (omega* near/6 fat*)

\#46 (diet* or food*)

\#47 margarine*

\#48 butter

\#49 meat

\#50 fish

\#51 vegetable*

\#52 fruit*

\#53 legum*

\#54 soy*

$\# 55$ (\#22 or \#23 or \#24 or \#25 or \#26 or \#27 or \#28 or \#29 or \# 30)

$\# 56$ (\#31 or \#32 or \#33 or \#34 or \#35 or \#36 or \#37 or \#38 or \# 39 or \#40)

$\# 57$ (441 or \#42 or \#43 or \#44 or \#45 or \#46 or \#47 or \#48 or \# 49 or \#50)

\#58 (\#51 or \#52 or \#53 or \#54)

$\# 59$ (\#55 or \#56 or \#57 or \#58)

\#60 (\#20 or \#21 or \#59)

\#61 MeSH descriptor HEALTH EDUCATION explode all trees \#62 MeSH descriptor COUNSELING explode all trees \#63 MeSH descriptor COMMUNICATION explode all trees \#64 MeSH descriptor PRACTICE GUIDELINES this term only \#65 MeSH descriptor BEHAVIOR THERAPY explode all trees \#66 (\#61 or \#62 or \#63 or \#64 or \#65)

\#67 (\#60 and \#66)

\#68 counsel* $^{*}$

\#69 advice

\#70 leaflet*

$\# 71$ video* $^{*}$

\#72 (poster or posters )

\#73 (educate* or educational )

\#74 MeSH descriptor Life Style explode all trees

\#75 MeSH descriptor Risk Reduction Behavior this term only \#76 (lifestyle near/6 change* )

\#77 (lifestyle near/6 program*)

\#78 (diet* near/6 change*)

$\# 79$ (\#61 or \#62 or \#63 or \#64 or \#65 or \#66 or \#67 or \#68 or \# 69 or \#70)

$\# 80$ (\#71 or \#72 or \#73 or \#74 or \#75 or \#76 or \#77)

$\# 81$ (\#80 and \#60)

\#82 (health next behavi* near/6 intervention*)

\#83 guideline*

\#84 brief next intervention*

\#85 diet* next therap* in Abstract

\#86 MeSH descriptor diet therapy this term only

\#87 (diet near/6 plan)

\#88 diet* next therap* in Record Title

\#89 diet* next intervention* $^{*}$

\#90 diet* $^{*}$ next treatment*

Dietary advice for reducing cardiovascular risk (Review)

Copyright $\odot 2009$ The Cochrane Collaboration. Published by John Wiley \& Sons, Ltd. 
\#91 MeSH descriptor food habits this term only

\#92 (behavi* near/3 change* ${ }^{*}$

\#93 motivat*

\#94 MeSH descriptor motivation this term only

$\# 95$ (\#82 or \#83 or \#84 or \#85 or \#86 or \#87 or \#88 or \#89 or \#

90 or \#91 or \#92 or \#93 or \#94)

\#96 (\#95 and \#60)

\#97 (\#96 or \#81)

Handsearching and other sources

In the original review, bibliographies of systematic reviews addressing food based dietary interventions relevant to cardiovascular disease were checked as a source of RCTs. Cochrane Review Groups in areas related to this review include the Diabetes Group, Stroke Group, Renal Group, Hypertension Group and Peripheral Vascular Disease Group. These groups were contacted and asked to search their trials registers for relevant trials.

Experts in the field were contacted for references to studies not yet identified by the search process. Experts are defined as members of the Cochrane Heart Group, persons who served as author (not necessarily the primary author) on more than one trial meeting inclusion criteria for the review; or the contact author for any relevant trial; or the contact author for any relevant systematic review. No language restrictions were applied and evaluations of all relevant non-English articles were obtained.

\section{Data collection and analysis}

\section{Selection of studies}

For the original search the titles and then the abstracts of potentially relevant references were read independently by two reviewers. Articles were rejected only if both reviewers determined from the title or abstract that the article was not a report of a randomised controlled trial; or the trial did not address food based dietary advice relevant to cardiovascular disease; or the trial was of less than 3 months duration; or the intervention was multi-factorial.

The results of the updated search were checked by one reviewer to eliminate those studies that were definitely not relevant to the review. Remaining records were checked by two reviewers independently. All papers that were thought to be of relevance were obtained and read by two reviewers independently. Two reviewers independently selected trials to be included in the review using the predetermined inclusion criteria. A proforma was used to determine study inclusion status. Disagreements were resolved by discussion or by consultation with a third reviewer.

\section{Data extraction and management}

Data on participants, interventions, outcomes and trial quality were extracted independently by two reviewers using a proforma. Disagreements were resolved by discussion. Chief investigators were contacted to provide additional relevant information. Data on potential effect modifiers were abstracted, including the setting of the trial (work site, community, home or health care facility), duration of the intervention and the follow-up, intensity of advice giving (number of scheduled contacts), and proportion of participants who were women.

\section{Assessment of methodological quality of included studies}

Quality assessment was based on reporting of the randomisation procedure, allocation concealment, and blinding of outcome assessment. Allocation concealment (concealing group assignment) was considered adequate if participants were randomised individually after recruitment was complete. Allocation concealment was considered inadequate in cluster randomised trials where all participants at a given location were assigned to the same intervention or control group. Trial personnel and participants in trials of dietary advice, as with other behavioural interventions, cannot be blinded to the nature of the intervention. Where report of the trial method indicated that outcome measures were determined without knowledge of group assignment, blinding of outcome assessment was considered adequate.

\section{Measures of intervention effect}

All outcomes were continuously distributed. We compared net differences between baseline and follow-up measurements and calculated the difference in means and $95 \%$ confidence interval for each outcome measure (Cochrane Handbook). We combined net differences across studies using a random-effects model. Where standard deviation differences were not reported in the source papers, we made allowance for within participant correlation from baseline to follow-up measurements by using the correlation coefficient between the two (see Cochrane Handbook for details and Follmann 1992).

\section{Unit of analysis issues}

\section{Studies with multiple intervention groups}

Data for the control group were used for each intervention group comparison. The weight assigned to the control group was reduced by dividing the control group $\mathrm{N}$ by the number of intervention groups.

\section{Cross-over trials}

Data for the two periods were combined only if the study design ensured minimal carry-over effects.

\section{Cluster randomised trials}

Cluster randomised trials were analysed using the unit of randomisation (cluster) as the number of observations. Where necessary, individual level means and standard deviations adjusted for clustering were utilised together with the number of clusters in the denominator, in order to weight the trials appropriately.

\section{Missing data}

If a trial collected an outcome measure at more than one time point the longest period of follow up with $20 \%$ or fewer dropouts was utilised.

\section{Assessment of reporting biases}

The primary outcome measurements, apart from blood pressure, depend on laboratory analysis. Potential reporting bias is likely to be important only in the case of trial personnel involved in blood pressure measurement. Secondary outcomes in this review are the self-reported measures of dietary intake. Measures of diet 
are considered to be, at best, weak estimates of actual behaviour and behaviour change.

\section{Subgroup analysis and investigation of heterogeneity}

For each outcome, a test of heterogeneity was carried out. If we detected substantial heterogeneity $(\mathrm{P}<0.1)$, we looked for possible explanations (e.g. participants and intervention). Regardless of the magnitude of heterogeneity, where six or more trials provided data for a given outcome, results were grouped according to five potential effect-modifying factors:

- Gender: women, men, mixed;

- Disease risk group: general population, high cardiovascular disease risk, high cancer risk;

- Intervention setting: healthcare, community/workplace/ home;

- Intervention intensity: low, high (more than three scheduled personal contacts with participants enrolled in the intervention $\operatorname{arm}(s)$ of a trial); and

- Trial duration: short, long (follow up at 12 months or more).

\section{RES U L T S}

\section{Description of studies}

See: Characteristics of included studies; Characteristics of excluded studies; Characteristics of ongoing studies.

\section{Results of search}

The searches generated 45,100 hits. Screening of titles and abstracts identified 299 papers for formal inclusion or exclusion. Of these 38 trials met the inclusion criteria. Fifteen new trials were included following the updated search, a substantial increase on the 23 included in the original review.

Details of the studies included in the review are shown in the table of characteristics of included studies. Reasons for exclusion for the majority of studies included greater than $20 \%$ missing outcome data at follow up without an intention-to-treat analysis, the control group did not receive minimal intervention or no intervention and insufficient data for analysis despite contact or attempted contact with investigators. Details and reasons for exclusion for the studies which most closely missed the strict inclusion criteria are presented in the table of excluded studies.

\section{Included studies}

Details of methods, participants, interventions and outcome measures are presented in the included studies table. Thirty-eight trials with 46 trial arms were included with 17871 participants/clusters randomised. Twenty-six of the 38 included trials were conducted in the USA.

\section{Weight change}

Twenty-one of the 29 individually randomised trials provided information on initial weight and/or weight loss during follow-up.
Baseline body mass index (BMI) was approximately $30 \mathrm{~kg} / \mathrm{m}^{2}$ in two trials (Cheng 2004; Cox 1996) while other trials involved participants with lower BMI. Net mean weight loss in the intervention groups during follow up was $1 \mathrm{~kg}$ or less in 13 trials (Anderson high fibre; Anderson low fibre; Baron men 1990; Baron women 1990; Bloemberg 1991; Brekke 2005; Cheng 2004; Hellenius 1993; John 2002; Maskarinec 1999; Neil dietitian1995; Neil nurse 1995; Sacerdote 2006; Smith-Warner 2000; Takahashi 2006; van der Veen 2002), $1.1 \mathrm{~kg}$ in one (Schatzkin 2000) and $1.8 \mathrm{~kg}$ in one (Henderson WHTV 1990).

Gender

Twenty-five trials enrolled men and women, and of these one presented the findings by gender (Baron men 1990; Baron women 1990). Ten trials enrolled women only, three men only.

\section{Disease risk group}

Seventeen trials enrolled participants without screening, of which three involved American women with high prevalence of food poverty (Coates WHT MP 1999; Cox 1996; Havas 1998), two recruited American women through direct contact and mailings (Elder promotora; Elder tailored; Gann 2003), three involved clients of American health maintenance organisations (Kristal 2000; Lutz non-tailored; Stevens 2003), two recruited from healthcare settings in Italy and the UK (John 2002; Sacerdote 2006), one recruited from Black American churches (Fuemmeler 2006) and three from US worksites (Beresford 2006; Buller 1999; Sorensen worksite).

Thirteen trials enrolled participants on the basis of cardiovascular disease risk factor screening, of which six involved cholesterol screening (Anderson high fibre; Bloemberg 1991; Cheng 2004; Hellenius 1993; Keyserling 1997; Neil dietitian 1995; van der Veen 2002), four blood pressure screening (Koopman 1990; Little 2004; TOHP II 1997; TOHP I 1992) and one plasma homocysteine screening (Riddell 2000). One trial enrolled siblings of CHD patients diagnosed before 60 years of age with at least one other risk factor (eg. high cholesterol or blood pressure levels) (Moy 2001), and one recruited first degree relatives of type-2 diabetic patients (Brekke 2005).

Three trials enrolled people who were at increased risk of breast cancer (Djuric combination; Djuric high F\&V; Henderson WHTV 1990; Maskarinec 1999), one trial enrolled people at increased risk of cervical cancer (Rock 2001), two trials enrolled people at increased risk of colorectal cancer (Schatzkin 2000; Smith-Warner 2000) and one trial enrolled car workers being screened for colorectal cancer (Tilley 1999).

\section{Intervention setting}

Most studies involved interventions in healthcare settings (25 studies), while others were set in the work place (four studies), community centres (six studies) or exclusively in the home (three studies) using telephone and mail (Kristal 2000; Lutz non-tailored; Lutz tailored 1999; Lutz tailored\&goals; Rock 2001).

\section{Intervention intensity}

Fifteen trials involved an intervention design with between one 
and three scheduled contacts. Twenty-three trials involved a design with between four brief interventions and 50 hours of individual counselling over four years (Schatzkin 2000).

\section{Trial duration}

The modal duration of follow-up was 12 months (12 studies). There were six short duration trials: three of 3 months (Baron men 1990; Baron women 1990; Elder promotora; Elder tailored; Koopman 1990; Riddell 2000 ) and two of 4 months (Cheng 2004; Keyserling 1997). Nineteen studies contributed results for 12-48 months of follow-up.

Six or more trials provide results for serum total cholesterol, blood pressure, total dietary fat and fruit and vegetable intake and five subgroup analyses, as above, are displayed to explore effect modification.

\section{Risk of bias in included studies}

In general, details of the methods utilised in the included studies in this review were not well reported (Moher 2001). The methodological quality of the included studies as reported in the source papers is summarised in Table 3.

\section{Randomisation}

All trials involved randomisation, but the methods were poorly described.

\section{Allocation concealment}

Three of the 29 individually randomised trials appeared to have used an adequate allocation concealment method (Little 2004; Schatzkin 2000; TOHP II 1997). Nine studies involved cluster randomisation and allocation concealment was considered adequate in one case (Buller 1999).

\section{Blinding of outcome assessment}

Blinding of participants to the intervention is not possible in trials of behavioural advice, however outcome assessment can be conducted by trial personnel without knowledge of group allocation. Primary outcomes in this review are cardiovascular disease risk factors and biomarkers of dietary intake. With the exception of blood pressure, these outcomes are relatively free of the risk of information bias. There was some indication of blinding in the reports of 12 trials (Anderson high fibre; Anderson low fibre; Beresford 1997; Bloemberg 1991; Coates WHT MP 1999; Hellenius 1993; Keyserling 1997; Maskarinec 1999; Neil dietitian1995; Neil nurse 1995; Riddell 2000; Sacerdote 2006; Smith-Warner 2000; TOHP I 1992). The secondary outcomes are self-reported measures of dietary intake, commonly based on a food frequency questionnaire. In no case was there adequate description of the procedures used to blind the assessors of dietary intake during data collection or analysis.

\section{Unit of analysis issues}

Nine trials were cluster randomised. In one community trial a cross-over design was used such that each site acted as its own control and site was the unit of analysis (Havas 1998). In a work place trial 41 pairs of employee cliques (informal social networks) were the unit of randomisation and analysis (Buller 1999). In two further work place trials, worksite was the unit of randomisation, but data were analysed at the level of the individual. We used worksite as the denominator for the meta-analysis (Tilley 1999; TOHP I 1992). Another worksite trial analysed data at the level of the cluster (Beresford 2006). Three trials based in clinics used physician practice as the unit of randomisation but analysed at individual level. Analysis allowed for random effects of clinic and physician practice, with physician nested within clinic. We used physician as the denominator for the meta-analysis (Beresford 1997; Keyserling 1997; van der Veen 2002). One trial was based in Black American churches where data were analysed the individual level taking account of clustering (Fuemmeler 2006). We used churches as the denominator in the meta-analysis.

\section{Loss to follow up}

Our inclusion criteria specified that loss to follow up was no more than $20 \%$. We used the longest reported follow-up data for each trial meeting our inclusion criteria. Drop out rose to more than $20 \%$ at longer follow up in several trials (Baron men 1990; Baron women 1990; Coates WHT MP 1999; Djuric combination; Djuric high F\&V; Elder promotora; Elder tailored; TOHP I 1992) and the proportion taking lipid-lowering medication exceeded $10 \%$ after 4 months in another (Keyserling 1997).

\section{Effects of interventions}

For the variables fruit and vegetable consumption, dietary fibre, high density lipoprotein (HDL) cholesterol, and micronutrients, an increase in value from baseline to follow up indicates improvement with the dietary intervention. Summary statistics are based on a random-effects model.

Any dietary advice versus no dietary advice (comparison 01) Blood pressure and urinary sodium (outcomes 01, 02, 03)

Systolic blood pressure and diastolic blood pressure were reported in eight studies (6223 participants randomised). Two trials focused on salt reduction (TOHP I 1992; TOHP II 1997), one on salt reduction plus increased dietary fibre and polyunsaturated fatty acid intakes (Koopman 1990), and one on sodium reduction and increased intake of vitamin $\mathrm{C}$ and carotene by increasing fruit and vegetable intake (Takahashi 2006). One trial focused on increasing fruit and vegetable intake (John 2002), and the others more broadly on healthy eating advice (Hellenius 1993; Little 2004; Sacerdote 2006). Initial mean BP in the control group of these studies was in the range $125 / 84$ to $154 / 93 \mathrm{mmHg}$ (Table 4).

Systolic blood pressure was reduced by $2.06 \mathrm{mmHg}$ (difference in means $-2.06,95 \%$ CI -3.19 to -0.92 ), and diastolic blood pressure by $1.15 \mathrm{mmHg}$ (difference in means $-1.15,95 \% \mathrm{CI}-1.85$ to -0.46 ) with dietary advice. Twenty-four hour urinary sodium output was reported in three trials of salt reduction (Koopman 1990; TOHP I 1992; TOHP II 1997; 1533 participants randomised). Urinary sodium output was reduced by $44.18 \mathrm{mmol} / 24 \mathrm{hr}$ (difference in means $-44.18,95 \%$ CI -54.74 to -33.62 ). 
Blood lipids (outcomes 04, 05, 06, 07)

Total blood cholesterol was reported in 13 studies (17 trial arms, 2124 participants/clusters randomised). All trials involved healthy eating advice designed to lower cholesterol, except one trial and one trial arm that focused on increasing fruit and vegetable intake ( Djuric high F\&V; Maskarinec 1999). Fibre intake was emphasised in three trial arms (Anderson high fibre; Baron men 1990; Baron women 1990). Initial mean total cholesterol in the control group of the trials was in the range 4.4 to $7.4 \mathrm{mmol} / \mathrm{L}$ (Table 4 ).

There was a small but significant reduction in total cholesterol with advice of $0.16 \mathrm{mmol} / \mathrm{l}$ (difference in means $-0.16,95 \% \mathrm{CI}-0.25$ to -0.06). There was a similar reduction in low density lipoprotein (LDL) cholesterol in 10 studies (14 trial arms, 1484 participants/ clusters randomised) of $0.18 \mathrm{mmol} / \mathrm{L}$ (difference in means -0.18 , $95 \%$ CI -0.27 to -0.10$)$. There was no effect of advice on HDL cholesterol in nine studies (13 trial arms, 1481 participants randomised). Triglyceride levels were reported in four studies (five trial arms, 429 participants randomised) where dietary advice had no effect.

Other biomarkers (outcomes 08, 09, 10, 11, 12, 13, 14, 15, 16, 17)

Plasma $\alpha$-carotene and $\beta$-carotene were reported in three trials (four trial arms, 779 and 765 participants randomised respectively) all of which focused on increasing fruit and vegetable intake (Djuric combination; Djuric high F\&V; John 2002; Rock 2001). There was heterogeneity in the trial effects and changes with the dietary intervention were in the expected direction but did not reach statistical significance. These trials also reported plasma lutein, lycopene and $\beta$-cryptoxanthin. Similarly, there was heterogeneity in the trial effects but small increases in both lutein (difference in means $0.02 \mu \mathrm{mol} / \mathrm{L}$ (95\% CI 0.01 to 0.04$)$ ) and $\beta$-cryptoxanthin (difference in means $0.07 \mu \mathrm{mol} / \mathrm{L}$ (95\%CI 0.02 to 0.11 ) with the dietary intervention which were statistically significant. There was no effect of dietary advice on plasma lycopene.

Plasma $\alpha$-tocopherol, $\gamma$-tocopherol and plasma ascorbic acid were reported in two trials (three trial arms, 750 participants randomised). There was no effect of dietary advice on $\alpha$-tocopherol or $\gamma$-tocopherol. There was an increase in plasma ascorbic acid with dietary advice but this did not reach statistical significance. Total plasma carotenoids were measured in two trials (113 participants randomised) where the effect of dietary advice was in the expected direction but was not statistically significant.

Red cell folate was measured in one trial (Riddell 2000) which focused on increasing intake of folate rich foods. The effect was in the expected direction but was not statistically significant.

Dietary fat and dietary saturated fatty acids (outcomes 18, 19) Total dietary fat intake was reported in 18 studies (20 trial arms, 6170 participants/clusters randomised). All data are presented as changes from baseline with the exception of one trial (Elder promotora, Elder tailored) where only final follow-up data were available. Dietary advice reflected consensus healthy eating guidelines in ten trial arms (Anderson low fibre; Beresford 1997;
Bloemberg 1991; Brekke 2005; Cox 1996; Hellenius 1993; Little 2004; Stevens 2003; Tilley 1999; van der Veen 2002). Five trials aimed to reduce fat intake to $20 \%$ or less of calories (Coates WHT MP 1999; Gann 2003; Henderson WHTV 1990; Moy 2001; Schatzkin 2000). One trial focused on increasing fruit and vegetable intake (Schatzkin 2000), and one on reducing salt and increasing fruit and vegetable intake (Takahashi 2006).

Total dietary fat intake expressed as a percentage of total calories fell by $4.49 \%$ with intervention overall (difference in means $-4.49 \%$; 95\%CI -6.66 to -2.31$)$. There was substantial heterogeneity $(\mathrm{P}<$ 0.00001 ) in the trial effects, with the largest effects seen in four of the five trials that aimed to reduce fat intake to $20 \%$ or less of calories. The Women's Health Trial Minority Populations study, based in Georgia, Alabama and Florida (Coates WHT MP 1999), obtained a large reduction in total fat intake $(10.8 \%)$ whereas another trial among US low income women (Cox 1996) was less effective (5.1\% reduction). A trial among predominantly male US car workers (Tilley 1999) obtained a non-significant reduction in fat intake (1.2\%).

Saturated fatty acid intake was reported in a subset of 10 of these trials (12 trial arms, 3157 participants randomised). Saturated fatty acid intake was reduced by $2.36 \%$ with dietary advice (difference in means $-2.36 \%$; $95 \%$ CI -3.39 to -1.32 ). There was heterogeneity $(\mathrm{P}<0.00001)$ in the trial effects, with a large effect seen in a trial that recruited women with increased risk of breast cancer (Henderson WHTV 1990).

\section{Fruit and vegetables (outcomes 20, 21, 22)}

Fifteen studies (18 trial arms, 8416 participants/clusters randomised) reported the combined outcome of servings of fruit and vegetables per day. All trials aimed to increase the number of fruit and vegetable servings eaten. Five trials also aimed to reduce fat intake (Kristal 2000; Sacerdote 2006; Schatzkin 2000; Stevens 2003; Tilley 1999). For one study (Schatzkin 2000), servings of fruit and vegetables were expressed as intake per 1000 calories rather than servings per day. The data provided for this study have been multiplied by the mean number of calories consumed per day as reported.

Fruit and vegetable intake in those given dietary intervention increased by 1.25 servings (difference in means) (95\% CI 0.70 to 1.81). There was heterogeneity $(\mathrm{P}<0.00001)$ in the trial effects, with a large effect seen in a trial of men and women at increased risk of colorectal cancer (Smith-Warner 2000) and in women at increased risk of cervical cancer (Rock 2001). Three US trials with low income and blue collar participants (Buller 1999; Havas 1998; Tilley 1999) obtained small increases in mean fruit and vegetable intake (range 0.24-0.43 servings per day).

Intakes of fruit and vegetables were reported separately in eight trials (nine trial arms, 4439 participants/clusters randomised) for fruit and in seven trials (eight trial arms, 4412 participants/clusters randomised) for vegetables. There was an increase in both fruit intake alone (difference in means $0.67,95 \%$ CI 0.07 to 1.28 ), and vegetable intake alone (difference in means $0.92 ; 95 \% \mathrm{CI}$

Dietary advice for reducing cardiovascular risk (Review) 
0.34 to 1.49$)$ with the intervention. There was heterogeneity $(\mathrm{P}<$ $0.00001)$ in both sets of trials.

\section{Dietary fibre (outcome 23)}

Dietary fibre intake was reported in seven studies (nine trial arms, 2981 participants randomised). Participants in these trials were given dietary advice that included fat reduction as well as fibre advice, with the exception of one that focused on increasing fruit and vegetable intake (Maskarinec 1999). For one study (Schatzkin 2000), fibre intake was expressed per 1000 calories rather than servings per day. The data provided for this study were multiplied by the mean number of calories consumed per day as reported. People given the dietary intervention increased dietary fibre intake by 5.99 grams per day (difference in means) compared to those on control treatment (95\% CI 1.12 to 10.86). There was heterogeneity $(\mathrm{P}<0.00001)$ in the trial effects, with a large effect seen in a 4-year trial of individuals at increased risk of colorectal cancer (Schatzkin 2000).

Dietary intake of micronutrients (outcomes 24, 25)

Three trials (five trial arms, 2335 participants randomised) report dietary intake of vitamin $\mathrm{C}$ (ascorbic acid). Dietary intake of vitamin C increased by $53.39 \mathrm{mg} /$ day with dietary advice (difference in means, $95 \%$ CI 31.97 to 74.80 ) but there was significant heterogeneity in trial effects.

Dietary intake of $\beta$-carotene was reported in two trials (three trial arms, 542 participants randomised). There was an increase of $3.39 \mathrm{mg} /$ day (difference in means, $95 \%$ CI 1.20 to 5.59 ) but again there was heterogeneity in the trial effects.

One trial (Lanza men 2001; Lanza women 2001) reports also dietary intake of folate and vitamin $\mathrm{E}$, where the authors found a statistically significant increase in dietary folate with the intervention, but no change in vitamin $\mathrm{E}$ intake. Similarly, no intervention effect was seen on dietary intake of $\alpha$ and $\delta$-tocopherol in another trial (Djuric combination; Djuric high F\&V).

Subgroup analyses (Comparison 02)

Eight or more trials provide results for total blood cholesterol, blood pressure, total dietary fat and fruit and vegetable intake. We present subgroup analyses of these outcomes, for gender, disease risk group, intervention setting, intervention intensity and trial duration. These sub-group findings should be treated with caution as self-report outcomes are subject to reporting bias and subgroup analyses in aggregated data without formal statistical interaction tests may generate spurious false positive and false negative findings.

\section{Gender}

In general, women were more likely than men to report reduced dietary fat intake, increased fruit and vegetable intakes. Men, unlike women, achieved modest but significant cholesterol-lowering. There were large intervention effects on fat intake in the two Women's Health Trial pilot studies (Coates WHT MP 1999; Henderson WHTV 1990).

\section{Disease risk group}

Participants at higher risk of cardiovascular disease did not report greater reductions in dietary fat intake but there was a tendency for greater reductions in total cholesterol. Reductions in total dietary fat intake were reported more frequently in those at high risk of cancer and there was a statistically significantly greater reported intake of fruit and vegetables in this group (2.69 servings/day, $95 \%$ CI 1.53 to 3.85$)$ compared to the general population $(0.62$ servings/day, $95 \%$ CI 0.32 to 0.93$)$. One trial with participants at increased risk of colorectal cancer obtained a mean net increase in consumption of 5.1 servings per day (Smith-Warner 2000). There were no differences in SBP or DBP between the general population and those at high risk of CVD.

\section{Intervention setting}

Trials conducted in healthcare settings tended to show greater reporting of reduced dietary fat and increased fruit and vegetable consumption than workplace/community settings. However, no differences in blood cholesterol reductions were found.

\section{Intervention intensity}

Overall, high intensity interventions, involving more than three scheduled personal contacts with participants enrolled in the intervention $\operatorname{arm}(s)$ of a trial, tended to be associated with larger effects than low intensity interventions. The difference in effect size between subgroups was statistically significant for total dietary fat (high intensity, difference in means $-5.72 \%, 95 \%$ CI -7.75 to 3.69 , low intensity, difference in means $-1.68 \%(-3.13$ to -0.23$)$ ). However there was heterogeneity in the effects within the high intensity subgroup. A similar pattern was seen for reported fruit and vegetable intake. However, no differences in blood cholesterol or blood pressure reductions were found.

\section{Trial duration}

The trial duration used in these analyses is the maximum trial follow-up period where non-participation at that follow-up was less than $20 \%$ for the outcome of interest (see Loss to follow up above). Overall, there was no evidence that longer duration trials, with follow up at 12 months or more, obtained smaller reported dietary changes or blood cholesterol and blood pressure changes.

\section{DISCUSSION}

The aim of this review is to evaluate the evidence for the sustained effectiveness of dietary advice in adults free of disease.

\section{Summary of main results}

The review shows that dietary advice promotes modestly beneficial changes in reported dietary intake (lower salt and fat, higher fibre and fruit and vegetables) and in some cardiovascular risk factors (blood pressure, total cholesterol, LDL cholesterol). The trial participants were healthy adults studied for at least 3 months and

Dietary advice for reducing cardiovascular risk (Review) 
up to 4 years (median duration 10 months). There was some evidence that dietary advice was more effective when individuals were recruited on the basis of increased risk of cardiovascular disease or cancer, but beneficial changes were obtained when individuals were not screened at recruitment.

Advice to reduce fat intake (total and saturated fatty acids), and to increase dietary fibre, fruit and vegetable consumption was associated with a reduction over 3-24 months of follow up for blood total cholesterol of $0.16 \mathrm{mmol} / \mathrm{L}$ and for LDL cholesterol $0.18 \mathrm{mmol} /$ L. Advice to reduce salt intake and/or reduce fat and increase fruit and vegetable and fibre consumption over 3-36 months of follow up was associated with a reduction in blood pressure of 2.07 $\mathrm{mmHg}$ systolic and $1.15 \mathrm{mmHg}$ diastolic. Advice to reduce salt intake was associated with a reduced 24-hour urinary sodium excretion of $44.2 \mathrm{mmol}$.

Reported fruit and vegetable intake increased by 1.25 servings per day with dietary intervention over 6 to 48 months of follow up. Dietary fibre intake increased with intervention over 3 to 48 months by $5.99 \mathrm{~g}$ per day. Reported total dietary fat intake expressed as a percentage of total calorie intake fell by $4.49 \%$ with intervention over 3-48 months. The corresponding reduction in saturated fatty acid intake was $2.36 \%$.

\section{Overall completeness and applicability of evidence}

More than 10,000 randomised individuals/clusters contributed data to most of the outcomes discussed in this review, including the "objective" outcomes blood cholesterol, blood pressure and urinary sodium output. For total dietary fat and fruit and vegetable intake this number was approximately 14,300 . There was a lack of evidence in relation to plasma triglycerides and folate. Since the search for the original review to the year 2000, three new trials measuring plasma antioxidants have been included, with over 700 participants randomised (Djuric combination; Djuric high F\&V; John 2002; Rock 2001). Small changes were seen with the intervention for lutein and $\beta$-cryptoxanthin but there was heterogeneity in the trial effects. With the advent of new trials, evidence for changes in plasma antioxidants with dietary advice will be more complete.

Dietary changes are effective in modifying risk when adherence is high, but there has been uncertainty about the effects of giving advice to healthy adults. Trials involving well-motivated individuals being fed controlled diets in metabolic wards (Mensink 1992), institutions (Dayton 1969; Frantz 1989; Turpeinen 1979), or the community (Appel 1997) do not assess the real-world effect of dietary advice. This review assembles the evidence that dietary advice is effective in less selected participants drawn from communities and work places.

A number of gaps in the evidence of the effects of dietary advice are apparent in the studies identified to date. In the original review (searching to year 2000) it was noted that there was a lack of high quality trials of cholesterol lowering by diet among unscreened healthy adults. Since this time, two trials have been published and included in the review, one based in the UK showing no effect of the intervention on cholesterol levels (John 2002), and one based in the US showing effects in the desirable direction but not statistically significant (Stevens 2003). In addition, we found no evidence from countries other than the USA of the effect of cholesterol-lowering dietary interventions provided outside healthcare settings. This is surprising, given the importance of population cholesterol levels for cardiovascular disease prevention, but in part reflects the narrow inclusion criteria used in this review. Speculatively, it may be more efficient to provide dietary advice together with other forms of healthy eating promotion in the community or work place (Thorogood 2007). We did not identify trials meeting the inclusion criteria that used quality of life outcomes or economic evaluation.

Five US trials (11,427 participants) provided evidence of the effect of dietary advice, limited to dietary fat and fruit and vegetable intake, among low income women (Coates WHT MP 1999; Cox 1996; Havas 1998) and blue collar workers (Buller 1999; Tilley 1999). One trial showed a large reduction in fat intake at 6 months among minority ethnic group and low socioeconomic class women (Coates WHT MP 1999). The two trials involving American, predominantly male, blue collar workers were not effective in increasing fruit and vegetable intake at 6 months (Buller 1999) or 2 years (Tilley 1999).

Although there are 11 trials of advice to increase fruit and vegetable intake among unscreened healthy adults, only two were based outside the USA (John 2002; Sacerdote 2006).

\section{Overall quality, strength and consistency of evidence}

The majority of trials were conducted in the USA (26 trials). Most trials involved individual randomisation (29). There were nine cluster-randomised trials, eight were based in the USA, three in work places, two in healthcare settings and one in community centres, and one was based in a healthcare setting in the Netherlands (van der Veen 2002). To limit selection bias we restricted loss to follow-up to $20 \%$ and in consequence data from shorter follow-up periods often had to be utilised for the longer duration trials. Descriptions of the trials, including methods used in randomisation, allocation concealment and blinding of outcome assessment, were in general poor, in comparison with the CONSORT recommendations (Moher 2001). Only two of the individually randomised trials and one of the six cluster-randomised trials showed evidence of adequate allocation concealment.

The primary outcomes (blood pressure, lipids and other biomarkers) used in this review are broadly free of information bias. For urinary sodium output, short-term salt restriction, or over-compliance bias, before the follow-up urine sample may have been 
large enough to contribute to the large observed intervention effect. The three trials with both blood presusre and urinary sodium measures showed some evidence of inconsistency, in that large reductions in sodium output (TOHP I 1992; TOHP II 1997) were not associated with large reductions in blood pressure. The third trial (Koopman 1990) was small and of short (3 months) duration.

The secondary outcome measures were based on self-reported dietary intakes. Some of the intervention effects assessed by self-report were substantial, and may in part reflect information (reporting) bias, either on the part of participants or the trial personnel responsible for coding and analysing diet questionnaires. A particular weakness of the trial reports in this review is the absent or poor description of blinding of assessors to group allocation. Information bias may explain in part the discrepant findings for vitamin $\mathrm{C}$, the only outcome measured both by self-report and biomarker. Intake assessed by self-report was found to increase substantially in response to intervention, whereas the corresponding effect assessed by plasma ascorbate assay was not significant.

Weight loss during the trials may potentially confound changes in dietary composition indexed by blood pressure and blood cholesterol. We excluded studies that had weight loss as a main aim; however weight loss as a consequence of the recommended dietary alteration could add to the apparent effect of dietary change by causing temporary reductions in blood pressure and cholesterol. Twenty-one of the 29 individually randomised trial reports provided information on initial weight and weight loss and this was reassuring. Net mean weight loss in these intervention groups during the trials was in the range $0-1.8 \mathrm{~kg}$.

Interventions varied considerably in terms of the nature of the dietary advice. Two main groups are evident: those giving broad healthy eating advice that followed consensus guidelines (COMA 1994; HSS 2005) on fat, fibre, fruit and vegetables (Anderson high fibre; Anderson low fibre; Baron men 1990; Baron women 1990; Beresford 1997; Bloemberg 1991; Brekke 2005; Cheng 2004; Cox 1996; Djuric combination; Djuric high F\&V; Elder promotora; Elder tailored; Fuemmeler 2006; Gann 2003; Hellenius 1993; Henderson WHTV 1990; Keyserling 1997; Kristal 2000; Little 2004; Moy 2001; Neil dietitian1995; Neil nurse 1995; Sacerdote 2006; Schatzkin 2000; Stevens 2003; Takahashi 2006; Tilley 1999; van der Veen 2002) and those focused on increasing fruit and vegetable consumption along the lines of "5-a-day" campaigns (Beresford 2006; Buller 1999; Havas 1998; John 2002; Lutz non-tailored; Lutz tailored 1999; Lutz tailored\&goals; Maskarinec 1999; Rock 2001; Smith-Warner 2000; Sorensen work+family; Sorensen worksite). In addition, three trials emphasised salt restriction (Koopman 1990; TOHP I 1992; TOHP II 1997), another aimed to reduce fat consumption to $20 \%$ of energy or less among low income women (Coates WHT MP 1999) and another aimed to increase folate-rich food consumption (Riddell 2000). The trials involving broad healthy eating advice were consistent in their modest effects on blood total cholesterol reduction. The two Women's Health Trials (Coates WHT MP 1999; Henderson WHTV 1990) achieved very large reductions in dietary fat intake, but blood cholesterol was not measured. Trial interventions that advised an increase in fruit and vegetable consumption obtained similar increases in intake, with the exception of two that obtained much larger reported effects among participants presumably motivated by awareness of their increased risk of colorectal cancer (Schatzkin 2000; Smith-Warner 2000).

The intervention varied considerably among the included trials in terms of the mode of delivery of the dietary advice. Our subgroup analysis of the effect of intensity, based on the frequency of scheduled contacts, provide some evidence that higher intensity intervention is associated with larger dietary changes, particularly for dietary fat intake. Lower intensity interventions are more likely to be adopted in routine health care. There was heterogeneity in the effects within the subgroup of high intensity trials largely due to those with participants at increased cancer risk (Henderson WHTV 1990; Schatzkin 2000; Smith-Warner 2000). We expected to find that the effect of intervention would decline with duration of the trial. There was no evidence that this was the case, comparing longer duration trials with follow up at 12 months or more with those of shorter duration.

Of the 38 trials with 46 intervention arms meeting the inclusion criteria, 20 (23 intervention arms, 8795 participants/clusters randomised) recruited participants without some form of screening to identify people at elevated risk of disease, compared to the general population. By design, participants were predominantly free of diagnosed chronic disease and not taking lipid-lowering or hypotensive medication, but there was evidence of a greater effect of advice in the trials with increased cancer risk participants. This may be a sign of greater motivation among these participants compared with those in healthy population trials, and it may be that some of the effects reported here would be smaller for dietary advice offered to a healthy population.

\section{Potential biases in the review process}

Two aspects of selection bias are relevant to this review. First, our decision was to restrict the review to trials of dietary intervention alone to avoid the potential confounding effects due to other behavioural interventions, such as exercise advice, on our primary outcomes. The effect of this restriction may also be to overestimate the effectiveness of dietary advice if in practice it is given simultaneously with other health promotion interventions. Second, we decided to limit dropout to $20 \%$ or less to avoid selection bias in effect estimation, rather than to perform sensitivity analysis to examine the consequences of varying dropout rates. The effect of this restriction has been to exclude a number of well-known trials with a relatively high dropout rate (e.g. Boyd 1990; HPTR 1990). 
In addition, we may be biasing our findings by limiting our evidence to trials with conscientious participants.

\section{Agreements and disagreements with other studies or reviews}

Two Cochrane reviews have examined interventions to reduce blood pressure in normotensive people. One studied the efficacy of reduced sodium intake rather than the effectiveness of advice to reduce sodium intake, and hence selected only trials that showed a reduction in sodium excretion of at least $40 \mathrm{mmol} / 24$ hours $(\mathrm{He}$ 2004). The authors found a median reduction in normotensive people of $74 \mathrm{mmol} / 24$ hours that was associated with a fall of $2.03 \mathrm{mmHg}(95 \% \mathrm{CI}-2.56$ to 1.50$)$ in systolic and $0.99 \mathrm{mmHg}$ (95\% CI -1.40 to 0.57 ) in diastolic pressure. Another Cochrane review included trials of interventions aimed at sodium reduction of at least 6 months duration (Hooper 2004a). Three trials in normotensives were identified giving a mean reduction in sodium excretion of $35 \mathrm{mmol} / 24$ hours ( $95 \%$ CI -47.2 to 23.9 ) and a mean reduction of systolic pressure of $1.1 \mathrm{mmHg}(95 \% \mathrm{CI}-1.8$ to 0.4 ) and of diastolic pressure of $0.6 \mathrm{mmHg}$ ( $95 \% \mathrm{CI}-1.5$ to 0.3 ). The fall in sodium excretion is compatible with our findings of a fall in sodium excretion of $44.2 \mathrm{mmol} / 24$ hours (95\% CI -57.7 to 33.6). However, we have found a slightly larger effect on blood pressure with a fall in systolic pressure of $2.07 \mathrm{mmHg}(95 \% \mathrm{CI}$ -3.19 to 0.95$)$ and diastolic pressure of $1.15 \mathrm{mmHg}(95 \% \mathrm{CI}$ 1.85 to 0.48$)$. Hooper et al concluded that 'resulting falls of 1.1 $\mathrm{mmHg}$ systolic and $0.6 \mathrm{mmHg}$ in diastolic blood pressure may be useful at a population level; however the intensity of intervention applied to individuals required to achieve this is not realistic for community control of high blood pressure'. In our review, two large studies targeting salt reduction (TOHP I 1992; TOHP II 1997) involved intensive interventions whereas the remaining six studies involved low intensity interventions. In subgroup analysis there was no evidence of an effect of intervention intensity on outcome although there was heterogeneity in the trial effects in the low intensity group, possibly reflecting the different intervention types, with three targeting salt reduction as well as general healthy eating advice, and three targeting reductions in fat and/or increasing fruit, vegetable and fibre consumption. Given the evidence of effectiveness of low intensity interventions is limited, and given the importance of processed food as a source of sodium, we agree with Hooper et al that "changes in food production and catering practices" are needed (Hooper 2004a).

A further Cochrane review (Hooper 2000) examined the effectiveness of interventions to reduce dietary fat, but has only reported on mortality and cardiovascular events and not changes in lipid levels, although these were included as secondary outcomes. Within healthcare, a Cochrane review has assessed the effects of dietary advice given by a dietitian compared with other health professionals (Thompson 2003), concluding that dietitians were better than doctors at lowering blood cholesterol, but not other diet-related outcomes, in the short to medium term.

\section{A U THORS'CONCLUSIONS}

\section{Implications for practice}

We made estimates, corrected for regression dilution bias, of the effects of reductions in serum cholesterol, and diastolic BP on the incidence of coronary heart disease and stroke. Based on randomised controlled trials in primary prevention, a reduction of 0.6 $\mathrm{mmol} / \mathrm{L}(10 \%)$ in serum cholesterol will reduce coronary heart disease by $25 \%$ (Law 1994). The estimated effect of a $5 \mathrm{mmHg}$ reduction of diastolic BP, based on cohort studies, is a $21 \%$ reduction in coronary heart disease and a $34 \%$ reduction in stroke. (MacMahon 1994) Applying these estimates to our summary effects the dietary intervention may reduce coronary heart disease incidence by $12 \%$ ( $5 \%$ due to cholesterol lowering) and stroke by $11 \%$. The estimates assume the observed changes in dietary habits would be sustained, and that the reductions in risk attributable to the changes in cholesterol and diastolic BP can be combined additively.

Our review suggests that the average changes in individual nutrients and related risk factors obtained through dietary advice are likely to be relatively small. When aggregated across the entire dietary pattern, however, several small changes in food habits may lead to greater health gains than the above estimates would suggest. In support of this view, the Lyon Diet Heart trial of a Mediterranean-type obtained a reduction of more than $50 \%$, compared to the control group, in the recurrence of fatal and nonfatal cardiovascular disease over 4 years of study (De Lorgeril 1999).

The public health significance of national dietary patterns is not disputed. Here we have assembled the evidence on the effectiveness of dietary advice given to individuals and small groups in a variety of settings. The review shows that brief interventions are modestly effective in reducing blood lipid levels, blood pressure and dietary fat intake, and increasing fruit and vegetable intake. Variation in the nature and combination of the messages given across the included studies meant that it was not possible to identify "best advice". The extent of dietary change is influenced by the intensity and duration of intervention, and by perceived disease risk. There appears to be little if any gain in effectiveness by locating health promotion in primary care in contrast to work places and other non-healthcare settings. Brief dietary interventions aimed at the whole population are likely to produce health gain; however the workload and cost to the UK National Health Service and other healthcare systems requires careful assessment (Brunner 2006).

\section{Implications for research}

Questions remain about the most effective way to promote dietary change among healthy adults. Systematic research is needed on the effectiveness of non-individualised modes of dietary health promotion at population and community level (Thorogood 2007). There is a shortage of evidence on the effectiveness of minimal interventions, and their specific components, to promote dietary 
change in UK healthcare and other settings. High quality trials with follow up for 1 year or more are notably sparse. Trials utilising quality of life outcomes or cost-effectiveness evaluation are lacking. If health promotion is targeted in deprived areas $(\mathrm{DOH}$ 2004) with a high proportion of minority ethnic groups, it may be that dietary change will depend as much on wider determinants, particularly access and availability of healthy foods (Morris 2004) as it will on information and motivation.

\section{ACKNOWLEDGEMENTS}

We are grateful to Gillian Hewitt who contributed to the original iteration of this review (first published in issue 4, 2005), by carrying out literature searches, library research and appraisal of abstracts. With thanks to Drs Sorensen and Stoddard from the Treatwell 5-a-day study for providing additional data. With thanks to Drs Coates, Feng, Kuniyuki and Bowen for providing additional data from their study, the Women's Health Trial Feasibility Study in Minority Populations. With thanks to Dr Maskarinec for clarifying the nature of the intervention setting in her study, and Dr Ross Prentice for clarifying the nature of the intervention settings in the Women's Health Trial Vanguard Study and Feasibility Study in Minority Populations. With thanks to Dr Beresford for providing additional data for the Seattle 5-a-day worksite programme, and to Dr Djuric for providing additional data from the Nutrition and Breast Health Study. We are grateful for the contributions of Annie Beaumont, Sam Pearson and Jean Persaud to the review process.

\section{R E F E R E N C E S}

\section{References to studies included in this review}

Anderson high fibre \{published data only\} Anderson JW, Garrity TF, Wood CL, Whitis SE, Smith BM, Oeltgen PR. Prospective, randomized, controlled comparison of the effects of low-fat and low-fat plus highfiber diets on serum lipid concentrations. American Journal of Clinical Nutrition 1992;56(5):887-94.

Anderson low fibre \{published data only\} Anderson JW, Garrity TF, Wood CL, Whitis SE, Smith BM, Oeltgen PR. Prospective, randomized, controlled comparison of the effects of low-fat and low-fat plus highfiber diets on serum lipid concentrations. American Journal of Clinical Nutrition 1992;56(5):887-94.

Baron men 1990 \{published data only\}

Baron JA, Gleason R, Crowe B, Mann JI. Preliminary trial of the effect of general practice based nutritional advice. British Journal of General Practice 1990;40(333):137-41.

Baron women 1990 \{published data only\}

Baron JA, Gleason R, Crowe B, Mann JI. Preliminary trial of the effect of general practice based nutritional advice. British Journal of General Practice 1990;40(333):137-41.

Beresford 1997 \{published data only\} Beresford SAA, Curry SJ, Kristal AR, Lazovich D, Feng Z, Wagner $\mathrm{EH}$. A dietary intervention in primary care practice: the eating patterns study. American Journal of Public Health 1997;87(4):610-6.

Beresford 2006 \{published and unpublished data\} Beresford SA, Johnson KC, Ritenbaugh C, Lasser NL, Snetselaar LG, Black HR, et al.Low-fat dietary pattern and risk of colorectal cancer: the Women's Health Initiative Randomized Controlled Dietary Modification Trial. JAMA 2006;295(6):643-54
Bloemberg 1991 \{published data only\}

* Bloemberg BPM, Kromhout D, Goddijn HE, Jansen A, Obermann-deBoer GL. The impact of the guidelines for a healthy diet of the Netherlands Nutrition Council on total and high density lipoprotein cholesterol in hypercholesterolemic free-living men. American Journal of Epidemiology 1991;134(1):39-48.

Brekke 2005 \{published data only\}

* Brekke HK, Jansson PA, Lenner RA. Long-term (1- and 2-year) effects of lifestyle intervention in type 2 diabetes relatives. Diabetes Research \& Clinical Practice 2005 Dec;70 (3):225-34.

Brekke HK, Jansson PA, Månsson JE, Lenner RA. Lifestyle changes can be achieved through counseling and followup in first-degree relatives of patients with type 2 diabetes. Journal of the American Dietetic Association 2003;103(7): 835-43.

Brekke HK, Lenner RA, Taskinen MR, Mansson JE, Funahashi T, Matsuzawa Y, et al.Lifestyle modification improves risk factors in type 2 diabetes relatives. Diabetes Research \& Clinical Practice 2005 Apr;68(1):18-28.

Buller 1999 \{published data only\} Buller DB, Morrill C, Taren D, Aickin M, Sennott-Miller L, Buller MK, et al.Randomized trial testing the effect of peer education at increasing fruit and vegetable intake. Journal of the National Cancer Institute 1999;91(17):1491-1500.

Cheng 2004 \{published data only\} Cheng C, Graziani C, Diamond JJ. Cholesterol-lowering effect of the Food for Heart Nutrition Education Program. Journal of the American Dietetic Association 2004;104(12): 1868-72.

Coates WHT MP 1999 \{published and unpublished data\} Bowen D, Clifford CK, Coates R, Evans M, Fenf Z, Fouad M, et al.The women's health trial feasibility study in 
minority populations: design and baseline descriptions. Annals of Epidemiology 1996;6:507-19.

Coates RJ, Bowen DJ, Kristal AR, Feng Z, Oberman A, Hall WD, et al.The women's health trial feasibility study in minority populations: changes in dietary intakes. American Journal of Epidemiology 1999;149(12):1104-12.

Cox 1996 \{published data only\}

Cox RH, Gonzales-Vigilar MCRV, Novascone MA, SilvaBarbeau I. Impact of cancer intervention on diet related cardiovascular disease risks of white and African-American EFNEP clients. Journal of Nutrition Education 1996;28: 209-18.

Djuric combination \{published and unpublished data\} Djuric Z, Ren J, Mekhovich O, Venkatranamoorthy R, Heilbrun LK. Effects of high fruit-vegetable and/or low-fat intervention on plasma micronutrient levels. Journal of the American College of Nutrition 2006;25(3):178-87.

Radakovich K, Heilbrun LK, Venkatranamamoorthy R, Lababidi S, Klurfeld DM, Djuric Z. Women participating in a dietary intervention trial maintain dietary changes without much effect on household members. Nutrition and Cancer 2006;55(1):44-52.

Djuric high F\&V \{published and unpublished data\}

* Djuric Z, Ren J, Mekhovich O, Venkatranamoorthy R, Heilbrun LK. Effects of high fruit-vegetable and/or low-fat intervention on plasma micronutrient levels. Journal of the American College of Nutrition 2006 Jun;25(3):178-87. Radakovich K, Heilbrun LK, Venkatranamamoorthy R, Lababidi S, Klurfeld DM, Djuric Z. Women participating in a dietary intervention trial maintain dietary changes without much effect on household members. Nutrition \& Cancer 2006;55(1):44-52.

Elder promotora \{published data only\}

Elder JP, Ayala GX, Campbell NR, Arredondo EM, Slymen DJ, Baquero B, et al.Long-term effects of a communication intervention for Spanish-dominant Latinas. American Journal of Preventive Medicine 2006 Aug;31(2):159-66.

Elder tailored \{published data only\}

Elder JP, Ayala GX, Campbell NR, Arredondo EM, Slymen DJ, Baquero B, et al.Long-term effects of a communication intervention for Spanish-dominant Latinas. American Journal of Preventive Medicine 2006 Aug;31(2):159-66.

Fuemmeler 2006 \{published data only\}

Fuemmeler BF, Masse LC, Yaroch AL, Resnicow K, Campbell MK, Carr C, et al.Psychosocial mediation of fruit and vegetable consumption in the body and soul effectiveness trial. Health Psychology 2006;25(4):474-83.

Gann 2003 \{published data only\}

Gann PH, Chatterton RT, Gapstur SM, Liu K, Garside D, Giovanazzi S, et al.The effects of a low-fat/high-fiber diet on sex hormone levels and menstrual cycling in premenopausal women: a 12-month randomized trial (the diet and hormone study). Cancer 2003;98:1870-9.

Havas 1998 \{published data only\}

Havas S, Anliker J, Damron D, Langenberg P, Ballesteros M, Feldman R. Final results of the Maryland WIC 5-a- day promotion program. American Journal of Public Health 1998;88(8):1161-7.

Hellenius 1993 \{published data only\}

Hellenius ML, de Faire U, Berglund B, Hamsten A, Krakau I. Diet and exercise are equally effective in reducing risk for cardiovascular disease. Results from a randomised controlled study in men with slightly to moderately raised cardiovascular risk factors. Atherosclerosis 1993;103:81-91.

Henderson WHTV 1990 \{published data only\} Gorbach SL, Morrill-LaBrode A, Woods MN, Dwyer JT, Selles WD, Henderson M, et al.Changes in food patterns during a low-fat dietary intervention in women. Journal of the American Dietetic Association 1990;90(6):802-9.

* Henderson MM, Kushi LH, Thompson DJ, Gorbach SL, Clifford CK, Insull WJ, et al.Feasibility of a randomized trial of a low-fat diet for the prevention of breast cancer: dietary compliance in the Women's Health Trial Vanguard Study. Preventive Medicine 1990;19(2):115-33.

Insull W, Henderson MM, Prentice RL, Thompson DJ, Clifford C, Goldman S, et al.Results of a randomized feasibility study of a low-fat diet. Archives of Internal Medicine 1990;150(2):421-7.

John 2002 \{published data only\} John JH, Ziebland S, Yudkin P, Roe LS, Neil HA. Effects of fruit and vegetable consumption on plasma antioxidant concentrations and blood pressure: a randomised controlled trial. Lancet 2002;359(9322):1969-74.

Keyserling 1997 \{published data only\}

Keyserling TC, Ammerman AS, Davis CE, Mok MC, Garrett J, Simpson R. A randomized controlled trial of a physician-directed treatment program for low-income patients with high blood cholesterol: The southeast cholesterol project. Archives of Family Medicine 1997;6(2): $135-45$.

Koopman 1990 \{published data only\}

Koopman H, Spreeuwenberg C, Westerman RF, Donker AJM. Dietary treatment of patients with mild to moderate hypertension in a general practice: a pilot intervention study (1). The first three months. Journal of Human Hypertension 1990;4(4):368-71.

Kristal 2000 \{published data only\} Kristal AR, Curry SJ, Shattuck AL, Feng Z, Li S. A randomized trial of a tailored, self-help dietary intervention: The Puget Sound Eating Patterns Study. Preventive Medicine 2000;31(4):380-9.

Lanza men 2001 \{published data only\}

* Lanza E, Schatzkin A, Daston C, Corle D, Freedman L, Ballard-Barbash R, et al.Implementation of a 4-y, highfiber, high-fruit-and-vegetable, low-fat dietary intervention: results of dietary changes in the Polyp Prevention Trial. American Journal of Clinical Nutrition 2001;74(3):387-401. Schatzkin A, Lanza E, Corle D, Lance P, Iber F, Caan B, et al.Lack of effect of a low-fat, high-fiber diet on the recurrence of colorectal adenomas. New England Journal of Medicine 2000;342(16):1149-55. 
Lanza women 2001 \{published data only\}

* Lanza E, Schatzkin A, Daston C, Corle D, Freedman L, Ballard-Barbash R, et al.Implementation of a 4-y, highfiber, high-fruit-and-vegetable, low-fat dietary intervention: results of dietary changes in the Polyp Prevention Trial. American Journal of Clinical Nutrition 2001;74(3):387-401. Schatzkin A, Lanza E, Corle D, Lance P, Iber F, Caan B, et al.Lack of effect of a low-fat, high-fiber diet on the recurrence of colorectal adenomas. New England Journal of Medicine 2000;342(16):1149-55.

Little 2004 \{published data only\}

Little P, Kelly J, Barnett J, Dorward M, Margetts B, Warm D. Randomised controlled factorial trial of dietary advice for patients with a single high blood pressure reading in primary care. BMJ 2004;328(7447):1054.

Lutz non-tailored \{published data only\} Lutz SF, Ammerman AS, Atwood JR, Campbell MK, DeVellis RF, Rosamond WD. Innovative newsletter interventions improve fruit and vegetable consumption in healthy adults. Journal of the American Dietetic Association 1999;99(6):705-9.

Lutz tailored\&goals \{published data only\} Lutz SF, Ammerman AS, Atwood JR, Campbell MK, DeVellis RF, Rosamond WD. Innovative newsletter interventions improve fruit and vegetable consumption in healthy adults. Journal of the American Dietetic Association 1999;99(6):705-9.

Lutz tailored 1999 \{published data only\} Lutz SF, Ammerman AS, Atwood JR, Campbell MK, DeVellis RF, Rosamond WD. Innovative newsletter interventions improve fruit and vegetable consumption in healthy adults. Journal of the American Dietetic Association 1999;99(6):705-9.

Maskarinec 1999 \{published data only\} Maskarinec G, Chan CL, Meng L, Franke AA, Cooney RV. Exploring the feasibility and effects of a high-fruit and -vegetable diet in healthy women. Cancer Epidemiology, Biomarkers \& Prevention 1999;8(10):919-24.

Moy 2001 \{published data only\}

Moy TF, Yanek LR, Raquen $\sim$ JV, Bezirdjian PJ, Blumenthal RS, Wilder LB, et al.Dietary counseling for high blood cholesterol in families at risk of coronary disease. Preventive Cardiology 2001;4(4):158-64.

Neil dietitian1995 \{published data only\}

Neil HAW, Roe L, Godlee RJP, Moore JW, Clark GMG, Brown J, et al.Randomised trial of lipid lowering dietary advice in general practice:the effects on serum lipids, lipoproteins, and antioxidants. BMJ 1995;310:569-73.

Neil nurse 1995 \{published data only\} Neil HAW, Roe L, Godlee RJP, Moore JW, Clark GMG, Brown J, et al.Randomised trial of lipid lowering dietary advice in general practice:the effects on serum lipids, lipoproteins, and antioxidants. BMJ 1995;310:569-73.
Riddell 2000 \{published data only\}

Riddell LJ, Chisholm A, Williams S, Mann JI. Dietary strategies for lowering homocysteine concentrations.

American Journal of Clinical Nutrition 2000;71(6):1448-54.

\section{Rock 2001 \{published data only\}}

Rock CL, Moskowitz A, Huizar B, Saenz CC, Clark JT, Daly TL, et al.High vegetable and fruit diet intervention in premenopausal women with cervical intraepithelial neoplasia. Journal of the American Dietetic Association 2001; 101(10): 1167-74.

Sacerdote 2006 \{published data only\}

Sacerdote C, Fiorini L, Rosato R, Audenino M, Valpreda M, Vineis P. Randomized controlled trial: Effect of nutritional counselling in general practice. International Journal of Epidemiology 2006;35(2):409-15.

Schatzkin 2000 \{published data only\}

* Schatzkin A, Lanza E, Corle D, Lance P, Iber F, Caan B, et al.The Polyp Prevention Trial Study Group: Lack of effect of a low-fat, high fibre diet on the recurrence of colorectal adenomas. New England Journal of Medicine 2000;342(16): $1149-55$.

Schatzkin A, Lanza E, Freedman LS, Tangrea J, Cooper MR Marshall JR, et al.The polyp prevention trial I: Rationale, design, recruitment and baseline participant characteristics. Cancer Epidemiology, Biomarkers \& Prevention 1996;5: 375-83.

Smith-Warner 2000 \{published data only\} Smith-Warner SA, Elmer PJ, Tharp TM, Fosdick L, Randall $\mathrm{B}$, Gross $\mathrm{M}$, et al.Increasing vegetable and fruit intake: Randomized intervention and monitoring in an at-risk population. Cancer Epidemiology, Biomarkers \& Prevention 2000;9(3):307-317.

Sorensen work+family \{published and unpublished data\} Sorensen G, Stoddard A, Peterson K, Cohen N, Hunt MK, Stein E, et al.Increasing fruit and vegetable consumption through worksites and families in the Treatwell 5-a-day study. American Journal of Public Health 1999;89(1):54-60.

Sorensen worksite \{published and unpublished data\} Sorensen G, Stoddard A, Peterson K, Cohen N, Hunt MK, Stein $\mathrm{E}$, et al.Increasing fruit and vegetable consumption through worksites and families in the Treatwell 5-a-day study. American Journal of Public Health 1999;89(1):54-60.

Stevens 2003 \{published data only\} Stevens VJ, Glasgow RE, Toobert DJ, Karanja N, Smith KS. One-year results from a brief, computer-assisted intervention to decrease consumption of fat and increase consumption of fruits and vegetables. Preventive Medicine 2003;36(5):594-600.

Takahashi 2006 \{published data only\}

* Takahashi Y, Sasaki S, Okubo S, Hayashi M, Tsugane S. Blood pressure change in a free-living population-based dietary modification study in Japan. Journal of Hypertension 2006;24(3):451-8.

Takashashi Y, Sasaki S, Takahashi M, Okubo S, Hayashi M, Tsugane S. A population-based intervention trial in a high risk area for stomach cancer and stroke: changes in intakes 
and related biomarkers. Preventive Medicine 2003;37(5): $432-41$.

Tilley 1999 \{published data only\}

* Tilley BC, Glanz K, Kristal AR, Hirst K, Li S, Vernon SW, et al.Nutrition intervention for high-risk auto workers: results of the Next Step Trial. Preventive Medicine 1999;28 (3):284-92.

Tilley BC, Vernon SW, Glanz K, Myers R, Sanders K, Lu M, et al.Worksite cancer screening and nutrition intervention for high-risk auto workers: design and baseline findings of the Next Step Trial. Preventive Medicine 1997;26:227-35.

TOHP I 1992 \{published data only\}

Whelton PK, Hebert PR, Cutler JA, Applegate WB, Eberlein KA, Klag MJ, et al.Baseline characteristics of participants in phase 1 of the trials of hypertension prevention. Annals of Epidemiology 1992;2:295-310.

* Whelton PK, Kumanyika SK, Cook NR, Cutler JA, Borhani NO, Hennekens CH, et al.Efficacy of nonpharmacologic interventions in adults with highnormal blood pressure: results from phase 1 of the Trials of Hypertension Prevention. Trials of hypertension prevention collaborative research group. American Journal of Clinical Nutrition 1997;65(2 Suppl):652s-60s.

TOHP II 1997 \{published data only\}

* Whelton PK, Appel L, Charleston J, Dalcin A, Haythornthwaite J, Rosofsky W, et al.Effects of weight loss and sodium reduction intervention on blood pressure and hypertension incidence in overweight people with high-normal blood pressure. The trials of hypertension prevention, phase II. Archives of Internal Medicine 1997;157 (6):657-67.

van der Veen 2002 \{published data only\}

van der Veen J, Bakx C, van den Hoogen H, Verheijden M, van den Bosch W, van Ween C, et al.Stage-matched nutrition guidance for patients at elevated risk for cardiovascular disease: a randomized intervention study in family practice. Journal of Family Practice 2002;51(9): $751-8$.

\section{References to studies excluded from this review}

\section{Ammerman 2003 \{published data only\}}

Ammerman AS, Keyserling T, Atwood J, Thompson R, Simpson SH. High-quality nutrition counselling for hypercholesterolaemia by public health nurses in rural areas does not affect total blood cholesterol. Evidence Based Healthcare 2003;7(4):187-9.

* Ammerman AS, Keyserling TC, Atwood JR, Hosking JD, Zayed H, Krasny C. A randomized controlled trial of a public health nurse directed treatment program for rural patients with high blood cholesterol. Preventive Medicine 2003;36:340-51.

\section{Anderson 2001 \{published data only\}}

Anderson JV, Bybee DI, Brown RM, McLean DF, Garcia $\mathrm{EM}$, Breer ML, et al.5 a day fruit and vegetable intervention improves consumption in a low income population. Journal of the American Dietetic Association 2001;101(2):195-202.
Bhargava 2004 \{published data only\}

Bhargava A, Hays J. Behavioral variables and education are predictors of dietary change in the Women's Health Trial: Feasibility Study in Minority Populations. Preventive Medicine 2004;38(4):442-51.

Boyd 1990 \{published data only\}

Boyd NF, Cousins M, Beaton M, Kriukov V, Lockwood G, Tritchler D. Quantitative changes in dietary fat intake and serum cholesterol in women: results from a randomized, controlled trial. American Journal of Clinical Nutrition 1990;52(3):470-6.

Braeckman 1999 \{published and unpublished data\} Braeckman L, De Bacquer D, Maes L, De Backer G. Effects of a low-intensity worksite-based nutrition intervention. Occupational Medicine 1999;49(8):549-55.

Burke 2005 \{published data only\} Burke LE, Dunbar-Jacob J, Orchard TJ, Sereika SM. Improving adherence to a cholesterol-lowering diet: a behavioral intervention study. Patient Education \& Counseling 2005;57(1):134-42.

Cappuccio 2006 \{published data only\} Cappuccio FP, Kerry SM, Micah FB, Plange-Rhule J, Eastwood JB. A community programme to reduce salt intake and blood pressure in Ghana. BMC Public Health 2006;6:13.

Chalmers 1986 \{published data only\} Chalmers J, Morgan T, Doyle A, Dickson B, Hopper J, Mathews J, et al.Australian National Health and Medical Research Council dietary salt study in mild hypertension. Journal of Hypertension - Supplement 1986;4(6):S629-37.

Colombo 2005 \{published data only\} Colombo C, Muti P, Pala V, Cavalleri A, Venturelli E, Locardi M, et al.Plant-based diet, serum fatty acid profile, and free radicals in postmenopausal women: the diet and androgens (DIANA) randomized trial. International Journal of Biological Markers $2005 \mathrm{Jul} ; 20(3): 169-76$.

Eid 2006 \{published data only\}

Eid HMA, Arnesen H, Hjerkinn EM, Lyberg T, Ellingsen I, Seljeflot I. Effect of diet and omega-3 fatty acid intervention on asymmetric dimethylarginine. Nutrition \& Metabolism 2006;3:1-10

Estruch 2006 \{published data only\}

Estruch R, Martinez-Gonzalez MA, Corella D, SalasSalvado J, Ruiz-Gutierrez V, Covas MI, et al.Effects of a Mediterranean-style diet on cardiovascular risk factors: a randomized trial. Annals of Internal Medicine 2006;145(1): $1-11$.

Fehily 1983 \{published data only\}

Fehily AM, Burr ML, Phillips KM, Deadman NM. The effect of fatty fish on plasma lipid and lipoprotein concentrations. American Journal of Clinical Nutrition 1983;38(3):349-51.

Fitzgibbon 2004 \{published data only\} Fitzgibbon ML, Gapstur SM, Knight SJ. Results of Mujeres Felices por ser Saludables: a dietary/breast health 
randomized clinical trial for Latino women. Annals of Behavioral Medicine 2004;28(2):95-104.

\section{Fries 2005 \{published data only\}}

Fries E, Edinboro P, McClish D, Manion L, Bowen D, Beresford SA, et al.Randomized trial of a low-intensity dietary intervention in rural residents: the Rural Physician Cancer Prevention Project. American Journal of Preventive Medicine 2005;28(2):162-8.

Havas 2003 \{published data only\}

Havas S, Anliker J, Greenberg D, Block G, Block T, Blik C, et al.Final results of the Maryland WIC Food for Life Program. Preventive Medicine 2003;37(5):406-16.

Henkin 2000 \{published data only\}

Henkin Y, Shai I, Zuk R, Brickner D, Zuilli I, Neumann $\mathrm{L}$, et al.Dietary treatment of hypercholesterolemia: do dietitians do it better? A randomized, controlled trial. American Journal of Medicine 2000;109(7):549-55.

HPTR 1990 \{published data only\}

Hypertension Prevention Trial Research Group. The hypertension prevention trial: three-year effects of dietary changes on blood pressure. Archives of Internal Medicine 1990;150(1):153-62.

Hunt 2001 \{published data only\}

Hunt MK, Lobb R, Delichatsios HK, Stone C, Emmons K, Gillman MW. Process evaluation of a clinical preventive nutrition intervention. Preventive Medicine 2001;33(2 Pt 1):82-90.

Hyman 1998 \{published data only\}

Hyman DJ, Ho KSI, Dunn JK, Simons-Morton D. Dietary intervention for cholesterol reduction in public clinic patients. American Journal of Preventive Medicine 1998;15 (2):139-45.

Iso 2002 \{published data only\}

Iso H, Imano H, Nakagawa Y, Kiyama M, Kitamura A, Sato $S$, et al.One-year community-based education program for hypercholesterolemia in middle-aged Japanese: a long-term outcome at 8-year follow-up. Atherosclerosis 2002;164(1): 195-202.

Korhonen 2003 \{published data only\}

Korhonen M, Kastarinen M, Uusitupa M, Puska P, Nissinen A. The effect of intensified diet counseling on the diet of hypertensive subjects in primary health care: a 2-year open randomized controlled trial of lifestyle intervention against hypertension in eastern Finland. Preventive Medicine 2003; 36(1):8-16

Leduc 1994 \{published data only\}

Leduc CP, Cherniak D, Faucher J. Effectiveness of a group dietary intervention on hypercholesterolemia: a randomised controlled clinical trial. Atherosclerosis 1994;109(1-2):149.

Marcus 2001 \{published data only\}

Marcus AC, Heimendinger J, Wolfe P, Fairclough D, Rimer BK, Morra M, et al.A randomized trial of a brief intervention to increase fruit and vegetable intake: a replication study among callers to the CIS. Preventive Medicine 2001;33(3):204-16.
Martin 2006 \{published data only\}

Martin LJ, Greenberg CV, Kriukov V, Minkin S, Jenkins DJ, Boyd NF. Intervention with a low-fat, high-carbohydrate diet does not influence the timing of menopause. American Journal of Clinical Nutrition 2006 Oct;84(4):920-8.

Ni Mhurchu 1998 \{published data only\} Ni Mhurchu C, Margetts BM, Speller V. Randomised clinical trial comparing the effectiveness of two dietary interventions for patients with hyperlipidaemia. Clinical Science 1998;95:479-87.

Ockene 1999 \{published data only\} Ockene IS, Hebert JR, Ockene JK, Saperia GM, Stanek E, Nicolosi R, et al.Effect of physician-delivered nutrition counseling training and an office-support program on saturated fat intake, weight, and serum lipid measurements in a hyperlipidemic population: Worcester area trial for counseling in hyperlipidemia (WATCH). Archives of Internal Medicine 1999;159(7):725-31.

Resnicow 2001 \{published data only\} Resnicow K, Jackson A, Wang T, De AK, McCarty F, Dudley WN, et al.A motivational interviewing intervention to increase fruit and vegetable intake through Black churches: results of the Eat for Life trial. American Journal of Public Health 2001;91(10):1686-93.

Richards 2006 \{published data only\} Richards A, Kattelmann KK, Ren C. Motivating 18- to 24year-olds to increase their fruit and vegetable consumption. Journal of the American Dietetic Association 2006;106(9): 1405-11.

Sartorelli 2005 \{published data only\} Sartorelli DS, Sciarra EC, Franco LJ, Cardoso MA. Beneficial effects of short-term nutritional counselling at the primary health-care level among Brazilian adults. Public Health Nutrition 2005;8(7):820-5.

Simon 1997 \{published data only\}

Simon MS, Heilbrun LK, Boomer-Allison, Kresge C, Depper J, Kim PN, et al.A randomized trial of a low-fat dietary intervention in women at high risk for breast cancer. Nutrition \& Cancer 1997;27(2):136-42.

Smith 1997 \{published data only\}

Smith AM, Owen N, Baghurst KI. Influence of socioeconomic status on the effectiveness of dietary counselling in healthy volunteers. Journal of Nutrition Education 1997;29(1):27-35.

Sorensen 1992 \{published data only\} Sorensen G, Morris DM, Hunt MK, Hebert JR, Harris DR, Stoddard A, et al.Work-site nutrition intervention and employees' dietary habits: the Treatwell program. American Journal of Public Health 1992;82(6):877-80.

Torjesen 1997 \{published data only\}

Torjesen PA, Birkeland KI, Anderssen SA, Hjermann I, Holme I, Urdal P. Lifestyle changes may reverse development of the insulin resistance syndrome. The Oslo Diet and Exercise Study: a randomized trial. Diabetes Care 1997;20 (1):26-31. 
WHI 2006 \{published data only\}

Beresford SA, Johnson KC, Ritenbaugh C, Lasser NL, Snetselaar LG, Black HR, et al.Low-fat dietary pattern and risk of colorectal cancer: the Women's Health Initiative Randomized Controlled Dietary Modification Trial. JAMA 2006;295(6):643-54.

* Howard BV, Van HL, Hsia J, Manson JE, Stefanick ML, Wassertheil-Smoller $S$, et al.Low-fat dietary pattern and risk of cardiovascular disease: the Women's Health Initiative Randomized Controlled Dietary Modification Trial. JAMA 2006;295(6):655-66.

Prentice RL, Caan B, Chlebowski RT, Patterson R, Kuller LH, Ockene JK, et al.Low-fat dietary pattern and risk of invasive breast cancer: the Women's Health Initiative Randomized Controlled Dietary Modification Trial. JAMA 2006;295(6):629-42.

Willaing 2004 \{published data only\}

Willaing I, Ladelund S, Jorgensen T, Simonsen T, Nielsen LM. Nutritional counselling in primary health care: a randomized comparison of an intervention by general practitioner or dietician. European Journal of Cardiovascular Prevention \& Rehabilitation 2004;11(6):513-20.

Williams-Piehota \{published data only\}

Williams-Piehota P, Pizarro J, Navarro Silvera SA, Mowad L, Salovey P. Need for cognition and message complexity in motivating fruit and vegetable intake among callers to the cancer information service. Health Communication 2006;19 (1):75-84

\section{References to ongoing studies}

\section{Bowen 2004 \{published data only\}}

Bowen DJ, Beresford SA, Vu T, Feng Z, Tinker L, Hart A, Jr, et al.Baseline data and design for a randomized intervention study of dietary change in religious organizations. Preventive Medicine 2004;39(3):602-11.

\section{Additional references}

\section{Appel 1997}

Appel LJ, Moore TJ, Obarzanek E, Vollmer WM, Svetkey LP, Sacks FM, et al.A clinical trial of the effects of dietary patterns on blood pressure. New England Journal of Medicine 1997;336:1117-24.

\section{Avenell 2004}

Avenell A, Broom J, Brown TJ, Poobalan A, Aucott L, Stearns SC, et al.Systematic review of the long-term effects and economic consequences of treatments for obesity and implications for health improvement. Health Technology Assessment. Winchester, UK, 2004; Vol. 8, issue 21.

Brunner 2006

Brunner EJ. Commentary: What is the best way to promote healthy eating?. International Journal of Epidemiology 2006; 35:414-7. [MEDLINE: PMID: 16507640]

\section{Campbell 2002}

Campbell K, Waters E, O’Meara S, Kelly S, Brown T, Summerbell C. Interventions for preventing obesity in children. Cochrane Database of Systematic Reviews 2005, Issue 3. [DOI: 10.1002/14651858.CD001871.pub2]

\section{Campbell 2003}

Summerbell CD, Ashton V, Campbell KJ, Edmunds L, Waters E. Interventions for treating obesity in children. Cochrane Database of Systematic Reviews 2003, Issue 3. [DOI: 10.1002/14651858.CD001872]

\section{Cappuccio 1991}

Cappuccio FP, MacGregor GA. Does potassium supplementation lower blood pressure? A meta-analysis of published trials. Journal of Hypertension 1991;9:465-73.

\section{Cochrane Handbook}

Deeks JJ, Higgins, JPT, Altman DG, editors. Analysing and presenting results. In: Higgins JPT, Green S editor(s). Cochrane Handbook for Systematic Reviews of Interventions 4.2.6 [updated September 2006]; Section 8. In: The Cochrane Library, Issue 4, 2006. Chichester UK: John Wiley \& Sons Ltd, 2006.

\section{COMA 1994}

Committee on Medical Aspects of Food Policy. Nutritional Aspects of Cardiovascular Disease. London: HMSO, 1994.

\section{Dayton 1969}

Dayton S, Pearce M. Prevention of coronary heart disease and other complications of atherosclerosis by modified diet. American Journal of Medicine 1969;46:751-62.

\section{De Lorgeril 1999}

De Lorgeril M, Salen P, Martin J-L, Monjaud I, Delaye J, Mamelle N. Mediterranean diet, traditional risk factors, and the rate of cardiovascular complications after myocardial infarction. Final report of the Lyon Diet Heart Study. Circulation 1999;99(6):778-85.

\section{Dickersin 1994}

Dickersin K, Scherer R, Lefebvre C. Identifying relevant studies for systematic reviews. BMJ 1994;309:1286-91.

\section{DOH 2004}

Department of Health. Choosing health: making healthier choices easier. London: Department of Health, 2004. [: CM6374]

FHSG 1994

Family Heart Study Group. Randomised controlled trial evaluating cardiovascular screening and intervention in general practice: principal results of British family heart study. British Medical Journal 1994;308:313-20.

Follmann 1992

Follman D, Elliot P, Suh I, Cutler J. Variance imputation for overviews of clinical trials with continuous response. Journal of Clinical Epidemiology 1992;45:769-73.

Frantz 1989

Frantz DIJ, Dawson AE, Ashman LP, Gatewood CL, Bartsch EG, Kuba K, et al.Test of effect of lipid lowering by diet on cardiovascular risk. Arteriosclerosis 1989;9:129-35.

\section{He 2004}

He FJ, MacGregor GA. Effect of longer-term modest salt reduction on blood pressure. Cochrane Database 
of Systematic Reviews 2004, Issue 1. [DOI: 10.1002/ 14651858.CD004937]

\section{Hooper 2000}

Hooper L, Summerbell CD, Higgins JPT, Thompson RL, Clements G, Capps N, et al.Reduced or modified dietary fat for prevention of cardiovascular disease. Cochrane Database of Systematic Reviews 2000, Issue 2. [DOI: 10.1002/ 14651858.CD002137]

Hooper 2004a

Hooper L, Bartlett C, Davey Smith G, Ebrahim S. Advice to reduce dietary salt for prevention of cardiovascular disease. Cochrane Database of Systematic Reviews 2004, Issue 1. [DOI: 10.1002/14651858.CD003656.pub2]

\section{Hooper 2004b}

Hooper L, Thompson RL, Harrison RA, Summerbell CD, Moore $\mathrm{H}$, Worthington $\mathrm{HV}$, et al.Omega 3 fatty acids for prevention and treatment of cardiovascular disease. Cochrane Database of Systematic Reviews 2004, Issue 4. [DOI: 10.1002/14651858.CD003177.pub2]

\section{HSS 2005}

US Dept of Health and Human Services, US Dept of Agriculture. Dietary guidelines for Americans. http:/ /www.healthierus.gov/dietaryguidelines/ [accessed 195 2005]. Washington: US Government Printing Office, 2005.

Hunninghake 1993

Hunninghake DB, Evan MD, Stein EA, Dujovne CA, Harris WS, Feldman EB, et al.The efficacy of intensive dietary therapy alone or combined with lovastatin in outpatients with hypercholesterolemia. New England Journal of Medicine 1993;328:1213-9.

Kelly 2004

Kelly S, Frost G, Whittaker V, Summerbell C. Low glycaemic index diets for coronary heart disease. Cochrane Database of Systematic Reviews 2004, Issue 4. [DOI: 10.1002/14651858.CD004467.pub2]

\section{Knoops 2004}

Knoops KTB, de Groot LCPM, Kromhout D, Perrin AE, Moreiras-Varela O, Menotti A, et al.Mediterranean diet, lifestyle factors, and 10 Year mortality in elderly European men and women. JAMA 2004;12:1433-9.

Law 1994

Law MR, Wald NJ, Thompson SG. By how much and how quickly does reduction in serum cholesterol concentration lower risk of ischaemic heart disease?. BMJ 1994;308: $367-72$.

\section{Lefebvre 1996}

Lefebvre C, McDonald S. Development of a sensitive search strategy for reports of randomised controlled trials in EMBASE. Paper presented at the Fourth International Cochrane Colloquium 20-24 Oct. Adelaide, Australia. 1996.

\section{MacMahon 1994}

MacMahon S, Peto R, Cutler J, Collins R, Sorlie P, Neaton $\mathrm{J}$, et al.Blood pressure, stroke, and coronary heart disease.
Part 1, prolonged differences in blood pressure: prospective observational studies corrected for the regression dilution bias. Lancet 1990;335:765-74.

\section{Mensink 1992}

Mensink RP, Zock PL, Katan MB, Hornstra G. Effect of dietary cis and trans fatty acids on serum lipoprotein (a) levels in humans. Journal of Lipid Research 1992;33: 1493-501.

\section{Moher 2001}

Moher D, Schulz KF, Altman DG. The CONSORT statement: revised recommendations for improving the quality of reports on parallel-group randomised trial. Lancet 2001;357:1191-4.

\section{Morris 2004}

Morris JN, Deeming C. Minimum incomes for healthy living (MIHL): next thrust in UK social policy?. Policy and Politics 2004;32:441-54.

\section{Pirozzo 2002}

Pirozzo S, Summerbell CD, Cameron C, Glasziou P. Advice on low-fat diets for obesity. Cochrane Database of Systematic Reviews 2002, Issue 2. [DOI: 10.1002/ 14651858.CD003640]

\section{Ramsay 1991}

Ramsay LE, Yeo WW, Jackson PR. Dietary reduction of serum cholesterol concentration: time to think again. BMJ 1991;303:953-7.

\section{Thompson 2003}

Thompson RL, Summerbell CD, Hooper L, Higgins JPT, Little PS, Talbot D, et al.Dietary advice given by a dietitian versus other health professional or self-help resources to reduce blood cholesterol. Cochrane Database of Systematic Reviews 2003, Issue 3. [DOI: 10.1002/ 14651858.CD001366]

\section{Thorogood 2007}

Thorogood M, Simera I, Dowler E, Summerbell C, Brunner EJ. A systematic review of population and community dietary interventions to prevent cancer. Nutrition Research Reviews 2007;20:74-88. [: doi: 10.1017/ S0954422407733073]

\section{Trichopoulou 2005}

Trichopoulou A, Orfanos P, Norat T, Bueno-de-Mesquita B, Ocke MC, Peeters PH, et al.Modified Mediterranean diet and survival: EPIC-elderly prospective cohort study. $B M J$ 2005;330:991-5.

Turpeinen 1979

Turpeinen O, Karvonen MJ, Pekkarinen M, Miettinen M, Elosuo R, Paavilainen E. Dietary prevention of coronary heart disease: the Finnish mental hospital study. International Journal of Epidemiology 1979;8:99-118.

\section{Watts 1992}

Watts GF, Lewis B, Brunt JNH, Lewis ES, Coltart DJ, Smith LDR, et al.Effects on coronary artery disease of lipid-lowering diet, or diet plus cholestyramine, in the St Thomas' Atherosclerosis Regression Study (STARS). Lancet 1992;339:563-9. 
WHO 2003

World Health Organization. Technical Report Series No 916 :

Diet, nutrition and the prevention of chronic diseases. Report

of the joint WHO/FAO expert consultation. Geneva: World Health Organization, 2003.

* Indicates the major publication for the study 


\section{CHARACTERISTICS OF STUDIES}

\section{Characteristics of included studies [ordered by study ID]}

\section{Anderson high fibre}

\begin{tabular}{|c|c|c|}
\hline Methods & \multicolumn{2}{|c|}{ RCT of parallel group design. The control group $\mathrm{N}$ is halved to take account of the 2 intervention arms } \\
\hline Participants & \multicolumn{2}{|c|}{$\begin{array}{l}\text { High risk - total cholesterol } 5.2-7.8 \mathrm{mmol} / \mathrm{L} \text { on } 2 \text { screenings } 2 \text { weeks apart. Recruited from major em- } \\
\text { ployers, churches and shopping centres in the USA. } 177 \text { participants randomised, } 59.6 \% \text { men, mean age } \\
40.6 \text { years }\end{array}$} \\
\hline Interventions & \multicolumn{2}{|c|}{$\begin{array}{l}\text { Two interventions - both AHA-type cholesterol lowering diets. This trial arm included a high-carbohydrate } \\
\text { fibre diet }(50 \mathrm{~g} / \text { day). Both arms included a } 10 \text { week diet education seminar series ( } 1 \text { hour/week) followed } \\
\text { by } 30 \text { minute individual counselling sessions, plus } 4 \text { home visits from dietitians. Comparison group } \\
\text { received no intervention. Follow up at } 12 \text { months }\end{array}$} \\
\hline Outcomes & \multicolumn{2}{|c|}{ Dietary fibre, total dietary fat and saturated fatty acids $(\% \mathrm{Kcal})$, total, HDL and LDL cholesterol } \\
\hline \multicolumn{3}{|l|}{ Notes } \\
\hline \multicolumn{3}{|l|}{ Risk of bias } \\
\hline Item & Authors' judgement & Description \\
\hline Allocation concealment? & Unclear & B - Unclear \\
\hline
\end{tabular}

Anderson low fibre

\begin{tabular}{|c|c|c|}
\hline Methods & \multicolumn{2}{|c|}{ RCT of parallel group design. } \\
\hline Participants & \multicolumn{2}{|c|}{$\begin{array}{l}\text { High risk - total cholesterol } 5.2-7.8 \mathrm{mmol} / \mathrm{l} \text { on } 2 \text { screenings } 2 \text { weeks apart. Recruited from major employers, } \\
\text { churches and shopping centres in the USA. } 177 \text { participants randomised, } 59.6 \% \text { men, mean age } 40.6 \\
\text { years }\end{array}$} \\
\hline Interventions & \multicolumn{2}{|c|}{$\begin{array}{l}\text { Two interventions - both AHA-type cholesterol lowering diets. This trial arm included a recommended } \\
\text { approximately. } 15 \mathrm{~g} \text { /day fibre diet. See 'Anderson high fibre' for further details of intervention. Follow up } \\
\text { at } 12 \text { months }\end{array}$} \\
\hline Outcomes & \multicolumn{2}{|c|}{ Dietary fibre, total dietary fat and saturated fatty acids (\% Kcal), total, HDL and LDL cholesterol } \\
\hline \multicolumn{3}{|l|}{ Notes } \\
\hline \multicolumn{3}{|l|}{ Risk of bias } \\
\hline Item & Authors' judgement & Description \\
\hline Allocation concealment? & Unclear & B - Unclear \\
\hline
\end{tabular}

Dietary advice for reducing cardiovascular risk (Review) 


\begin{tabular}{|c|c|c|}
\hline Methods & \multicolumn{2}{|c|}{ RCT of parallel group design. } \\
\hline Participants & \multicolumn{2}{|c|}{$\begin{array}{l}\text { Healthy individuals recruited from GP lists in Abingdon, Oxfordshire. } 437 \text { subjects randomised, 51\% } \\
\text { men with mean age } 41.9 \text { years. Men and women have been analysed separately }\end{array}$} \\
\hline Interventions & \multicolumn{2}{|c|}{$\begin{array}{l}\text { Intervention administered by practice nurse. Individual or group session lasting } 30 \text { minutes on dietary } \\
\text { advice to decrease total fat intake to } 30-35 \% \text { of calories and increase dietary fibre. A booklet was also } \\
\text { given to participants on basic ideas of diet, recipes and advice concerning local restaurants. There was a } \\
\text { brief follow-up session at } 1 \text { and } 3 \text { months. The comparison group were told they were part of a nutrition } \\
\text { survey but were offered no dietary advice. Follow up at } 3 \text { and } 12 \text { months ( } 3 \text { month data used as follow- } \\
\text { up less than } 80 \% \text { at } 12 \text { months) }\end{array}$} \\
\hline Outcomes & \multicolumn{2}{|c|}{ Total cholesterol, HDL and LDL cholesterol, dietary fibre. } \\
\hline \multicolumn{3}{|l|}{ Notes } \\
\hline \multicolumn{3}{|l|}{ Risk of bias } \\
\hline Item & Authors' judgement & Description \\
\hline Allocation concealment? & Unclear & B - Unclear \\
\hline \multicolumn{3}{|l|}{ Baron women 1990} \\
\hline Methods & \multicolumn{2}{|c|}{ RCT of parallel group design. } \\
\hline Participants & \multicolumn{2}{|c|}{$\begin{array}{l}\text { Healthy individuals recruited from GP lists in Abingdon, Oxfordshire. } 437 \text { subjects randomised, } 49 \% \\
\text { women with mean age } 41.5 \text { years. Men and women have been analysed separately }\end{array}$} \\
\hline Interventions & \multicolumn{2}{|c|}{$\begin{array}{l}\text { See Baron } 1990 \text { for details of intervention. Followup at } 3 \text { and } 12 \text { months ( } 3 \text { month data used as follow- } \\
\text { up less than } 80 \% \text { at } 12 \text { months) }\end{array}$} \\
\hline Outcomes & \multicolumn{2}{|c|}{ Total cholesterol, HDL and LDL cholesterol, dietary fibre. } \\
\hline \multicolumn{3}{|l|}{ Notes } \\
\hline \multicolumn{3}{|l|}{ Risk of bias } \\
\hline Item & Authors' judgement & Description \\
\hline Allocation concealment? & Unclear & B - Unclear \\
\hline
\end{tabular}




\begin{tabular}{|c|c|c|}
\hline Methods & \multicolumn{2}{|c|}{$\begin{array}{l}\text { Cluster RCT. Physician practice was unit of randomisation. Analysis was at individual level, allowing for } \\
\text { random effects of clinic and physician practice, with physician nested within clinic. The denominator } \\
\text { used in this review is the physician }\end{array}$} \\
\hline Participants & \multicolumn{2}{|c|}{$\begin{array}{l}28 \text { GP practices in } 6 \text { primary care clinics in the USA. Participants attending routine visits without major } \\
\text { illness were recruited. } 2111 \text { participants, } 32 \% \text { men, } 25.5 \% \text { greater than } 65 \text { years }\end{array}$} \\
\hline Interventions & \multicolumn{2}{|c|}{$\begin{array}{l}\text { Low intensity dietary intervention to increase fibre and reduce fat intake. Self-help booklet developed by } \\
\text { the authors based on behavioural change principles from social learning theory and a brief motivational } \\
\text { message from the physician. The control group received no intervention. Follow up at } 12 \text { months }\end{array}$} \\
\hline Outcomes & \multicolumn{2}{|c|}{ Total dietary fat (\% Kcal). } \\
\hline \multicolumn{3}{|l|}{ Notes } \\
\hline \multicolumn{3}{|l|}{ Risk of bias } \\
\hline Item & Authors' judgement & Description \\
\hline Allocation concealment? & Unclear & B - Unclear \\
\hline
\end{tabular}

Beresford 2006

Methods Cluster RCT. Worksite was the unit of randomisation. Blocking criteria included baseline survey response rates, type and size of worksite and \% of female employees. Analysis was at the level of the cluster

Participants 28 worksites (educational, medical and other) were randomised. All worksites with food serving cafeterias and with between 250 and 2000 employees within the greater metropolitan area of Seattle, USA were eligible

Interventions The Special Intervention developed around the stages of change model addressing both the work environment and individual behaviour change. Each worksite had an employee advisory board (EAB) using a protocol specifying minimum activities required at each worksite and general structure for organising and implementing the intervention activities. The EAB met with a member of the research group approximately every 2 weeks, who provided materials, assisted with activities and participated in EAB meetings. The EABs took responsibility for tailoring the intervention. Intervention messages included increasing awareness about 5 a day and introducing the idea of eating more F\&V in the workplace. The intervention targeted transition points from precontemplation to contemplation, contemplation to preparation, preparation to action and action to maintainance. The control group received a minimal intervention which encouraged eating more F\&V using posters and brochures, newsletters, food demonstrations and a self help manual. Follow up was at 24 months

Outcomes Fruit and vegetable servings/day

Notes

Risk of bias

Dietary advice for reducing cardiovascular risk (Review) 
Beresford 2006 (Continued)

\begin{tabular}{lll}
\hline Item & Authors' judgement & Description \\
\hline Allocation concealment? & Unclear & B - Unclear \\
\hline
\end{tabular}

Bloemberg 1991

\begin{tabular}{|c|c|c|}
\hline Methods & \multicolumn{2}{|c|}{ RCT of parallel group design. } \\
\hline Participants & \multicolumn{2}{|c|}{ High risk - total cholesterol $6.5-10.0 \mathrm{mmol} / \mathrm{l} .80$ Dutch men randomised, mean age 47 years } \\
\hline Interventions & \multicolumn{2}{|c|}{$\begin{array}{l}\text { Individualised dietary advice from a dietitian with the aim to lower plasma cholesterol by } 1 \mathrm{mmol} / \mathrm{L} \text {. After } \\
\text { one week, advice reinforced by } 2 \text { follow-up calls. Information on healthy diet also mailed to participants } \\
\text { on } 5 \text { occasions. Intervention lasted } 6 \text { months. No details regarding the comparison group. Follow up at } \\
6 \text { months }\end{array}$} \\
\hline Outcomes & \multicolumn{2}{|c|}{ Total dietary fat and saturated fat $(\% \mathrm{Kcal})$, total cholesterol } \\
\hline \multicolumn{3}{|l|}{ Notes } \\
\hline \multicolumn{3}{|l|}{ Risk of bias } \\
\hline Item & Authors' judgement & Description \\
\hline Allocation concealment? & Unclear & B - Unclear \\
\hline
\end{tabular}

Brekke 2005

Methods

Participants

Interventions
RCT of parallel group design.

Non-diabetic first degree relatives of type 2 diabetic patients aged 25-55 with a medical history free of CHD recruited from outpatients clinics from questionnaires concerning family history of diabetes and advertisements in newspapers in the Goteborg area, Sweden. Exclusion criteria were diabetes (fasting blood glucose $>6.1 \mathrm{mmol} / \mathrm{L}$ or 2 hour blood glucose $>11.1 \mathrm{mmol} / \mathrm{L}$ or both), BMI $>35$, diseases or medications affecting glucose or lipid metabolism. 77 participants randomised, $60 \%$ men, mean age 43 years

Two intervention arms - diet and diet plus exercise and control group. This review is concerned only with the diet intervention. Dietary advice aimed to decrease saturated fat (goal 10\% of energy), increase monosaturated fat (goal 10-15\% of energy) and n-3 fatty acids (goal 1\% energy) from fatty fish and vegetable origin and for vegetables to take up one third of the lunch or dinner plate, increasing fruit and soluble fibre consumption as much as possible and increasing the intake of low GI foods. Dietician performed group counselling (3-11 participants/group with members of household who prepare food), sessions lasted 1-2 hours. There were 2 dietary education sessions 1-2 weeks apart at the beginning of the study. During the 16 week intervention period there was intensive follow-up with unannounced phone calls every 10 days ( 8 calls per person). Control group participants received a letter informing them to continue with their usual lifestyle. Follow-up was at 2 years. For ethical reasons after 1 year the control group began the intervention and were followed for a further 2 years. This review uses the follow-up data at 12 months 
Brekke 2005 (Continued)

\begin{tabular}{|c|c|c|}
\hline Outcomes & \multicolumn{2}{|c|}{$\begin{array}{l}\text { Plasma total cholesterol, LDL and HDL cholesterol and triglycerides }(\mathrm{mmol} / \mathrm{L}) \text {, total fat } \% \mathrm{Kcal} \text { and } \\
\text { saturated fat } \% \mathrm{Kcal} \text {, dietary fibre }(\mathrm{g} / 1000 \mathrm{Kcal} \text { - converted to g/day by assuming Kcal intake of } 2000)\end{array}$} \\
\hline \multicolumn{3}{|l|}{ Notes } \\
\hline \multicolumn{3}{|l|}{ Risk of bias } \\
\hline Item & Authors' judgement & Description \\
\hline Allocation concealment? & Unclear & B - Unclear \\
\hline
\end{tabular}

\section{Buller 1999}

\begin{tabular}{|c|c|c|}
\hline Methods & \multicolumn{2}{|c|}{$\begin{array}{l}\text { Cluster RCT. Employee cliques (informal social networks) were paired on several factors including mean } \\
\text { fruit and vegetable consumption at baseline, ethnicity, sex composition, and size. One clique of each pair } \\
\text { was randomly assigned to the intervention. Clique was the unit of analysis }\end{array}$} \\
\hline Participants & \multicolumn{2}{|c|}{$\begin{array}{l}41 \text { cluster pairs of cliques (informal social networks) of blue collar workers recruited from } 10 \text { public } \\
\text { employers in Arizona. Clusters include } 905 \text { workers of low socioeconomic class, } 75 \% \text { men, mean age } 42 \text {. } \\
1 \text { years }\end{array}$} \\
\hline Interventions & \multicolumn{2}{|c|}{$\begin{array}{l}\text { Peer education intervention to increase fruit and vegetable consumption. One employee from each clique } \\
\text { was recruited as a peer educator. In addition there was a 5-a-day program using worksite mail, cafeteria } \\
\text { promotions and speakers. The comparison group received this 5-a-day program but no peer education } \\
\text { intervention. Follow-up was at } 6 \text { months }\end{array}$} \\
\hline Outcomes & \multicolumn{2}{|c|}{ Fruit and vegetable servings per day. } \\
\hline \multicolumn{3}{|l|}{ Notes } \\
\hline \multicolumn{3}{|l|}{ Risk of bias } \\
\hline Item & Authors' judgement & Description \\
\hline Allocation concealment? & Yes & A - Adequate \\
\hline
\end{tabular}

Cheng 2004

\begin{tabular}{ll}
\hline Methods & RCT of parallel group design. \\
\hline Participants & $\begin{array}{l}\text { Participants with hypercholesterolaemia recruited from an urban academic primary care practice in } \\
\text { Philadelphia. Participants were either referred by phycians or referred themselves from posters in the prac- } \\
\text { tice. None of the participants were on lipid lowering medications and none had prior formal nutritional } \\
\text { counselling. } 208 \text { participants randomised, } 28.6 \% \text { men, mean age } 53.8 \text { years (range 25-101) }\end{array}$
\end{tabular}




\section{Cheng 2004 (Continued)}

\begin{tabular}{l} 
Interventions \\
$\begin{array}{l}\text { The intervention used the Food for Heart Programme, a core component of which is the dietary risk } \\
\text { assessment - a food frequency questionnare based on the } 20 \text { foods highest in saturated fat and cholesterol in } \\
\text { the American diet. The dietary risk assessment has } 4 \text { categories (meats, side dishes/desserts/snacks, dairy/ } \\
\text { eggs, fats/oils) each of which formed the basis of a brief focused visit to the practice. The intervention was } \\
\text { administed by a research assistant with no background in nutrition. Problem foods were identified and } \\
\text { advice sheets with suggestions for more healthy substitutes were given as well as a cook book with low fat } \\
\text { recipes. The control group received no intervention. Follow-up was at } 4 \text { months }\end{array}$ \\
\hline Outcomes
\end{tabular}

Notes

Risk of bias

\begin{tabular}{|c|c|c|}
\hline Item & Authors' judgement & Description \\
\hline Allocation concealment? & Unclear & B - Unclear \\
\hline
\end{tabular}

Coates WHT MP 1999

\begin{tabular}{|c|c|c|}
\hline Methods & \multicolumn{2}{|c|}{ RCT of parallel group design. } \\
\hline Participants & \multicolumn{2}{|c|}{$\begin{array}{l}\text { Post-menopausal women from minority and low socioeconomic class populations consuming at least } \\
35 \% \text { of energy from fat. Women recruited from clinics in Georgia, Alabama and Florida. Women had no } \\
\text { major chronic disease and were not on lipid-lowering medication. } 2208 \text { women randomised ( } 60 \% \text { to the } \\
\text { intervention), mean age } 60 \text { years }\end{array}$} \\
\hline Interventions & \multicolumn{2}{|c|}{$\begin{array}{l}\text { Intervention to reduce fat intake to } 20 \% \text { energy or less. A nutritionalist assigned fat gram goals to each } \\
\text { participant. Group sessions were held weekly for } 6 \text { weeks, fortnightly for } 6 \text { weeks, and monthly for } 9 \text { months } \\
\text { and then quarterly. Sessions included nutritional information and behavioural change strategies. Elements } \\
\text { of the program were enhanced or added to meet the needs of a diverse population. The comparison group } \\
\text { received "dietary guidelines for Americans" but were not counselled. Intervention lasted for } 2 \text { years, with } \\
\text { follow-up at } 6,12 \text { and } 18 \text { months. Data abstracted for } 6 \text { months follow-up as thereafter follow-up was } \\
\text { poor }\end{array}$} \\
\hline Outcomes & \multicolumn{2}{|c|}{ Total dietary fat and saturated fat (\% Kcal), fruit servings per day, vegetable servings per day } \\
\hline \multicolumn{3}{|l|}{ Notes } \\
\hline \multicolumn{3}{|l|}{ Risk of bias } \\
\hline Item & Authors' judgement & Description \\
\hline Allocation concealment? & Unclear & B - Unclear \\
\hline
\end{tabular}




\begin{tabular}{|c|c|c|}
\hline Methods & \multicolumn{2}{|c|}{ RCT of parallel group design. } \\
\hline Participants & \multicolumn{2}{|c|}{$\begin{array}{l}\text { Women with poor diet with high fat content from low income families in USA. } 150 \text { women randomised, } \\
\text { mean age } 29 \text { years, } 69 \% \text { black }\end{array}$} \\
\hline Interventions & \multicolumn{2}{|c|}{$\begin{array}{l}\text { Education series emphasising the prevention of cardiovascular disease and cancer by dietary and lifestyle } \\
\text { changes. Encouraged to decrease total and saturated fat intake, decrease salt intake, and increase con- } \\
\text { sumption of low fat milk products, fruit and vegetables, soluble fibre, complex carbohydrates, antioxidant } \\
\text { nutrients, calcium and potassium. Comparison group were taught about money management but received } \\
\text { no information on health or nutrition. Follow-up at } 6 \text { months }\end{array}$} \\
\hline Outcomes & \multicolumn{2}{|c|}{ Total dietary fat and saturated fat $(\% \mathrm{Kcal})$, fruit servings per day, vegetable servings per day } \\
\hline \multicolumn{3}{|l|}{ Notes } \\
\hline \multicolumn{3}{|l|}{ Risk of bias } \\
\hline Item & Authors' judgement & Description \\
\hline Allocation concealment? & Unclear & B - Unclear \\
\hline
\end{tabular}

\section{Djuric combination}

Methods RCT of parallel group design. The control group $\mathrm{N}$ is halved to take account of the two intervention arms

Participants $\quad$ Premenopausal women with at least one first degree relative with breast cancer, and consuming $>25 \%$ fat of total energy and $<5 /$ day F\&V. The study was based in the USA. Women were required to be in good general health with no expected changes lifestyle or the use of oral contraceptives. Women taking supplements were excluded. Women were recruited through community advertising for the Nutrition and Breast Health Study. 127 women were randomised to 3 intervention arms (high F\&V, low fat and a combination of low fat and high F\&V) and a control. Mean age was 37 years (range 21-50)

Interventions

$2 \times 2$ factorial trial design -3 intervention arms, high $\mathrm{F} \& \mathrm{~V}$ intake, low fat and a combination of high $\mathrm{F} \&$ $\mathrm{V}$ and low fat. The low fat arm was excluded from our analyses due to high loss to follow-up (leaving 82 participants randomised). The other intervention arms recieved individualised counselling every 2 weeks initially by a trained dietician, then monthly, and monthly group meetings for the intervention period of 12 months. The goal for the high $F \& V$ arm was to increase $F \& V$ to 9 servings/day in a specified variety to increase carotenoid intake. The goal for the combination arm was to decrease fat to $15 \%$ total energy from fat and increase $F \& V$ to 9 servings/day. Monthly meetings provided additional education on a variety of topics consistent with their dietary assignment. The control group recieved no dietary counselling and were told they should continue their usual diet. They received a one page daily food guide pyramid as a guide for healthy eating but this was not discussed. Follow-up was at 12 months. Longer term follow-up ( 2 years) was reported by the authors (Radakovich 2006) but loss to follow-up was greater than 20\%

Outcomes

Plasma total cholesterol, LDL and HDL cholesterol and triglycerides ( $\mathrm{mg} / \mathrm{dL}$ converted to $\mathrm{mmol} / \mathrm{l}$ ). Plasma alpha and beta carotene, lutein, lycopene, beta-cryptoxanthin, alpha and gamma-tocopherol and ascorbic acid (micrograms $/ \mathrm{ml}$ converted to micromol/l). Dietary intake of beta-carotene, ascorbic acid and alpha and gamma-tocopherol (micrograms $/ 1000 \mathrm{kcal} /$ day) 
Djuric combination (Continued)

\begin{tabular}{|c|c|c|}
\hline \multicolumn{3}{|l|}{ Notes } \\
\hline \multicolumn{3}{|l|}{ Risk of bias } \\
\hline Item & Authors' judgement & Description \\
\hline Allocation concealment? & Unclear & B - Unclear \\
\hline
\end{tabular}

\section{Djuric high F\&V}

\begin{tabular}{|c|c|c|}
\hline Methods & \multicolumn{2}{|c|}{ RCT of parallel group design. The control group $\mathrm{N}$ is halved to take account of the two intervention arms } \\
\hline Participants & \multicolumn{2}{|c|}{$\begin{array}{l}\text { Premenopausal women with at least one first degree relative with breast cancer, and consuming }>25 \% \\
\text { fat of total energy and }<5 / \text { day F\&V. The study was based in the USA. Women were required to be in } \\
\text { good general health with no expected changes lifestyle or the use of oral contraceptives. Women taking } \\
\text { supplements were excluded. Women were recruited through community advertising for the Nutrition } \\
\text { and Breast Health Study. } 127 \text { women were randomised to } 3 \text { intervention arms (high F\&V, low fat and a } \\
\text { combination of low fat and high F\&V) and a control. Mean age was } 37 \text { years (range 21-50) }\end{array}$} \\
\hline Interventions & \multicolumn{2}{|c|}{ see Djuric combination for details } \\
\hline Outcomes & \multicolumn{2}{|c|}{$\begin{array}{l}\text { Plasma total cholesterol, } \mathrm{LDL} \text { and HDL cholesterol and triglycerides }(\mathrm{mg} / \mathrm{dL} \text { converted to } \mathrm{mmol} / \mathrm{l}) \text {. } \\
\text { Plasma alpha and beta carotene, lutein, lycopene, beta-cryptoxanthin, alpha and gamma-tocopherol and } \\
\text { ascorbic acid (micrograms } / \mathrm{mL} \text { converted to micromol } / \mathrm{L} \text { ). Dietary intake of beta-carotene, ascorbic acid } \\
\text { and alpha and gamma-tocopherol (micrograms } / 1000 \mathrm{kcal} / \text { day) }\end{array}$} \\
\hline \multicolumn{3}{|l|}{ Notes } \\
\hline \multicolumn{3}{|l|}{ Risk of bias } \\
\hline Item & Authors' judgement & Description \\
\hline Allocation concealment? & Unclear & D - Not used \\
\hline
\end{tabular}

\section{Elder promotora}

\begin{tabular}{l|l} 
Methods & RCT of parallel group design. The control group N is halved to take account of the two intervention arms \\
\hline Participants & $\begin{array}{l}\text { Spanish dominant latinas from central and southern regions of San Diego county. Women were recruited } \\
\text { and assessed for eligibility using random digit dialing using a telephone list of Hispanic surname house- } \\
\text { holds. } 357 \text { women randomised, mean age } 40 \text { years }\end{array}$ \\
\hline
\end{tabular}

Interventions

Two intervention arms to decrease dietary fat and increase fibre - promotora and tailored. In the promotora arm participants recieved weekly visits or phone calls from promotoras (lay health advisors) over a 14 week period and 12 tailored newsletters with homework assignments mailed weekly. Promotoras worked with individuals to negotiate behaviour change and provide support and encouragement and the weekly newsletters were used to guide discussions. The tailored arm recieved the 12 weekly newsletters and 
Elder promotora (Continued)

homework assignments created by using baseline assessments for each individual. They provided feedback on assessments as well as personalised goal setting and dealing with identified barriers. The last newsletter contained information from the 12 week assessment and included changes achieved and steps to continue or maintain the change process. The control group recieved newsletters in Spanish covering the same content area, but they were off the shelf materials readily available to the public. Follow-up was at 12 months but data for this review were taken at 12 weeks due to the high loss to follow-up at 6 and 12 months

Outcomes

Total dietary fat and saturated fat (grams, converted to \% energy from fat by using Kcal intakes provided in the report). Only follow-up data were provided for these outcomes

Notes

Risk of bias

\begin{tabular}{lll}
\hline Item & Authors' judgement & Description \\
\hline Allocation concealment? & Unclear & D - Not used \\
\hline
\end{tabular}

Elder tailored

Methods

Participants

Interventions

Outcomes

Notes
RCT of parallel group design. The control group $\mathrm{N}$ is halved to take account of the two intervention arms

Spanish dominant latinas from central and southern regions of San Diego county. Women were recruited and assessed for eligibility using random digit dialing using a telephone list of Hispanic surname households. 357 women randomised, mean age 40 years

see Elder promotora for details.

Total dietary fat and saturated fat (grams, converted to \% energy from fat by using Kcal intakes provided in the report). Only follow-up data were provided for these outcomes

\section{Risk of bias}

\begin{tabular}{|c|c|c|}
\hline Item & Authors' judgement & Description \\
\hline Allocation concealment? & Unclear & D - Not used \\
\hline
\end{tabular}

Fuemmeler 2006

Methods

Cluster RCT. Churches were paired according to size and socioeconomic status of congregants and urban or rural geography and then each pair was randomised to intervention or control. Churches were the unit of analysis 


\section{Fuemmeler 2006 (Continued)}

Participants
Georgia, North and South Carolina, Delaware and Virginia, USA. Clusters contained 1020 individuals,
26.6\% men, mean age 49.7 years

Interventions

The Body and Soul intervention designed to increase $F \& V$ consumption included a set of core churchwide activities (e.g. serving F\&V after church services, food demonstrations and taster tests, invited speakers, messages in pastors sermons), self help materials (cook book and video containing spiritual and secular motivational messages targeting $\mathrm{F} \& \mathrm{~V}$ intake) and peer counselling based on the principles and techniques of motivational interviewing. Congregations nominated members to be part of an oversight committee responsible for implementing the Body and Soul intervention. The committee liased with the research team and members of the committee and peer counsellors were given training. The control group received the delayed intervention at 6 months. Follow-up was at 6 months

Outcomes $\quad F \& V$ (servings/day)

Notes

Risk of bias

\begin{tabular}{l|ll}
\hline Item & Authors' judgement & Description \\
\hline Allocation concealment? & Unclear & B - Unclear \\
\hline
\end{tabular}

Gann 2003

Methods RCT of parallel group design.

Participants Healthy women aged 20-40 years recruited by direct mailings and advertising in downtown Chicago. Women who were on diets, were pregnant or planning pregnancy and those on oral contraceptives were excluded. 213 women randomised, mean age 33 years

Interventions

Low fat high fibre dietary intervention. Goals were to reduce total fat intake to $<20 \%$, increase total fibre intake to $25-30 \mathrm{~g}$, increase $\mathrm{F} \& \mathrm{~V}$ intake to $>8$ servings/day, to eat more complex carbohydrates (carbohydrate intake $60-65 \% \mathrm{Kcal} /$ day) and protein intake $15-20 \% \mathrm{Kcal} /$ day. Women were not encouraged to reduce calorie intake. Intervention included classroom nutrition education (18 group classes) plus individual counselling ( 2 individual meetings in 12 months) to provide women with the knowledge and behavioural skills necessary to make a permanent lifestyle change. To maximise the impact of the intervention sessions, appropriate food was prepared and served. Sessions included practice shopping, label reading, meal preparation techniques and eating out and convienience foods were discussed. The control group were told to follow their usual diet and received a leaflet on healthy eating. After 12 month intervention period they received some of the materials given to the intervention group. Follow-up was at 12 months

Outcomes

Total fat \% Kcal, saturated fat ( $\mathrm{g}$ - converted to \% Kcal by using Kcal intake as reported), total dietary fibre (g/day)

Notes

Dietary advice for reducing cardiovascular risk (Review)

Copyright @ 2009 The Cochrane Collaboration. Published by John Wiley \& Sons, Ltd. 
Gann 2003 (Continued)

\section{Risk of bias}

\begin{tabular}{|c|c|c|}
\hline Item & Authors' judgement & Description \\
\hline Allocation concealment? & Unclear & B - Unclear \\
\hline
\end{tabular}

Havas 1998

Methods

Cluster RCT of cross-over design. Sites were switched 4 months after completion of phase 1. Each site acted as own control, using intention to treat analysis. Phase 1 participants were not eligible to enrol in phase 2. Specially employed peer educators conducted the intervention
Participants
Women on low incomes recruited from a government funded special supplemental nutrition program for women infants and children in Baltimore City. 16 sites where this program was carried out were randomised, involving 3122 women, of whom 40.5\% were aged between 18-24, 26.5\% between 25-29 and $33 \% 30$ years or more

Interventions

Five a day promotional program where the goal was to increase fruit and vegetable consumption by at least half a serving per day. Peer educators delivered 2 types of nutrition education - brief messages regarding increasing fruit and vegetable consumption at enrolment, and 3 group discussions of 45 minutes during the 6 month intervention period which included personal goal setting, overcoming perceived barriers and maintenance strategies. Printed materials, visual aids and booklets with recipes were distributed. Four individually tailored letters were sent over the 6 month period. Comparison group received no intervention. Follow-up at 8 months

Outcomes Fruit and vegetable servings per day.

Notes

Risk of bias

\begin{tabular}{|c|c|c|}
\hline Item & Authors' judgement & Description \\
\hline Allocation concealment? & Unclear & B - Unclear \\
\hline
\end{tabular}

Hellenius 1993

\begin{tabular}{ll} 
Methods & RCT of parallel group design. \\
\hline Participants & $\begin{array}{l}\text { Moderate/high risk - total cholesterol } 5.2-7.8 \mathrm{mmol} / \mathrm{L}, \mathrm{DBP} \text { less than or equal to } 100 \mathrm{mmHg}, \text { fasting } \\
\text { triglycerides less than or equal to } 5.6 \mathrm{mmol} / \mathrm{L}, \text { fasting blood glucose less than or equal to } 6.7 \mathrm{mmol} / \mathrm{L}, \\
\text { recruited from an ongoing prevention program in Sweden. } 160 \text { men randomised, mean age } 46.2 \text { years }\end{array}$ \\
\hline Interventions & $\begin{array}{l}\text { Three interventions - dietary advice alone, exercise alone and diet plus exercise. This review is concerned } \\
\text { only with the dietary intervention alone }(40 \text { men randomised). Physician provided individual verbal and } \\
\text { written information about diet in accordance with consensus documents, and participants also met with } \\
\text { a dietitian } 2 \text { weeks later for further advice concerning low fat diets. Compliance with the intervention }\end{array}$
\end{tabular}


Hellenius 1993 (Continued)

was checked at 3 months. The comparison group were told to continue with their lifestyle as previously.

Follow-up at 6 months

\begin{tabular}{l|l} 
Outcomes & Total dietary fat $(\% \mathrm{Kcal})$, total HDL and LDL cholesterol, triglycerides, SBP, DBP \\
\hline Notes &
\end{tabular}

\section{Risk of bias}

\begin{tabular}{|c|c|c|}
\hline Item & Authors' judgement & Description \\
\hline Allocation concealment? & Unclear & B - Unclear \\
\hline
\end{tabular}

Henderson WHTV 1990

\begin{tabular}{l|l}
\hline Methods & Multicentre RCT of parallel group design. \\
\hline Participants & $\begin{array}{l}\text { High risk - women recruited from clinical units in USA at increased risk of breast cancer (one or more } \\
\text { of the following - female first or second degree relative with breast cancer, one or more benign breast } \\
\text { biopsies, first birth after the age of } 30 \text { or nulliparous, or history of breast biopsy with atypical epithelial } \\
\text { hyperplasia. } 303 \text { women randomised, mean age } 54.8 \text { years }\end{array}$ \\
\hline Interventions & $\begin{array}{l}\text { Intervention to decrease fat intake to } 20 \% \text { of total calories and increase complex carbohydrate intake to } \\
\text { ensure adequate levels of vitamins and minerals. Nutritionalist led group sessions providing information } \\
\text { and behavioural skills to make lifestyle changes. Group sessions once a week for } 8 \text { weeks, twice a month } \\
\text { for the next } 6 \text { months and then monthly for } 12 \text { months. Individual sessions at } 2 \text { and } 12 \text { weeks. No details } \\
\text { regarding the comparison group. Follow-up at } 2 \text { years }\end{array}$ \\
\hline Outcomes & Total dietary fat (\% Kcal). \\
\hline Notes & \\
\hline
\end{tabular}

\section{Risk of bias}

\begin{tabular}{l|ll}
\hline Item & Authors' judgement & Description \\
\hline Allocation concealment? & Unclear & B - Unclear \\
\hline
\end{tabular}

\section{John 2002}

Methods

RCT of parallel group design.

Participants

Participants recruited from primary health care centres in Oxfordshire, UK. Participants aged between 25 and 64 years with no chronic diseases were eligible. Those who were pregnant or attempting to conceive or on dietary supplements were excluded. 729 participants randomised, $49 \%$ men, mean age 46 (SD 10. 1) years 
John 2002 (Continued)

\begin{tabular}{l|l}
\hline Interventions & $\begin{array}{l}\text { Brief negotiation method to increase F\&V consumption to at least } 5 \text { portions/day. A trained research nurse } \\
\text { discussed the benefits of eating more F\&V and presented a pictorial portion guide. The brief negotiation } \\
\text { method was used to encourage participants to identify specific and practical ways consistent with their } \\
\text { habits and preferences of eating more F\&V. Participants attended the health centre for } 2 \text { appointments } 6 \\
\text { months apart and were phoned } 2 \text { weeks after the first appointment to reinforce the message and discuss } \\
\text { any problems. At } 3 \text { months participants were sent a letter reinforcing the } 5 \text { a day message and a booklet } \\
\text { with seasonal recipes and strategy check list of ways to increase additional portions of F\&V. Participants } \\
\text { were given a copy of their individualised action plan, a fridge magnet with the } 5 \text { a day logo, a portion } \\
\text { guide and a 2 week self monitoring record book. The control group were asked to continue their usual } \\
\text { diet and received the intervention after } 6 \text { months. Follow-up was at } 6 \text { months }\end{array}$ \\
\hline Outcomes & $\begin{array}{l}\text { SBP and DBP (mmHg), plasma total cholesterol (mmol/L), plasma alpha and beta-carotene, lutein. } \\
\text { lycopene, beta-cryptoxanthin, alpha and gamma-tocopherol and ascorbic acid (all micromols/L) and F\& } \\
\text { V (servings/day) }\end{array}$ \\
\hline Item & \begin{tabular}{l} 
Notes \\
\hline Allocation concealment?
\end{tabular} \\
\hline Unclear \\
\hline Authors judgement
\end{tabular}

Keyserling 1997

Methods Cluster RCT. Data were analysed at the level of the individual, allowing for the effect of physician clusters. The denominator used in this review is the physician

Participants

42 primary care physicians from 21 community and rural health centres in North Carolina and Virginia were randomised. High risk patients with elevated LDL cholesterol (greater than $4.1 \mathrm{mmol} / \mathrm{L}$ or between $3.4-4.1 \mathrm{mmol} / \mathrm{l}$ plus 2 more risk factors or known $\mathrm{CHD}$ ) were identified during routine appointments. The number of participants was $372,67 \%$ were female, mean age 56 years

Interventions

Food for heart program dietary intervention administered by physicians. All underwent a 90 minute training session. The intervention included a brief dietary assessment and three 5-10 minute dietary counselling sessions including referral to a dietitian if LDL remained elevated at 4 months, and a prompt to consider lipid lowering drugs at 7 months if LDL remained elevated still. The comparison group was usual care. Follow-up was at 4, 7 and 12 months. Four month data were abstracted as greater than 10\% of participants were taking lipid lowering medication after this time

Outcomes Total cholesterol and LDL cholesterol.

Notes

Risk of bias

\begin{tabular}{lll}
\hline Item Authors' judgement & Description
\end{tabular}

Dietary advice for reducing cardiovascular risk (Review) 
Keyserling 1997 (Continued)

$\begin{array}{lll}\text { Allocation concealment? Unclear } & \text { B - Unclear }\end{array}$

Koopman 1990

\begin{tabular}{|c|c|c|}
\hline Methods & \multicolumn{2}{|c|}{ RCT of parallel group design. } \\
\hline Participants & \multicolumn{2}{|c|}{$\begin{array}{l}\text { High risk - mild to moderate hypertension (DBP } 90-110 \mathrm{mmHg} \text { on } 3 \text { separate occasions). Participants } \\
\text { recruited from a Dutch GP surgery - } 35 \text { randomised, } 46 \% \text { men, mean age } 45 \text { years }\end{array}$} \\
\hline Interventions & \multicolumn{2}{|c|}{$\begin{array}{l}\text { Pilot intervention of intensive dietary counselling by a dietitian in general practice. Participants visited } 3 \\
\text { times and goals were to have a daily intake of } 80-100 \mathrm{mmol} \text { sodium, } 30 \mathrm{~g} \text { of fibre, } 10-12 \% \text { of polyun- } \\
\text { saturated fatty acids. Comparison group told they would see the dietitian in } 3 \text { months. Follow-up at } 3 \\
\text { months }\end{array}$} \\
\hline Outcomes & \multicolumn{2}{|c|}{ SBP, DBP, urinary sodium. } \\
\hline \multicolumn{3}{|l|}{ Notes } \\
\hline \multicolumn{3}{|l|}{ Risk of bias } \\
\hline Item & Authors' judgement & Description \\
\hline Allocation concealment? & Unclear & B - Unclear \\
\hline
\end{tabular}

Kristal 2000

\begin{tabular}{|c|c|c|}
\hline Methods & \multicolumn{2}{|c|}{ RCT of parallel group design, individual randomisation stratified by age and sex } \\
\hline Participants & \multicolumn{2}{|c|}{$\begin{array}{l}\text { Participants were selected at random from enrollees from an American health maintenance organisation. } \\
1459 \text { subjects randomised, } 50 \% \text { men, mean age } 45.8 \text { years }\end{array}$} \\
\hline Interventions & \multicolumn{2}{|c|}{$\begin{array}{l}\text { Self-help manual of dietary change based on social learning theory designed to promote lower fat and higher } \\
\text { fruit and vegetable consumption. Manual included dietary information, dietary analysis with behavioural } \\
\text { feedback. Subjects also received a motivational phone call by a trained health educator and newsletters. } \\
\text { No details regarding the control group. Follow-up at } 12 \text { months }\end{array}$} \\
\hline Outcomes & \multicolumn{2}{|c|}{ Fruit and vegetable servings per day. } \\
\hline \multicolumn{3}{|l|}{ Notes } \\
\hline \multicolumn{3}{|l|}{ Risk of bias } \\
\hline Item & Authors' judgement & Description \\
\hline Allocation concealment? & Unclear & B - Unclear \\
\hline
\end{tabular}


Lanza men 2001

\begin{tabular}{ll}
\hline Methods & See Schatzkin 2000 for details. \\
\hline Participants & See Schatzkin 2000 for details. Data in this publication are analysed separately for men and women \\
\hline Interventions & See Schatzkin 2000 for details. \\
\hline Outcomes & $\begin{array}{l}\text { Unlike Schatzkin } 2000, \text { data are reported separately for men and women. Additional outcomes reported } \\
\text { in this publication are fruit }(\mathrm{g} / \mathrm{day}), \text { vegetables }(\mathrm{g} / \mathrm{day}) \text { and dietary intake of vitamin C (mg/day), vitamin } \\
\text { E (mg/day) and total carotenoids (micrograms/day) }\end{array}$ \\
\hline Notes & \\
\hline
\end{tabular}

\section{Risk of bias}

\begin{tabular}{|c|c|c|}
\hline Item & Authors' judgement & Description \\
\hline Allocation concealment? & Unclear & D - Not used \\
\hline
\end{tabular}

Lanza women 2001

\begin{tabular}{|c|c|c|}
\hline Methods & \multicolumn{2}{|c|}{ See Schatzkin 2000 for details. } \\
\hline Participants & \multicolumn{2}{|c|}{ See Schatzkin 2000 for details. Data in this publication are analysed separately for men and women } \\
\hline Interventions & \multicolumn{2}{|c|}{ See Schatzkin 2000 for details. } \\
\hline Outcomes & \multicolumn{2}{|c|}{$\begin{array}{l}\text { Unlike Schatzkin } 2000 \text {, data are reported separately for men and women. Additional outcomes reported } \\
\text { in this publication are fruit (g/day), vegetables (g/day) and dietary intake of vitamin } \mathrm{C}(\mathrm{mg} / \text { day), vitamin } \\
\mathrm{E}(\mathrm{mg} / \text { day) and total carotenoids (micrograms/day) }\end{array}$} \\
\hline \multicolumn{3}{|l|}{ Notes } \\
\hline \multicolumn{3}{|l|}{ Risk of bias } \\
\hline Item & Authors' judgement & Description \\
\hline Allocation concealment? & Unclear & D - Not used \\
\hline
\end{tabular}

Little 2004

Methods

Participants
RCT of parallel group design ( $2 \times 2 \times 2$ factorial trial).

Participants were recruited during the "watchful waiting" period for hypertension from 6 clinics in Southampton, UK. Inclusion criteria were one BP reading of $>160 / 90$ and not on antihypertensive treatment. Exclusion criteria were established hypertension and participants who were very ill or less able to change diet. 33 participants randomised to the prompts plus low salt intervention, 37 to the control (no intervention). Mean age was 55 (10) years, 56\% were male 
Little 2004 (Continued)

Interventions
prompts or use of healthy lifestyle prompts. We excluded the booklet intervention as it was multifactorial
(advice to reduce smoking, alcohol and weight as appropriate and exercise regularly). We also excluded the
healthy lifestle prompts alone as loss to follow-up was $>20 \%$ for this intervention. Our analysis focused on
the prompts plus low salt intervention with no intervention as the comparison group. Participants were
given a pot of low sodium salt and asked to use it in cooking and on food in place of normal salt. The
healthy lifestyle prompts included a fatty food swap sheet where participants were asked to swap foods
listed in one column with lower fat foods from the other column. Participants were asked to take the sheet
with them when shopping and place it in a prominent postion at home such as the fridge door. Fruit,
vegetable and fibre daily prompt sheets gave options to increase consumption of these. The intervention
(s) were administered by research nurses in GP surgeries. Interventions were reinforced at 4 weeks and 6
months. Control participants received no intervention. Follow-up was at 6 months

Outcomes $\quad \mathrm{SBP}$ and DBP $(\mathrm{mmHg})$, Total cholesterol, LDL cholesterol and HDL cholesterol ( $\mathrm{mmol} / \mathrm{L})$, total plasma carotenoids (mmol/L - converted to micromol/L) and \% energy from fat

Notes

$\mathrm{F} \& \mathrm{~V}$ (g/day) were also measured in this trial, but we were unable to verify the data with the authors and have therefore excluded this outcome

\section{Risk of bias}

\begin{tabular}{lll} 
Item Authors' judgement $\quad$ Description \\
\hline
\end{tabular}

Allocation concealment? Yes $\quad$ A - Adequate

\section{Lutz non-tailored}

Methods

RCT of parallel group design. The control group $\mathrm{N}$ is divided by 3 to take account of the 3 intervention arms

Participants

Healthy adults recruited from subscribers to an American health maintenance organisation. 710 participants randomised, $35.6 \%$ men, mean age 39.3 years

Interventions

Three interventions to increase fruit and vegetable consumption. The 3 interventions were non-tailored newsletters, computer tailored newsletters taking into consideration individual baseline survey dietary information, and tailored newsletters with goal setting - to increase fruit and vegetable consumption to 5 or more servings per day. The control group did not receive a newsletter. Newsletters were posted each month for 4 months to participants in the intervention groups. Follow-up was at 6 months

Outcomes

Fruit and vegetable servings per day.

Notes

Risk of bias

Item

Authors' judgement

Description

Dietary advice for reducing cardiovascular risk (Review) 
Lutz non-tailored (Continued)

\begin{tabular}{|c|c|c|}
\hline Allocation concealment? & Unclear & B - Unclear \\
\hline \multicolumn{3}{|l|}{ Lutz tailored\&goals } \\
\hline Methods & \multicolumn{2}{|c|}{$\begin{array}{l}\text { RCT of parallel group design. The control group } \mathrm{N} \text { is divided by } 3 \text { to take account of the } 3 \text { intervention } \\
\text { arms }\end{array}$} \\
\hline Participants & \multicolumn{2}{|c|}{$\begin{array}{l}\text { Healthy adults recruited from subscribers to a health maintenance organisation. } 710 \text { participants ran- } \\
\text { domised, } 35.6 \% \text { men, mean age } 39.3 \text { years }\end{array}$} \\
\hline Interventions & \multicolumn{2}{|c|}{ See 'Lutz non-tailored' for details of intervention. Follow-up was at 6 months } \\
\hline Outcomes & \multicolumn{2}{|c|}{ Fruit and vegetable servings per day. } \\
\hline \multicolumn{3}{|l|}{ Notes } \\
\hline \multicolumn{3}{|l|}{ Risk of bias } \\
\hline Item & Authors' judgement & Description \\
\hline Allocation concealment? & Unclear & B - Unclear \\
\hline
\end{tabular}

\section{Lutz tailored 1999}

\begin{tabular}{|c|c|c|}
\hline Methods & \multicolumn{2}{|c|}{$\begin{array}{l}\text { RCT of parallel group design. The control group } \mathrm{N} \text { is divided by } 3 \text { to take account of the } 3 \text { intervention } \\
\text { arms }\end{array}$} \\
\hline Participants & \multicolumn{2}{|c|}{$\begin{array}{l}\text { Healthy adults recruited from subscribers to a health maintenance organisation. } 710 \text { participants ran- } \\
\text { domised, } 35.6 \% \text { men, mean age } 39.3 \text { years }\end{array}$} \\
\hline Interventions & \multicolumn{2}{|c|}{ See 'Lutz non-tailored' for details of intervention. Follow-up was at 6 months } \\
\hline Outcomes & \multicolumn{2}{|c|}{ Fruit and vegetable servings per day. } \\
\hline \multicolumn{3}{|l|}{ Notes } \\
\hline \multicolumn{3}{|l|}{ Risk of bias } \\
\hline Item & Authors' judgement & Description \\
\hline Allocation concealment? & Unclear & B - Unclear \\
\hline
\end{tabular}


Maskarinec 1999

\begin{tabular}{|c|c|c|}
\hline Methods & \multicolumn{2}{|c|}{ RCT of parallel group design. } \\
\hline Participants & \multicolumn{2}{|c|}{$\begin{array}{l}\text { High risk - at increased risk of breast cancer (greater than } 50 \% \text { mammographic densities) and less than } \\
5 \text {-a-day. } 33 \text { women randomised, mean age } 48.9 \text { years, mostly of Asian decent. Based in Hawaii }\end{array}$} \\
\hline Interventions & \multicolumn{2}{|c|}{$\begin{array}{l}\text { Individualised dietary counselling program with dietitian - goal to incorporate } 9 \text { servings of fruit and veg- } \\
\text { etables in daily diet. Group meetings monthly for } 6 \text { months for cooking instructions and demonstrations. } \\
\text { Participants logged their daily intake of fruit and vegetables. The comparison group received nutritional } \\
\text { counselling on how to maintain a healthy diet. Follow-up at } 6 \text { months }\end{array}$} \\
\hline Outcomes & \multicolumn{2}{|c|}{ Total dietary fat $(\% \mathrm{Kcal})$, total cholesterol, fruit and vegetable servings per day, beta carotene } \\
\hline \multicolumn{3}{|l|}{ Notes } \\
\hline \multicolumn{3}{|l|}{ Risk of bias } \\
\hline Item & Authors' judgement & Description \\
\hline Allocation concealment? & Unclear & B - Unclear \\
\hline
\end{tabular}

Moy 2001

\begin{tabular}{ll} 
Methods & RCT of parallel group design. Randomisation was by family. \\
\hline Participants & $\begin{array}{l}\text { Healthy } 30-59 \text { year old brothers and sisters of patients with documented CHD diagnosed before the age of } \\
60 . \text { Siblings with at least one of the following risk factors were eligible: LDL cholesterol }>0 \text { or }=3.4 \mathrm{mmol} / \mathrm{L}, \\
\text { BP>or=140/90 or current use of antihypertensives or current smoking. } 235 \text { individuals were randomised, } \\
52 \% \text { men, mean age } 46 \text { (SD 7) years. This study was based in the USA }\end{array}$
\end{tabular}

Interventions $\quad$ Intervention focused primarily on decreasing total fat consumption and daily monitoring. Nurse counselling followed the National Cholesterol Education Programme Adult Treatment Panel II Guidelines which recommend dietary intervention as the first line approach in the treatment of hypercholesterolaemia. Participants were seen individually and with family members every 6-8 weeks by trained nurse counsellors (approximately 40 hours training by PI and dietician). Participants were given a "fat allowance" based on intake at baseline, current lifestyle and willingness to change. Participants were taught how to read food labels and use a fat counter to monitor and record total daily fat intake and negotiated their fat intake up or down with the nurse in counselling sessions. Physicians of siblings in the intervention group were asked explicitly not to manage dietary interventions. Participants in the usual care group were referred to physicians for dietary management. Physicians received specific detailed recommendations for risk factor management at baseline, 1 year and 2 years. Follow-up was at 2 years

Outcomes Plasma total cholesterol, LDL and HDL cholesterol and triglycerides (mmol/L), \% Kcal from total fat and $\%$ Kcal from saturated fat

Notes

Risk of bias

Dietary advice for reducing cardiovascular risk (Review) 
Moy 2001 (Continued)

\begin{tabular}{lll}
\hline Item & Authors' judgement & Description \\
\hline Allocation concealment? & Unclear & B - Unclear \\
\hline
\end{tabular}

Neil dietitian 1995

\begin{tabular}{l|l} 
Methods & RCT of parallel group design. The control group N is halved to take account of the two intervention arms \\
\hline Participants & $\begin{array}{l}\text { High risk - total cholesterol } 6-8.5 \text { mmol/L on repeat screening at a general practice in Oxfordshire. } 309 \\
\text { subjects randomised, } 53 \% \text { men, median age } 55 \text { years }\end{array}$ \\
\hline Interventions & $\begin{array}{l}\text { Three interventions all containing advice to decrease total daily fat consumption to } 30 \% \text { or less. Participants } \\
\text { were either randomised to receive advice from a dietitian or a nurse or to receive a leaflet containing } \\
\text { dietary information by post. Those randomised to see the dietitian received an individual appointment } \\
\text { of } 30 \text { minutes to discuss dietary habits and weight and offer advice to decrease fat consumption. At } 8 \\
\text { weeks participants had a further } 10 \text { minute appointment. Those randomised to see the nurse also had } \\
\text { an individual } 30 \text { minute appointment using a structure food frequency questionnaire and offered similar } \\
\text { advice to the dietitian with a further } 10 \text { minute appointment at } 8 \text { weeks. The comparison group to these } \\
2 \text { interventions was the leaflet. Follow-up was at } 6 \text { months }\end{array}$ \\
\hline Outcomes & \begin{tabular}{l} 
Total cholesterol, HDL and LDL cholesterol. \\
\hline Notes
\end{tabular} \\
\hline
\end{tabular}

\section{Risk of bias}

\begin{tabular}{l|ll}
\hline Item & Authors' judgement & Description \\
\hline Allocation concealment? & Unclear & B - Unclear \\
\hline
\end{tabular}

\section{Neil nurse 1995}

\begin{tabular}{l|l}
\hline Methods & RCT of parallel group design. The control group N is halved to take account of the two intervention arms \\
\hline Participants & $\begin{array}{l}\text { High risk - total cholesterol } 6-8.5 \mathrm{mmol} / \mathrm{L} \text { on repeat screening at a general practice in Oxfordshire. 309 } \\
\text { subjects randomised, } 53 \% \text { men, median age } 55 \text { years }\end{array}$ \\
\hline Interventions & See 'Neil 1995 dietitian' for details of intervention. Follow-up was at 6 months \\
\hline Outcomes & Total cholesterol, HDL and LDL cholesterol. \\
\hline Notes &
\end{tabular}

\section{Risk of bias}

Item 
Neil nurse 1995 (Continued)

\begin{tabular}{|c|c|c|}
\hline Allocation concealment? & Unclear & B - Unclear \\
\hline
\end{tabular}

Riddell 2000

Methods $\quad$ RCT of parallel group design, individual randomisation stratified by sex

Participants High risk - men and women with elevated plasma total homocysteine (greater than or equal to $9 \mathrm{micromol} /$ L). Sixty six subjects randomised aged $36-71$ years (61\% men) recruited from advertisements in local newspapers. Fifteen subjects were randomised to the intervention of interest to this review - increasing the consumption of folate rich foods, and 15 to the control group. Based in New Zealand

Interventions

Three interventions for decreasing homocysteine levels by increasing intake of folic acid - the first was supplementation, the second was consumption of fortified breakfast cereals and the third was increased consumption of folate rich foods. This review is concerned only with the third intervention. Subjects were asked to increase their intake of folate rich foods to 600 micrograms per day. Subjects were provided with a list of folate rich foods and were given detailed dietary information by a dietitian at recruitment and randomisation and reinforced advice by fortnightly phone calls. Additional encouragement was given by phone when required. The control group continued to follow a fat modified diet which was also used as a run in before randomisation in the intervention groups. The intervention lasted for 12 weeks and followup was 12 weeks

Outcomes $\quad$ Red cell folate.

Notes

Risk of bias

\begin{tabular}{l|l} 
Item Authors' judgement $\quad$ Description
\end{tabular}

$\begin{array}{lll}\text { Allocation concealment? Unclear } & \text { B - Unclear }\end{array}$

Rock 2001

\begin{tabular}{l|l}
\hline Methods & RCT of parallel group design. \\
\hline Participants & $\begin{array}{l}\text { Premenopausal women with cervical intraepithelial neoplasia (a precancerous condition) recruited from } \\
\text { primary care and gynecology medical practices in the USA. Women who were pregnant, lactating, were } \\
\text { post menopausal, had a previous history of cancer or a current diagnosis of any malignancies were excluded. } \\
56 \text { women were randomised with a mean age of } 27.8 \text { (SD 6) years }\end{array}$ \\
\hline
\end{tabular}

Interventions

Aim was to increase F\&V consumption to 8-10 servings/day. Specific strategies and food choices were identified and targeted through individualised counselling and guidance utilising a self management approach based on social cognitive behavioural theories. A dietician administered the intervention where counselling was by phone or internet with a minimum of weekly contact or more frequent if problems arose. The counselling protocol was supplemented by monthly newsletters and incentives to promote retention. The control group were provided with newsletters and incentives of a more general nature without specific nutrition information or dietray guidance. Follow-up was at 12 months but data are

Dietary advice for reducing cardiovascular risk (Review)

Copyright () 2009 The Cochrane Collaboration. Published by John Wiley \& Sons, Ltd. 
Rock 2001 (Continued)

presented only for 6 months follow-up

$\begin{array}{ll}\text { Outcomes } & \begin{array}{l}\text { Plasma alpha and beta-carotene, beta-cryptoxanthin, leutin, lycopene and total carotenoids (micrmol/L) } \\ \text {. F\&V servings/day }\end{array}\end{array}$
. F\&V servings/day

Notes

Table 1 in the paper provides dietary intake of micronutrients also but these are expressed only as medians and ranges. Contact authors to see if these data are available as means and SDs - for a future update

Risk of bias

\begin{tabular}{lll}
\hline Item & Author' judgement & Description \\
\hline Allocation concealment? & Unclear & B - Unclear \\
\hline
\end{tabular}

Sacerdote 2006

\begin{tabular}{|c|c|c|}
\hline Methods & \multicolumn{2}{|c|}{ RCT of parallel group design. } \\
\hline Participants & \multicolumn{2}{|c|}{$\begin{array}{l}\text { Healthy } 18-65 \text { year olds recruited from GP clinics in Italy. Inclusion criteria were } \mathrm{BMI}<30 \text { and no chronic } \\
\text { or severe diseases. Those visiting the GP for GI complaint or with dietary restrictions were excluded. } 3179 \\
\text { participants randomised ( } 1592 \text { intervention, } 1587 \text { control), mean age } 44.5(12.4) \text { years, } 50 \% \text { male }\end{array}$} \\
\hline Interventions & \multicolumn{2}{|c|}{$\begin{array}{l}\text { Personalised nutritional education intervention administered by a GP using a brochure based on Italian } \\
\text { guidelines for correct nutrition, 1998. Intervention focused on the importance of increasing consumption } \\
\text { of F\&V (goal }>5 / \text { day), fish (goal }>1 / \text { week) and olive oil (goal - use in place of other fats) and decreasing meat } \\
\text { (goal - <3/week), snacks and sweets. Participants randomised to the intervention visited the GP surgery } \\
3 \text { times over the } 12 \text { month intervention period - interviews lasted } 15 \text { minutes each. Control participants } \\
\text { recieved a "sham" intervention where they met the GP for a simpler non-personalised conversation without } \\
\text { the use of the brochure. Each GP took part in a } 4 \text { day training course on nutrition carried out by clinical } \\
\text { nutritionalists. Follow-up was at } 12 \text { months }\end{array}$} \\
\hline Outcomes & \multicolumn{2}{|c|}{ SBP and DBP (mmHg) and fruit and vegetable servings/week (converted to servings/day) } \\
\hline \multicolumn{3}{|l|}{ Notes } \\
\hline \multicolumn{3}{|l|}{ Risk of bias } \\
\hline Item & Authors' judgement & Description \\
\hline Allocation concealment? & Unclear & B - Unclear \\
\hline
\end{tabular}


Schatzkin 2000

\begin{tabular}{|c|c|c|}
\hline Methods & \multicolumn{2}{|c|}{ RCT of parallel group design. } \\
\hline Participants & \multicolumn{2}{|c|}{$\begin{array}{l}\text { High risk - one or more colorectal adenomas removed within } 6 \text { months before recruitment. Referrals from } \\
\text { endoscopists. } 2079 \text { randomised, } 64.5 \% \text { men, mean age } 61 \text { years. American multicentre study }\end{array}$} \\
\hline Interventions & \multicolumn{2}{|c|}{$\begin{array}{l}\text { Intensive counselling to follow a low fat (less than } 20 \% \text { calories), high fibre }(18 \mathrm{~g} / 1000 \text { cauls. }) \text { diet and } \\
\text { to increase fruit and vegetable consumption to } 3.5 \text { servings } / 1000 \text { cauls. Nutritional information and } \\
\text { behavioural modification techniques. More than } 50 \text { hours counselling sessions over } 4 \text { years. Comparison } \\
\text { group were given a standard brochure on healthy eating. Follow-up at } 4 \text { years }\end{array}$} \\
\hline Outcomes & \multicolumn{2}{|c|}{ Total dietary fat (\% Kcals), dietary fibre, fruit and vegetable servings per day } \\
\hline \multicolumn{3}{|l|}{ Notes } \\
\hline \multicolumn{3}{|l|}{ Risk of bias } \\
\hline Item & Authors' judgement & Description \\
\hline Allocation concealment? & Yes & A - Adequate \\
\hline
\end{tabular}

Smith-Warner 2000

\begin{tabular}{|c|c|c|}
\hline Methods & \multicolumn{2}{|c|}{ RCT of parallel group design, individual randomisation stratified by sex } \\
\hline Participants & \multicolumn{2}{|c|}{$\begin{array}{l}\text { High risk - men and women with recent history (previous } 5 \text { years) of colorectal adenomas recruited from } \\
\text { a gastroenterology clinic in Minnesota. } 201 \text { participants randomised, } 71 \% \text { men, mean age } 59.3 \text { years }\end{array}$} \\
\hline Interventions & \multicolumn{2}{|c|}{$\begin{array}{l}\text { Participants were asked to increase fruit and vegetable consumption to at least } 8 \text { servings per day. Clinic } \\
\text { visits at } 3,6,9 \text { and } 12 \text { months to reinforce this plus } 4 \text { additional individual diet intervention appointments. } \\
\text { Intervention used behaviour modification strategies derived from social learning theory and nutritional } \\
\text { counselling focused on goal setting. The control group continued their usual diet and were seen at } 3,6 \text {, } \\
9 \text { and } 12 \text { month clinic visits. Follow-up at } 12 \text { months }\end{array}$} \\
\hline Outcomes & \multicolumn{2}{|c|}{ Fruit and vegetable servings per day. } \\
\hline \multicolumn{3}{|l|}{ Notes } \\
\hline \multicolumn{3}{|l|}{ Risk of bias } \\
\hline Item & Authors' judgement & Description \\
\hline Allocation concealment? & Unclear & B - Unclear \\
\hline
\end{tabular}


Sorensen work+family

\begin{tabular}{|c|c|c|}
\hline Methods & \multicolumn{2}{|c|}{$\begin{array}{l}\text { Cluster RCT. Data were analysed at the level of the individual, allowing for clustering within worksites. } \\
\text { The denominator used in this review is the worksite. The control group } \mathrm{N} \text { is halved to take account of } \\
\text { the two intervention arms }\end{array}$} \\
\hline Participants & \multicolumn{2}{|c|}{$\begin{array}{l}22 \text { worksites in USA randomised including } 1359 \text { employees at community health centres. } 84 \% \text { women, } \\
\text { participants described as healthy and from racially and ethnically diverse backgrounds. No details regarding } \\
\text { age }\end{array}$} \\
\hline Interventions & \multicolumn{2}{|c|}{$\begin{array}{l}\text { Two interventions to increase fruit and vegetable consumption - one based at the worksite only, where } \\
\text { workers participated in program planning whose aims were to change individual behaviour and make } \\
\text { changes in the worksite environment. The other intervention included the worksite intervention plus a } \\
\text { family intervention involving a written learn at home program, an annual newsletter, annual family festival } \\
\text { and periodic mailings. The comparison group received a minimal intervention comprising exposure to } \\
\text { national media campaigns and a } 1 \text { hour general nutrition presentation. This minimal intervention was } \\
\text { received also by both intervention groups. Follow-up was at } 19.5 \text { months }\end{array}$} \\
\hline Outcomes & \multicolumn{2}{|c|}{ Fruit and vegetable servings per day. } \\
\hline \multicolumn{3}{|l|}{ Notes } \\
\hline \multicolumn{3}{|l|}{ Risk of bias } \\
\hline Item & Authors' judgement & Description \\
\hline Allocation concealment? & Unclear & B - Unclear \\
\hline \multicolumn{3}{|l|}{ Sorensen worksite } \\
\hline Methods & \multicolumn{2}{|c|}{$\begin{array}{l}\text { Cluster RCT. Data were analysed at the level of the individual, allowing for clustering within worksites. } \\
\text { The denominator used in this review is the worksite. The control group } \mathrm{N} \text { is halved to take account of } \\
\text { the two intervention arms }\end{array}$} \\
\hline Participants & \multicolumn{2}{|c|}{$\begin{array}{l}22 \text { worksites in USA randomised including } 1359 \text { employees at community health centres. } 84 \% \text { women, } \\
\text { participants described as healthy and from racially and ethnically diverse backgrounds. No details regarding } \\
\text { age }\end{array}$} \\
\hline Interventions & \multicolumn{2}{|c|}{ See "Sorensen work+family' for details of intervention. Follow-up was at 19.5 months } \\
\hline Outcomes & \multicolumn{2}{|c|}{ Fruit and vegetable servings per day. } \\
\hline \multicolumn{3}{|l|}{ Notes } \\
\hline \multicolumn{3}{|l|}{ Risk of bias } \\
\hline Item & Authors' judgement & Description \\
\hline Allocation concealment? & Unclear & B - Unclear \\
\hline
\end{tabular}

Dietary advice for reducing cardiovascular risk (Review) 


\begin{tabular}{ll}
\hline Methods & RCT of parallel group design \\
\hline Participants & $\begin{array}{l}\text { Healthy women - members of a HMO in Oregon, USA. Women aged 40-70 (mean 53.8) years who had } \\
\text { a negative result on a recent screening mammogram. Women were only included if their total cholesterol } \\
\text { level was } 5.2 \mathrm{mmol} / \mathrm{L} \text { or greater (authors chose the top half of the cholesterol distribution to increase the } \\
\text { probability of detecting dietary change), and were willing to change dietary patterns and were willing } \\
\text { to consider regular breast self-exam (control condition - recruitment emphasised cancer prevention and } \\
\text { control). Women were excluded if they were taking statins or had treatment for cancer in the previous } \\
\text { year. } 616 \text { women were randomised (308 intervention, } 308 \text { control) }\end{array}$ \\
\hline
\end{tabular}

Interventions

The dietary intervention combined strategies from motivational interviewing, problem solving and social cognitive theory. Experienced masters degree level counsellors provided individual counselling based in a research clinic. The first individual counselling session ( $45 \mathrm{mins}$ ) focused on decreasing fat and increasing fruit and vegetables and wholegrains. Participants were provided feedback from a baseline questionnaire and asked to select one of two goals (decreasing fat or increasing fruit and vegetables). The second counselling session ( 45 mins) 2-3 weeks later focused on the goal participants had not chosen at the first session. Telephone support was given 2-3 weeks after the second session and again 2-3 weeks later (510 mins each). Participants randomised to the control arm received an intervention focused on breast self examination where individuals received one counselling session and 2 follow-up phone calls but no dietary recommendations. Follow-up was at 12 months

Outcomes

Total cholesterol (mg/dL converted to $\mathrm{mmol} / \mathrm{L}$ ), \% energy from fat and $\mathrm{F} \& \mathrm{~V}$ (servings/day)

Notes

Risk of bias

Item Authors' judgement $\quad$ Description

Allocation concealment? Unclear $\quad$ B - Unclear

Takahashi 2006

Methods RCT of crossover design but data analysed and presented as a parallel group design at time of cross-over at 12 months

Participants $\quad$ Participants from 2 rural villages in Japan recruited through public magazines and posters. Individuals were eligible if they were aged between 40 and 69 and had physician permission to participate if under medical treatment or dietary control. 550 participants randomised, $32 \%$ men, mean age 56 years. Of the participants in the control group at baseline, $9.6 \%$ had hypertension, $2.9 \%$ had diabetes and $9.6 \%$ had hyperlipidaemia

Interventions

Tailored dietary intervention to encourage a decrease in sodium intake and an increase in vitamin $\mathrm{C}$ and carotene intake via increasing F\&V consumption. Dietary goals were to decrease salt to less than 8 and $10 \mathrm{~g} /$ day in women and men respectively and increase carotene intake to more than 5000 micrograms/day and vitamin $C$ intake to more than $200 \mathrm{mg} /$ day. The intervention consisted of 2 individualised dietary counselling sessions at baseline and 5 months ( 15 minutes each), a group lecture half way through the intervention, and 2 newsletters. Control subjects recieved the intervention at 12 months (cross-over period) . Follow-up data were presented at 12 months

Dietary advice for reducing cardiovascular risk (Review) 
Takahashi 2006 (Continued)

\begin{tabular}{|c|c|c|}
\hline Outcomes & \multicolumn{2}{|c|}{$\begin{array}{l}\mathrm{SBP} \text { and } \mathrm{DBP}(\mathrm{mmHg}) \text {, fruit and vegetable intake ( } \mathrm{g} / \text { day converted to servings/day using a typical } 80 \mathrm{~g} \\
\text { serving), dietary fibre (g/day), dietary intake of vitamin C ( } \mathrm{mg} / \text { day), alpha and beta-carotene (micrograms/ } \\
\text { day) }\end{array}$} \\
\hline \multicolumn{3}{|l|}{ Notes } \\
\hline \multicolumn{3}{|l|}{ Risk of bias } \\
\hline Item & Authors' judgement & Description \\
\hline Allocation concealment? & Unclear & B - Unclear \\
\hline
\end{tabular}

Tilley 1999

\begin{tabular}{|c|c|c|}
\hline Methods & \multicolumn{2}{|c|}{$\begin{array}{l}\text { Cluster RCT. Data were analysed at the level of the individual, allowing for difference in covariates between } \\
\text { control and treatment worksites. The denominator used in this review is the worksite }\end{array}$} \\
\hline Participants & \multicolumn{2}{|c|}{$\begin{array}{l}28 \text { car industry worksites in USA randomised. } 5042 \text { automobile employees believed to be at increased } \\
\text { risk of colorectal cancer. } 96 \% \text { men, mean age } 55.5 \text { years }\end{array}$} \\
\hline Interventions & \multicolumn{2}{|c|}{$\begin{array}{l}\text { Screening programme for colorectal cancer plus nutritional intervention and educational booklet. Nutri- } \\
\text { tional intervention included worksite classes encouraging increased fruit and vegetable and fibre and re- } \\
\text { duced fat consumption, self help materials and feedback from food frequency questionnaires. Newsletters } \\
\text { were mailed quarterly. The intervention was repeated in year } 2 \text { of the trial. The control group received the } \\
\text { screening program only. Follow-up at } 12 \text { months and } 2 \text { years. } 2 \text { year follow-up was used in the analysis }\end{array}$} \\
\hline Outcomes & \multicolumn{2}{|c|}{ Total dietary fat ( $\% \mathrm{Kcal})$, fruit and vegetable servings per day } \\
\hline \multicolumn{3}{|l|}{ Notes } \\
\hline \multicolumn{3}{|l|}{ Risk of bias } \\
\hline Item & Authors' judgement & Description \\
\hline Allocation concealment? & Unclear & B - Unclear \\
\hline
\end{tabular}

\section{TOHP I 1992}

\begin{tabular}{l|l}
\hline Methods & Multicentre RCT of parallel group design. \\
\hline Participants & $\begin{array}{l}\text { High risk - DBP } 80-89 \mathrm{mmHg} \text { not on antihypertensive medication recruited from } 10 \text { medical centres in } \\
\text { the USA. } 2182 \text { participants randomised overall, } 744 \text { to the sodium reduction trial. } 71.3 \% \text { were men, age } \\
\text { range } 30-54 \text { years }\end{array}$ \\
\hline Interventions & $\begin{array}{l}\text { Several non-pharmacological interventions aimed at reducing blood pressure. This review is concerned } \\
\text { only with the intervention to reduce sodium. Intervention administered by trained professionals and } \\
\text { involved participant education and motivation, skills to change behaviour, goal setting and problem }\end{array}$
\end{tabular}


TOHP I 1992 (Continued)

solving. The objective was to decrease urinary sodium to less than $80 \mathrm{mmol} / 24$ hours. The intervention included 8 group and 2 individual sessions in the first 3 months with less frequent counselling thereafter but a minimum contact of 1 individual meeting every 2 months. No details given regarding the comparison group. Follow-up at 6,12 and 18 months. Data abstracted for 12 months for urinary sodium and 18 months for blood pressure

Outcomes SBP, DBP, urinary sodium.

Notes

\section{Risk of bias}

\begin{tabular}{l|l|l}
\hline Item & Authors' judgement & Description \\
\hline Allocation concealment? & Unclear & B - Unclear \\
\hline
\end{tabular}

\section{TOHP II 1997}

\begin{tabular}{|c|c|c|}
\hline Methods & \multicolumn{2}{|c|}{ Multicentre RCT of parallel group design. } \\
\hline Participants & \multicolumn{2}{|c|}{$\begin{array}{l}\text { High risk - moderately overweight with high normal DBP }-83-89 \mathrm{mmHg} \text { recruited from } 9 \text { medical } \\
\text { centres in the USA. } 2382 \text { participants randomised, } 66.6 \% \text { men, mean age } 43.7 \text { years }\end{array}$} \\
\hline Interventions & \multicolumn{2}{|c|}{$\begin{array}{l}\text { Two interventions - one to promote weight loss, the other to reduce sodium intake. This review is concerned } \\
\text { only with the latter. Goal was to reduce sodium intake to } 80 \mathrm{mmol} / \text { day. Group sessions and counselling } \\
\text { weekly for } 10 \text { weeks, then } 4 \text { monthly sessions followed by } 1 \text { or } 2 \text { monthly contacts and refresher sessions } \\
\text { offered. Sessions provided core knowledge and behavioural skills to reduce sodium intake. Intervention } \\
\text { administered by trained dietitians, psychologists and health counsellors. Comparison group received no } \\
\text { active intervention. Follow-up was at } 6,18 \text { and } 36 \text { months. The } 3 \text { year follow-up was used in the analysis }\end{array}$} \\
\hline Outcomes & \multicolumn{2}{|c|}{ SBP, DBP, urinary sodium. } \\
\hline \multicolumn{3}{|l|}{ Notes } \\
\hline \multicolumn{3}{|l|}{ Risk of bias } \\
\hline Item & Authors' judgement & Description \\
\hline Allocation concealment? & Yes & A - Adequate \\
\hline
\end{tabular}

van der Veen 2002

Methods Cluster RCT. Data were analysed at the level of the individual, allowing for clustering within GP practices. The denominator used in this review is the GP practice

Participants

Participants at elevated risk of CVD recruited from 9 GP practices joining the Nijmegen Monitoring Project, University Medical Centre St Radboud, Netherlands. Eligibility criteria included a dietary fat 
van der Veen 2002 (Continued)

intake of $>37 \%$ or saturated fat intake of $>12 \%$, hypertension, diabetes, total cholesterol $>$ or $=6.2 \mathrm{mmol} /$ L but no manifest CVD. $89 \%$ of control participants had hypertension at baseline, and $7 \%$ had diabetes. The 9 GP practices included 143 individuals, $26.5 \%$ men, mean age 58 years

Stage matched nutrition counselling performed by GPs with selective referral to dieticians if patients
reached the action stage (stages of change model). In precontemplation counselling is aimed at raising
consiousness about dietary behaviour and on motivation to change dietary behaviour in the contemplation
stage. Individuals met with the GP on 3 occasions 2 weeks apart for approximately 10 minutes. If
participants reached the action stage and were referred to the dietician there were 3 appointments - the
first was 30-40 minutes, the other 2 were $10-15$ minutes, appointments were 2-8 weeks apart. Counselling
focused on decreasing saturated fat intake and was tailored to the individual. Participants in the control
group received usual care. Follow-up was at 12 months

Outcomes Plasma total cholesterol ( $\mathrm{mg} / \mathrm{dl}$ converted to $\mathrm{mmol} / \mathrm{l})$, total fat $\% \mathrm{Kcal}$ and saturated fat $\%$ Kcal

Notes

Risk of bias

\begin{tabular}{l|ll}
\hline Item & Author' judgement & Description \\
\hline Allocation concealment? & Unclear & B - Unclear \\
\hline
\end{tabular}

$\mathrm{F} \& \mathrm{~V}=$ fruit and vegetables

Characteristics of excluded studies [ordered by study ID]

\begin{tabular}{l|l}
\hline Study & Reason for exclusion \\
\hline Ammerman 2003 & Greater than $20 \%$ of participants were lost to follow up. \\
\hline Anderson 2001 & Greater than $20 \%$ of participants were lost to follow up. \\
\hline Bhargava 2004 & Greater than $20 \%$ of participants were lost to follow up. \\
\hline Boyd 1990 & Outcomes are reported in only $70 \%$ of those participants randomised \\
\hline Braeckman 1999 & $\begin{array}{l}\text { Additional data were provided by the authors to allow analysis in meta-view but unfortunately the numbers of } \\
\text { participants followed up for the outcomes of interest were poor at approximately } 60 \% \text { of those randomised }\end{array}$ \\
\hline Burke 2005 & Greater than 25\% of participants had a history of CVD. \\
\hline
\end{tabular}

Cappuccio 2006 Control group did not receive minimal intervention or no intervention

Dietary advice for reducing cardiovascular risk (Review) 
(Continued)

\begin{tabular}{|c|c|}
\hline Chalmers 1986 & $\begin{array}{l}\text { Data available in the published report could not be used as the baseline data and changes in DBP with the } \\
\text { intervention relative to baseline were missing. The authors were contacted, but unfortunately these data could } \\
\text { not be retrieved given the age of this study }\end{array}$ \\
\hline Colombo 2005 & Control group did not receive minimal intervention or no intervention \\
\hline Eid 2006 & Greater than $25 \%$ of participants had verified CVD at baseline \\
\hline Estruch 2006 & Greater than $50 \%$ of participants had Type 2 diabetes at baseline \\
\hline Fehily 1983 & $\begin{array}{l}\text { Data available in the published report could not be used as the baseline data and changes in total, HDL and } \\
\text { LDL cholesterol with the intervention relative to baseline were missing. This additional data was requested from } \\
\text { the authors but there was no response after several attempts to contact them }\end{array}$ \\
\hline Fitzgibbon 2004 & Greater than $20 \%$ of participants were lost to follow up. \\
\hline Fries 2005 & Greater than $20 \%$ of participants were lost to follow up. \\
\hline Havas 2003 & $20 \%$ of participants were pregnant during the trial. Pregnancy was an exclusion criteria \\
\hline
\end{tabular}

Henkin $2000 \quad$ RCT of effect of dietitian advice over and above physician advice. Control group did not receive minimal intervention or no intervention

HPTR 1990 Data available in the published report could not be used as the variance at baseline for SBP, DBP and urinary sodium was missing. This additional data was requested from the authors but there was no response after several attempts to contact them
Hunt 2001 Data available in the published report on F\&V could not be used as the variance at baseline and follow-up were missing. Authors were contacted but they were unable to provide missing data

Hyman 1998 Data available in the published report on total cholesterol could not be used as the variance at follow-up was missing. Authors were contacted but they were unable to provide missing data

Iso 2002 Control group did not receive minimal intervention or no intervention

Korhonen $2003 \quad$ RCT of weight loss, alcohol reduction and exercise.

Leduc 1994 Study published in abstract form only. No information regarding the participation rate or nature of the intervention. We were unable to contact the authors for further information

Marcus $2001 \quad$ Greater than $20 \%$ of participants were lost to follow up.

Martin $2006 \quad$ Greater than $20 \%$ of participants were lost to follow up.

Ni Mhurchu 1998 Greater than 20\% of participants were lost to follow up. 
(Continued)

Ockene 1999 Variance of outcome variables not available at follow-up. More than $10 \%$ of the control group were taking lipid lowering medication during the trial

Resnicow $2001 \quad$ Data available in the published report on F\&V consumption could not be used as the variance at baseline and follow-up and the number of individuals available at follow-up were missing. Authors were contacted but they were unable to provide missing data

Richards $2006 \quad$ Greater than $20 \%$ of participants were lost to follow up.

Sartorelli 2005 Intervention included advice to increase exercise (multifactorial intervention). The exercise advice tended to increase walking for $30 \mathrm{~min} /$ day ( $42 \%$ intervention group v. $24 \%$ control group, $\mathrm{p}=0.15$ at 1 year)

Simon 1997 Greater than $20 \%$ of participants were lost to follow up.

Smith 1997 Data available in the published report on dietary fat as a percentage of energy could not be used as there were missing variances at baseline and follow-up. Authors were contacted but they were unable to provide missing data

Sorensen 1992 Data available in the published report on dietary fat as a percentage of energy and dietary fibre could not be used as there were missing variances at baseline and follow-up. Authors were contacted but they were unable to provide missing data due to the age of the study

Torjesen 1997 Participants were selected to be overweight or obese, and the primary aim of the trial was weight loss.

WHI 2006

There was extensive use of medications (estrogens, statins, diabetic medications, aspirin) during the trial

Willaing 2004 Control group did not receive minimal intervention or no intervention

Williams-Piehota Greater than $20 \%$ of participants were lost to follow up.

\section{Characteristics of ongoing studies [ordered by study ID]}

\section{Bowen 2004}

Trial name or title The "Eating for a Healthy Life (EHL)" project

\begin{tabular}{ll}
\hline Methods & \\
\hline Participants & $\begin{array}{l}\text { Members of religious organisations (cluster RCT where } 40 \text { religious organisations were randomised - 2175 } \\
\text { individuals) }\end{array}$ \\
\hline Interventions & $\begin{array}{l}\text { Intervention package of self-help books and motivational messages and social interactions designed to change } \\
\text { dietary behaviours (lowering fat and increasing F\&V consumption) }\end{array}$
\end{tabular}


Bowen 2004 (Continued)

Outcomes Primary outcomes were fat and F\&V related behaviours using the Fat and Fibre Behaviour (FFB) Questionnaire

Starting date

Unclear - intervention was 9 months with 12 months follow-up. Finalloutcome data collected in 2003 so likely start date 2002

Contact information Dr Bowen - dbowen@fhcrc.org

Notes 
DATA AND ANALYSES

\section{Comparison 1. Any dietary intervention versus no intervention}

\begin{tabular}{|c|c|c|c|c|}
\hline Outcome or subgroup title & $\begin{array}{l}\text { No. of } \\
\text { studies }\end{array}$ & $\begin{array}{c}\text { No. of } \\
\text { participants }\end{array}$ & Statistical method & Effect size \\
\hline $\begin{array}{l}1 \text { Systolic blood pressure, change } \\
\text { from baseline }(\mathrm{mmHg})\end{array}$ & 8 & 6223 & Mean Difference (IV, Random, 95\% CI) & $-2.07[-3.19,-0.95]$ \\
\hline $\begin{array}{l}2 \text { Diastolic blood pressure, change } \\
\text { from baseline }(\mathrm{mmHg})\end{array}$ & 8 & 6223 & Mean Difference (IV, Random, 95\% CI) & $-1.15[-1.85,-0.46]$ \\
\hline $\begin{array}{l}3 \text { Urinary sodium output } \\
\text { ( } \mathrm{mmol} / 24 \mathrm{hr} \text { ), change from } \\
\text { baseline }\end{array}$ & 3 & 1533 & Mean Difference (IV, Random, 95\% CI) & $\begin{array}{l}-44.18[-54.74,-33 . \\
62]\end{array}$ \\
\hline $\begin{array}{l}4 \text { Total cholesterol ( } \mathrm{mmol} / \mathrm{l}) \text {, } \\
\text { change from baseline }\end{array}$ & 17 & 2124 & Mean Difference (IV, Random, 95\% CI) & $-0.16[-0.25,-0.06]$ \\
\hline $\begin{array}{l}5 \text { LDL cholesterol ( } \mathrm{mmol} / \mathrm{l}) \\
\text { change from baseline }\end{array}$ & 14 & 1484 & Mean Difference (IV, Random, 95\% CI) & $-0.18[-0.27,-0.10]$ \\
\hline $\begin{array}{l}6 \text { HDL cholesterol ( } \mathrm{mmol} / \mathrm{l}), \\
\text { change from baseline }\end{array}$ & 13 & 1481 & Mean Difference (IV, Random, 95\% CI) & Not estimable \\
\hline $\begin{array}{l}7 \text { Triglycerides }(\mathrm{mmol} / \mathrm{l}) \text {, change } \\
\text { from baseline }\end{array}$ & 5 & 429 & Mean Difference (IV, Random, 95\% CI) & $0.00[-0.13,0.13]$ \\
\hline $\begin{array}{l}8 \text { Plasma alpha-carotene } \\
\text { (nanomol/L), change from } \\
\text { baseline }\end{array}$ & 4 & 779 & Mean Difference (IV, Random, 95\% CI) & $\begin{array}{l}368.29[-125.86 \\
862.44]\end{array}$ \\
\hline $\begin{array}{l}9 \text { Plasma } ß \text {-carotene (nanomol/L), } \\
\text { change from baseline }\end{array}$ & 4 & 765 & Mean Difference (IV, Random, 95\% CI) & $\begin{array}{l}272.05[-52.03,596 . \\
14]\end{array}$ \\
\hline $\begin{array}{l}10 \text { Plasma alpha-tocopherol } \\
\text { (micromol/L), change from } \\
\text { baseline }\end{array}$ & 3 & 750 & Mean Difference (IV, Random, 95\% CI) & $-3.11[-8.87,2.65]$ \\
\hline $\begin{array}{l}11 \text { Plasma gamma-tocopherol } \\
\text { (micromol/L), change from } \\
\text { baseline }\end{array}$ & 3 & 750 & Mean Difference (IV, Random, 95\% CI) & $-0.33[-1.07,0.41]$ \\
\hline $\begin{array}{l}12 \text { Plasma lycopene (micromol/L), } \\
\text { change from baseline }\end{array}$ & 4 & 807 & Mean Difference (IV, Random, 95\% CI) & $-0.01[-0.04,0.01]$ \\
\hline $\begin{array}{l}13 \text { Plasma lutein (micromol/L), } \\
\text { change from baseline }\end{array}$ & 4 & 798 & Mean Difference (IV, Random, 95\% CI) & $0.02[0.00,0.04]$ \\
\hline $\begin{array}{l}14 \text { Plasma beta-cryptoxanthin } \\
\text { (micromol/L), change from } \\
\text { baseline }\end{array}$ & 4 & 772 & Mean Difference (IV, Random, 95\% CI) & $0.07[0.02,0.11]$ \\
\hline $\begin{array}{l}15 \text { Plasma total carotenoids } \\
\text { (micromol/L), change from } \\
\text { baseline }\end{array}$ & 2 & 113 & Mean Difference (IV, Random, 95\% CI) & $0.97[-0.84,2.78]$ \\
\hline $\begin{array}{l}16 \text { Plasma ascorbic acid } \\
\text { (micromol/L), change from } \\
\text { baseline }\end{array}$ & 3 & 750 & Mean Difference (IV, Random, 95\% CI) & $\begin{array}{l}12.47[-18.81,43 . \\
75]\end{array}$ \\
\hline $\begin{array}{l}17 \text { Red cell folate (nanomol/L), } \\
\text { change from baseline }\end{array}$ & 1 & 30 & Mean Difference (IV, Random, 95\% CI) & $\begin{array}{l}74.0[-44.16,192 . \\
16]\end{array}$ \\
\hline 18 Total dietary fat $(\% \mathrm{Kcal})$ & 20 & 6170 & Mean Difference (IV, Random, 95\% CI) & $-4.49[-6.66,-2.31]$ \\
\hline
\end{tabular}




\begin{tabular}{|c|c|c|c|c|}
\hline $\begin{array}{l}19 \text { Dietary saturated fatty acids (\% } \\
\text { Kcal) }\end{array}$ & 12 & 3157 & Mean Difference (IV, Random, 95\% CI) & $-2.36[-3.39,-1.32]$ \\
\hline $\begin{array}{l}20 \text { Fruit and vegetable (servings } \\
\text { per day), change from baseline }\end{array}$ & 18 & 8416 & Mean Difference (IV, Random, 95\% CI) & $1.25[0.70,1.81]$ \\
\hline $\begin{array}{l}21 \text { Fruit (servings per day), change } \\
\text { from baseline }\end{array}$ & 9 & 4439 & Mean Difference (IV, Random, 95\% CI) & $0.67[0.07,1.28]$ \\
\hline $\begin{array}{l}22 \text { Vegetable (servings per day), } \\
\text { change from baseline }\end{array}$ & 8 & 4412 & Mean Difference (IV, Random, 95\% CI) & $0.92[0.34,1.49]$ \\
\hline $\begin{array}{l}23 \text { Dietary fibre (grams per day), } \\
\text { change from baseline }\end{array}$ & 9 & 2981 & Mean Difference (IV, Random, 95\% CI) & $5.99[1.12,10.86]$ \\
\hline $\begin{array}{l}24 \text { Dietary intake of ascorbic acid } \\
\text { (mg/day), change from baseline }\end{array}$ & 5 & 2335 & Mean Difference (IV, Random, 95\% CI) & $53.39[31.97,74.80]$ \\
\hline $\begin{array}{l}25 \text { Dietary intake of beta-carotene } \\
\text { ( } \mathrm{mg} / \text { day), change from baseline }\end{array}$ & 3 & 542 & Mean Difference (IV, Random, 95\% CI) & $3.39[1.20,5.59]$ \\
\hline
\end{tabular}

Comparison 2. Subgroup analyses

\begin{tabular}{|c|c|c|c|c|}
\hline Outcome or subgroup title & $\begin{array}{l}\text { No. of } \\
\text { studies }\end{array}$ & $\begin{array}{c}\text { No. of } \\
\text { participants }\end{array}$ & Statistical method & Effect size \\
\hline 1 Total cholesterol (gender) & 17 & 1858 & Mean Difference (IV, Random, 95\% CI) & $-0.18[-0.28,-0.08]$ \\
\hline 1.1 Women & 5 & 557 & Mean Difference (IV, Random, 95\% CI) & $-0.02[-0.23,0.19]$ \\
\hline 1.2 Men & 3 & 343 & Mean Difference (IV, Random, 95\% CI) & $-0.24[-0.41,-0.08]$ \\
\hline 1.3 Mixed & 9 & 958 & Mean Difference (IV, Random, 95\% CI) & $-0.21[-0.36,-0.05]$ \\
\hline 2 Total dietary fat (gender) & 20 & 6170 & Mean Difference (IV, Random, 95\% CI) & $-4.49[-6.66,-2.31]$ \\
\hline 2.1 Women & 8 & 3208 & Mean Difference (IV, Random, 95\% CI) & $-6.77[-10.01,-3.53]$ \\
\hline 2.2 Men & 3 & 186 & Mean Difference (IV, Random, 95\% CI) & $-3.11[-4.79,-1.42]$ \\
\hline 2.3 Mixed & 9 & 2776 & Mean Difference (IV, Random, 95\% CI) & $-2.90[-6.83,1.04]$ \\
\hline $\begin{array}{l}3 \text { Fruit \& vegetable servings/day } \\
\quad \text { (gender) }\end{array}$ & 19 & 8469 & Mean Difference (IV, Random, 95\% CI) & $1.27[0.72,1.82]$ \\
\hline 3.1 Women & 5 & 1298 & Mean Difference (IV, Random, 95\% CI) & $1.98[0.96,2.99]$ \\
\hline 3.2 Men & 2 & 1214 & Mean Difference (IV, Random, 95\% CI) & $1.43[-0.60,3.47]$ \\
\hline 3.3 Mixed & 12 & 5957 & Mean Difference (IV, Random, 95\% CI) & $0.91[0.33,1.48]$ \\
\hline 4 Total cholesterol (risk group) & 17 & 2124 & Mean Difference (IV, Random, 95\% CI) & $-0.16[-0.25,-0.06]$ \\
\hline 4.1 General population & 3 & 906 & Mean Difference (IV, Random, 95\% CI) & $-0.09[-0.28,0.10]$ \\
\hline 4.2 CVD risk high & 11 & 1117 & Mean Difference (IV, Random, 95\% CI) & $-0.20[-0.33,-0.07]$ \\
\hline 4.3 Cancer risk high & 3 & 101 & Mean Difference (IV, Random, 95\% CI) & $-0.13[-0.46,0.20]$ \\
\hline 5 Total dietary fat (risk group) & 20 & 6170 & Mean Difference (IV, Random, 95\% CI) & $-4.49[-6.66,-2.31]$ \\
\hline 5.1 General population & 8 & 3393 & Mean Difference (IV, Random, 95\% CI) & $-4.26[-8.09,-0.43]$ \\
\hline 5.2 CVD risk high & 8 & 650 & Mean Difference (IV, Random, 95\% CI) & $-2.91[-3.97,-1.85]$ \\
\hline 5.3 Cancer risk high & 4 & 2127 & Mean Difference (IV, Random, 95\% CI) & $-8.86[-13.68,-4.04]$ \\
\hline $\begin{array}{l}6 \text { Fruit \& vegetable servings/day } \\
\quad \text { (risk group) }\end{array}$ & 18 & 8416 & Mean Difference (IV, Random, 95\% CI) & $1.25[0.70,1.81]$ \\
\hline 6.1 General population & 13 & 6322 & Mean Difference (IV, Random, 95\% CI) & $0.62[0.32,0.93]$ \\
\hline 6.2 CVD risk high & 0 & 0 & Mean Difference (IV, Random, 95\% CI) & Not estimable \\
\hline 6.3 Cancer risk high & 5 & 2094 & Mean Difference (IV, Random, 95\% CI) & $2.69[1.53,3.85]$ \\
\hline 7 SBP mmHg (risk group) & 8 & 6223 & Mean Difference (IV, Random, 95\% CI) & $-2.07[-3.19,-0.95]$ \\
\hline 7.1 General population & 3 & 4317 & Mean Difference (IV, Random, 95\% CI) & $-2.18[-4.47,0.11]$ \\
\hline 7.2 CVD high risk & 5 & 1906 & Mean Difference (IV, Random, 95\% CI) & $-1.96[-3.41,-0.51]$ \\
\hline
\end{tabular}

Dietary advice for reducing cardiovascular risk (Review)

Copyright $\odot 2009$ The Cochrane Collaboration. Published by John Wiley \& Sons, Ltd. 
8 DBP mmHg (risk group)

8.1 General population

8.2 CVD high risk

9 Total cholesterol (setting)

9.1 Healthcare settings

9.2

Community/workplace/home

settings

10 Total dietary fat (setting)

10.1 Healthcare settings

10.2

Community/workplace/home settings

11 Fruit \& vegetable servings/day (setting)

11.1 Healthcare settings

11.2

Community/workplace/home settings

12 Total cholesterol (intensity)

12.1 Low intensity

12.2 High intensity

13 Total dietary fat (intensity)

13.1 Low intensity

13.2 High intensity

14 Fruit $\&$ vegetable servings/day (intensity)

14.1 Low intensity

14.2 High intensity

15 SBP mmHg (intensity)

15.1 Low intensity

15.2 High intensity

16 DBP mmHg (intensity)

16.1 Low intensity

16.2 High intensity

17 Total cholesterol (duration)

17.1 Short duration (3-6

months)

17.2 Long duration (12+

months)

18 Total dietary fat (duration)

18.1 Short duration (3-6 months)

18.2 Long duration ( $12+$ months)

19 Fruit $\&$ vegetable servings/day (duration)

19.1 Short duration (6-8 months)

19.2 Long duration (12+ months)
6170

2426

3744

8416

6984
Mean Difference (IV, Random, 95\% CI) Mean Difference (IV, Random, 95\% CI) Mean Difference (IV, Random, 95\% CI) Mean Difference (IV, Random, 95\% CI) Mean Difference (IV, Random, 95\% CI) Mean Difference (IV, Random, 95\% CI)

Mean Difference (IV, Random, 95\% CI) Mean Difference (IV, Random, 95\% CI)

Mean Difference (IV, Random, 95\% CI)

Mean Difference (IV, Random, 95\% CI)

Mean Difference (IV, Random, 95\% CI)

Mean Difference (IV, Random, 95\% CI)

Mean Difference (IV, Random, 95\% CI) Mean Difference (IV, Random, 95\% CI) Mean Difference (IV, Random, 95\% CI) Mean Difference (IV, Random, 95\% CI) Mean Difference (IV, Random, 95\% CI) Mean Difference (IV, Random, 95\% CI) Mean Difference (IV, Random, 95\% CI)

Mean Difference (IV, Random, 95\% CI) Mean Difference (IV, Random, 95\% CI) Mean Difference (IV, Random, 95\% CI) Mean Difference (IV, Random, 95\% CI) Mean Difference (IV, Random, 95\% CI) Mean Difference (IV, Random, 95\% CI) Mean Difference (IV, Random, 95\% CI) Mean Difference (IV, Random, 95\% CI) Mean Difference (IV, Random, 95\% CI)

Mean Difference (IV, Random, 95\% CI)

1052 Mean Difference (IV, Random, 95\% CI)

Mean Difference (IV, Random, 95\% CI)

Mean Difference (IV, Random, 95\% CI)

Mean Difference (IV, Random, 95\% CI)

Mean Difference (IV, Random, 95\% CI)

Mean Difference (IV, Random, 95\% CI)

Mean Difference (IV, Random, 95\% CI)
$-1.15[-1.85,-0.46]$

$-0.84[-1.74,0.07]$

$-1.46[-2.62,-0.31]$

$-0.16[-0.25,-0.06]$

$-0.14[-0.25,-0.04]$

$-0.27[-0.47,-0.07]$

$-4.49[-6.66,-2.31]$

$-5.22[-7.80,-2.64]$

$-3.15[-4.73,-1.56]$

$1.25[0.70,1.81]$

1.88 [1.07, 2.70]

$0.83[0.20,1.47]$

$-0.16[-0.25,-0.06]$

$-0.09[-0.20,0.01]$

$-0.23[-0.39,-0.07]$

$-4.49[-6.66,-2.31]$

$-1.68[-3.13,-0.23]$

$-5.72[-7.75,-3.69]$

$1.25[0.70,1.81]$

$0.66[0.20,1.11]$

$1.64[0.78,2.51]$

$-2.07[-3.19,-0.95]$

$-1.87[-4.30,0.57]$

$-2.04[-2.77,-1.30]$

$-1.15[-1.85,-0.46]$

$-1.22[-2.62,0.19]$

$-1.16[-1.72,-0.59]$

$-0.16[-0.25,-0.06]$

$-0.14[-0.26,-0.02]$

$-0.22[-0.40,-0.03]$

$-4.49[-6.66,-2.31]$

$-3.76[-7.56,0.05]$

$-4.90[-8.02,-1.78]$

$1.25[0.70,1.81]$

$1.24[0.49,1.99]$

$1.26[0.40,2.12]$

Dietary advice for reducing cardiovascular risk (Review) 
$20 \mathrm{SBP} \mathrm{mmHg}$ (duration)

20.1 Short duration (3-6 months)

20.2 Long duration $12+$ months

$21 \mathrm{DBP} \mathrm{mmHg}$ (duration)

21.1 Short duration (3-6 months)

21.2 Long duration (12+ months)
86223 Mean Difference (IV, Random, 95\% CI)

Mean Difference (IV, Random, 95\% CI)

$-2.07[-3.19,-0.95]$

Mean Difference (IV, Random, 95\% CI)

$-1.94[-2.77,-1.11]$

$8 \quad 6223$

Mean Difference (IV, Random, 95\% CI)

$-1.15[-1.85,-0.46]$

$4 \quad 859$

4
Mean Difference (IV, Random, 95\% CI)

$-1.77[-4.29,0.75]$

Mean Difference (IV, Random, 95\% CI)
$-1.03[-1.55,-0.52]$

\section{Analysis I.I. Comparison I Any dietary intervention versus no intervention, Outcome I Systolic blood pressure, change from baseline $(\mathrm{mmHg})$.}

Review: Dietary advice for reducing cardiovascular risk

Comparison: I Any dietary intervention versus no intervention

Outcome: I Systolic blood pressure, change from baseline $(\mathrm{mmHg})$

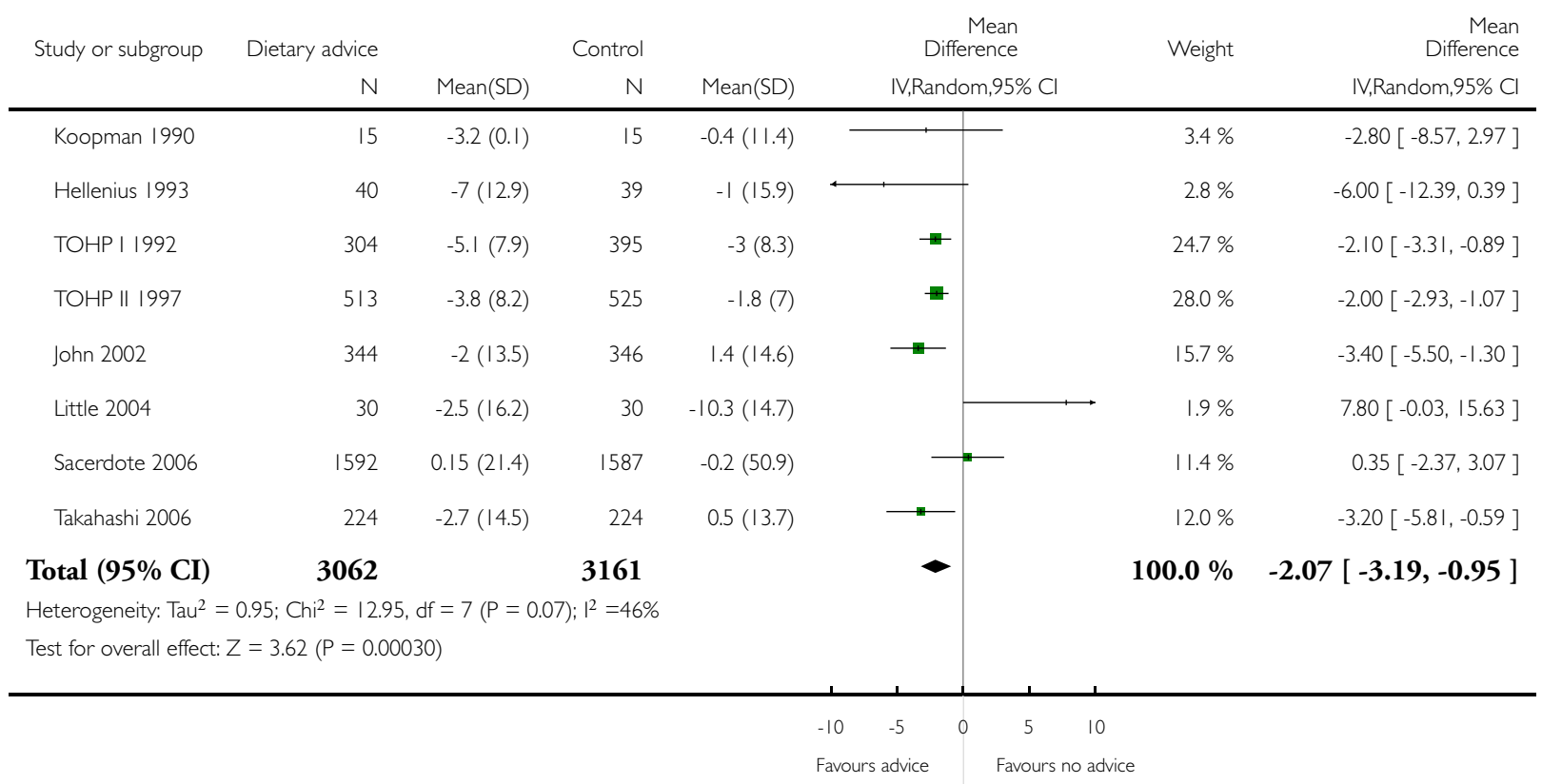


Analysis I.2. Comparison I Any dietary intervention versus no intervention, Outcome 2 Diastolic blood pressure, change from baseline $(\mathrm{mmHg})$.

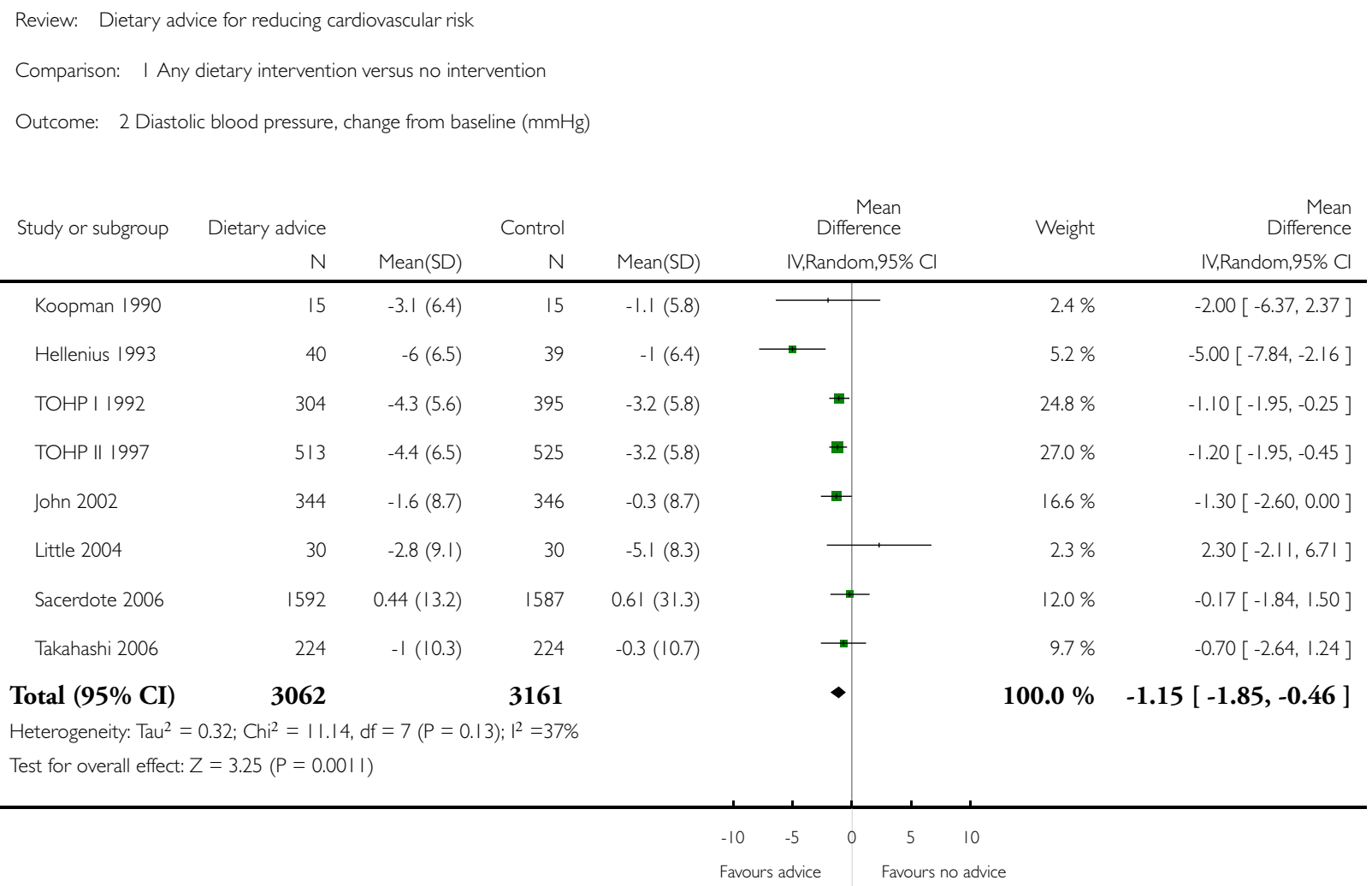


Analysis I.3. Comparison I Any dietary intervention versus no intervention, Outcome 3 Urinary sodium output (mmol/24 hr), change from baseline.

Review: Dietary advice for reducing cardiovascular risk

Comparison: I Any dietary intervention versus no intervention

Outcome: 3 Urinary sodium output ( $\mathrm{mmol} / 24 \mathrm{hr}$ ), change from baseline

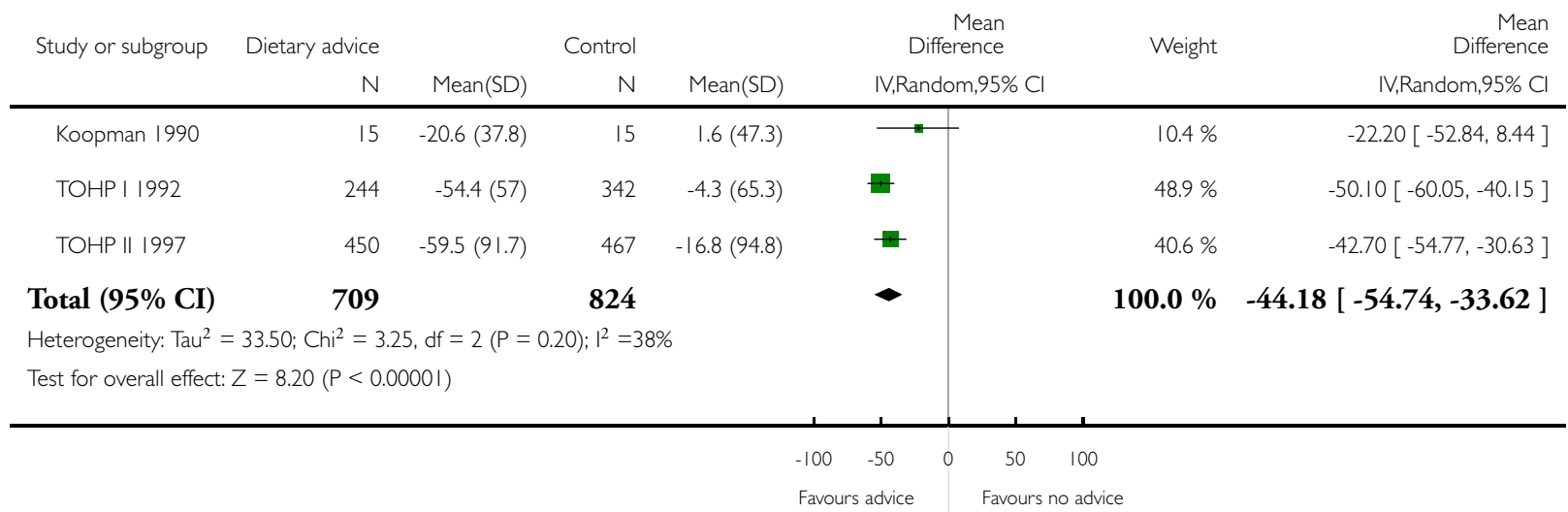




\section{Analysis I.4. Comparison I Any dietary intervention versus no intervention, Outcome 4 Total cholesterol ( $\mathrm{mmol} / \mathrm{l})$, change from baseline.}

Review: Dietary advice for reducing cardiovascular risk

Comparison: I Any dietary intervention versus no intervention

Outcome: 4 Total cholesterol (mmol/l), change from baseline

\begin{tabular}{|c|c|c|c|c|c|c|c|}
\hline \multirow[t]{2}{*}{ Study or subgroup } & \multirow{2}{*}{$\begin{array}{r}\text { Dietary advice } \\
N\end{array}$} & \multicolumn{3}{|c|}{ Control } & $\begin{array}{r}\text { Mean } \\
\text { Difference }\end{array}$ & \multirow[t]{2}{*}{ Weight } & \multirow{2}{*}{$\begin{array}{r}\text { Mean } \\
\text { Difference } \\
\text { IV,Random,95\% Cl }\end{array}$} \\
\hline & & Mean(SD) & $\mathrm{N}$ & Mean(SD) & IV,Random,95\% Cl & & \\
\hline Baron women 1990 & 87 & $-0.06(0.87)$ & 87 & $-0.13(0.98)$ & 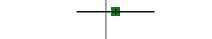 & $7.0 \%$ & $0.07[-0.21,0.35]$ \\
\hline Baron men 1990 & 93 & $-0.19(0.77)$ & 91 & $0.11(0.81)$ & - & $8.6 \%$ & $-0.30[-0.53,-0.07]$ \\
\hline Bloemberg 1991 & 39 & $-0.32(0.85)$ & 41 & $-0.02(0.79)$ & & $5.0 \%$ & $-0.30[-0.66,0.06]$ \\
\hline Anderson low fibre & 47 & $-0.59(0.62)$ & 25 & $-0.42(0.57)$ & 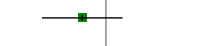 & $6.7 \%$ & $-0.17[-0.46,0.12]$ \\
\hline Anderson high fibre & 48 & $-0.79(0.62)$ & 25 & $-0.42(0.57)$ & - & $6.8 \%$ & $-0.37[-0.65,-0.09]$ \\
\hline Hellenius 1993 & 40 & $-0.19(0.95)$ & 39 & $-0.13(0.62)$ & & $5.1 \%$ & $-0.06[-0.41,0.29]$ \\
\hline Neil dietitian 1995 & 103 & $-0.1(0.67)$ & 51 & $-0.13(0.63)$ & & $9.1 \%$ & $0.03[-0.19,0.25]$ \\
\hline Neil nurse 1995 & 104 & $-0.18(0.69)$ & 51 & $-0.13(0.63)$ & & $9.0 \%$ & $-0.05[-0.27,0.17]$ \\
\hline Keyserling 1997 & 22 & $-0.33(0.65)$ & 20 & $-0.21(0.67)$ & & $4.3 \%$ & $-0.12[-0.52,0.28]$ \\
\hline Maskarinec 1999 & 13 & $0.23(0.52)$ & 16 & $0.31(1.07)$ & & $2.2 \%$ & $-0.08[-0.68,0.52]$ \\
\hline Brekke 2005 & 24 & $0.1(0.6)$ & 19 & $0.24(0.54)$ & 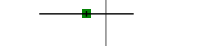 & $5.3 \%$ & $-0.14[-0.48,0.20]$ \\
\hline Cheng 2004 & 91 & $-0.4(0.65)$ & 84 & $-0.06(0.57)$ & $\longrightarrow$ & $10.6 \%$ & $-0.34[-0.52,-0.16]$ \\
\hline Djuric combination & 23 & $0(0.83)$ & 12 & $0.18(0.78)$ & & $2.5 \%$ & $-0.18[-0.74,0.38]$ \\
\hline Djuric high F\%V & 25 & $0.05(0.92)$ & 12 & $0.18(0.78)$ & & $2.4 \%$ & $-0.13[-0.70,0.44]$ \\
\hline Moy 200I & 117 & $-0.71(3.16)$ & 118 & $0.5 \mathrm{I}(2.5 \mathrm{I})$ & & $1.6 \%$ & $-1.22[-1.95,-0.49]$ \\
\hline Stevens 2003 & 277 & $-0.19(0.65)$ & 271 & $-0.16(0.7 I)$ & $\rightarrow$ & $13.7 \%$ & $-0.03[-0.14,0.08]$ \\
\hline van der Veen 2002 & 4 & $-1.2(1.98)$ & 5 & $-0.87(2.15)$ & & $0.1 \%$ & $-0.33[-3.03,2.37]$ \\
\hline Total $(95 \% \mathrm{CI})$ & 1157 & & 967 & & $\bullet$ & $100.0 \%$ & $-0.16[-0.25,-0.06]$ \\
\hline \multicolumn{8}{|c|}{ Heterogeneity: $\mathrm{Tau}^{2}=0.01 ; \mathrm{Ch}^{2}=27.38, \mathrm{df}=16(\mathrm{P}=0.04) ; \mathrm{I}^{2}=42 \%$} \\
\hline
\end{tabular}


Analysis I.5. Comparison I Any dietary intervention versus no intervention, Outcome 5 LDL cholesterol ( $\mathrm{mmol} / \mathrm{l})$, change from baseline.

Review: Dietary advice for reducing cardiovascular risk

Comparison: I Any dietary intervention versus no intervention

Outcome: $5 \mathrm{LDL}$ cholesterol $(\mathrm{mmol} / \mathrm{l})$, change from baseline

\begin{tabular}{|c|c|c|c|c|c|c|c|}
\hline \multirow[t]{2}{*}{ Study or subgroup } & \multirow{2}{*}{$\begin{array}{r}\text { Dietary advice } \\
\mathrm{N}\end{array}$} & \multicolumn{3}{|c|}{ Control } & \multirow{2}{*}{$\begin{array}{c}\text { Mean } \\
\text { Difference } \\
\text { IV,Random,95\% Cl }\end{array}$} & \multirow[t]{2}{*}{ Weight } & \multirow{2}{*}{$\begin{array}{r}\text { Mean } \\
\text { Difference } \\
\text { IV,Random,95\% Cl }\end{array}$} \\
\hline & & Mean(SD) & $N$ & Mean(SD) & & & \\
\hline Baron women 1990 & 77 & $0(0.79)$ & 81 & $0.03(0.94)$ & & $7.2 \%$ & $-0.03[-0.30,0.24]$ \\
\hline Baron men 1990 & 85 & $-0.39(0.75)$ & 81 & $-0.04(0.77)$ & $\longrightarrow$ & $9.0 \%$ & $-0.35[-0.58,-0.12]$ \\
\hline Anderson low fibre & 47 & $-0.56(0.55)$ & 25 & $-0.4(0.43)$ & $\longrightarrow$ & $9.0 \%$ & $-0.16[-0.39,0.07]$ \\
\hline Anderson high fibre & 48 & $-0.75(0.55)$ & 25 & $-0.4(0.43)$ & $\longrightarrow$ & $9.1 \%$ & $-0.35[-0.58,-0.12]$ \\
\hline Hellenius 1993 & 40 & $-0.3(0.76)$ & 39 & $-0.15(0.56)$ & $\longrightarrow$ & $6.4 \%$ & $-0.15[-0.44,0.14]$ \\
\hline Neil dietitian 1995 & 103 & $-0.11(0.65)$ & 51 & $-0.19(0.64)$ & $=$ & $9.8 \%$ & $0.08[-0.14,0.30]$ \\
\hline Neil nurse 1995 & 104 & $-0.18(0.68)$ & 51 & $-0.19(0.64)$ & & $9.7 \%$ & $0.01[-0.21,0.23]$ \\
\hline Keyserling 1997 & 22 & $-0.33(0.76)$ & 20 & $-0.22(0.66)$ & & $3.4 \%$ & $-0.11[-0.54,0.32]$ \\
\hline Brekke 2005 & 24 & $0.01(0.59)$ & 19 & $0.28(0.46)$ & + & $5.8 \%$ & $-0.27[-0.58,0.04]$ \\
\hline Cheng 2004 & 91 & $-0.32(0.58)$ & 84 & $-0.01(0.56)$ & $\rightarrow$ & $13.0 \%$ & $-0.31[-0.48,-0.14]$ \\
\hline Djuric combination & 23 & $-0.05(0.85)$ & 12 & $0.28(0.79)$ & - & $2.1 \%$ & $-0.33[-0.90,0.24]$ \\
\hline Djuric high F\%V & 25 & $0.05(0.85)$ & 12 & $0.28(0.79)$ & & $2.1 \%$ & $-0.23[-0.79,0.33]$ \\
\hline Little 2004 & 30 & $0.01(0.57)$ & 30 & $0.09(0.75)$ & 7 & $5.1 \%$ & $-0.08[-0.42,0.26]$ \\
\hline Moy 2001 & 117 & $-0.69(1.1)$ & 118 & $-0.4(0.8)$ & 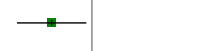 & $8.3 \%$ & $-0.29[-0.54,-0.04]$ \\
\hline Total $(95 \%$ CI $)$ & 836 & & 648 & & $\bullet$ & $100.0 \%$ & $-0.18[-0.27,-0.10]$ \\
\hline \multicolumn{8}{|c|}{ Heterogeneity: $\operatorname{Tau}^{2}=0.01 ; \mathrm{Chi}^{2}=17.99, \mathrm{df}=13(\mathrm{P}=0.16) ; 1^{2}=28 \%$} \\
\hline \multicolumn{8}{|c|}{ Test for overall effect: $Z=4.16(P=0.000032)$} \\
\hline
\end{tabular}


Analysis I.6. Comparison I Any dietary intervention versus no intervention, Outcome 6 HDL cholesterol ( $\mathrm{mmol} / \mathrm{l})$, change from baseline.

Review: Dietary advice for reducing cardiovascular risk

Comparison: I Any dietary intervention versus no intervention

Outcome: $6 \mathrm{HDL}$ cholesterol $(\mathrm{mmol} / \mathrm{l})$, change from baseline

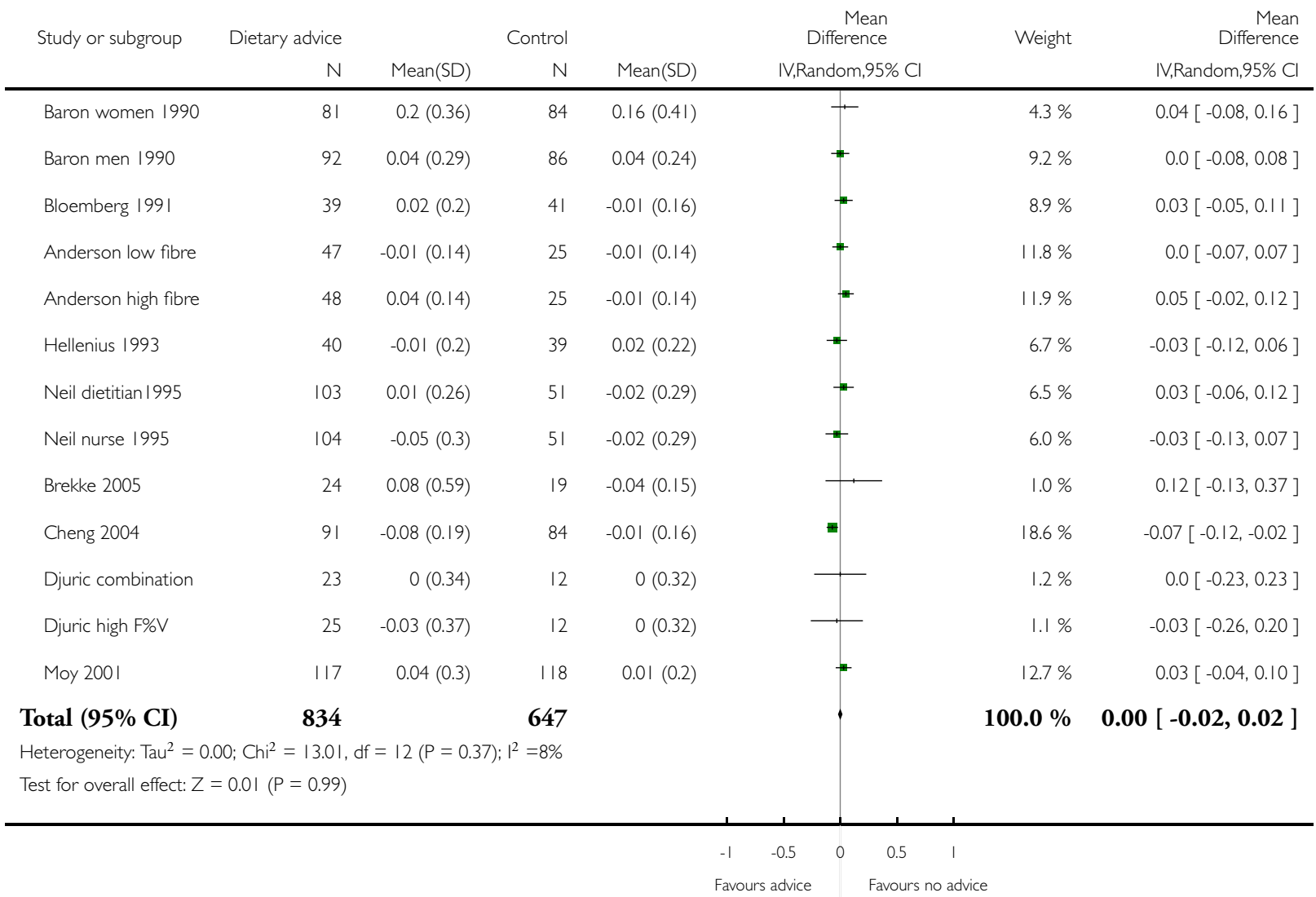


Analysis I.7. Comparison I Any dietary intervention versus no intervention, Outcome 7 Triglycerides ( $\mathrm{mmol} / \mathrm{l})$, change from baseline.

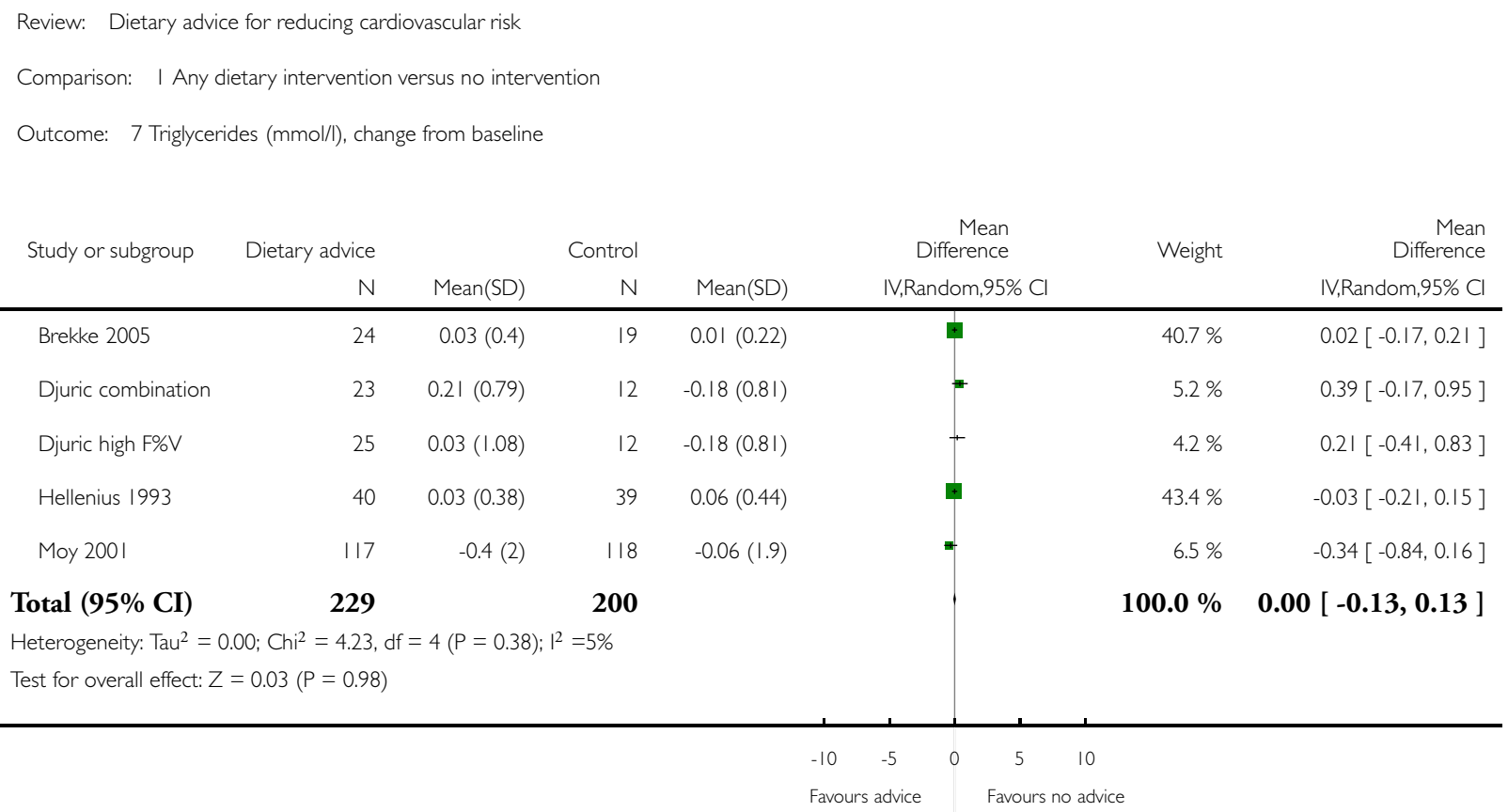


Analysis I.8. Comparison I Any dietary intervention versus no intervention, Outcome 8 Plasma alphacarotene (nanomol/L), change from baseline.

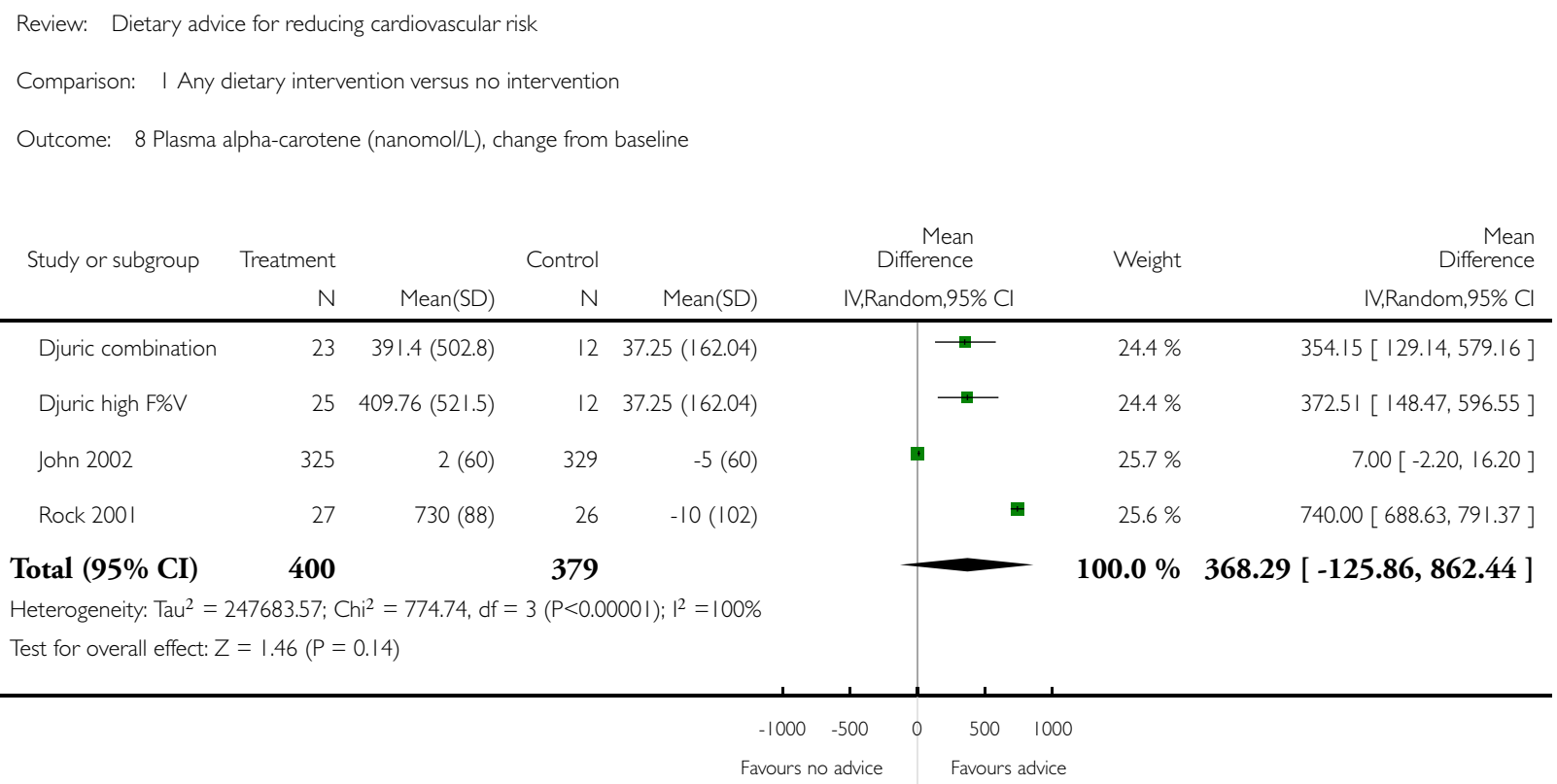


Analysis I.9. Comparison I Any dietary intervention versus no intervention, Outcome 9 Plasma ß-carotene (nanomol/L), change from baseline.

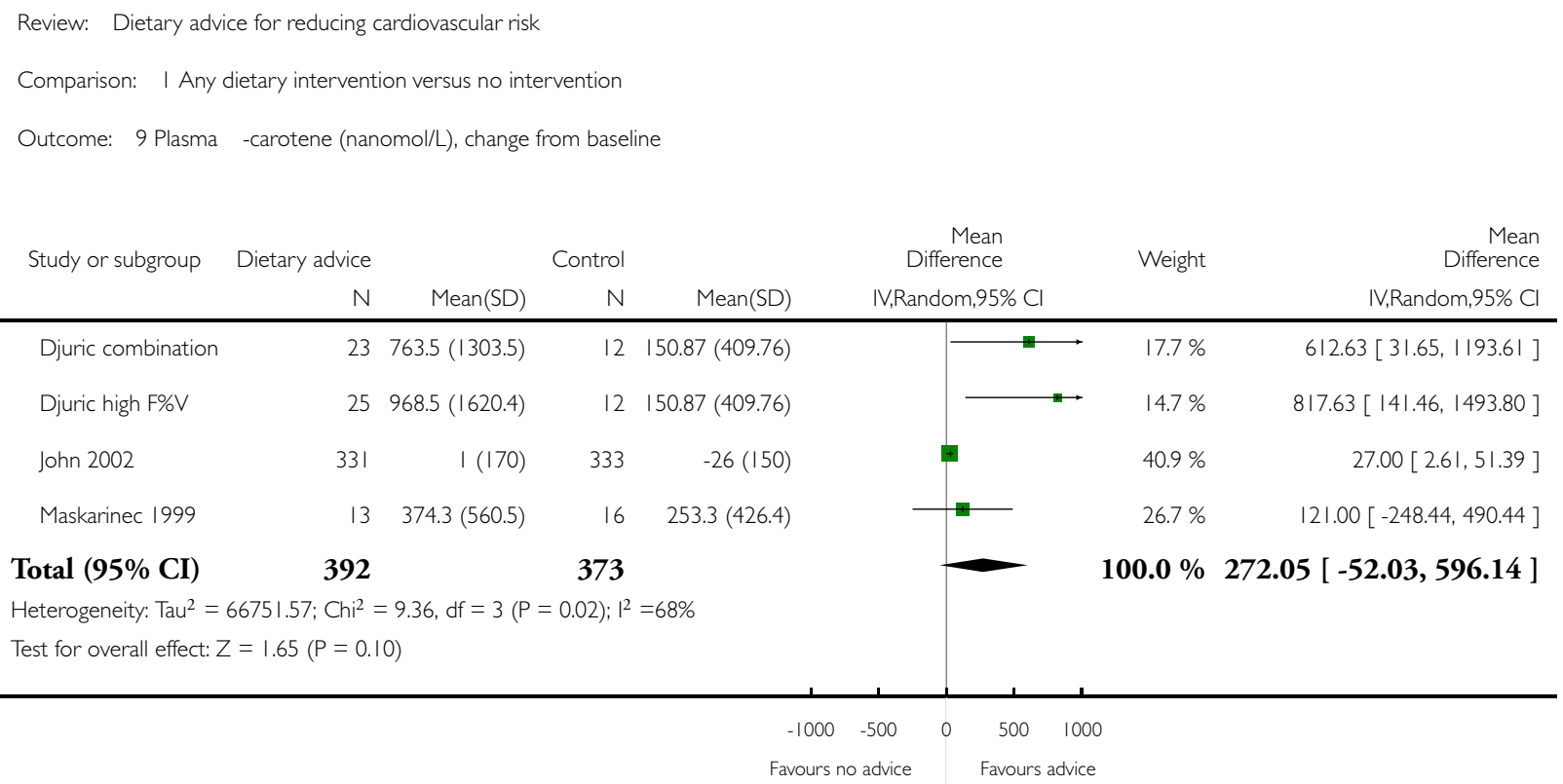


Analysis I.10. Comparison I Any dietary intervention versus no intervention, Outcome I0 Plasma alphatocopherol (micromol/L), change from baseline.

Review: Dietary advice for reducing cardiovascular risk

Comparison: I Any dietary intervention versus no intervention

Outcome: 10 Plasma alpha-tocopherol (micromol/L), change from baseline

\begin{tabular}{|c|c|c|c|c|c|c|c|}
\hline \multirow[t]{2}{*}{ Study or subgroup } & \multirow{2}{*}{$\begin{array}{r}\text { Treatment } \\
\mathrm{N}\end{array}$} & \multicolumn{3}{|c|}{ Control } & $\begin{array}{r}\text { Mean } \\
\text { Difference }\end{array}$ & \multirow[t]{2}{*}{ Weight } & \multirow{2}{*}{$\begin{array}{r}\text { Mean } \\
\text { Difference } \\
\text { IV,Random,95\% Cl }\end{array}$} \\
\hline & & Mean(SD) & $\mathrm{N}$ & Mean(SD) & IV,Random,95\% Cl & & \\
\hline Djuric combination & 23 & $0.69(11.26)$ & 12 & $6.78(14.16)$ & $\rightleftarrows$ & $23.0 \%$ & $-6.09[-15.33,3.15]$ \\
\hline Djuric high F\%V & 25 & $-1.69(15.18)$ & 12 & $6.78(14.16)$ & $\leftarrow$ & $20.9 \%$ & $-8.47[-18.45,|.5|]$ \\
\hline John 2002 & 337 & $0.43(4.04)$ & 341 & $0.31(4.04)$ & + & $56.0 \%$ & $0.12[-0.49,0.73]$ \\
\hline Total $(95 \%$ CI $)$ & 385 & & 365 & & & $100.0 \%$ & $-3.11[-8.87,2.65]$ \\
\hline \multicolumn{8}{|c|}{ Heterogeneity: $\operatorname{Tau}^{2}=15.32 ; \mathrm{Chi}^{2}=4.55, \mathrm{df}=2(\mathrm{P}=0.10) ; \mathbf{1}^{2}=56 \%$} \\
\hline Test for overall effect: Z & $=1.06(P=0$ & & & & & & \\
\hline
\end{tabular}

Analysis I.I I. Comparison I Any dietary intervention versus no intervention, Outcome I I Plasma gammatocopherol (micromol/L), change from baseline.

Review: Dietary advice for reducing cardiovascular risk

Comparison: I Any dietary intervention versus no intervention

Outcome: I I Plasma gamma-tocopherol (micromol/L), change from baseline

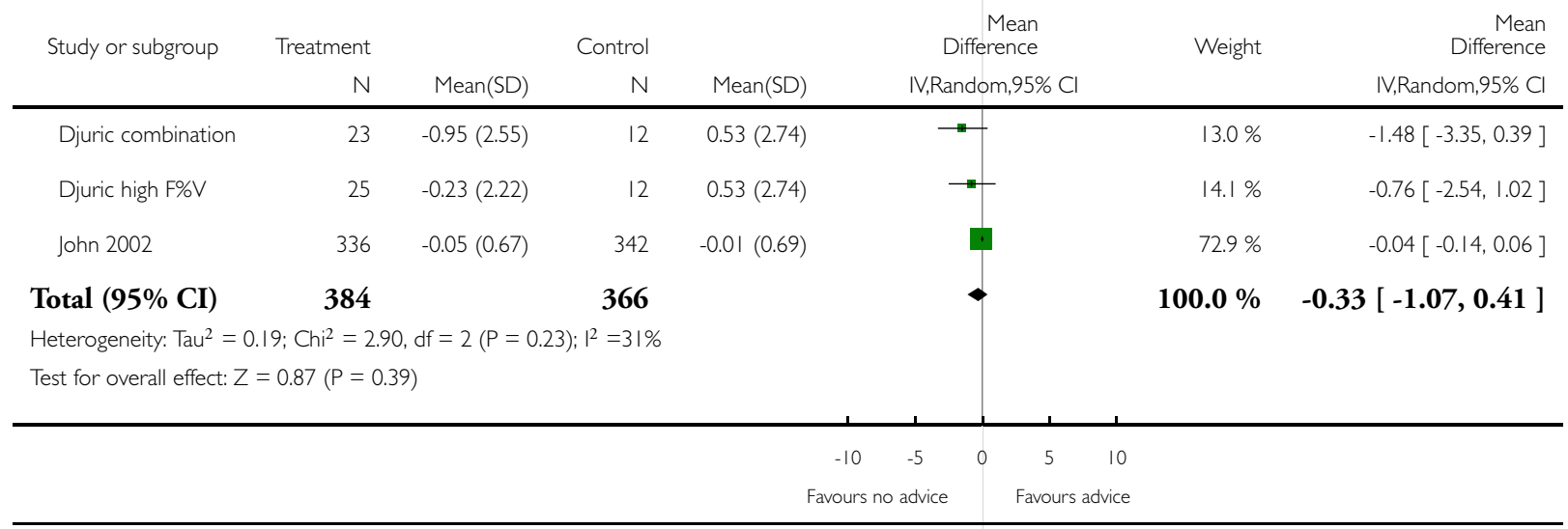

Dietary advice for reducing cardiovascular risk (Review)

Copyright $\odot 2009$ The Cochrane Collaboration. Published by John Wiley \& Sons, Ltd. 


\section{Analysis I.I2. Comparison I Any dietary intervention versus no intervention, Outcome I 2 Plasma}

lycopene (micromol/L), change from baseline.

Review: Dietary advice for reducing cardiovascular risk

Comparison: I Any dietary intervention versus no intervention

Outcome: 12 Plasma lycopene (micromol/L), change from baseline

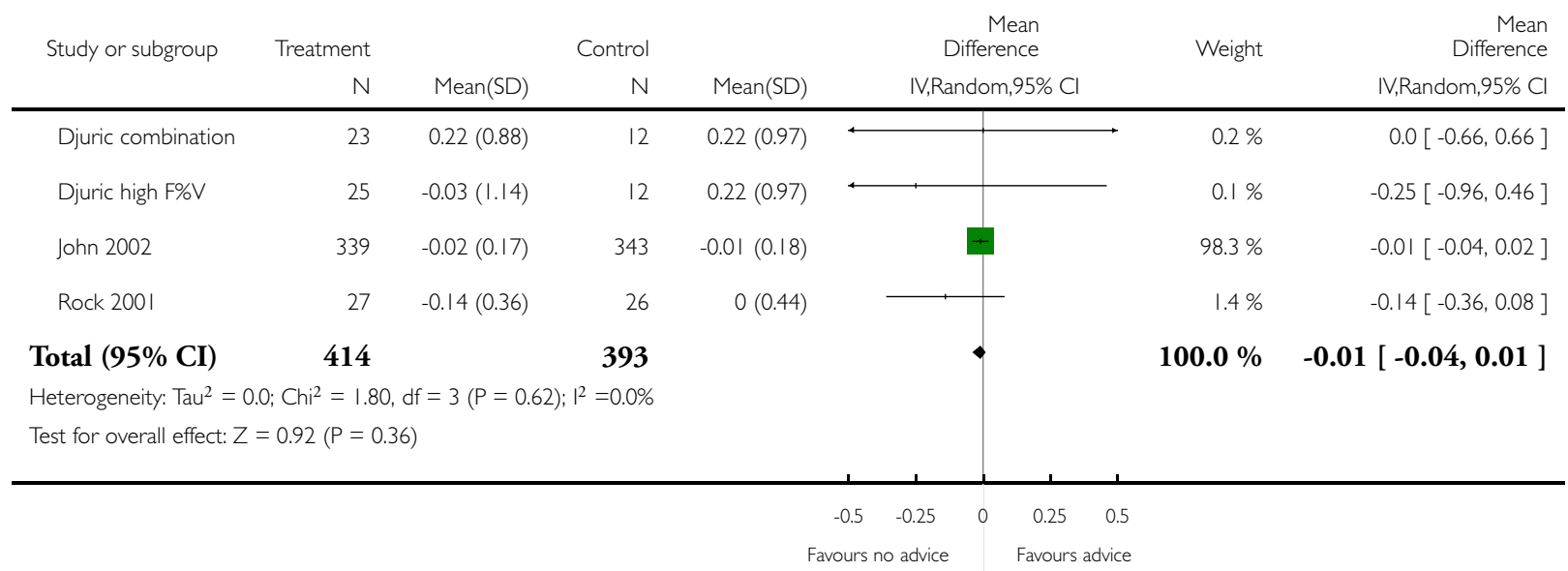


Analysis I.13. Comparison I Any dietary intervention versus no intervention, Outcome I3 Plasma lutein (micromol/L), change from baseline.

Review: Dietary advice for reducing cardiovascular risk

Comparison: I Any dietary intervention versus no intervention

Outcome: 13 Plasma lutein (micromol/L), change from baseline

\begin{tabular}{|c|c|c|c|c|c|c|c|c|c|}
\hline \multirow[t]{2}{*}{ Study or subgroup } & \multirow{2}{*}{$\begin{array}{r}\text { Treatment } \\
\mathrm{N}\end{array}$} & \multicolumn{3}{|c|}{ Control } & \multicolumn{3}{|c|}{$\begin{array}{r}\text { Mean } \\
\text { Difference }\end{array}$} & Weight & \multirow{2}{*}{$\begin{array}{r}\text { Mean } \\
\text { Difference } \\
\text { IV,Random,95\% Cl }\end{array}$} \\
\hline & & Mean(SD) & N & Mean(SD) & \multicolumn{3}{|c|}{ IV,Random,95\% Cl } & & \\
\hline Djuric combination & 23 & $0.19(0.7)$ & 12 & $0.03(0.26)$ & & & & $0.3 \%$ & $0.16[-0.16,0.48]$ \\
\hline Djuric high F\%V & 25 & $0.09(0.26)$ & 12 & $0.03(0.26)$ & & & & $0.9 \%$ & $0.06[-0.12,0.24]$ \\
\hline John 2002 & 339 & $0.01(0.13)$ & 334 & $-0.01(0.1)$ & & & & $97.1 \%$ & $0.02[0.00,0.04]$ \\
\hline Rock 2001 & 27 & $0.09(0.26)$ & 26 & $-0.02(0.24)$ & & & & $1.6 \%$ & $0.11[-0.02,0.24]$ \\
\hline Total (95\% CI) & 414 & & 384 & & & & - & $100.0 \%$ & $0.02[0.00,0.04]$ \\
\hline \multicolumn{10}{|c|}{ Heterogeneity: $\operatorname{Tau}^{2}=0.0 ; \mathrm{Chi}^{2}=2.57, \mathrm{df}=3(\mathrm{P}=0.46) ; \mathrm{I}^{2}=0.0 \%$} \\
\hline \multicolumn{10}{|c|}{ Test for overall effect: $Z=2.53(P=0.01 \mathrm{I})$} \\
\hline & & & & & -0.5 & -0.25 & 0.25 & 0.5 & \\
\hline \multicolumn{10}{|c|}{ Favours no advice $\quad$ Favours advice } \\
\hline
\end{tabular}


Analysis I.I4. Comparison I Any dietary intervention versus no intervention, Outcome I4 Plasma betacryptoxanthin (micromol/L), change from baseline.

Review: Dietary advice for reducing cardiovascular risk

Comparison: I Any dietary intervention versus no intervention

Outcome: 14 Plasma beta-cryptoxanthin (micromol/L), change from baseline

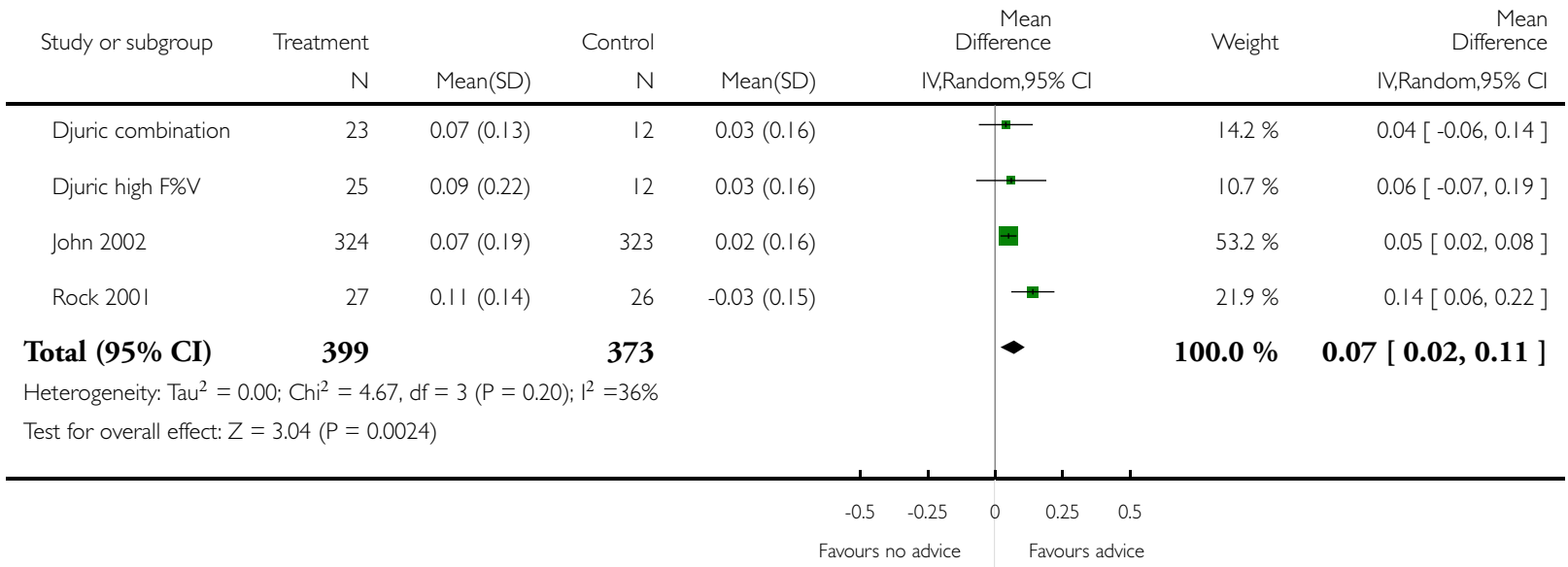

Analysis I.I5. Comparison I Any dietary intervention versus no intervention, Outcome I5 Plasma total carotenoids (micromol/L), change from baseline.

Review: Dietary advice for reducing cardiovascular risk

Comparison: I Any dietary intervention versus no intervention

Outcome: 15 Plasma total carotenoids (micromol/L), change from baseline

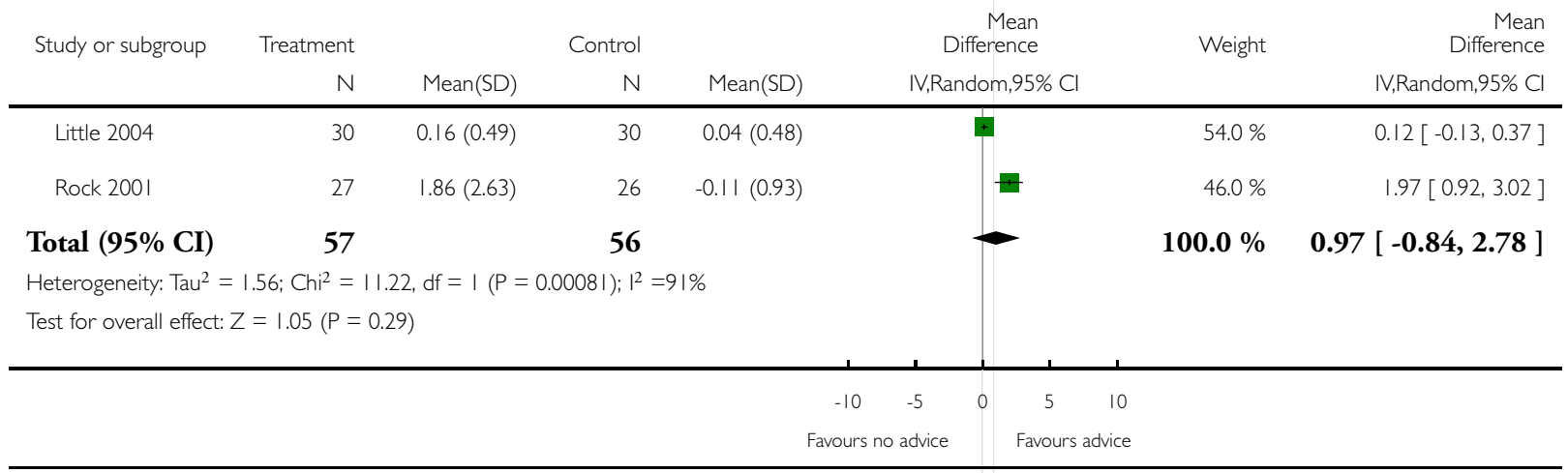

Dietary advice for reducing cardiovascular risk (Review)

Copyright () 2009 The Cochrane Collaboration. Published by John Wiley \& Sons, Ltd. 


\section{Analysis I.16. Comparison I Any dietary intervention versus no intervention, Outcome I 6 Plasma ascorbic}

acid (micromol/L), change from baseline.

Review: Dietary advice for reducing cardiovascular risk

Comparison: I Any dietary intervention versus no intervention

Outcome: 16 Plasma ascorbic acid (micromol/L), change from baseline

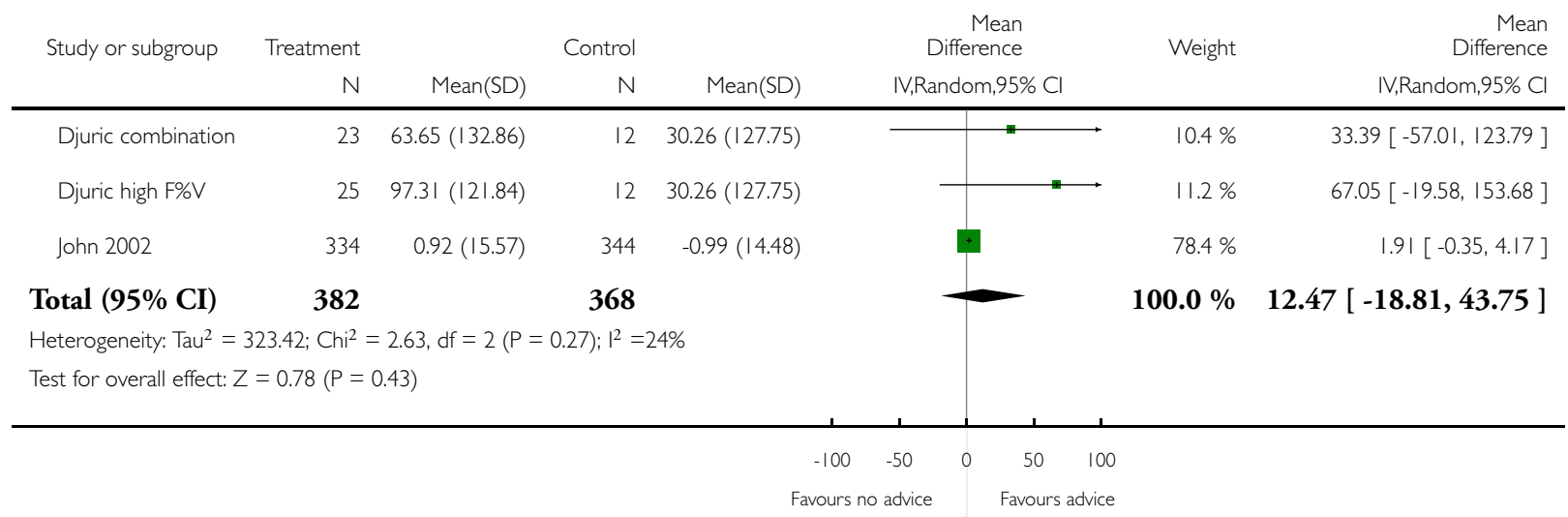


Analysis I.I7. Comparison I Any dietary intervention versus no intervention, Outcome I7 Red cell folate (nanomol/L), change from baseline.

Review: Dietary advice for reducing cardiovascular risk

Comparison: I Any dietary intervention versus no intervention

Outcome: 17 Red cell folate (nanomol/L), change from baseline

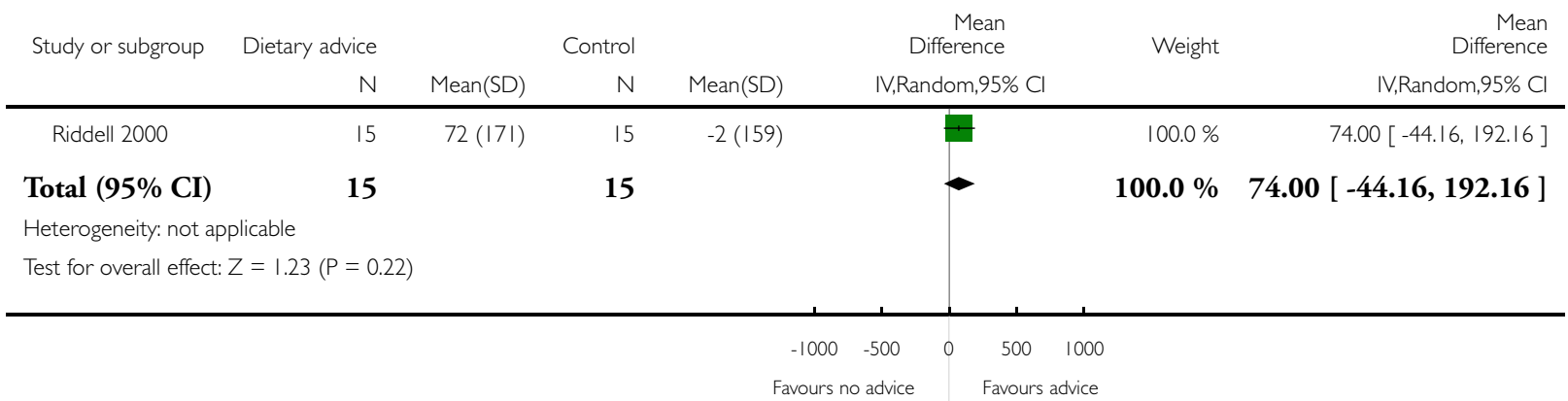


Analysis I.18. Comparison I Any dietary intervention versus no intervention, Outcome 18 Total dietary fat (\% Kcal).

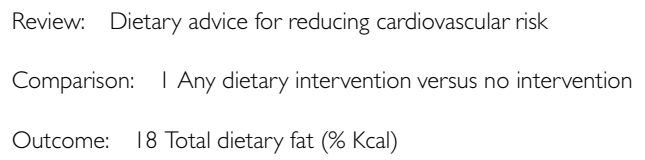

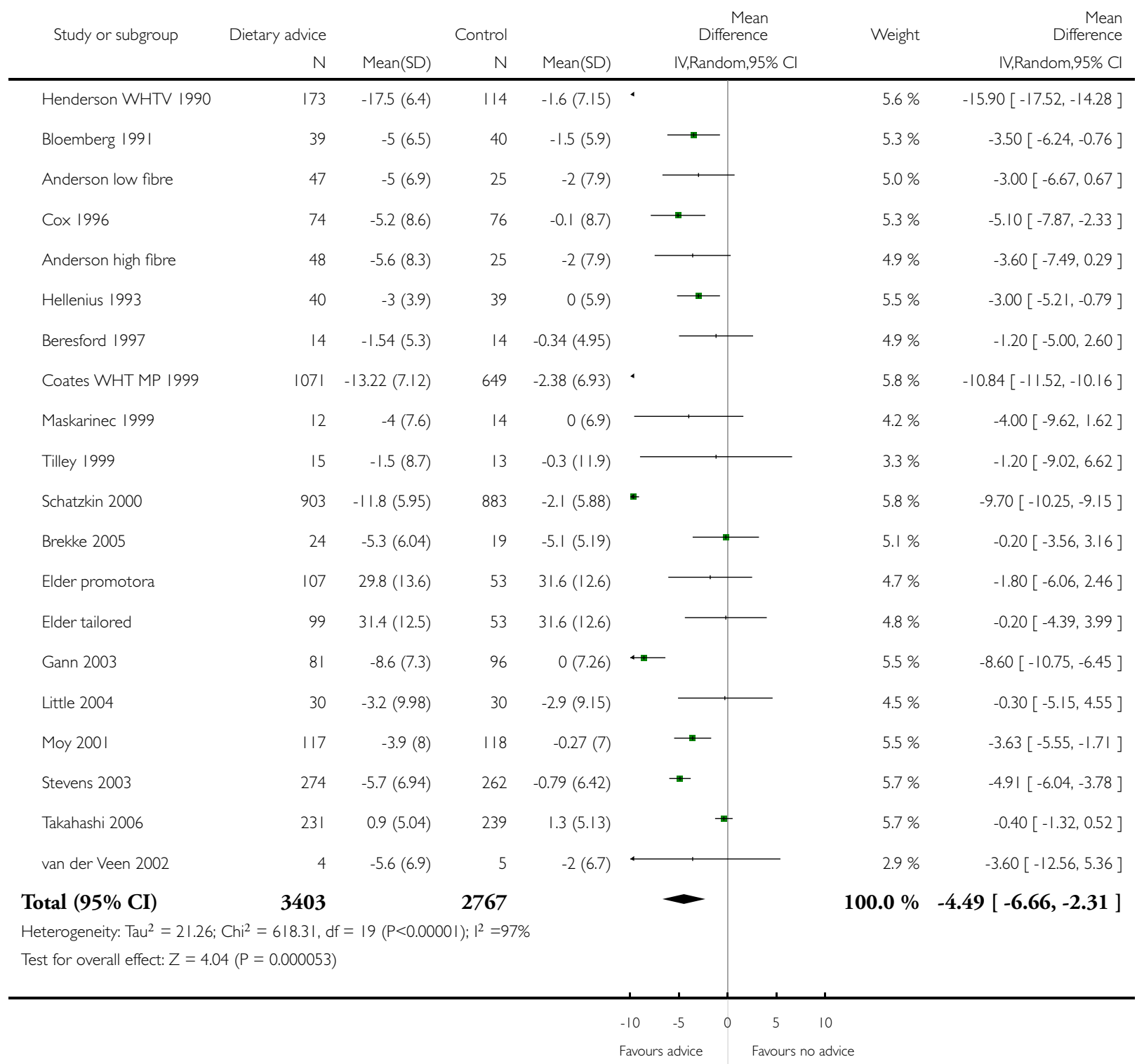


Analysis I.19. Comparison I Any dietary intervention versus no intervention, Outcome 19 Dietary saturated fatty acids (\% Kcal).

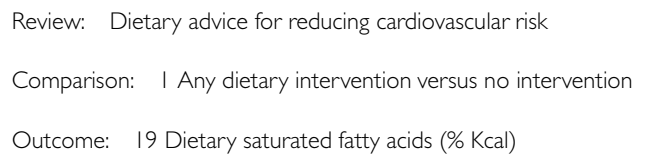

\begin{tabular}{|c|c|c|c|c|c|c|c|c|c|}
\hline \multirow{3}{*}{$\begin{array}{l}\text { Study or subgroup } \\
\text { Henderson WHTV } 1990\end{array}$} & \multirow{3}{*}{$\begin{array}{r}\text { Dietary advice } \\
N\end{array}$} & \multirow{3}{*}{\multicolumn{2}{|c|}{$\begin{array}{r}\text { Control } \\
\mathrm{N}\end{array}$}} & \multirow{3}{*}{\multicolumn{2}{|c|}{$\frac{\text { Mean(SD) }}{-0.6(3.34)}$}} & \multirow{2}{*}{\multicolumn{2}{|c|}{$\begin{array}{c}\text { Mean } \\
\text { Difference } \\
\text { IV,Random,95\% Cl }\end{array}$}} & \multirow{3}{*}{$\begin{array}{l}\text { Weight } \\
9.7 \%\end{array}$} & \multirow{3}{*}{$\begin{array}{r}\text { Mean } \\
\text { Difference } \\
\text { IV,Random,95\% Cl } \\
-6.20[-6.95,-5.45]\end{array}$} \\
\hline & & & & & & & & & \\
\hline & & & & & & \multirow{2}{*}{$\begin{array}{l}+ \\
-\end{array}$} & & & \\
\hline Bloemberg 1991 & 39 & $-4.3(3.9)$ & 40 & $-0.7(2.9)$ & & & & $8.4 \%$ & $-3.60[-5.12,-2.08]$ \\
\hline Anderson low fibre & 47 & $-2(3.5)$ & 25 & $-1(3.6)$ & & \multicolumn{2}{|l|}{$\rightarrow$} & $7.9 \%$ & $-1.00[-2.73,0.73]$ \\
\hline Anderson high fibre & 48 & $-3(2.7)$ & 25 & $-1(3.6)$ & & \multicolumn{2}{|l|}{$\longrightarrow$} & $8.2 \%$ & $-2.00[-3.60,-0.40]$ \\
\hline Coates WHT MP 1999 & $|07|$ & $-4.21(2.64)$ & 649 & $-0.8(2.72)$ & & \multicolumn{2}{|l|}{$=$} & $10.1 \%$ & $-3.41[-3.67,-3.15]$ \\
\hline Cox 1996 & 74 & $-2.3(4.3)$ & 76 & $0.5(4.35)$ & & \multicolumn{2}{|l|}{ 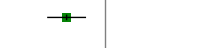 } & $8.6 \%$ & $-2.80[-4.18,-1.42]$ \\
\hline Brekke 2005 & 24 & $-4.7(3.31)$ & 19 & $-3.9(3.22)$ & & \multicolumn{2}{|l|}{$\rightarrow$} & $7.5 \%$ & $-0.80[-2.76,1.16]$ \\
\hline Elder promotora & 107 & $10.04(4.98)$ & 53 & $10.6(4.63)$ & & \multicolumn{2}{|l|}{$\rightarrow$} & $8.3 \%$ & $-0.56[-2.12,1.00]$ \\
\hline Elder tailored & 99 & I $0.7(4.99)$ & 53 & $10.6(4.63)$ & & & $8.2 \%$ & $0.10[-1.49,1.69]$ \\
\hline Gann 2003 & 81 & $-3.79(3.82)$ & 96 & $-0.22(5.2)$ & & \multicolumn{2}{|l|}{-} & $8.7 \%$ & $-3.57[-4.90,-2.24]$ \\
\hline Moy 200I & 117 & $-1.4(3)$ & 118 & $-0.01(3)$ & & \multicolumn{2}{|l|}{ 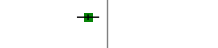 } & $9.7 \%$ & $-1.39[-2.16,-0.62]$ \\
\hline van der Veen 2002 & 4 & $-2.6(2.7)$ & 5 & $-0.9(2.6)$ & & \multirow{2}{*}{$<$} & & $4.7 \%$ & $-1.70[-5.19,1.79]$ \\
\hline Total $(95 \% \mathrm{CI})$ & 1884 & & 1273 & & & & & $100.0 \%$ & $-2.36[-3.39,-1.32]$ \\
\hline \multicolumn{10}{|c|}{ Heterogeneity: $\operatorname{Tau}^{2}=2.74 ; \mathrm{Chi}^{2}=|28.99, \mathrm{df}=||(\mathrm{P}<0.0000 \mathrm{I}) ;|^{2}=91 \%$} \\
\hline \multicolumn{6}{|c|}{ Test for overall effect: $Z=4.46(P<0.0000 I)$} & & & & \\
\hline & & & & & -10 & -5 & 5 & 10 & \\
\hline & & & & & Fav & advice & our & advice & \\
\hline
\end{tabular}


Analysis I.20. Comparison I Any dietary intervention versus no intervention, Outcome 20 Fruit and vegetable (servings per day), change from baseline.

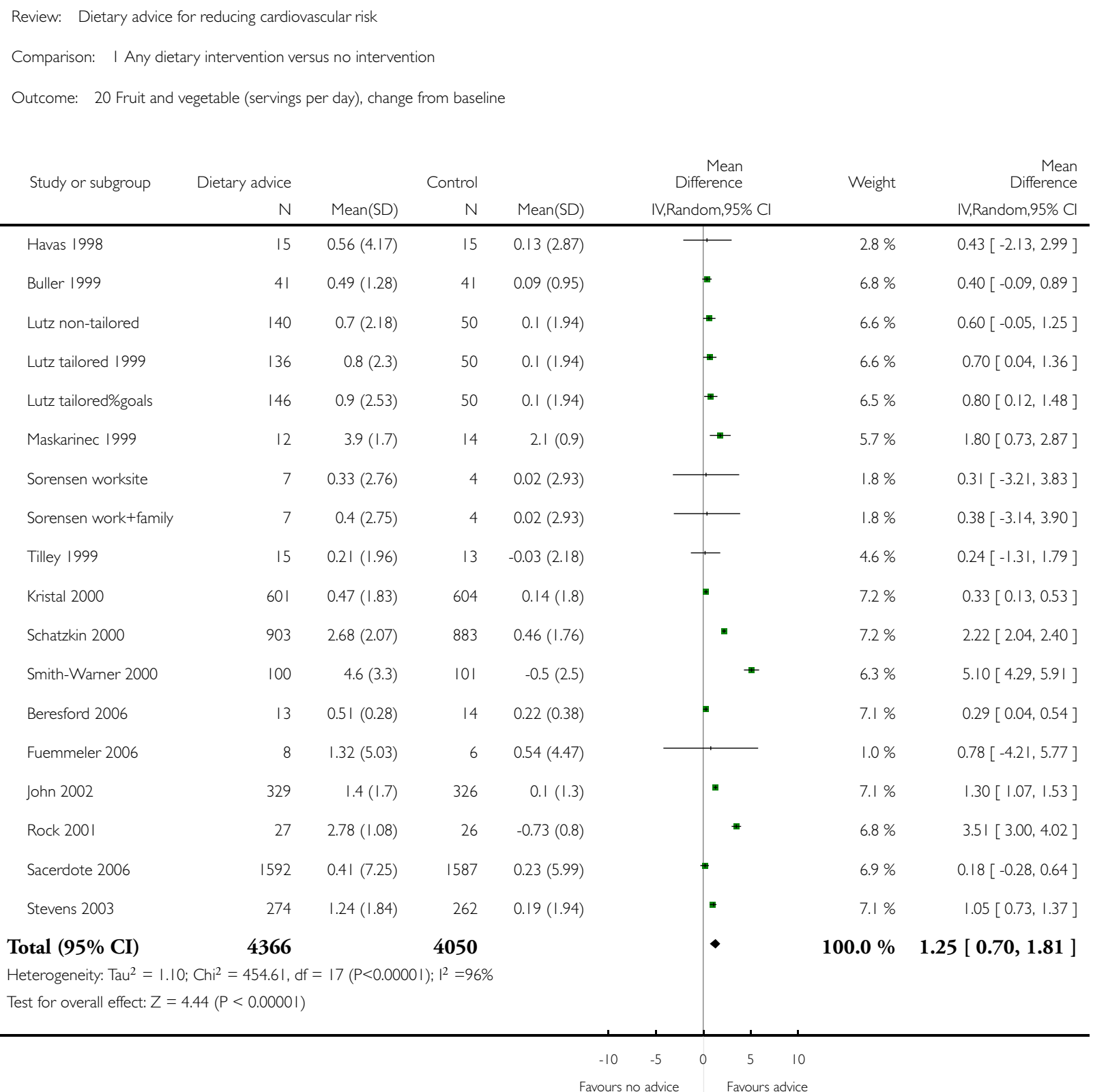

Dietary advice for reducing cardiovascular risk (Review) 


\section{Analysis 1.21. Comparison I Any dietary intervention versus no intervention, Outcome 2 I Fruit (servings}

per day), change from baseline.

Review: Dietary advice for reducing cardiovascular risk

Comparison: I Any dietary intervention versus no intervention

Outcome: 21 Fruit (servings per day), change from baseline

\begin{tabular}{|c|c|c|c|c|c|c|c|c|c|}
\hline \multirow[t]{2}{*}{ Study or subgroup } & \multirow{2}{*}{$\begin{array}{r}\text { Dietary advice } \\
\mathrm{N}\end{array}$} & \multicolumn{3}{|c|}{ Control } & \multirow{2}{*}{\multicolumn{3}{|c|}{$\begin{array}{c}\text { Mean } \\
\text { Difference } \\
\text { IV,Random,95\% Cl }\end{array}$}} & \multirow[t]{2}{*}{ Weight } & \multirow{2}{*}{$\begin{array}{r}\text { Mean } \\
\text { Difference } \\
\text { IV,Random,95\% Cl }\end{array}$} \\
\hline & & Mean(SD) & $N$ & Mean(SD) & & & & & \\
\hline Cox 1996 & 74 & I.I (9.6) & 76 & $0(1.74)$ & & & - & $4.7 \%$ & $1.10[-1.12,3.32]$ \\
\hline Coates WHT MP 1999 & |07| & $0.4(1.16)$ & 649 & $0.01(0.99)$ & & & I & $13.0 \%$ & $0.39[0.29,0.49]$ \\
\hline Maskarinec 1999 & 12 & $-2(1.1)$ & 14 & $0.7(1.04)$ & & $\Psi$ & & $10.5 \%$ & $-2.70[-3.53,-1.87]$ \\
\hline Tilley 1999 & 15 & $0.12(1.4)$ & 13 & $-0.1(1.74)$ & & & 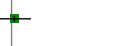 & $8.7 \%$ & $0.22[-0.96,1.40]$ \\
\hline Smith-Warner 2000 & 100 & $2.5(2.47)$ & 101 & $-0.3(1.66)$ & & & \# & $11.7 \%$ & $2.80[2.22,3.38]$ \\
\hline Beresford 2006 & 13 & $0.51(0.28)$ & 14 & $0.22(0.38)$ & & & 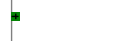 & $12.8 \%$ & $0.29[0.04,0.54]$ \\
\hline Lanza men 2001 & 605 & $2.14(2.1)$ & 581 & $0.28(1.62)$ & & & I & $12.9 \%$ & $1.86[1.65,2.07]$ \\
\hline Lanza women 2001 & 318 & ।.7। (I.76) & 335 & $0.17(0.19)$ & & & i & $12.9 \%$ & $1.54[1.35,1.73]$ \\
\hline Takahashi 2006 & 224 & $0.3(1.22)$ & 224 & $0.03(1.14)$ & & & I & $12.9 \%$ & $0.27[0.05,0.49]$ \\
\hline Total (95\% CI) & 2432 & & 2007 & & & & $\bullet$ & $100.0 \%$ & $0.67[0.07,1.28]$ \\
\hline \multicolumn{10}{|c|}{ Heterogeneity: $\operatorname{Tau}^{2}=0.73 ; \mathrm{Chi}^{2}=360.77, \mathrm{df}=8(\mathrm{P}<0.0000 \mathrm{I}) ; \mathrm{I}^{2}=98 \%$} \\
\hline \multicolumn{10}{|c|}{ Test for overall effect: $Z=2.19(P=0.029)$} \\
\hline & & & & & -10 & -5 & 5 & 10 & \\
\hline
\end{tabular}


Analysis 1.22. Comparison I Any dietary intervention versus no intervention, Outcome 22 Vegetable (servings per day), change from baseline.

Review: Dietary advice for reducing cardiovascular risk

Comparison: I Any dietary intervention versus no intervention

Outcome: 22 Vegetable (servings per day), change from baseline

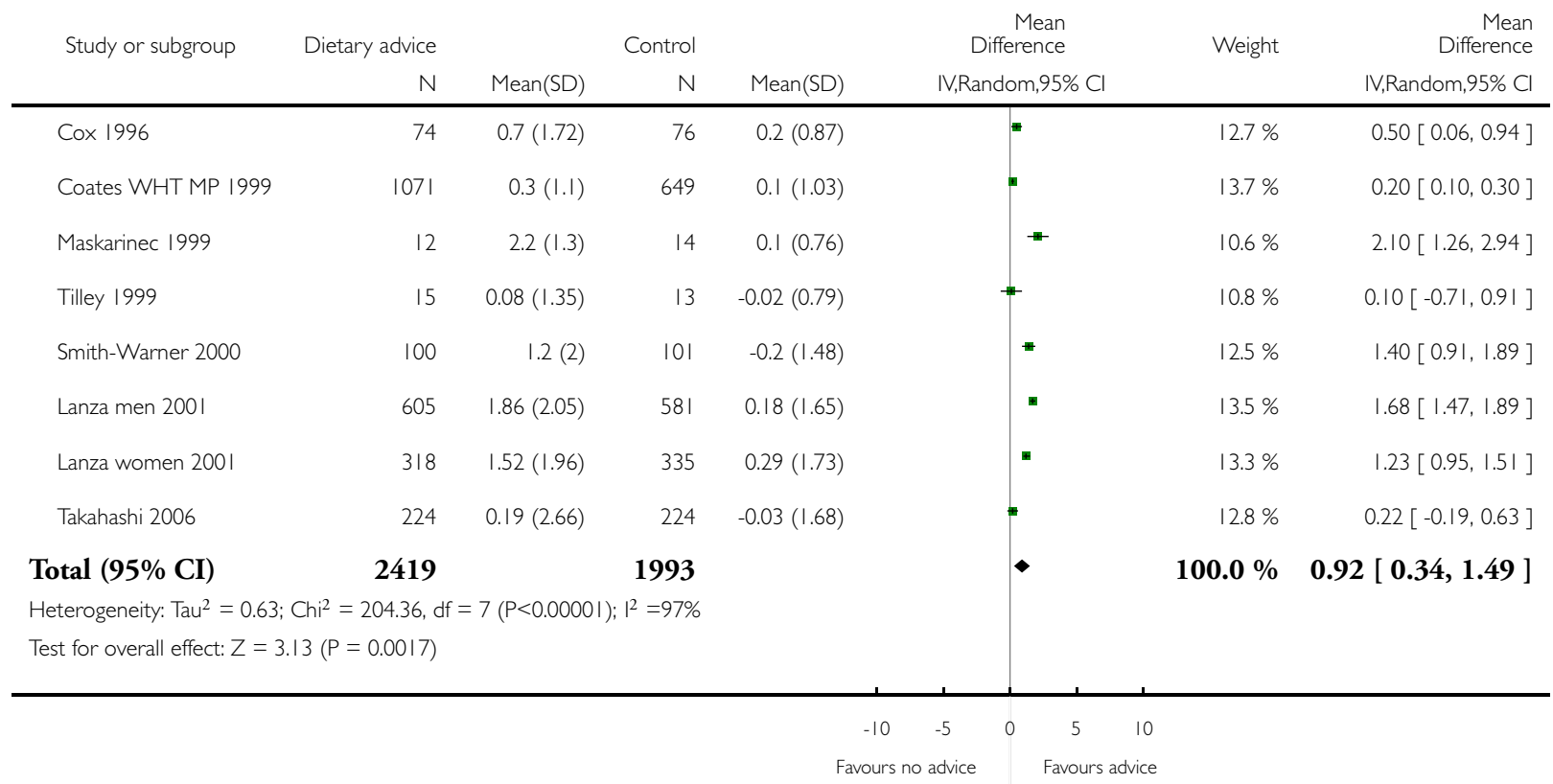


Analysis I.23. Comparison I Any dietary intervention versus no intervention, Outcome 23 Dietary fibre (grams per day), change from baseline.

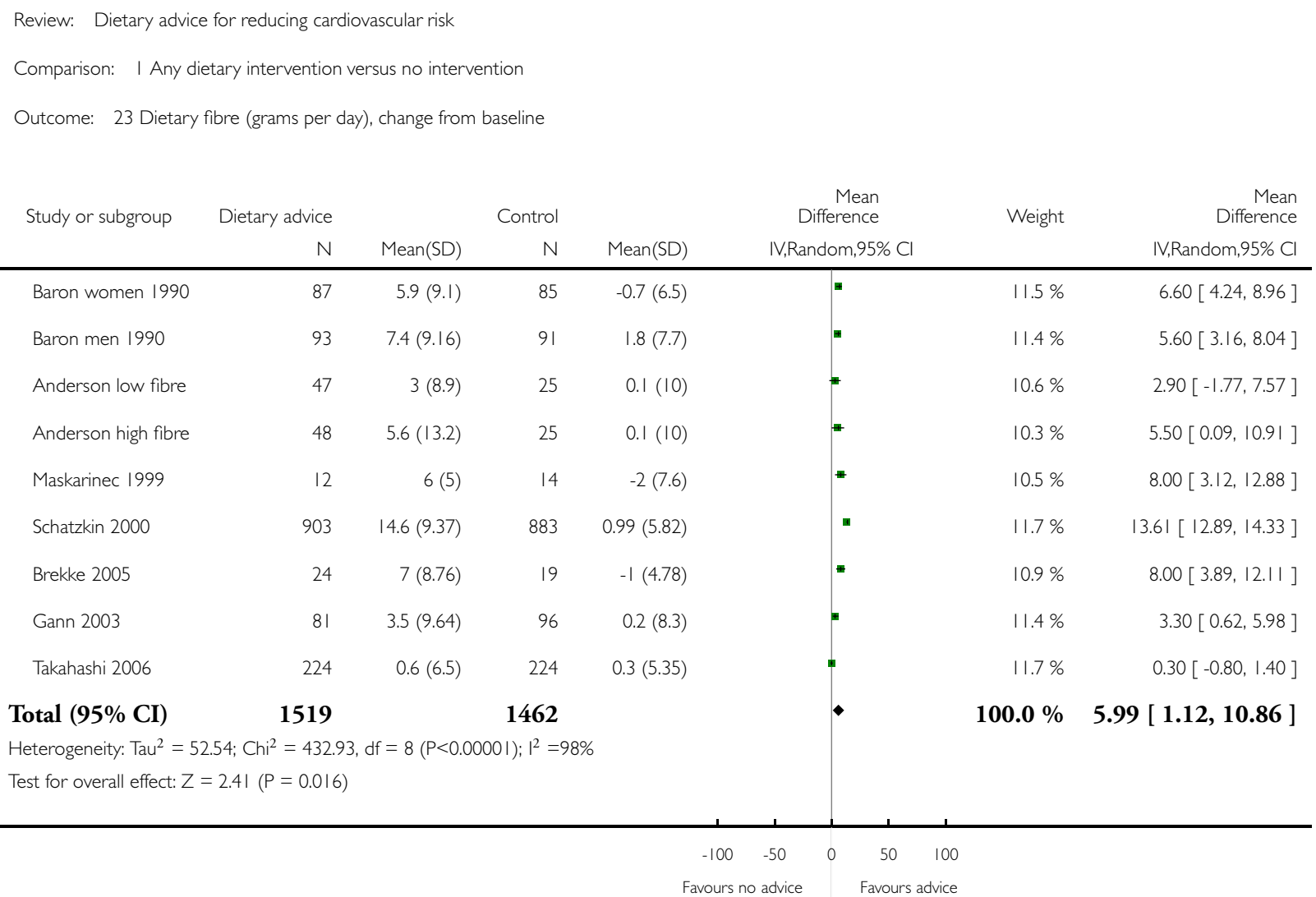


Analysis I.24. Comparison I Any dietary intervention versus no intervention, Outcome 24 Dietary intake of ascorbic acid ( $\mathrm{mg} / \mathrm{day})$, change from baseline.

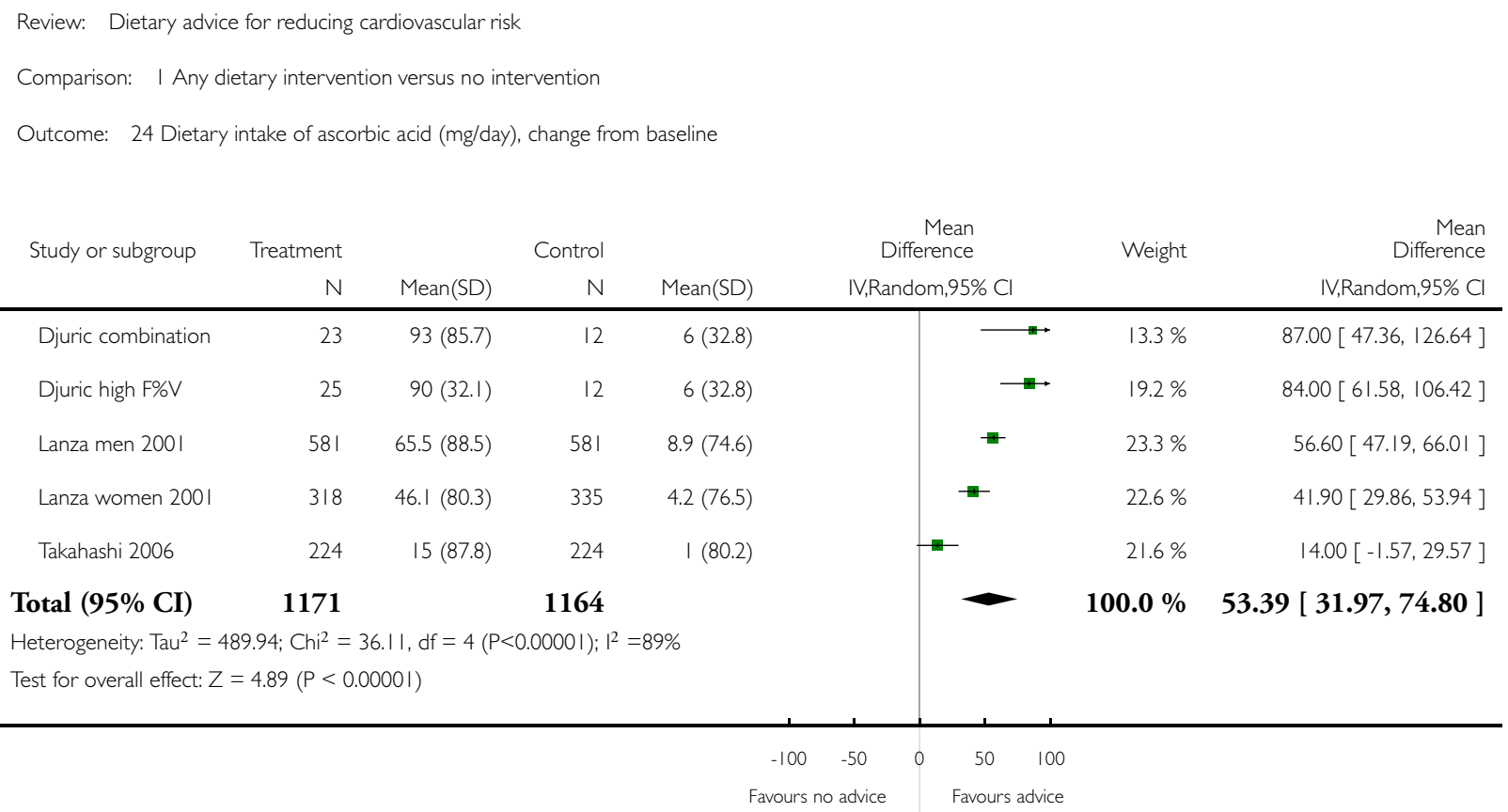


Analysis I.25. Comparison I Any dietary intervention versus no intervention, Outcome 25 Dietary intake of beta-carotene ( $\mathrm{mg} / \mathrm{day})$, change from baseline.

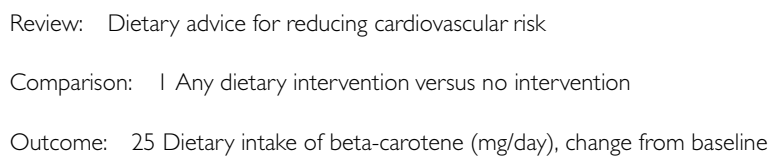

\begin{tabular}{|c|c|c|c|c|c|c|c|c|c|}
\hline \multirow{3}{*}{$\begin{array}{l}\text { Study or subgroup } \\
\text { Djuric combination }\end{array}$} & \multirow{3}{*}{$\begin{array}{r}\text { Treatment } \\
\mathrm{N} \\
23\end{array}$} & \multirow{3}{*}{\multicolumn{2}{|c|}{$\begin{array}{r}\text { Control } \\
\mathrm{N} \\
12\end{array}$}} & \multirow{2}{*}{\multicolumn{4}{|c|}{$\begin{array}{c}\text { Mean } \\
\text { Difference } \\
\text { IV,Random,95\% Cl }\end{array}$}} & \multirow{3}{*}{$\begin{array}{l}\text { Weight } \\
31.6 \%\end{array}$} & \multirow{3}{*}{$\begin{array}{r}\text { Mean } \\
\text { Difference } \\
\text { IV,Random,95\% Cl } \\
5.49[4.09,6.89]\end{array}$} \\
\hline & & & & & & & & & \\
\hline & & & & \multicolumn{2}{|l|}{$0.65(1.5)$} & & 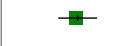 & & \\
\hline Djuric high F\%V & 25 & $3.88(2.17)$ & 12 & \multicolumn{2}{|l|}{$0.65(1.5)$} & & \# & $32.7 \%$ & $3.23[2.03,4.43]$ \\
\hline Takahashi 2006 & 231 & $1.86(3.03)$ & 239 & \multicolumn{2}{|l|}{$0.18(1.76)$} & & + & $35.7 \%$ & $1.68[1.23,2.13]$ \\
\hline Total $(95 \%$ CI $)$ & 279 & & 263 & & & & 一 & $100.0 \%$ & $3.39[1.20,5.59]$ \\
\hline \multicolumn{10}{|c|}{ Heterogeneity: $\mathrm{Tau}^{2}=3.46 ; \mathrm{Ch}^{2}=29.29, \mathrm{df}=2(\mathrm{P}<0.0000 \mathrm{I}) ; \mathrm{I}^{2}=93 \%$} \\
\hline \multicolumn{10}{|c|}{ Test for overall effect: $Z=3.03(P=0.0025)$} \\
\hline & & & & & -10 & -5 & 5 & 10 & \\
\hline
\end{tabular}




\section{Analysis 2.1. Comparison 2 Subgroup analyses, Outcome I Total cholesterol (gender).}

Review: Dietary advice for reducing cardiovascular risk

Comparison: 2 Subgroup analyses

Outcome: I Total cholesterol (gender)

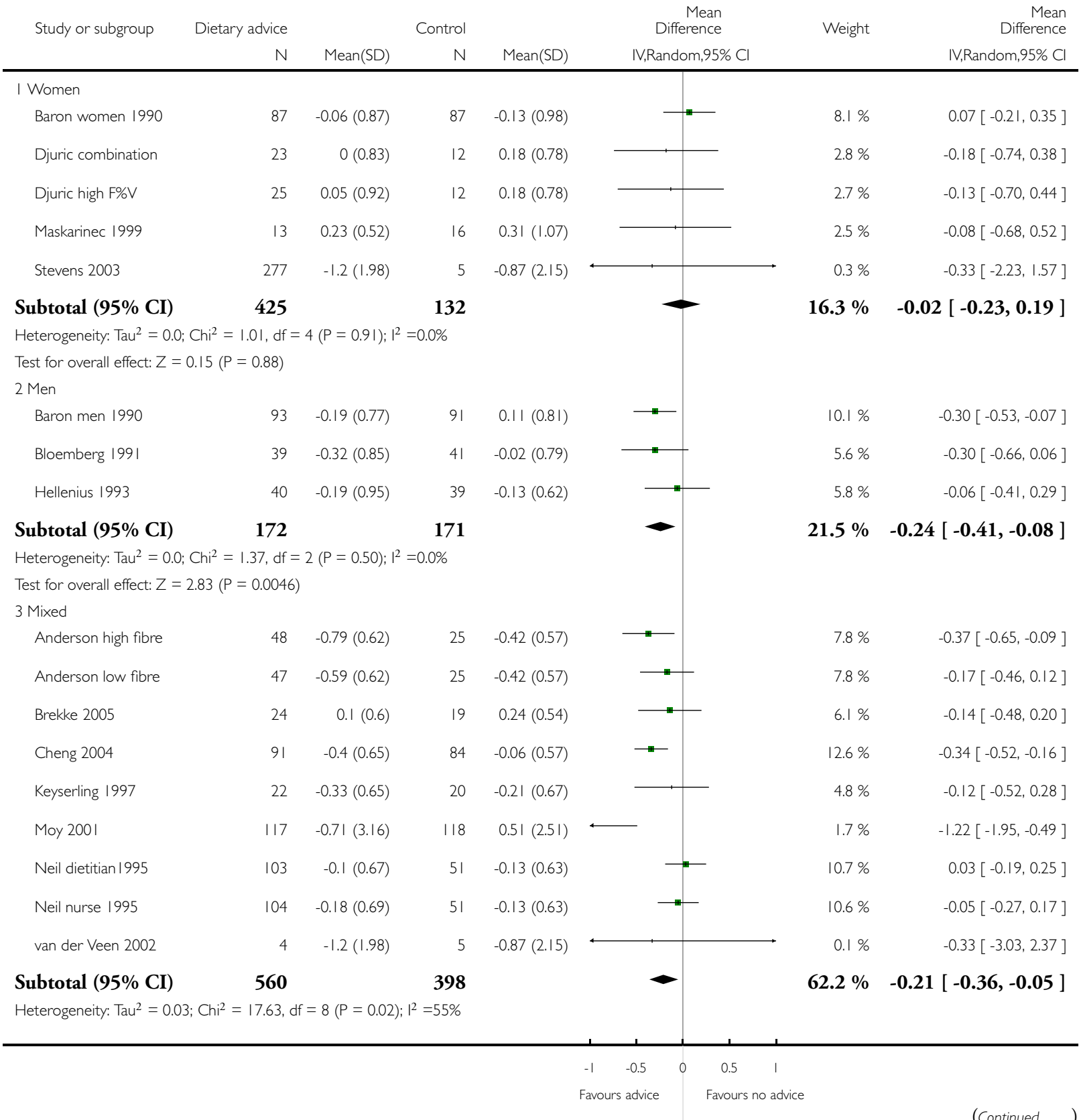

Dietary advice for reducing cardiovascular risk (Review) 


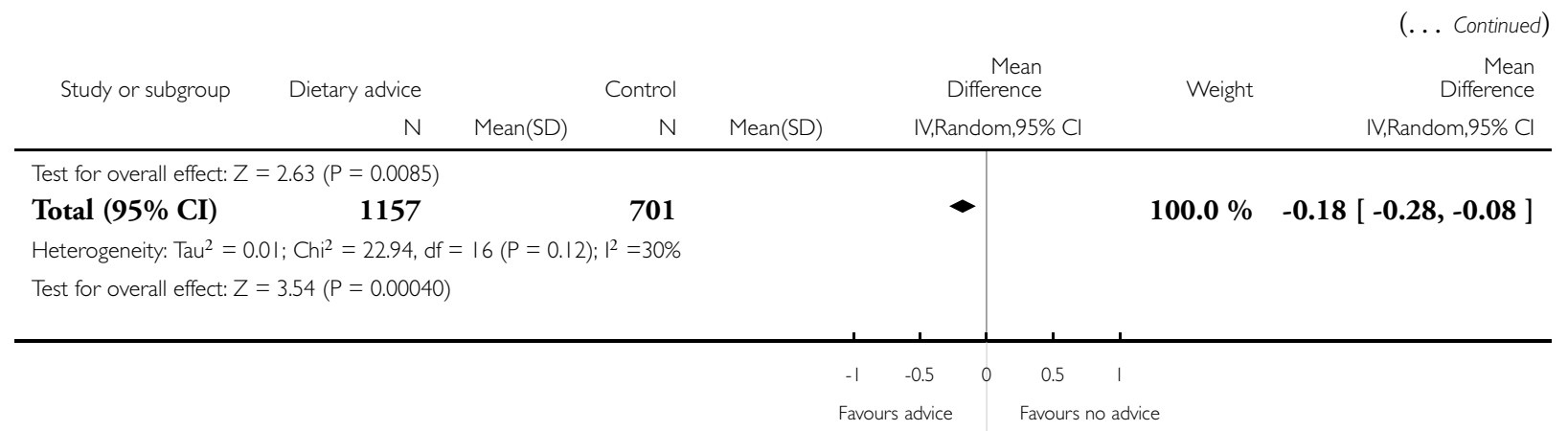

\section{Analysis 2.2. Comparison 2 Subgroup analyses, Outcome 2 Total dietary fat (gender).}

Review: Dietary advice for reducing cardiovascular risk

Comparison: 2 Subgroup analyses

Outcome: 2 Total dietary fat (gender)

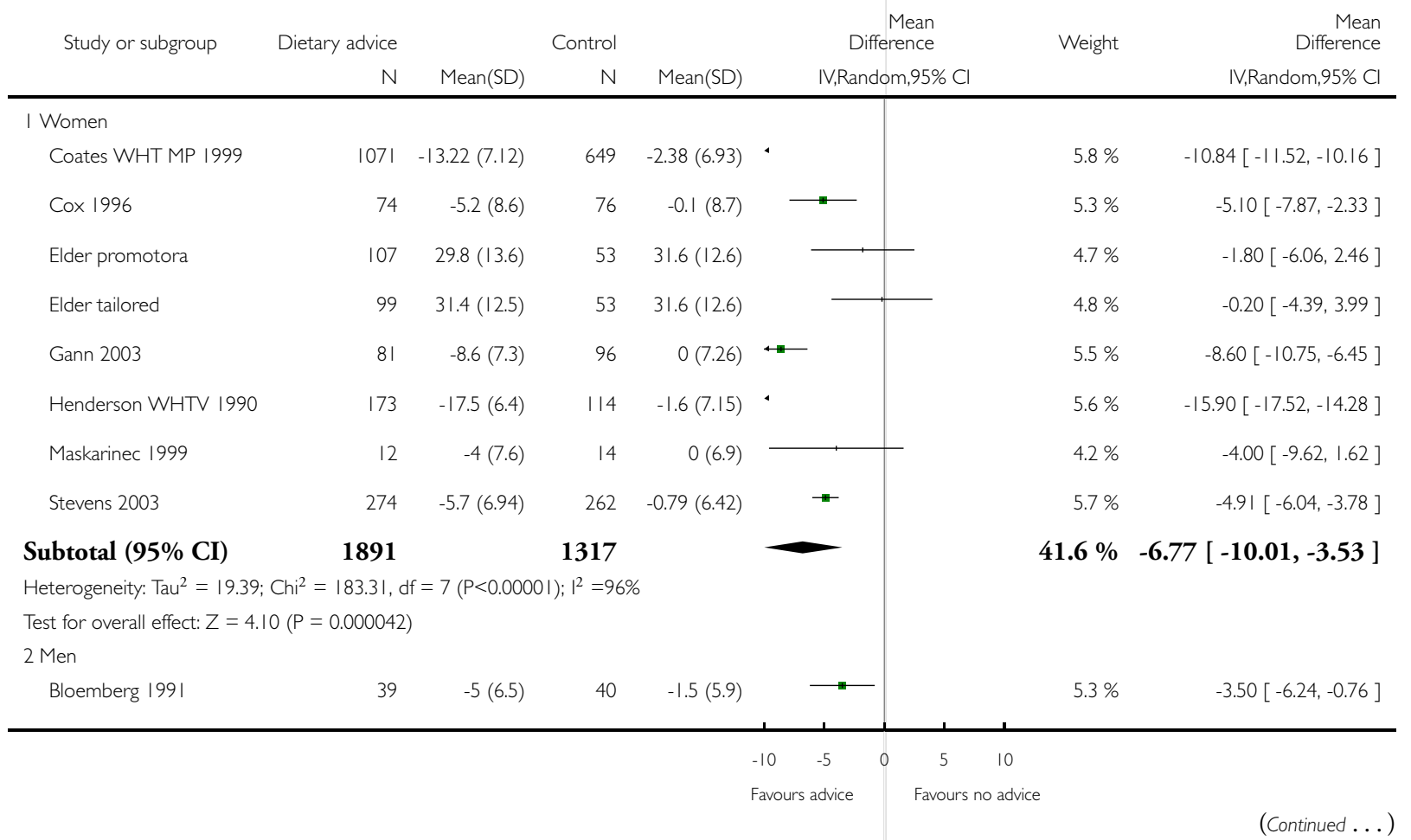

Dietary advice for reducing cardiovascular risk (Review) 


\begin{tabular}{|c|c|c|c|c|c|c|c|}
\hline \multirow[t]{2}{*}{ Study or subgroup } & Dietary advice & \multicolumn{3}{|c|}{ Control } & $\begin{array}{r}\text { Mean } \\
\text { Difference }\end{array}$ & \multirow[t]{2}{*}{ Weight } & \multirow{2}{*}{$\begin{array}{r}(\ldots \text { Continued) } \\
\text { Mean } \\
\text { Difference } \\
\text { IV,Random, } 95 \% \mathrm{Cl}\end{array}$} \\
\hline & $\mathrm{N}$ & Mean(SD) & $\mathrm{N}$ & Mean(SD) & IV,Rando & & \\
\hline Hellenius 1993 & 40 & $-3(3.9)$ & 39 & $0(5.9)$ & $\longrightarrow$ & $5.5 \%$ & $-3.00[-5.21,-0.79]$ \\
\hline Tilley 1999 & 15 & $-1.5(8.7)$ & 13 & $-0.3(11.9)$ & & $3.3 \%$ & $-1.20[-9.02,6.62]$ \\
\hline Subtotal $(95 \% \mathrm{CI})$ & 94 & & 92 & & 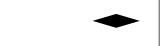 & $14.1 \%$ & $-3.11[-4.79,-1.42]$ \\
\hline \multicolumn{8}{|c|}{ Heterogeneity: $\operatorname{Tau}^{2}=0.0 ; \mathrm{Chi}^{2}=0.32, \mathrm{df}=2(\mathrm{P}=0.85) ; \mathrm{I}^{2}=0.0 \%$} \\
\hline \multicolumn{8}{|c|}{ Test for overall effect: $Z=3.62(P=0.00029)$} \\
\hline \multicolumn{8}{|l|}{3 Mixed } \\
\hline Anderson high fibre & 48 & $-5.6(8.3)$ & 25 & $-2(7.9)$ & & $4.9 \%$ & $-3.60[-7.49,0.29]$ \\
\hline Anderson low fibre & 47 & $-5(6.9)$ & 25 & $-2(7.9)$ & & $5.0 \%$ & $-3.00[-6.67,0.67]$ \\
\hline Beresford 1997 & 14 & $-1.54(5.3)$ & 14 & $-0.34(4.95)$ & & $4.9 \%$ & $-1.20[-5.00,2.60]$ \\
\hline Brekke 2005 & 24 & $-5.3(6.04)$ & 19 & $-5.1(5.19)$ & & $5.1 \%$ & $-0.20[-3.56,3.16]$ \\
\hline Little 2004 & 30 & $-3.2(9.98)$ & 30 & $-2.9(9.15)$ & & $4.5 \%$ & $-0.30[-5.15,4.55]$ \\
\hline Moy 2001 & 117 & $-3.9(8)$ & 118 & $-0.27(7)$ & $\longrightarrow$ & $5.5 \%$ & $-3.63[-5.55,-1.71]$ \\
\hline Schatzkin 2000 & 903 & $-11.8(5.95)$ & 883 & $-2.1(5.88)$ & $*$ & $5.8 \%$ & $-9.70[-10.25,-9.15]$ \\
\hline Takahashi 2006 & 231 & $0.9(5.04)$ & 239 & $1.3(5.13)$ & & $5.7 \%$ & $-0.40[-1.32,0.52]$ \\
\hline van der Veen 2002 & 4 & $-5.6(6.9)$ & 5 & $-2(6.7)$ & & $2.9 \%$ & $-3.60[-12.56,5.36]$ \\
\hline Subtotal $(95 \% \mathrm{CI})$ & 1418 & & 1358 & & 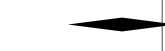 & $44.4 \%$ & $-2.90[-6.83,1.04]$ \\
\hline \multicolumn{8}{|c|}{ Heterogeneity: $\mathrm{Tau}^{2}=32.28 ; \mathrm{Chi}^{2}=340.93, \mathrm{df}=8(\mathrm{P}<0.0000 \mathrm{I}) ; \mathrm{I}^{2}=98 \%$} \\
\hline \multicolumn{8}{|c|}{ Test for overall effect: $Z=1.44(P=0.15)$} \\
\hline Total $(95 \% \mathrm{CI})$ & 3403 & & 2767 & & & $100.0 \%$ & $-4.49[-6.66,-2.31]$ \\
\hline \multicolumn{8}{|c|}{ Heterogeneity: $\mathrm{Tau}^{2}=21.26 ; \mathrm{Chi}^{2}=618.31, \mathrm{df}=19(\mathrm{P}<0.0000 \mathrm{I}) ; \mathrm{I}^{2}=97 \%$} \\
\hline Test for overall effect: $Z=$ & $04(P=0.000053)$ & & & & & & \\
\hline
\end{tabular}


Analysis 2.3. Comparison 2 Subgroup analyses, Outcome 3 Fruit \& vegetable servings/day (gender).

Review: Dietary advice for reducing cardiovascular risk

Comparison: 2 Subgroup analyses

Outcome: 3 Fruit \% vegetable servings/day (gender)

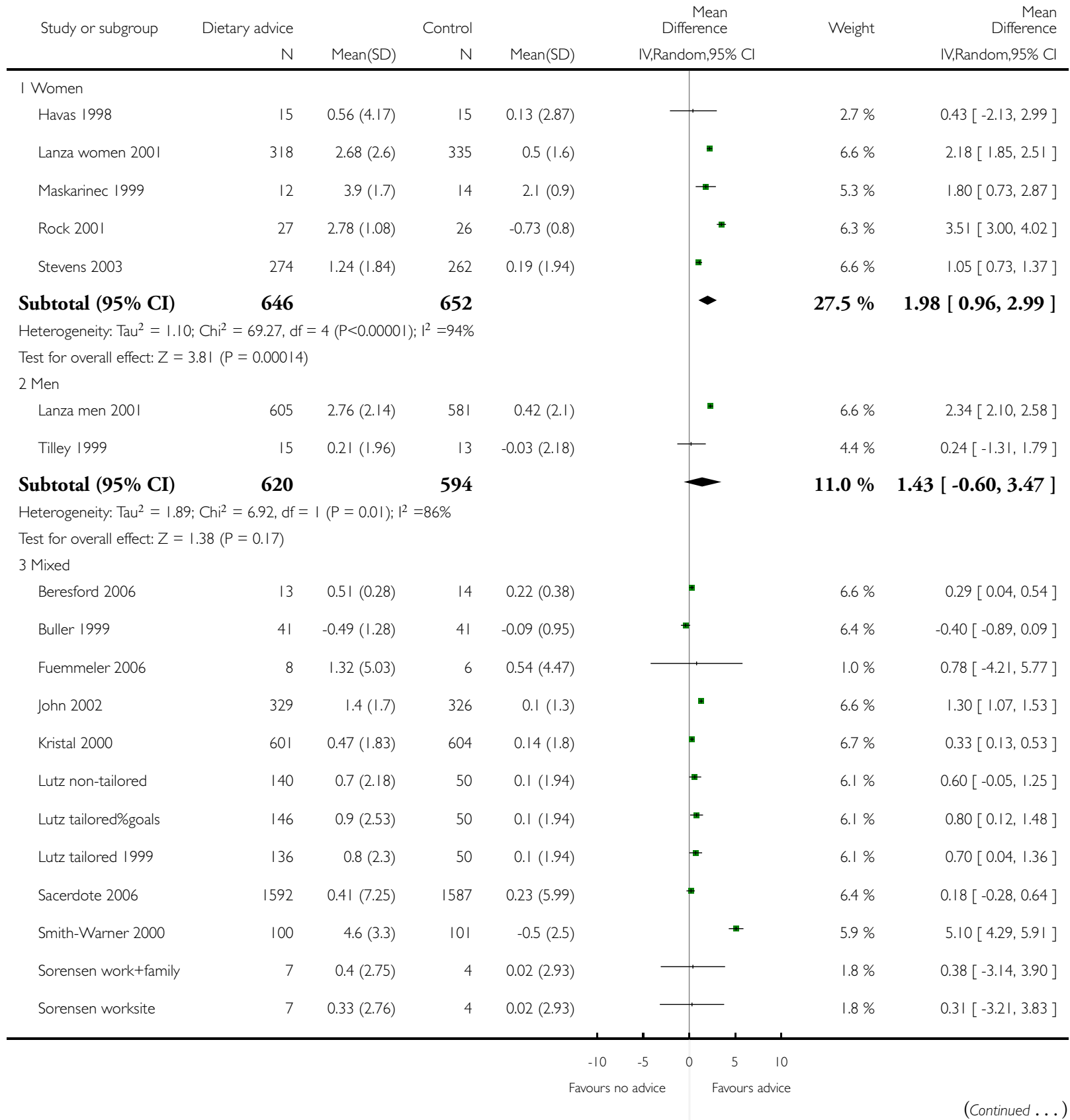

Dietary advice for reducing cardiovascular risk (Review) 


\begin{tabular}{|c|c|c|c|c|c|c|c|}
\hline \multirow[t]{2}{*}{ Study or subgroup } & \multirow{2}{*}{$\begin{array}{r}\text { Dietary advice } \\
N\end{array}$} & \multicolumn{3}{|c|}{ Control } & $\begin{array}{r}\text { Mean } \\
\text { Difference }\end{array}$ & \multirow[t]{2}{*}{ Weight } & \multirow[t]{2}{*}{$\begin{array}{r}\text { (... Continued) } \\
\text { Mean } \\
\text { Difference } \\
\text { IV.Random.95\% Cl }\end{array}$} \\
\hline & & Mean(SD) & $\mathrm{N}$ & Mean(SD) & IV,Random,95\% Cl & & \\
\hline Subtotal $(95 \% \mathrm{CI})$ & 3120 & & 2837 & & $\bullet$ & $61.5 \%$ & $0.91[0.33,1.48]$ \\
\hline \multicolumn{8}{|c|}{ Heterogeneity: $\mathrm{Tau}^{2}=0.76 ; \mathrm{Chi}^{2}=185.52, \mathrm{df}=1|(\mathrm{P}<0.0000 \mathrm{I}) ;|^{2}=94 \%$} \\
\hline \multicolumn{8}{|c|}{ Test for overall effect: $Z=3.06(P=0.0022)$} \\
\hline Total $(95 \%$ CI $)$ & 4386 & & 4083 & & $\bullet$ & $100.0 \%$ & $1.27[0.72,1.82]$ \\
\hline \multicolumn{8}{|c|}{ Heterogeneity: $\operatorname{Tau}^{2}=1.17 ; \mathrm{Chi}^{2}=477.03, \mathrm{df}=18(\mathrm{P}<0.00001) ;\left.\right|^{2}=96 \%$} \\
\hline \multicolumn{8}{|c|}{ Test for overall effect: $Z=4.53(P<0.0000 I)$} \\
\hline
\end{tabular}

Analysis 2.4. Comparison 2 Subgroup analyses, Outcome 4 Total cholesterol (risk group).

Review: Dietary advice for reducing cardiovascular risk

Comparison: 2 Subgroup analyses

Outcome: 4 Total cholesterol (risk group)

\begin{tabular}{|c|c|c|c|c|c|c|c|c|}
\hline \multirow[t]{2}{*}{ Study or subgroup } & \multirow{2}{*}{$\begin{array}{r}\text { Dietary advice } \\
\text { N }\end{array}$} & \multicolumn{3}{|c|}{ Control } & \multicolumn{2}{|c|}{$\begin{array}{r}\text { Mean } \\
\text { Difference }\end{array}$} & \multirow[t]{2}{*}{ Weight } & \multirow{2}{*}{$\begin{array}{r}\text { Mean } \\
\text { Difference } \\
\text { IV,Random,95\% Cl }\end{array}$} \\
\hline & & Mean(SD) & $\mathrm{N}$ & Mean(SD) & \multicolumn{2}{|c|}{ IV,Random,95\% Cl } & & \\
\hline \multicolumn{9}{|l|}{ I General population } \\
\hline Baron men 1990 & 93 & $-0.19(0.77)$ & 91 & $0.11(0.81)$ & - & & $8.6 \%$ & $-0.30[-0.53,-0.07]$ \\
\hline Baron women 1990 & 87 & $-0.06(0.87)$ & 87 & $-0.13(0.98)$ & & & $7.0 \%$ & $0.07[-0.21,0.35]$ \\
\hline Stevens 2003 & 277 & $-0.19(0.65)$ & 271 & $-0.16(0.7 I)$ & & & $13.7 \%$ & $-0.03[-0.14,0.08]$ \\
\hline Subtotal (95\% CI) & 457 & & 449 & & & & $29.3 \%$ & $-0.09[-0.28,0.10]$ \\
\hline \multicolumn{9}{|c|}{ Heterogeneity: $\operatorname{Tau}^{2}=0.02 ; \mathrm{Chi}^{2}=5.35, \mathrm{df}=2(P=0.07) ; \mathrm{I}^{2}=63 \%$} \\
\hline \multicolumn{9}{|c|}{ Test for overall effect: $Z=0.89(P=0.37)$} \\
\hline \multicolumn{9}{|l|}{$2 \mathrm{CVD}$ risk high } \\
\hline Anderson high fibre & 48 & $-0.79(0.62)$ & 25 & $-0.42(0.57)$ & $\rightarrow-$ & & $6.8 \%$ & $-0.37[-0.65,-0.09]$ \\
\hline Anderson low fibre & 47 & $-0.59(0.62)$ & 25 & $-0.42(0.57)$ & & - & $6.7 \%$ & $-0.17[-0.46,0.12]$ \\
\hline Bloemberg 199| & 39 & $-0.32(0.85)$ & 41 & $-0.02(0.79)$ & & & $5.0 \%$ & $-0.30[-0.66,0.06]$ \\
\hline \multirow[t]{3}{*}{ Brekke 2005} & 24 & $0.1(0.6)$ & 19 & $0.24(0.54)$ & $\longrightarrow$ & $\square$ & $5.3 \%$ & $-0.14[-0.48,0.20]$ \\
\hline & & & & & -0.5 & 0.5 & । & \\
\hline & & & & & Favours advice & Favours & advice & (Continued. \\
\hline
\end{tabular}

Dietary advice for reducing cardiovascular risk (Review)

Copyright @ 2009 The Cochrane Collaboration. Published by John Wiley \& Sons, Ltd. 


\begin{tabular}{|c|c|c|c|c|c|c|c|}
\hline \multirow[t]{2}{*}{ Study or subgroup } & \multirow{2}{*}{$\begin{array}{r}\text { Dietary advice } \\
\text { N }\end{array}$} & \multicolumn{3}{|c|}{ Control } & \multirow{2}{*}{$\begin{array}{c}\text { Mean } \\
\text { Difference } \\
\text { IV,Random,95\% Cl }\end{array}$} & \multirow[t]{2}{*}{ Weight } & \multirow{2}{*}{$\begin{array}{r}\text { (... Continued) } \\
\text { Mean } \\
\text { Difference } \\
\text { IV,Random, } 95 \% \mathrm{Cl}\end{array}$} \\
\hline & & Mean(SD) & $\mathrm{N}$ & Mean(SD) & & & \\
\hline Cheng 2004 & 91 & $-0.4(0.65)$ & 84 & $-0.06(0.57)$ & $\longrightarrow$ & $10.6 \%$ & $-0.34[-0.52,-0.16]$ \\
\hline Hellenius 1993 & 40 & $-0.19(0.95)$ & 39 & $-0.13(0.62)$ & - & $5.1 \%$ & $-0.06[-0.41,0.29]$ \\
\hline Keyserling 1997 & 22 & $-0.33(0.65)$ & 20 & $-0.21(0.67)$ & \begin{tabular}{l|l}
1 & \\
\end{tabular} & $4.3 \%$ & $-0.12[-0.52,0.28]$ \\
\hline Moy 2001 & 117 & $-0.7 \mid(3.16)$ & 118 & $0.5 \mid(2.51)$ & - & $1.6 \%$ & $-1.22[-1.95,-0.49]$ \\
\hline Neil dietitian 1995 & 103 & $-0.1(0.67)$ & 51 & $-0.13(0.63)$ & & $9.1 \%$ & $0.03[-0.19,0.25]$ \\
\hline Neil nurse 1995 & 104 & $-0.18(0.69)$ & 51 & $-0.13(0.63)$ & & $9.0 \%$ & $-0.05[-0.27,0.17]$ \\
\hline van der Veen 2002 & 4 & $-1.2(1.98)$ & 5 & $-0.87(2.15)$ & & $0.1 \%$ & $-0.33[-3.03,2.37]$ \\
\hline Subtotal (95\% CI) & 639 & & 478 & & - & $63.5 \%$ & $-0.20[-0.33,-0.07]$ \\
\hline \multicolumn{8}{|c|}{ Heterogeneity: $\mathrm{Tau}^{2}=0.02 ; \mathrm{Chi}^{2}=18.5 \mathrm{I}, \mathrm{df}=10(\mathrm{P}=0.05) ; \mathrm{I}^{2}=46 \%$} \\
\hline \multicolumn{8}{|c|}{ Test for overall effect: $Z=3.00(P=0.0027)$} \\
\hline \multicolumn{8}{|l|}{3 Cancer risk high } \\
\hline Djuric combination & 23 & $0(0.83)$ & 12 & $0.18(0.78)$ & & $2.5 \%$ & $-0.18[-0.74,0.38]$ \\
\hline Djuric high F\%V & 25 & $0.05(0.92)$ & 12 & $0.18(0.78)$ & & $2.4 \%$ & $-0.13[-0.70,0.44]$ \\
\hline Maskarinec 1999 & 13 & $0.23(0.52)$ & 16 & $0.31(1.07)$ & & $2.2 \%$ & $-0.08[-0.68,0.52]$ \\
\hline Subtotal $(95 \% \mathrm{CI})$ & 61 & & 40 & & & $7.1 \%$ & $-0.13[-0.46,0.20]$ \\
\hline \multicolumn{8}{|c|}{ Heterogeneity: $\mathrm{Tau}^{2}=0.0 ; \mathrm{Ch}^{2}=0.06, \mathrm{df}=2(\mathrm{P}=0.97) ; \mathrm{I}^{2}=0.0 \%$} \\
\hline \multicolumn{8}{|c|}{ Test for overall effect: $Z=0.78(P=0.43)$} \\
\hline Total $(95 \% \mathrm{CI})$ & 1157 & & 967 & & $\bullet$ & $100.0 \%$ & $-0.16[-0.25,-0.06]$ \\
\hline \multicolumn{8}{|c|}{ Heterogeneity: $\operatorname{Tau}^{2}=0.01 ; \mathrm{Chi}^{2}=27.38, \mathrm{df}=16(P=0.04) ; 1^{2}=42 \%$} \\
\hline \multicolumn{8}{|c|}{ Test for overall effect: $Z=3.26(P=0.0011)$} \\
\hline
\end{tabular}




\section{Analysis 2.5. Comparison 2 Subgroup analyses, Outcome 5 Total dietary fat (risk group).}

Review: Dietary advice for reducing cardiovascular risk

Comparison: 2 Subgroup analyses

Outcome: 5 Total dietary fat (risk group)

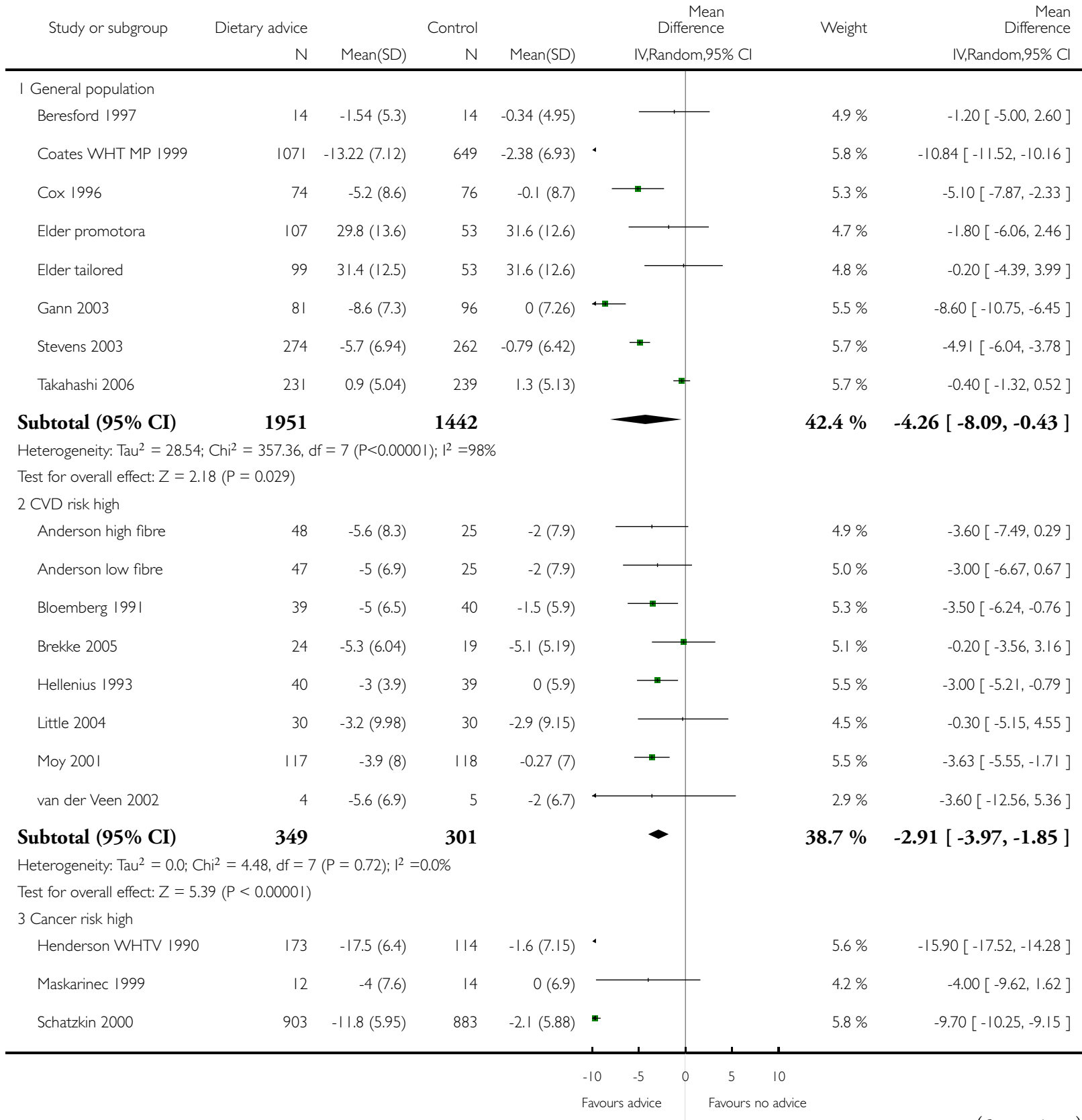

(Continued ....)

Dietary advice for reducing cardiovascular risk (Review)

Copyright $@ 2009$ The Cochrane Collaboration. Published by John Wiley \& Sons, Ltd. 


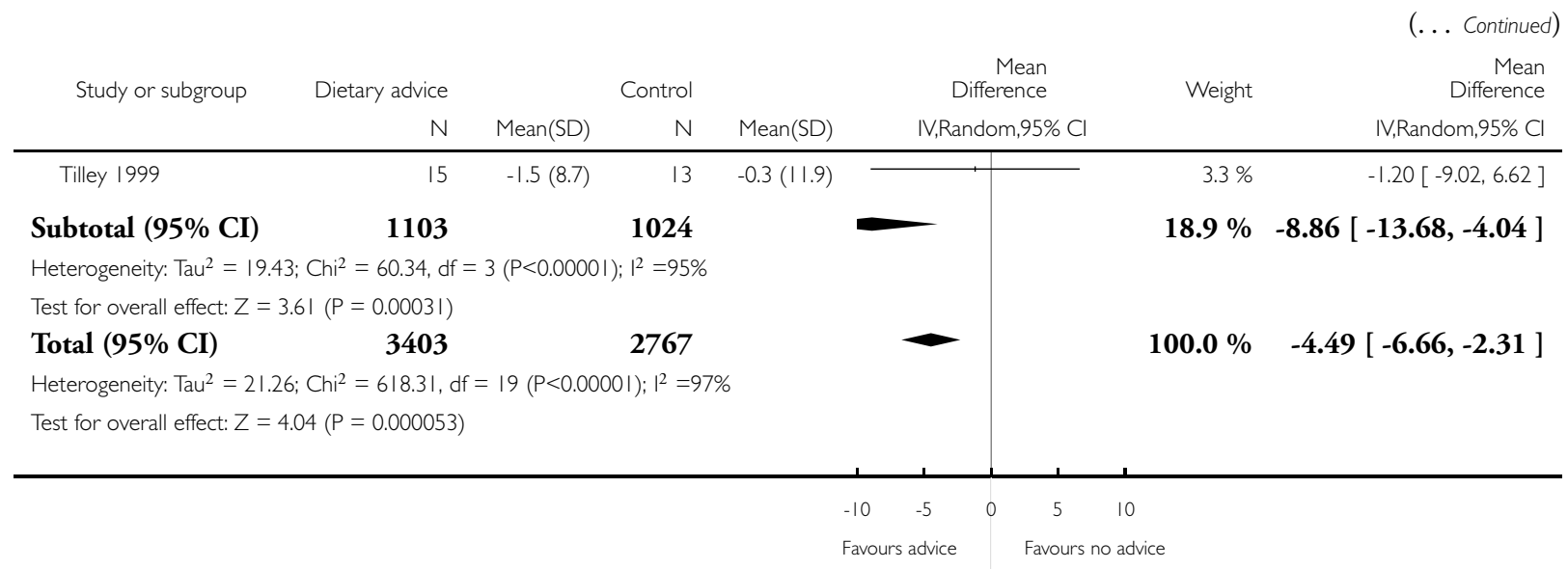

\section{Analysis 2.6. Comparison 2 Subgroup analyses, Outcome 6 Fruit \& vegetable servings/day (risk group).}

Review: Dietary advice for reducing cardiovascular risk

Comparison: 2 Subgroup analyses

Outcome: 6 Fruit \% vegetable servings/day (risk group)

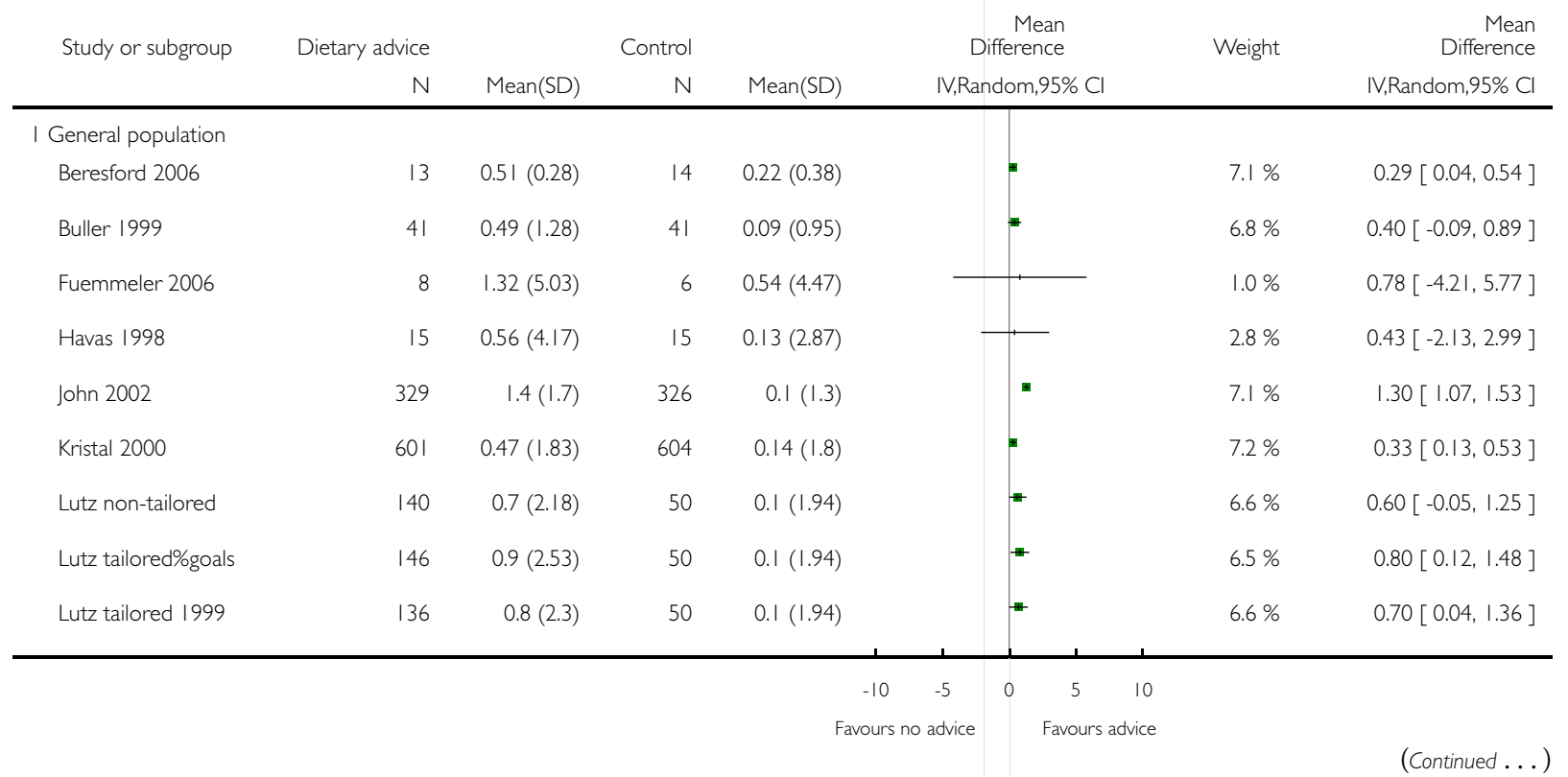

Dietary advice for reducing cardiovascular risk (Review) 


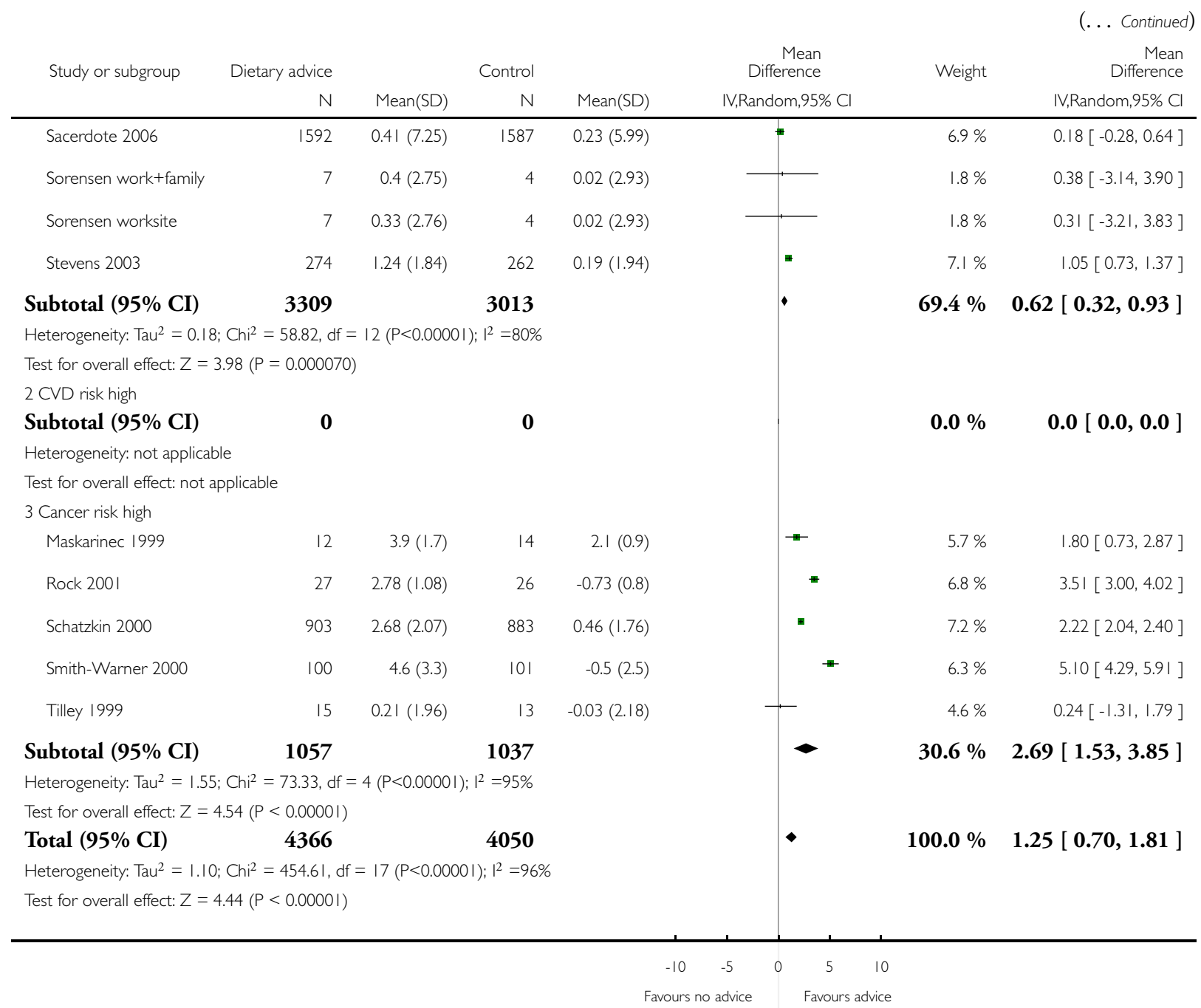




\section{Analysis 2.7. Comparison 2 Subgroup analyses, Outcome 7 SBP mmHg (risk group).}

Review: Dietary advice for reducing cardiovascular risk

Comparison: 2 Subgroup analyses

Outcome: $7 \mathrm{SBP} \mathrm{mmHg}$ (risk group)

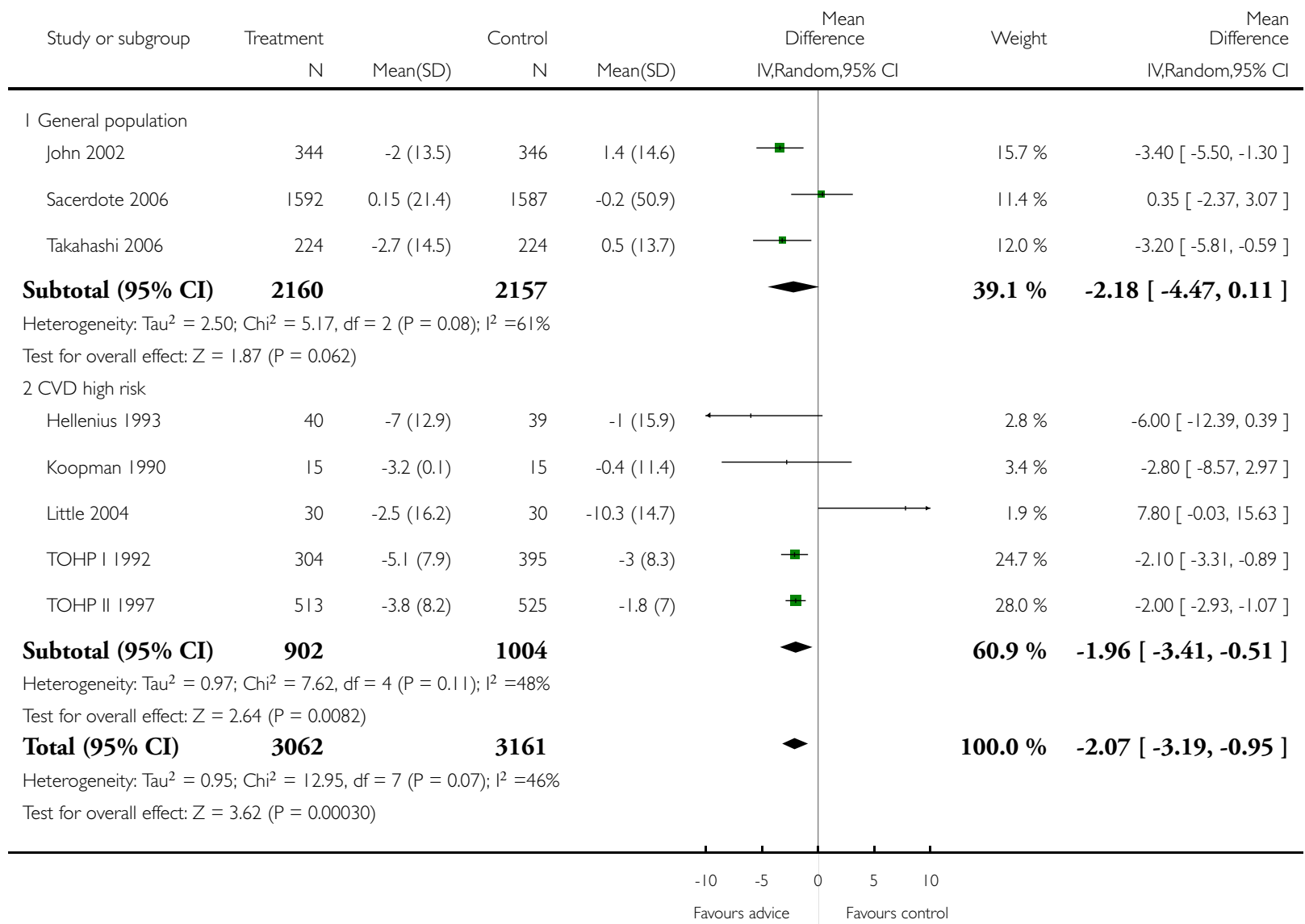




\section{Analysis 2.8. Comparison 2 Subgroup analyses, Outcome 8 DBP mmHg (risk group).}

Review: Dietary advice for reducing cardiovascular risk

Comparison: 2 Subgroup analyses

Outcome: $8 \mathrm{DBP} \mathrm{mmHg}$ (risk group)

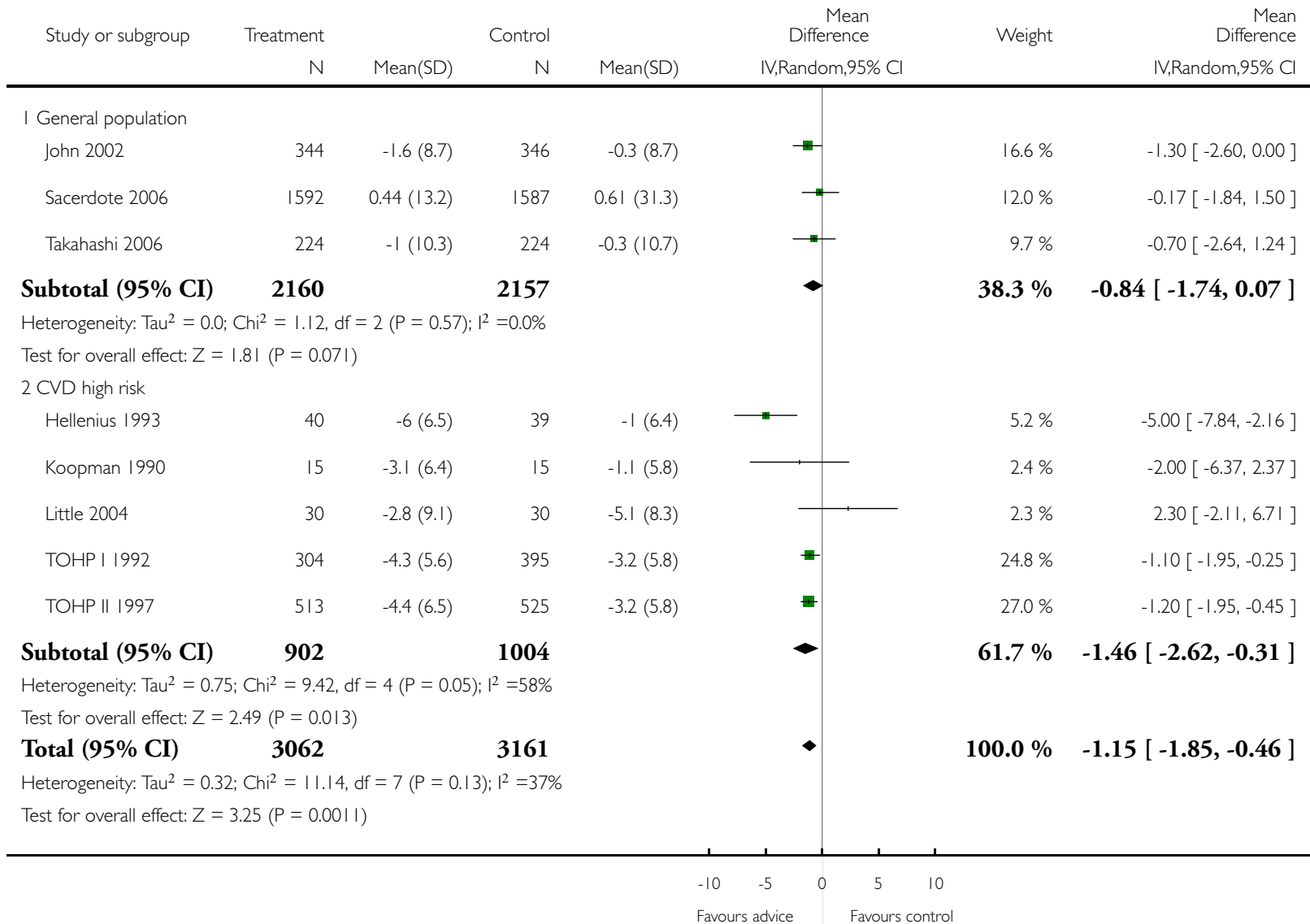




\section{Analysis 2.9. Comparison 2 Subgroup analyses, Outcome 9 Total cholesterol (setting).}

Review: Dietary advice for reducing cardiovascular risk

Comparison: 2 Subgroup analyses

Outcome: 9 Total cholesterol (setting)

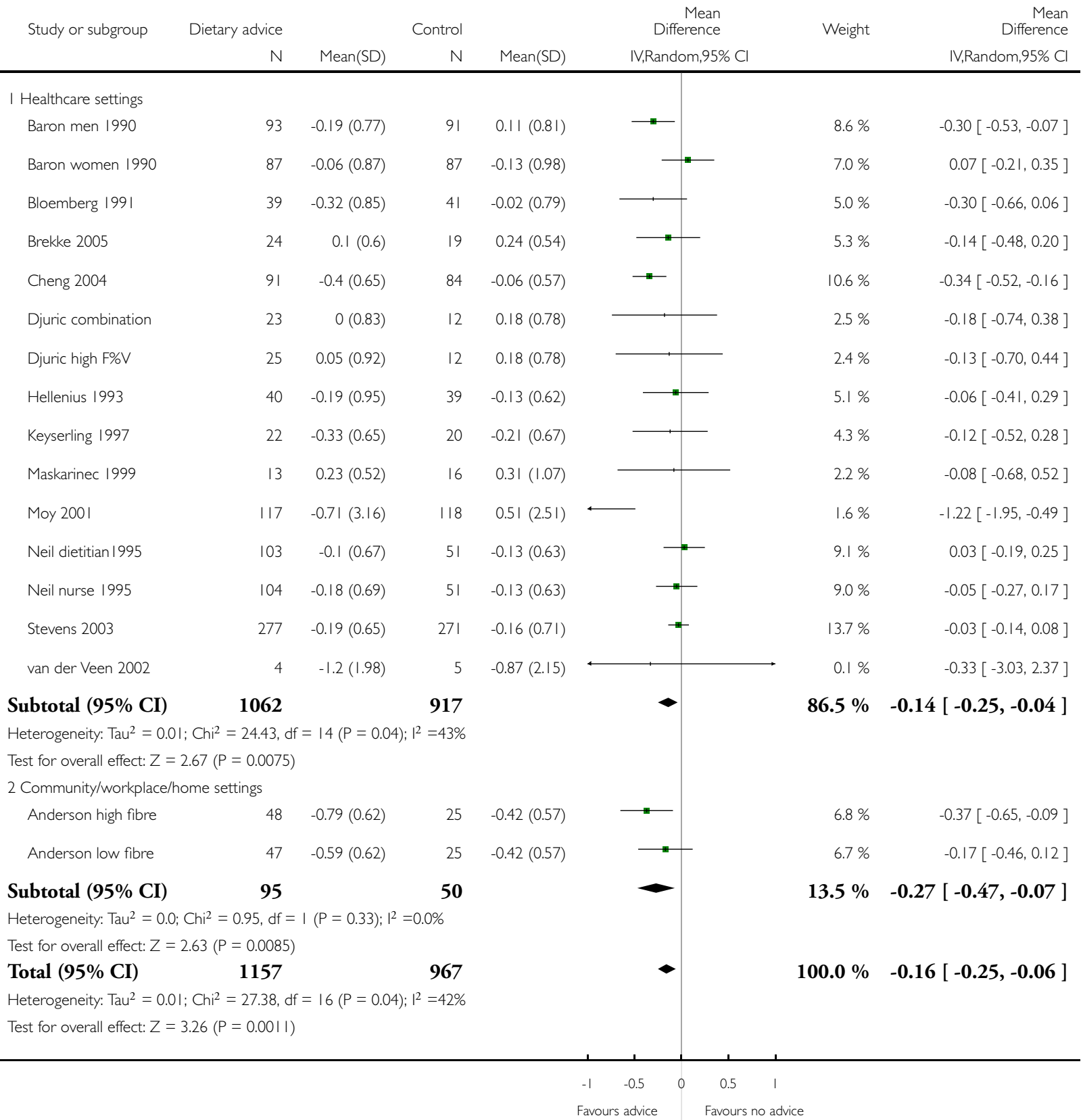

Dietary advice for reducing cardiovascular risk (Review)

Copyright @ 2009 The Cochrane Collaboration. Published by John Wiley \& Sons, Ltd. 


\section{Analysis 2.10. Comparison 2 Subgroup analyses, Outcome 10 Total dietary fat (setting).}

Review: Dietary advice for reducing cardiovascular risk

Comparison: 2 Subgroup analyses

Outcome: 10 Total dietary fat (setting)

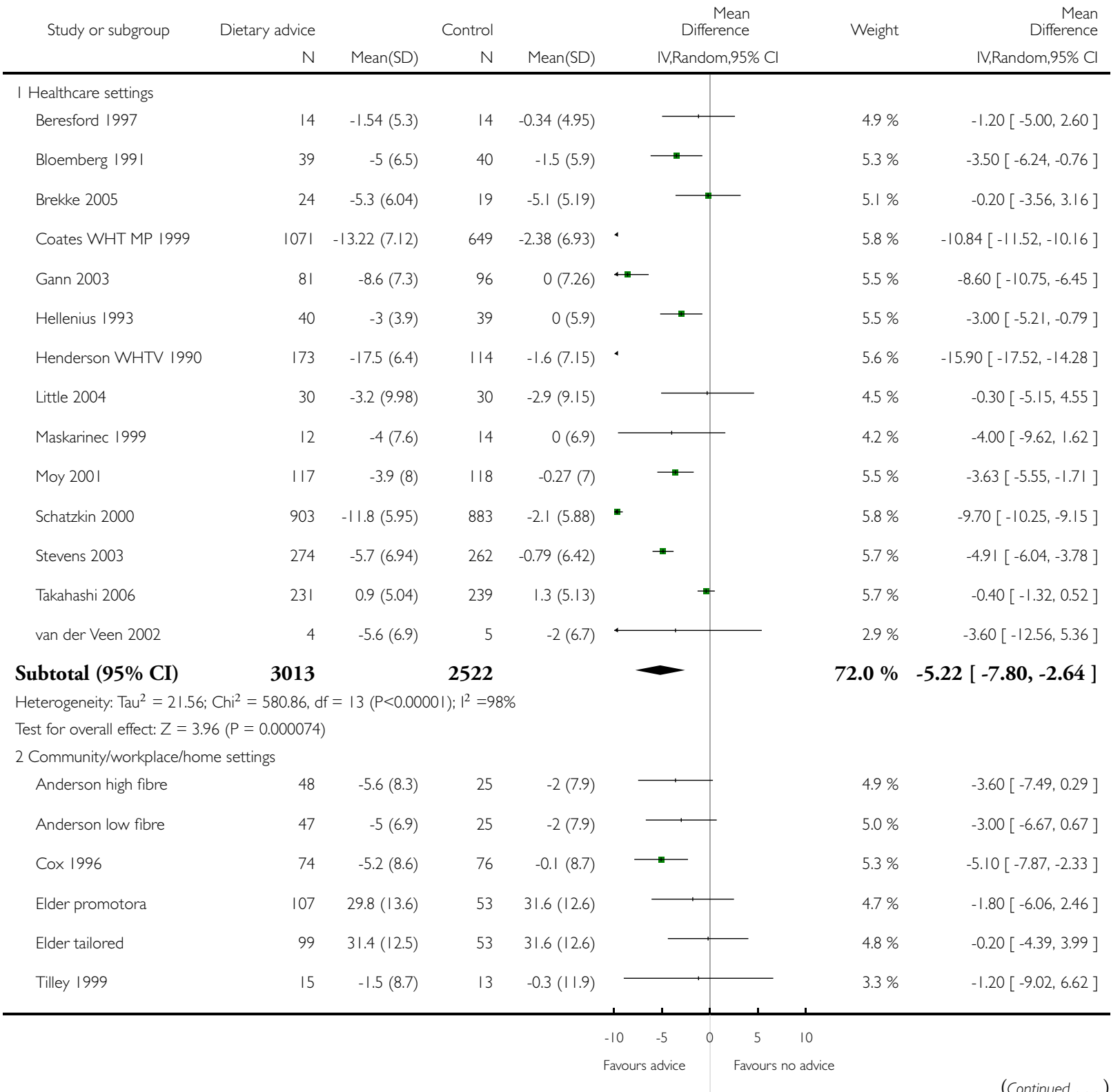

Dietary advice for reducing cardiovascular risk (Review) 


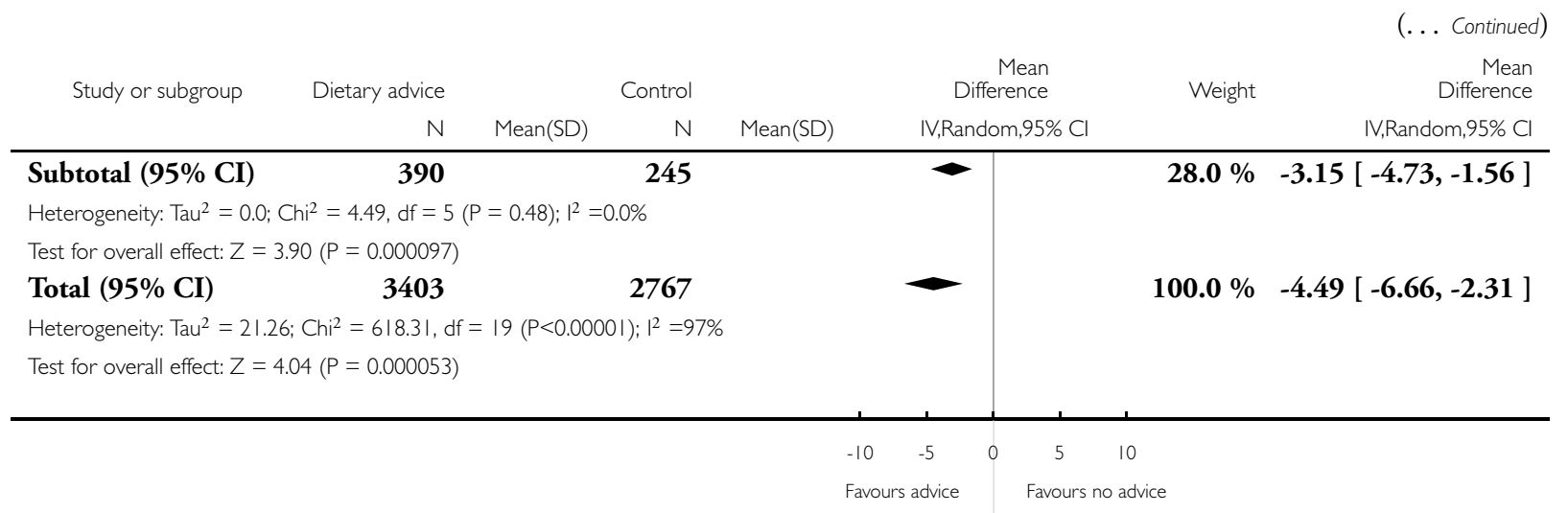

\section{Analysis 2.I I. Comparison 2 Subgroup analyses, Outcome I I Fruit \& vegetable servings/day (setting).}

Review: Dietary advice for reducing cardiovascular risk

Comparison: 2 Subgroup analyses

Outcome: I| Fruit \% vegetable servings/day (setting)

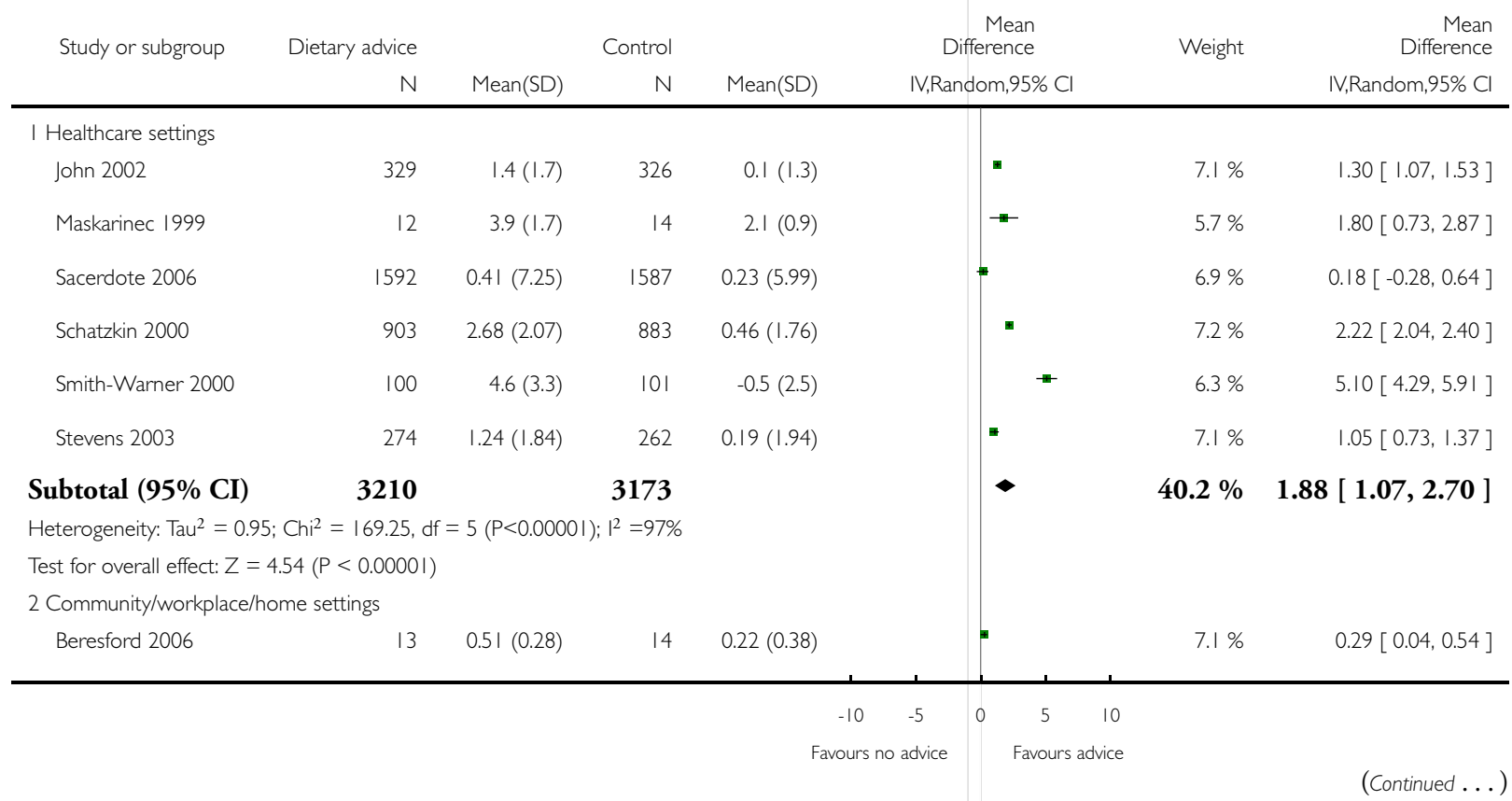

Dietary advice for reducing cardiovascular risk (Review)

Copyright @ 2009 The Cochrane Collaboration. Published by John Wiley \& Sons, Ltd. 


\section{Analysis 2.12. Comparison 2 Subgroup analyses, Outcome 12 Total cholesterol (intensity).}

Review: Dietary advice for reducing cardiovascular risk

Comparison: 2 Subgroup analyses

Outcome: 12 Total cholesterol (intensity)

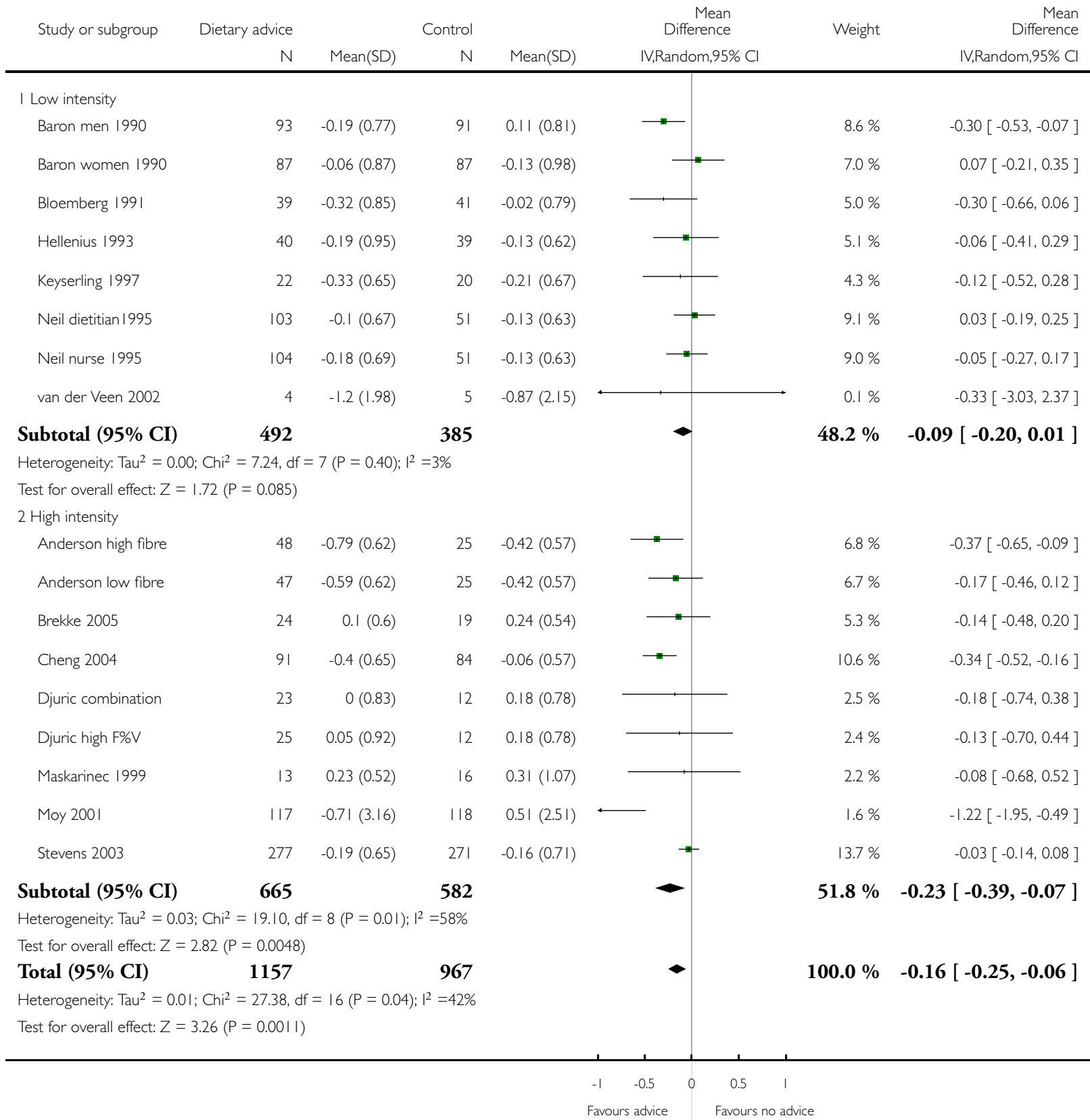

Dietary advice for reducing cardiovascular risk (Review)

Copyright @ 2009 The Cochrane Collaboration. Published by John Wiley \& Sons, Ltd. 


\section{Analysis 2.13. Comparison 2 Subgroup analyses, Outcome 13 Total dietary fat (intensity).}

Review: Dietary advice for reducing cardiovascular risk

Comparison: 2 Subgroup analyses

Outcome: 13 Total dietary fat (intensity)

\begin{tabular}{|c|c|c|c|c|c|c|c|c|}
\hline \multirow[t]{2}{*}{ Study or subgroup } & \multirow{2}{*}{$\begin{array}{r}\text { Dietary advice } \\
N\end{array}$} & \multicolumn{3}{|c|}{ Control } & \multirow{2}{*}{\multicolumn{2}{|c|}{$\begin{array}{c}\text { Mean } \\
\text { Difference } \\
\text { IV,Random,95\% Cl }\end{array}$}} & \multirow[t]{2}{*}{ Weight } & \multirow{2}{*}{$\begin{array}{r}\text { Mean } \\
\text { Difference } \\
\text { IV,Random,95\% Cl }\end{array}$} \\
\hline & & Mean(SD) & $\mathrm{N}$ & Mean(SD) & & & & \\
\hline \multicolumn{9}{|l|}{ I Low intensity } \\
\hline Beresford 1997 & 14 & $-1.54(5.3)$ & 14 & $-0.34(4.95)$ & & & $4.9 \%$ & $-1.20[-5.00,2.60]$ \\
\hline Bloemberg 1991 & 39 & $-5(6.5)$ & 40 & $-1.5(5.9)$ & $\longrightarrow$ & & $5.3 \%$ & $-3.50[-6.24,-0.76]$ \\
\hline Hellenius 1993 & 40 & $-3(3.9)$ & 39 & $0(5.9)$ & $\longrightarrow$ & & $5.5 \%$ & $-3.00[-5.21,-0.79]$ \\
\hline Little 2004 & 30 & $-3.2(9.98)$ & 30 & $-2.9(9.15)$ & & & $4.5 \%$ & $-0.30[-5.15,4.55]$ \\
\hline Takahashi 2006 & 231 & $0.9(5.04)$ & 239 & $1.3(5.13)$ & & & $5.7 \%$ & $-0.40[-1.32,0.52]$ \\
\hline van der Veen 2002 & 4 & $-5.6(6.9)$ & 5 & $-2(6.7)$ & $\leftarrow$ & & $2.9 \%$ & $-3.60[-12.56,5.36]$ \\
\hline Subtotal (95\% CI) & 358 & & 367 & & & & $28.9 \%$ & $-1.68[-3.13,-0.23]$ \\
\hline \multicolumn{9}{|c|}{ Heterogeneity: $\mathrm{Tau}^{2}=1.17 ; \mathrm{Chi}^{2}=8.39, \mathrm{df}=5(\mathrm{P}=0.14) ;\left.\right|^{2}=40 \%$} \\
\hline \multicolumn{9}{|c|}{ Test for overall effect: $Z=2.28(P=0.023)$} \\
\hline \multicolumn{9}{|l|}{2 High intensity } \\
\hline Anderson high fibre & 48 & $-5.6(8.3)$ & 25 & $-2(7.9)$ & & & $4.9 \%$ & $-3.60[-7.49,0.29]$ \\
\hline Anderson low fibre & 47 & $-5(6.9)$ & 25 & $-2(7.9)$ & & & $5.0 \%$ & $-3.00[-6.67,0.67]$ \\
\hline Brekke 2005 & 24 & $-5.3(6.04)$ & 19 & $-5.1(5.19)$ & & & $5.1 \%$ & $-0.20[-3.56,3.16]$ \\
\hline Coates WHT MP 1999 & $107 \mid$ & $-13.22(7.12)$ & 649 & $-2.38(6.93)$ & 4 & & $5.8 \%$ & $-10.84[-11.52,-10.16]$ \\
\hline Cox 1996 & 74 & $-5.2(8.6)$ & 76 & $-0.1(8.7)$ & $\longrightarrow$ & & $5.3 \%$ & $-5.10[-7.87,-2.33]$ \\
\hline Elder promotora & 107 & $29.8(13.6)$ & 53 & $31.6(12.6)$ & & & $4.7 \%$ & $-1.80[-6.06,2.46]$ \\
\hline Elder tailored & 99 & $31.4(12.5)$ & 53 & $31.6(12.6)$ & & & $4.8 \%$ & $-0.20[-4.39,3.99]$ \\
\hline Gann 2003 & 81 & $-8.6(7.3)$ & 96 & $0(7.26)$ & 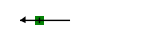 & & $5.5 \%$ & $-8.60[-10.75,-6.45]$ \\
\hline Henderson WHTV 1990 & 173 & $-17.5(6.4)$ & 114 & $-1.6(7.15)$ & $\cdot$ & & $5.6 \%$ & $-15.90[-17.52,-14.28]$ \\
\hline Maskarinec 1999 & 12 & $-4(7.6)$ & 14 & $0(6.9)$ & & & $4.2 \%$ & $-4.00[-9.62,1.62]$ \\
\hline Moy 2001 & 117 & $-3.9(8)$ & 118 & $-0.27(7)$ & $\longrightarrow$ & & $5.5 \%$ & $-3.63[-5.55,-1.7 \mid]$ \\
\hline Schatzkin 2000 & 903 & $-11.8(5.95)$ & 883 & $-2.1(5.88)$ & - & & $5.8 \%$ & $-9.70[-10.25,-9.15]$ \\
\hline Stevens 2003 & 274 & $-5.7(6.94)$ & 262 & $-0.79(6.42)$ & $\rightarrow$ & & $5.7 \%$ & $-4.91[-6.04,-3.78]$ \\
\hline \multirow[t]{3}{*}{ Tilley 1999} & 15 & $-1.5(8.7)$ & 13 & $-0.3(\mid 1.9)$ & & & $3.3 \%$ & $-1.20[-9.02,6.62]$ \\
\hline & & & & & -10 & 5 & 10 & \\
\hline & & & & & Favours advice & Favours & advice & \\
\hline
\end{tabular}

Dietary advice for reducing cardiovascular risk (Review) 


\begin{tabular}{|c|c|c|c|c|c|c|c|}
\hline \multirow[t]{2}{*}{ Study or subgroup } & \multirow{2}{*}{$\begin{array}{r}\text { Dietary advice } \\
\text { N }\end{array}$} & \multicolumn{3}{|c|}{ Control } & \multirow{2}{*}{$\begin{array}{c}\text { Mean } \\
\text { Difference } \\
\text { IV,Random,95\% Cl }\end{array}$} & \multirow[t]{2}{*}{ Weight } & \multirow{2}{*}{$\begin{array}{r}\text { Mean } \\
\text { Difference } \\
\text { IV,Random,95\% Cl }\end{array}$} \\
\hline & & Mean(SD) & $\mathrm{N}$ & Mean(SD) & & & \\
\hline Subtotal $(95 \% \mathrm{CI})$ & 3045 & & 2400 & & $\longrightarrow$ & $71.1 \%$ & $-5.72[-7.75,-3.69]$ \\
\hline \multicolumn{8}{|c|}{ Heterogeneity: $\mathrm{Tau}^{2}=12.24 ; \mathrm{Chi}^{2}=269.99, \mathrm{df}=13(\mathrm{P}<0.0000 \mathrm{I}) ; \mathbf{1}^{2}=95 \%$} \\
\hline \multicolumn{8}{|c|}{ Test for overall effect: $Z=5.53(P<0.0000 I)$} \\
\hline Total $(95 \% \mathrm{CI})$ & 3403 & & 2767 & & $\longrightarrow$ & $100.0 \%$ & $-4.49[-6.66,-2.31]$ \\
\hline \multicolumn{8}{|c|}{ Heterogeneity: $\mathrm{Tau}^{2}=21.26 ; \mathrm{Chi}^{2}=618.31, \mathrm{df}=19(\mathrm{P}<0.0000 \mathrm{I}) ; \mathrm{I}^{2}=97 \%$} \\
\hline \multicolumn{8}{|c|}{ Test for overall effect: $Z=4.04(P=0.000053)$} \\
\hline
\end{tabular}

Analysis 2.14. Comparison 2 Subgroup analyses, Outcome 14 Fruit \& vegetable servings/day (intensity).

Review: Dietary advice for reducing cardiovascular risk

Comparison: 2 Subgroup analyses

Outcome: 14 Fruit \% vegetable servings/day (intensity)

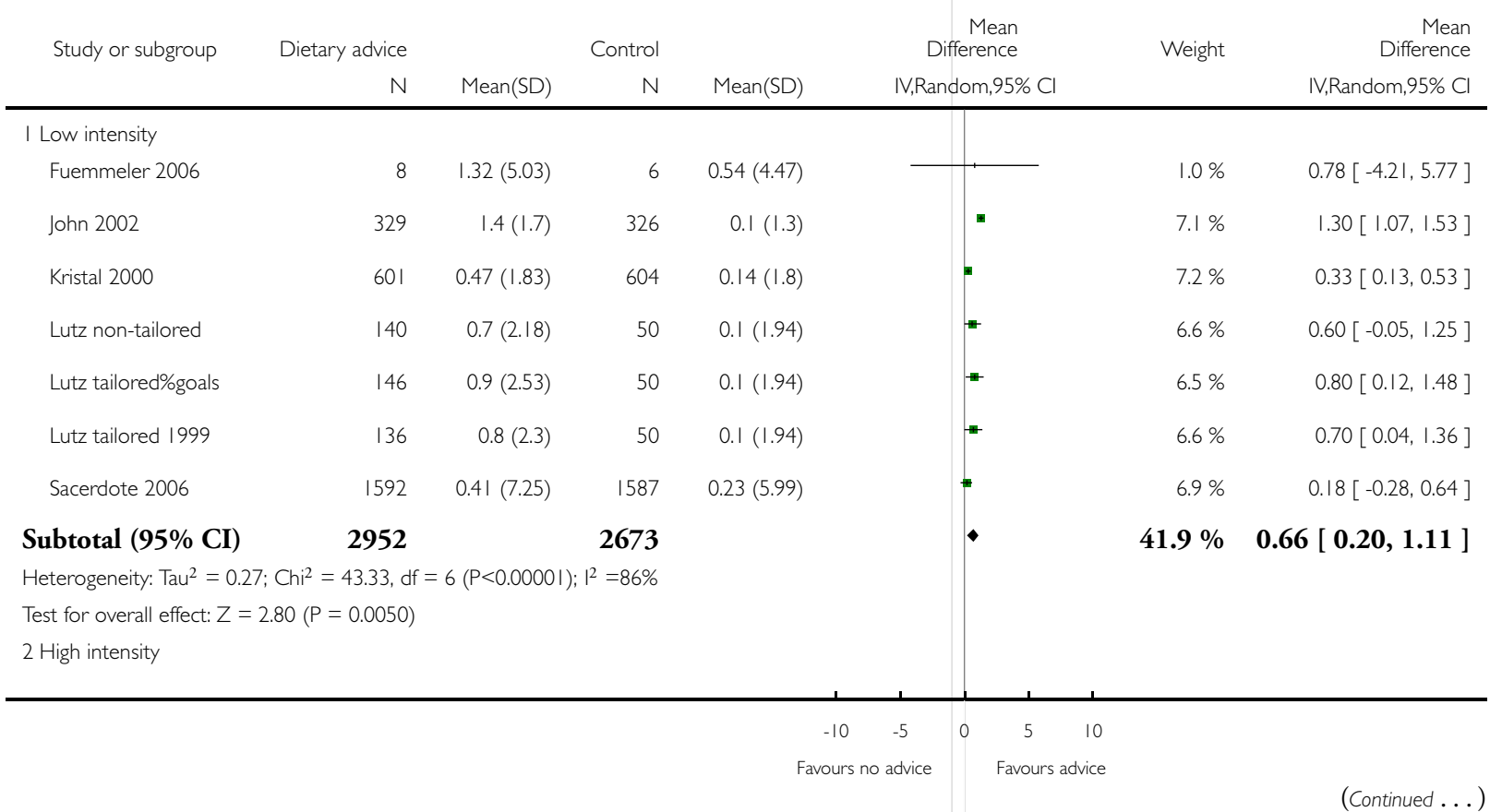

Dietary advice for reducing cardiovascular risk (Review)

Copyright $\odot 2009$ The Cochrane Collaboration. Published by John Wiley \& Sons, Ltd. 


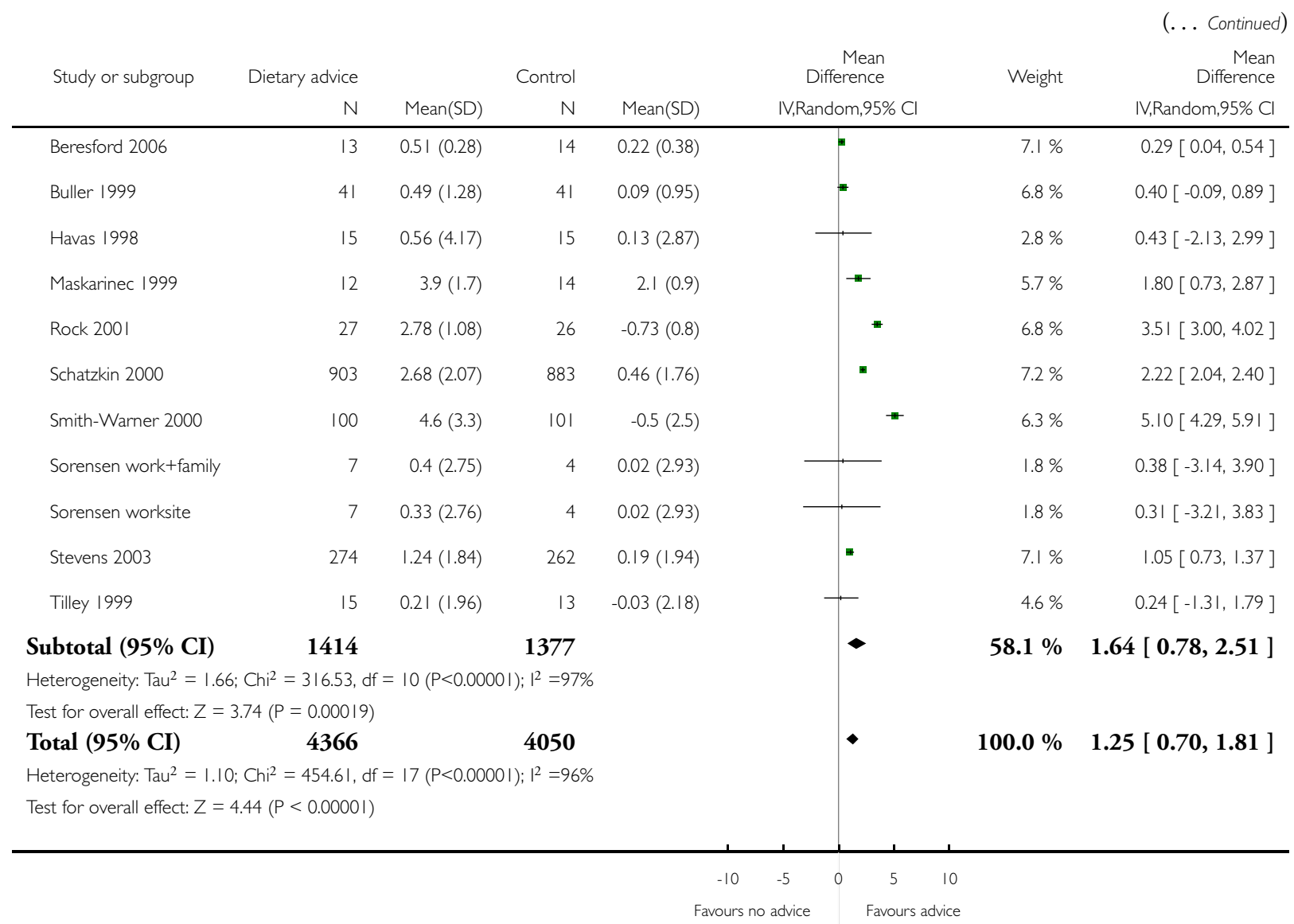




\section{Analysis 2.15. Comparison 2 Subgroup analyses, Outcome 15 SBP mmHg (intensity).}

Review: Dietary advice for reducing cardiovascular risk

Comparison: 2 Subgroup analyses

Outcome: $15 \mathrm{SBP} \mathrm{mmHg}$ (intensity)

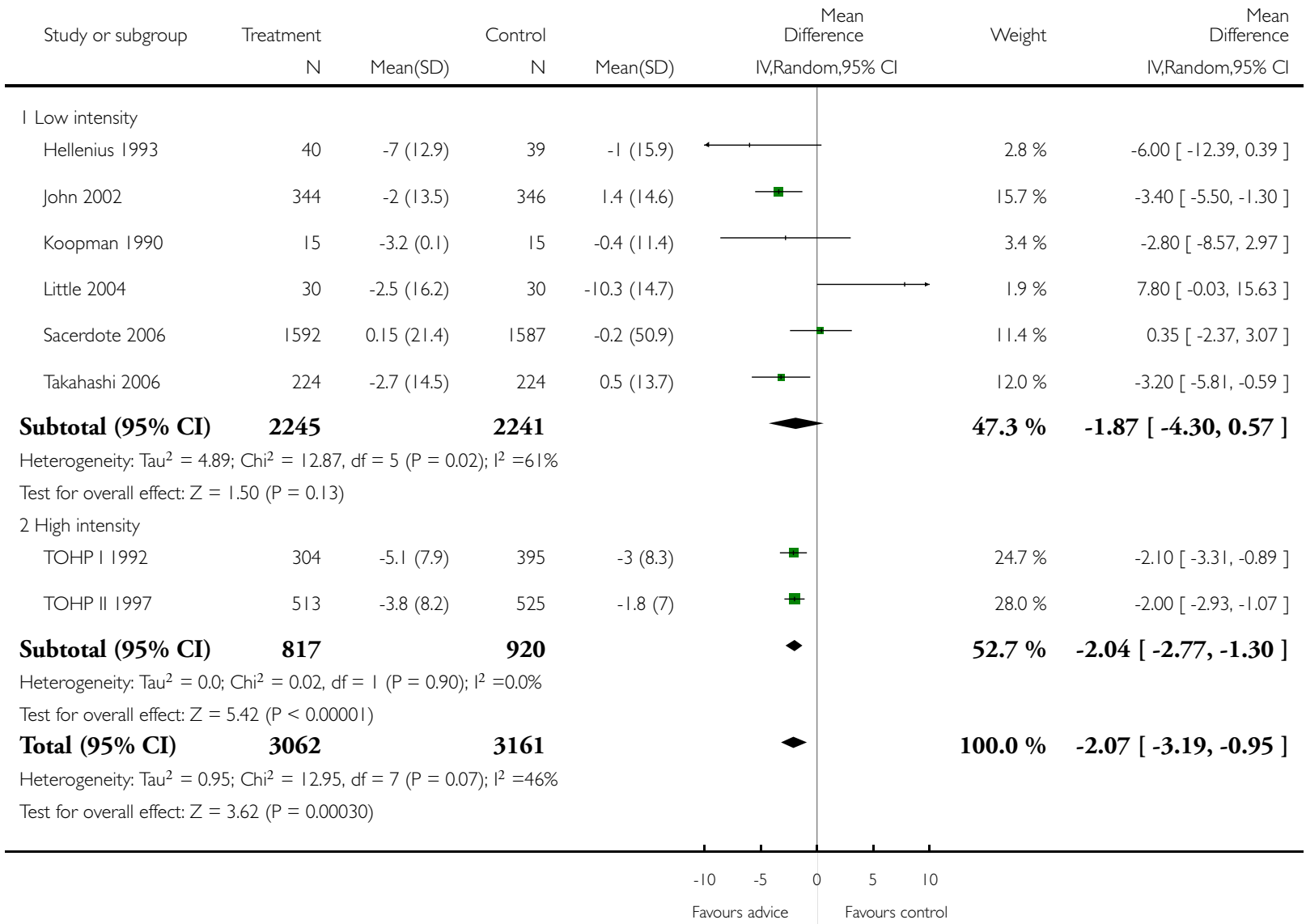




\section{Analysis 2.16. Comparison 2 Subgroup analyses, Outcome 16 DBP mmHg (intensity).}

Review: Dietary advice for reducing cardiovascular risk

Comparison: 2 Subgroup analyses

Outcome: $16 \mathrm{DBP} \mathrm{mmHg}$ (intensity)

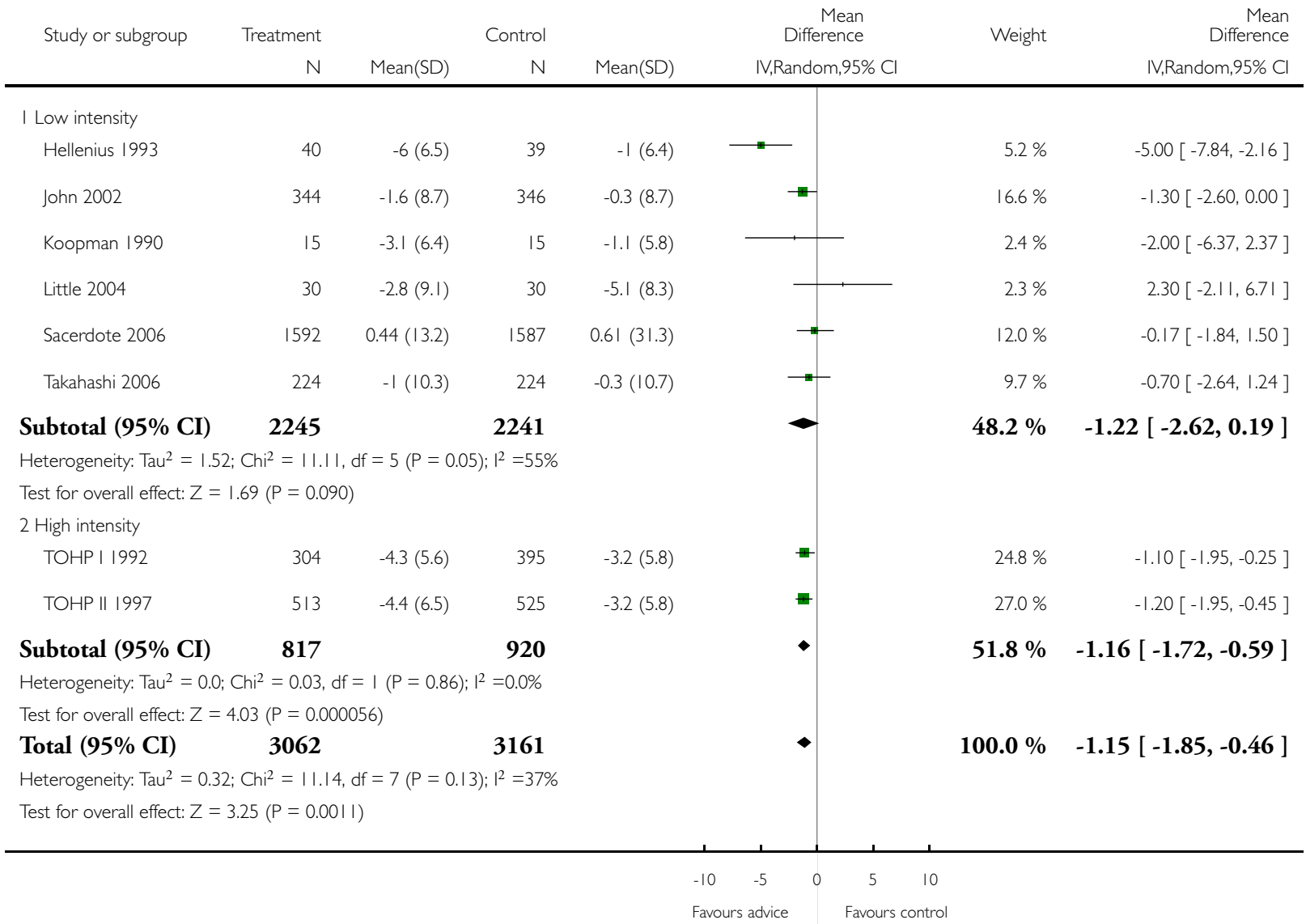




\section{Analysis 2.17. Comparison 2 Subgroup analyses, Outcome 17 Total cholesterol (duration).}

Review: Dietary advice for reducing cardiovascular risk

Comparison: 2 Subgroup analyses

Outcome: 17 Total cholesterol (duration)

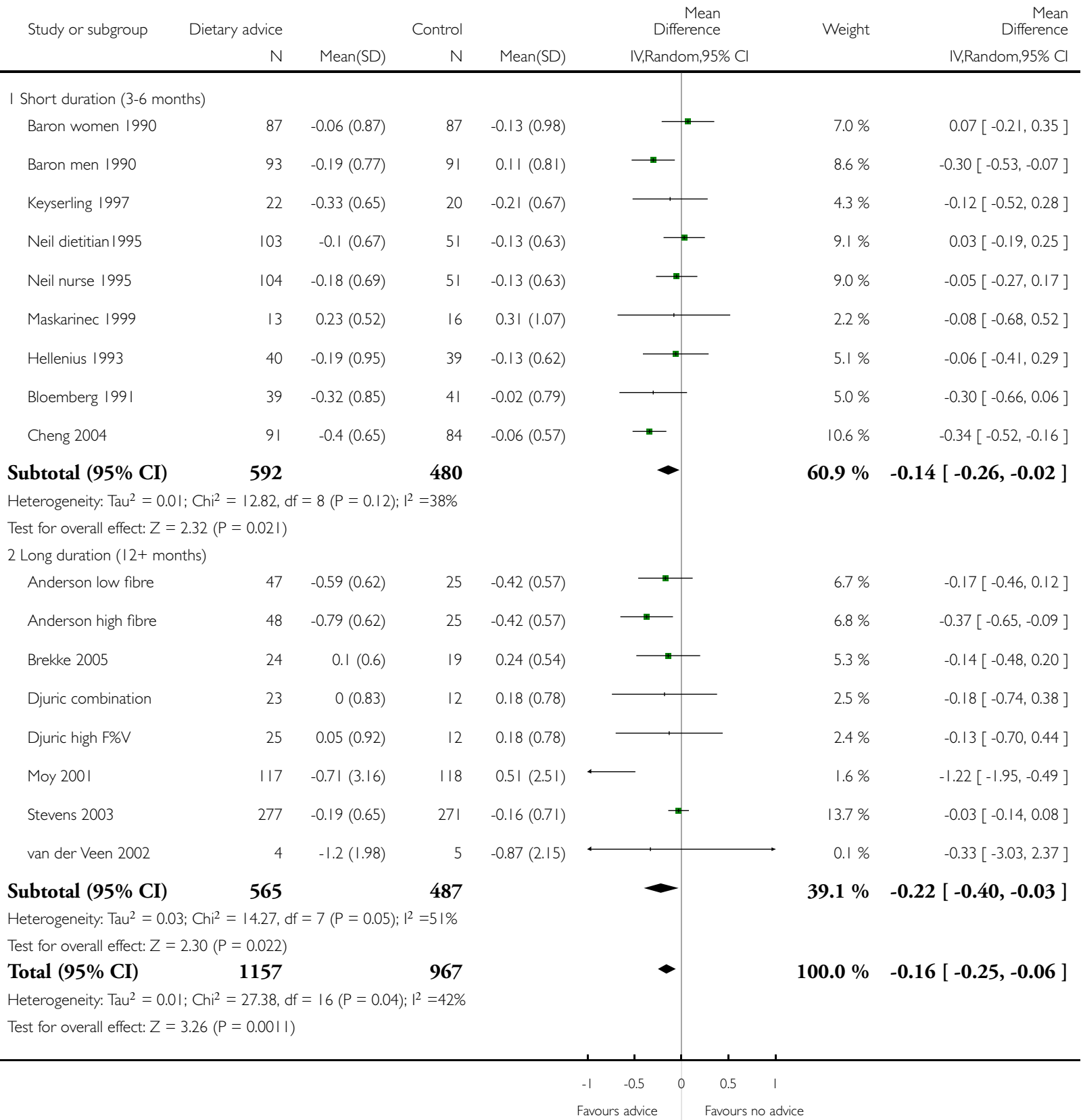

Dietary advice for reducing cardiovascular risk (Review)

Copyright @ 2009 The Cochrane Collaboration. Published by John Wiley \& Sons, Ltd. 


\section{Analysis 2.18. Comparison 2 Subgroup analyses, Outcome 18 Total dietary fat (duration).}

Review: Dietary advice for reducing cardiovascular risk

Comparison: 2 Subgroup analyses

Outcome: 18 Total dietary fat (duration)

\begin{tabular}{|c|c|c|c|c|c|c|c|c|c|}
\hline \multirow[t]{2}{*}{ Study or subgroup } & \multirow{2}{*}{$\begin{array}{r}\text { Dietary advice } \\
N\end{array}$} & \multicolumn{3}{|c|}{ Control } & \multirow{2}{*}{\multicolumn{3}{|c|}{$\begin{array}{c}\text { Mean } \\
\text { Difference } \\
\text { IV,Random,95\% Cl }\end{array}$}} & \multirow[t]{2}{*}{ Weight } & \multirow{2}{*}{$\begin{array}{r}\text { Mean } \\
\text { Difference } \\
\text { IV,Random,95\% Cl }\end{array}$} \\
\hline & & Mean(SD) & $\mathrm{N}$ & Mean(SD) & & & & & \\
\hline \multicolumn{10}{|l|}{ I Short duration (3-6 months) } \\
\hline Bloemberg 1991 & 39 & $-5(6.5)$ & 40 & $-1.5(5.9)$ & & & & $5.3 \%$ & $-3.50[-6.24,-0.76]$ \\
\hline Coates WHT MP 1999 & |07| & $-13.22(7.12)$ & 649 & $-2.38(6.93)$ & 4 & & & $5.8 \%$ & $-10.84[-11.52,-10.16]$ \\
\hline Cox 1996 & 74 & $-5.2(8.6)$ & 76 & $-0.1(8.7)$ & & & & $5.3 \%$ & $-5.10[-7.87,-2.33]$ \\
\hline Hellenius 1993 & 40 & $-3(3.9)$ & 39 & $0(5.9)$ & & $\longrightarrow$ & & $5.5 \%$ & $-3.00[-5.21,-0.79]$ \\
\hline Maskarinec 1999 & 12 & $-4(7.6)$ & 14 & $0(6.9)$ & & & - & $4.2 \%$ & $-4.00[-9.62,1.62]$ \\
\hline Elder promotora & 107 & $29.8(13.6)$ & 53 & $31.6(12.6)$ & & & & $4.7 \%$ & $-1.80[-6.06,2.46]$ \\
\hline Elder tailored & 99 & $31.4(12.5)$ & 53 & $31.6(12.6)$ & & & & $4.8 \%$ & $-0.20[-4.39,3.99]$ \\
\hline Little 2004 & 30 & $-3.2(9.98)$ & 30 & $-2.9(9.15)$ & & & & $4.5 \%$ & $-0.30[-5.15,4.55]$ \\
\hline Subtotal (95\% CI) & 1472 & & 954 & & & & & $40.0 \%$ & $-3.76[-7.56,0.05]$ \\
\hline \multicolumn{10}{|c|}{ Heterogeneity: $\mathrm{Tau}^{2}=26.74 ; \mathrm{Chi}^{2}=122.63, \mathrm{df}=7(\mathrm{P}<0.0000 \mathrm{I}) ; \mathrm{I}^{2}=94 \%$} \\
\hline \multicolumn{10}{|c|}{ Test for overall effect: $Z=1.94(P=0.053)$} \\
\hline \multicolumn{10}{|l|}{2 Long duration ( $12+$ months) } \\
\hline Anderson high fibre & 48 & $-5.6(8.3)$ & 25 & $-2(7.9)$ & & & & $4.9 \%$ & $-3.60[-7.49,0.29]$ \\
\hline Anderson low fibre & 47 & $-5(6.9)$ & 25 & $-2(7.9)$ & & & & $5.0 \%$ & $-3.00[-6.67,0.67]$ \\
\hline Beresford 1997 & 14 & $-1.54(5.3)$ & 14 & $-0.34(4.95)$ & & & & $4.9 \%$ & $-1.20[-5.00,2.60]$ \\
\hline Tilley 1999 & 15 & $-1.5(8.7)$ & 13 & $-0.3(11.9)$ & & & & $3.3 \%$ & $-1.20[-9.02,6.62]$ \\
\hline Henderson WHTV 1990 & 173 & $-17.5(6.4)$ & 114 & $-1.6(7.15)$ & 4 & & & $5.6 \%$ & $-15.90[-17.52,-14.28]$ \\
\hline Schatzkin 2000 & 903 & $-11.8(5.95)$ & 883 & $-2.1(5.88)$ & $*$ & & & $5.8 \%$ & $-9.70[-10.25,-9.15]$ \\
\hline Brekke 2005 & 24 & $-5.3(6.04)$ & 19 & $-5.1(5.19)$ & & & & $5.1 \%$ & $-0.20[-3.56,3.16]$ \\
\hline Gann 2003 & 81 & $-8.6(7.3)$ & 96 & $0(7.26)$ & $\longleftarrow$ & & & $5.5 \%$ & $-8.60[-10.75,-6.45]$ \\
\hline Moy 2001 & 117 & $-3.9(8)$ & 118 & $-0.27(7)$ & & $\longrightarrow$ & & $5.5 \%$ & $-3.63[-5.55,-1.7 \mid]$ \\
\hline Stevens 2003 & 274 & $-5.7(6.94)$ & 262 & $-0.79(6.42)$ & & 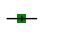 & & $5.7 \%$ & $-4.91[-6.04,-3.78]$ \\
\hline Takahashi 2006 & 231 & $0.9(5.04)$ & 239 & $1.3(5.13)$ & & & & $5.7 \%$ & $-0.40[-1.32,0.52]$ \\
\hline \multirow[t]{3}{*}{ van der Veen 2002} & 4 & $-5.6(6.9)$ & 5 & $-2(6.7)$ & $\longleftarrow$ & & & $2.9 \%$ & $-3.60[-12.56,5.36]$ \\
\hline & & & & & -10 & -5 & 5 & 10 & \\
\hline & & & & & Favours a & advice & Favours & advice & \\
\hline
\end{tabular}

Dietary advice for reducing cardiovascular risk (Review) 


\begin{tabular}{|c|c|c|c|c|c|c|c|}
\hline \multirow[t]{2}{*}{ Study or subgroup } & \multirow{2}{*}{$\begin{array}{r}\text { Dietary advice } \\
\mathrm{N}\end{array}$} & \multicolumn{3}{|c|}{ Control } & $\begin{array}{r}\text { Mean } \\
\text { Difference }\end{array}$ & \multirow[t]{2}{*}{ Weight } & \multirow{2}{*}{$\begin{array}{r}\text { Mean } \\
\text { Difference } \\
\text { IV,Random,95\% Cl }\end{array}$} \\
\hline & & Mean(SD) & $\mathrm{N}$ & Mean(SD) & IV,Random,95\% Cl & & \\
\hline Subtotal $(95 \% \mathrm{CI})$ & 1931 & & 1813 & & 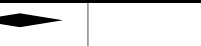 & $60.0 \%$ & $-4.90[-8.02,-1.78]$ \\
\hline \multicolumn{8}{|c|}{ Heterogeneity: $\mathrm{Tau}^{2}=26.91 ; \mathrm{Chi}^{2}=468.18, \mathrm{df}=1 \mid(\mathrm{P}<0.0000 \mathrm{I}) ; \mathrm{I}^{2}=98 \%$} \\
\hline \multicolumn{8}{|c|}{ Test for overall effect: $Z=3.08(P=0.0021)$} \\
\hline Total $(95 \% \mathrm{CI})$ & 3403 & & 2767 & & $\longrightarrow$ & $100.0 \%$ & $-4.49[-6.66,-2.31]$ \\
\hline \multicolumn{8}{|c|}{ Heterogeneity: $\mathrm{Tau}^{2}=21.26 ; \mathrm{Chi}^{2}=618.31, \mathrm{df}=19(\mathrm{P}<0.0000 \mathrm{I}) ; \mathrm{I}^{2}=97 \%$} \\
\hline \multicolumn{8}{|c|}{ Test for overall effect: $Z=4.04(P=0.000053)$} \\
\hline
\end{tabular}

Analysis 2.19. Comparison 2 Subgroup analyses, Outcome 19 Fruit \& vegetable servings/day (duration).

Review: Dietary advice for reducing cardiovascular risk

Comparison: 2 Subgroup analyses

Outcome: 19 Fruit \% vegetable servings/day (duration)

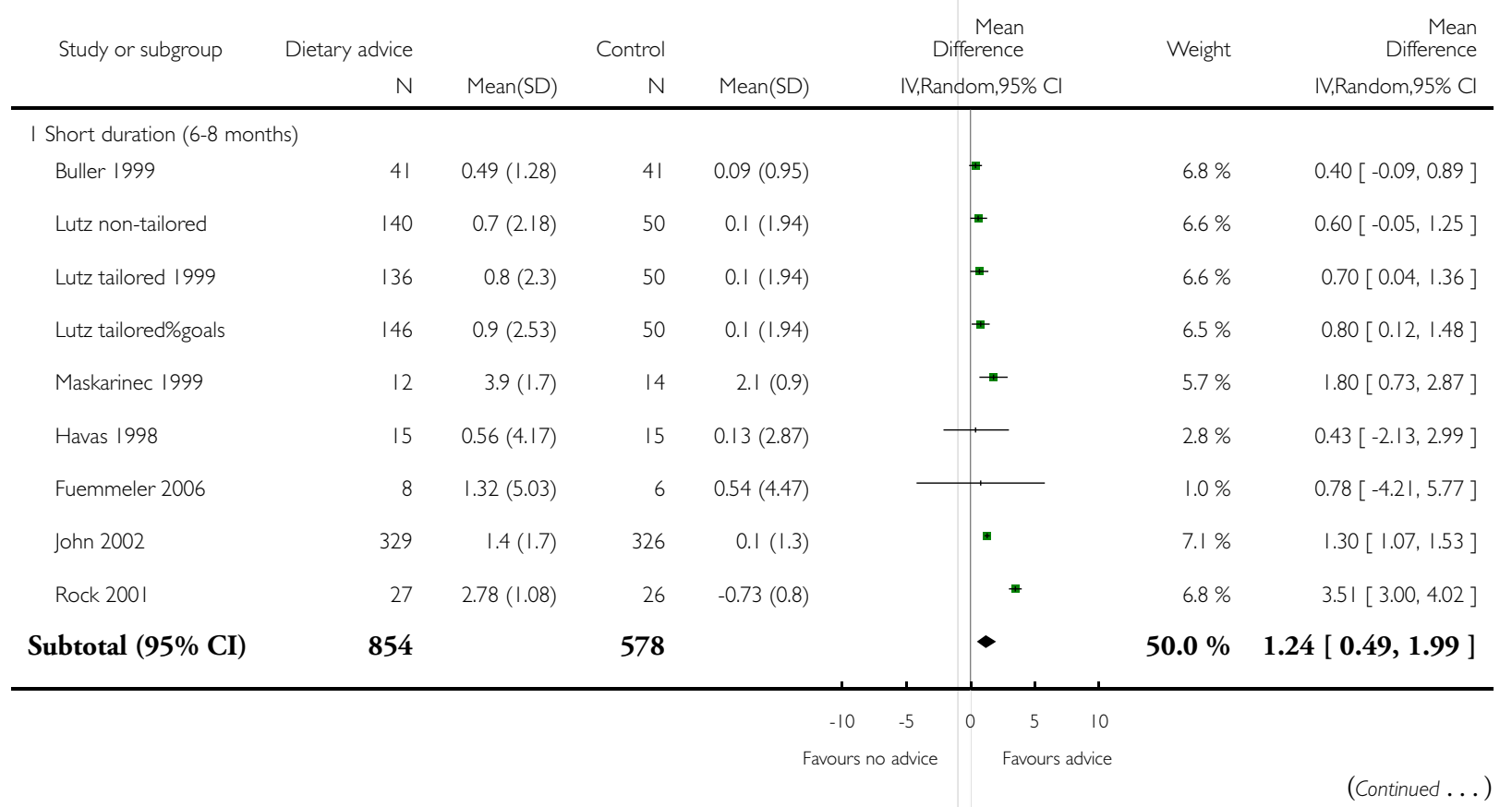

Dietary advice for reducing cardiovascular risk (Review) 


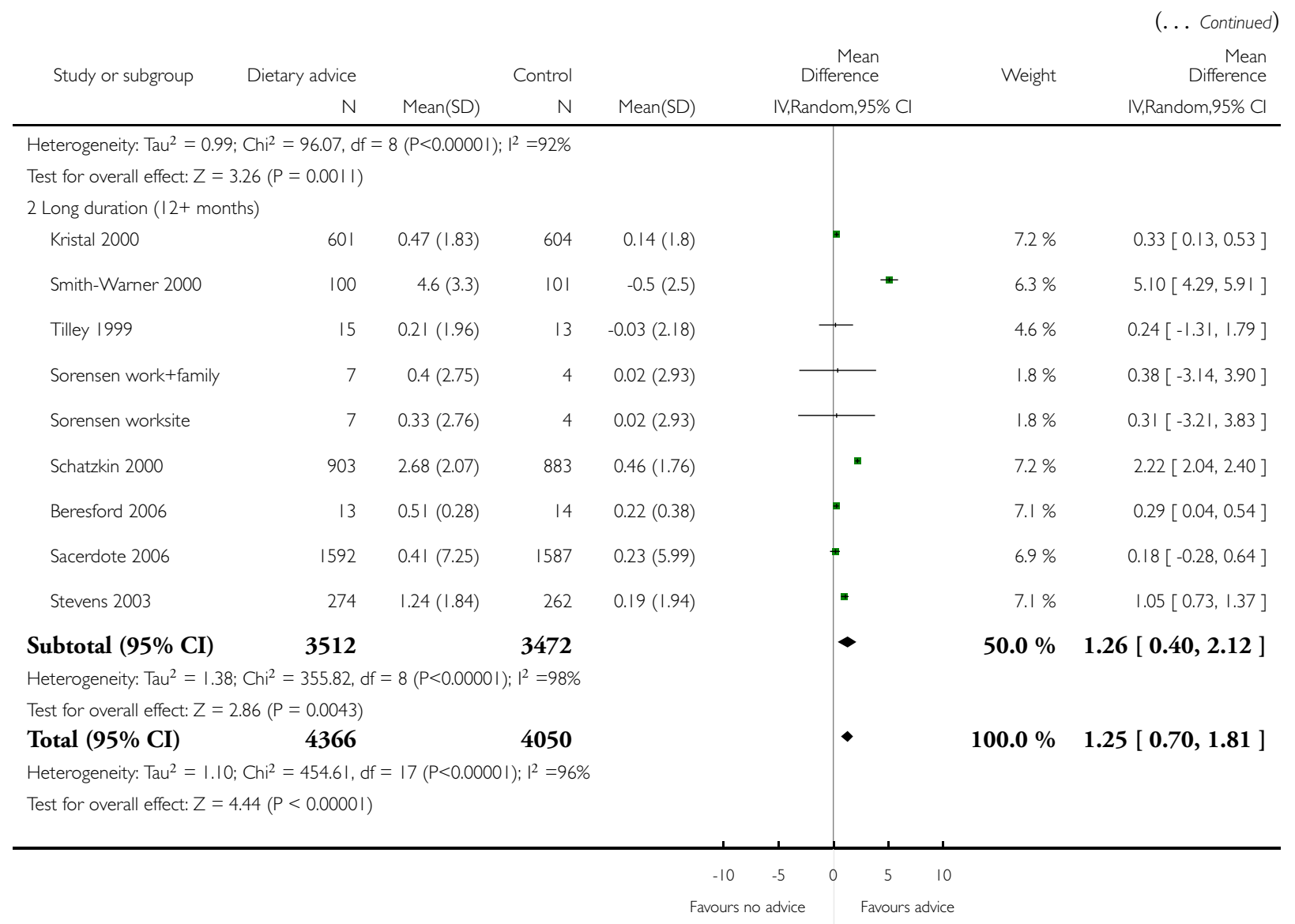




\section{Analysis 2.20. Comparison 2 Subgroup analyses, Outcome 20 SBP mmHg (duration).}

Review: Dietary advice for reducing cardiovascular risk

Comparison: 2 Subgroup analyses

Outcome: $20 \mathrm{SBP} \mathrm{mmHg}$ (duration)

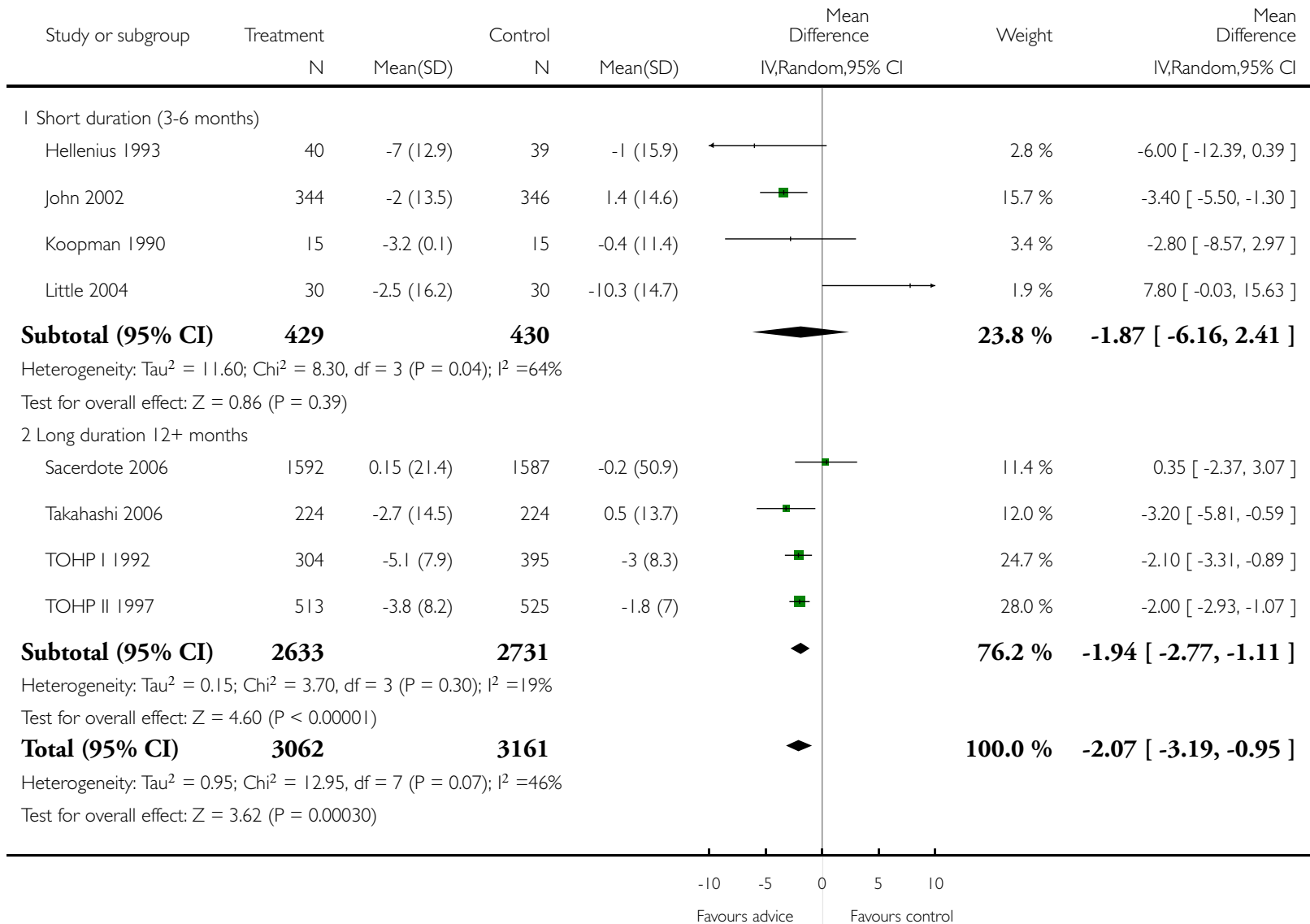




\section{Analysis 2.21. Comparison 2 Subgroup analyses, Outcome 21 DBP mmHg (duration).}

Review: Dietary advice for reducing cardiovascular risk

Comparison: 2 Subgroup analyses

Outcome: $21 \mathrm{DBP} \mathrm{mmHg}$ (duration)

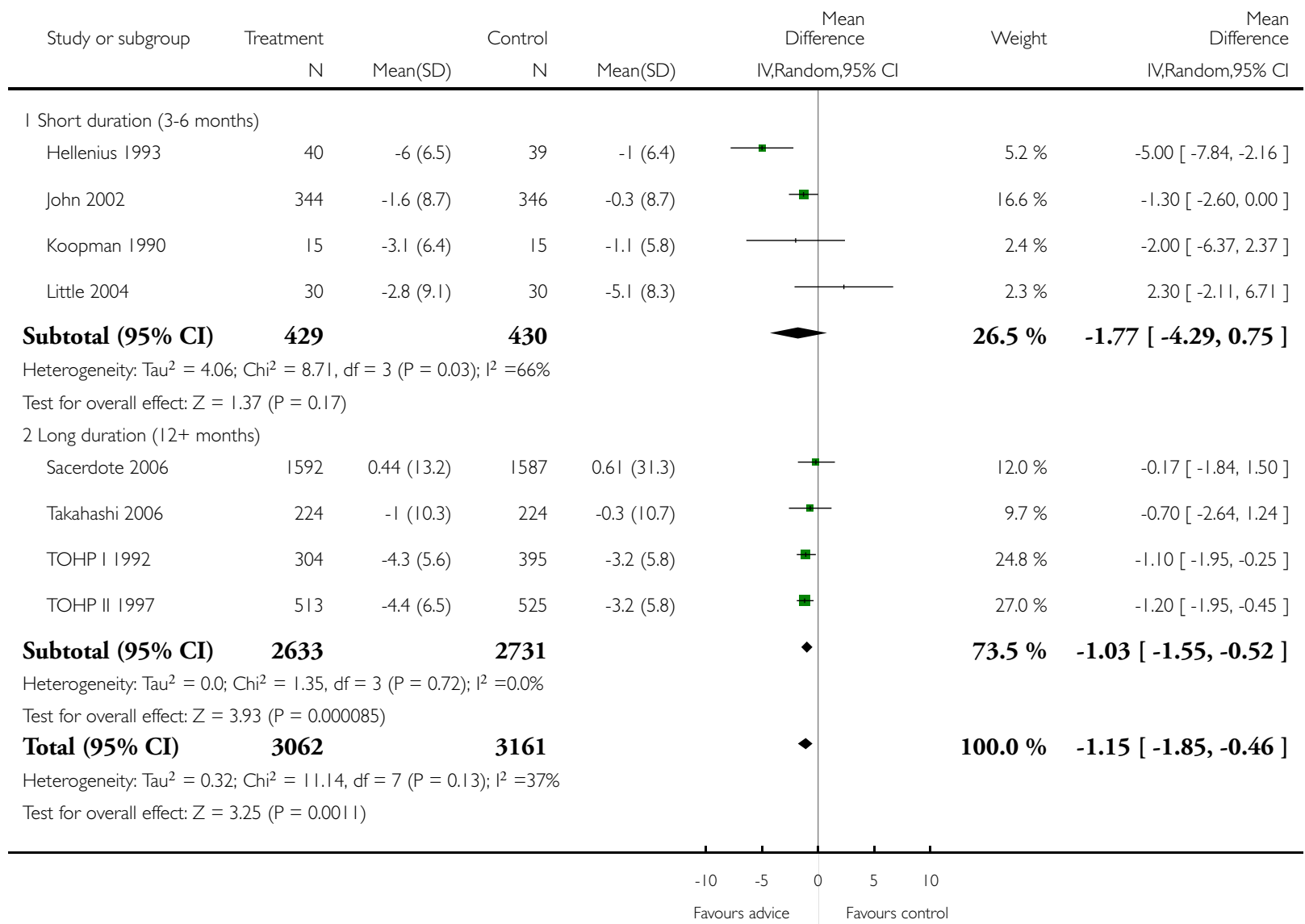

\section{ADDITIONAL TABLES}

Table 1. MEDLINE (Ovid) search strategy

\footnotetext{
1 exp Communication/

2 exp Counseling/

3 exp Health Education/

4 Life Style/
}

Copyright @ 2009 The Cochrane Collaboration. Published by John Wiley \& Sons, Ltd. 
Table 1. MEDLINE (Ovid) search strategy (Continued)

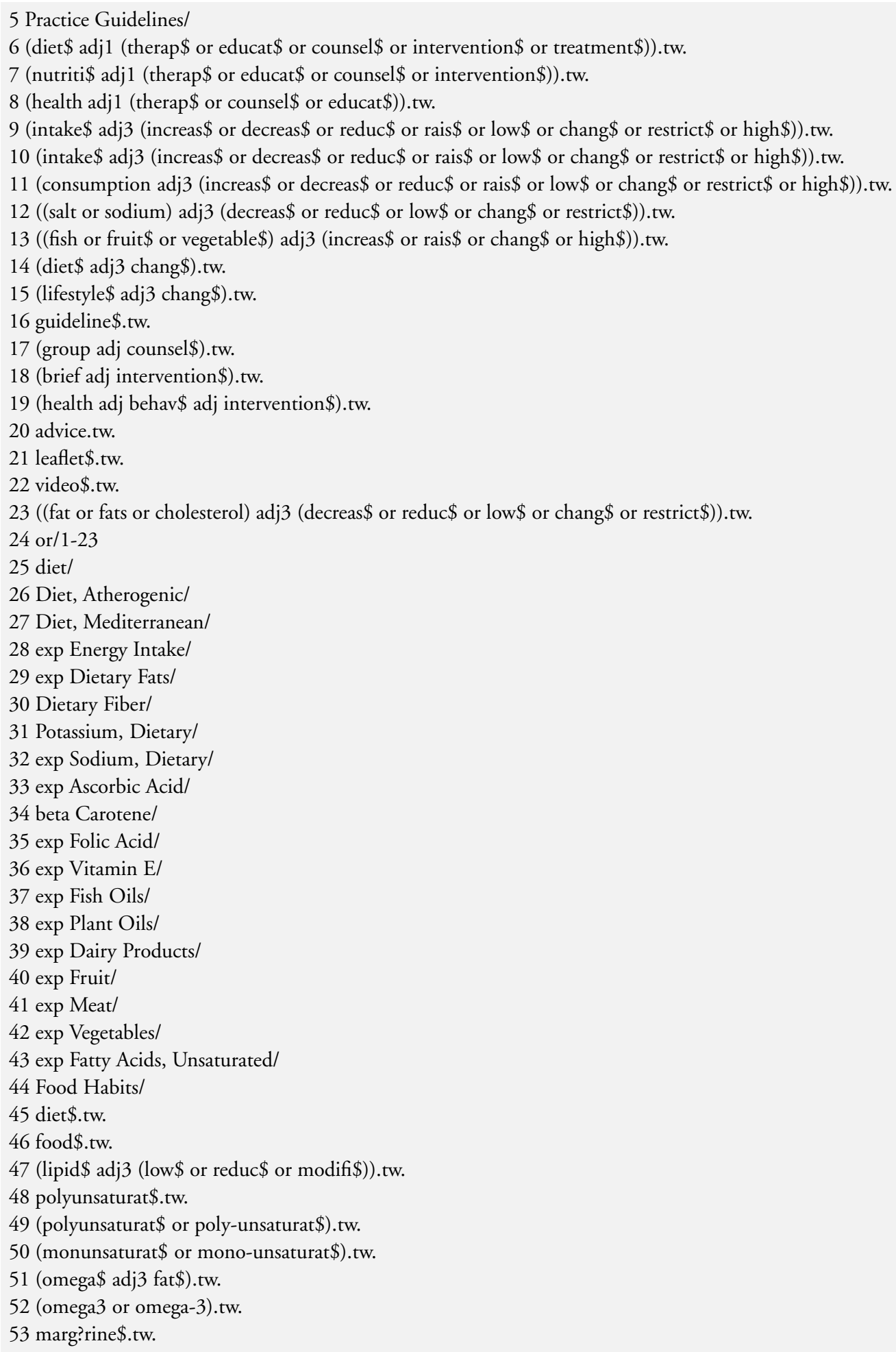

Dietary advice for reducing cardiovascular risk (Review) 
Table 1. MEDLINE (Ovid) search strategy (Continued)

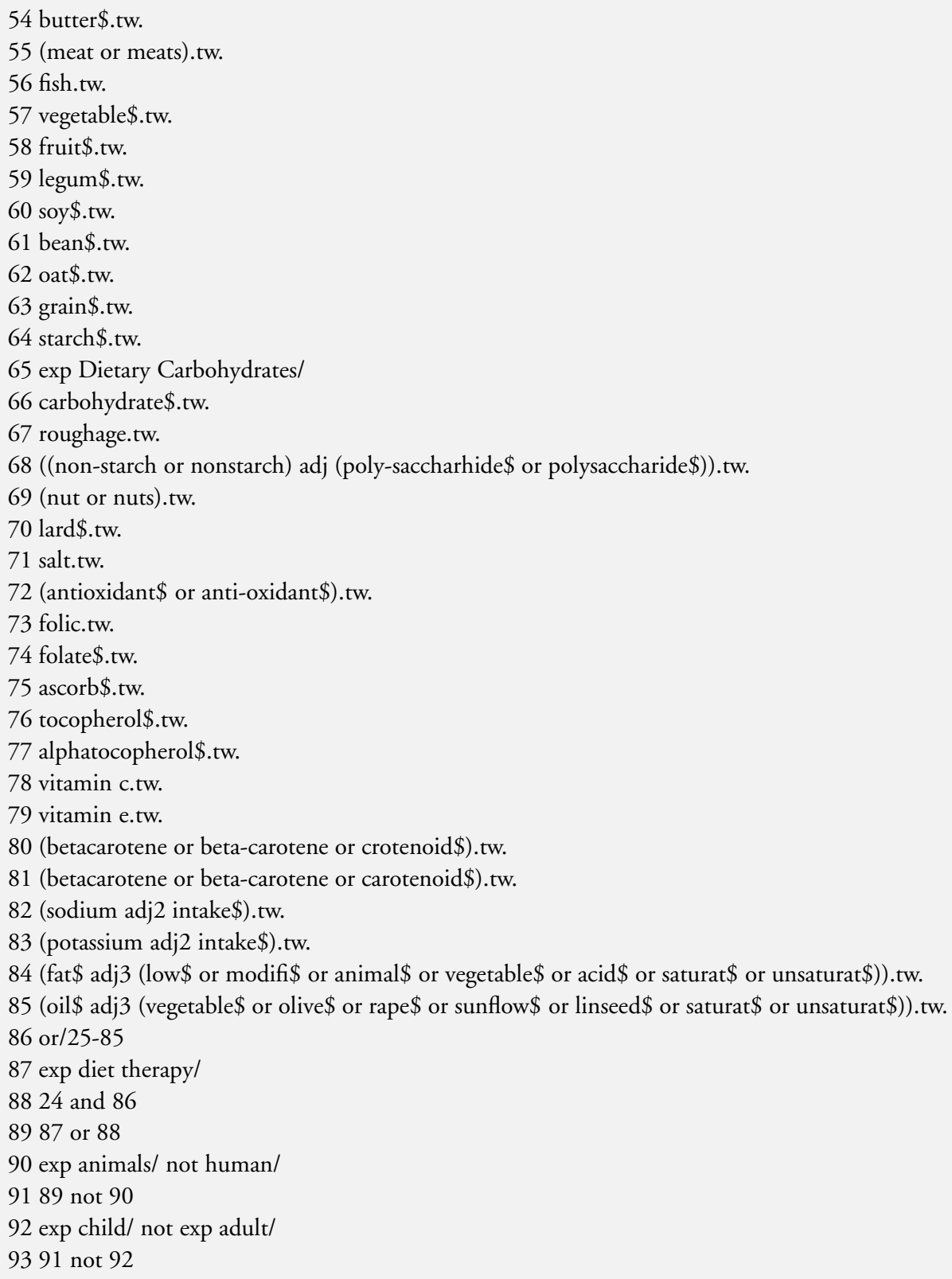

Table 2. EMBASE (Ovid) search strategy

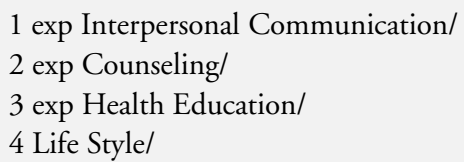

Dietary advice for reducing cardiovascular risk (Review)

Copyright $\odot 2009$ The Cochrane Collaboration. Published by John Wiley \& Sons, Ltd. 


\section{Table 2. EMBASE (Ovid) search strategy (Continued)}

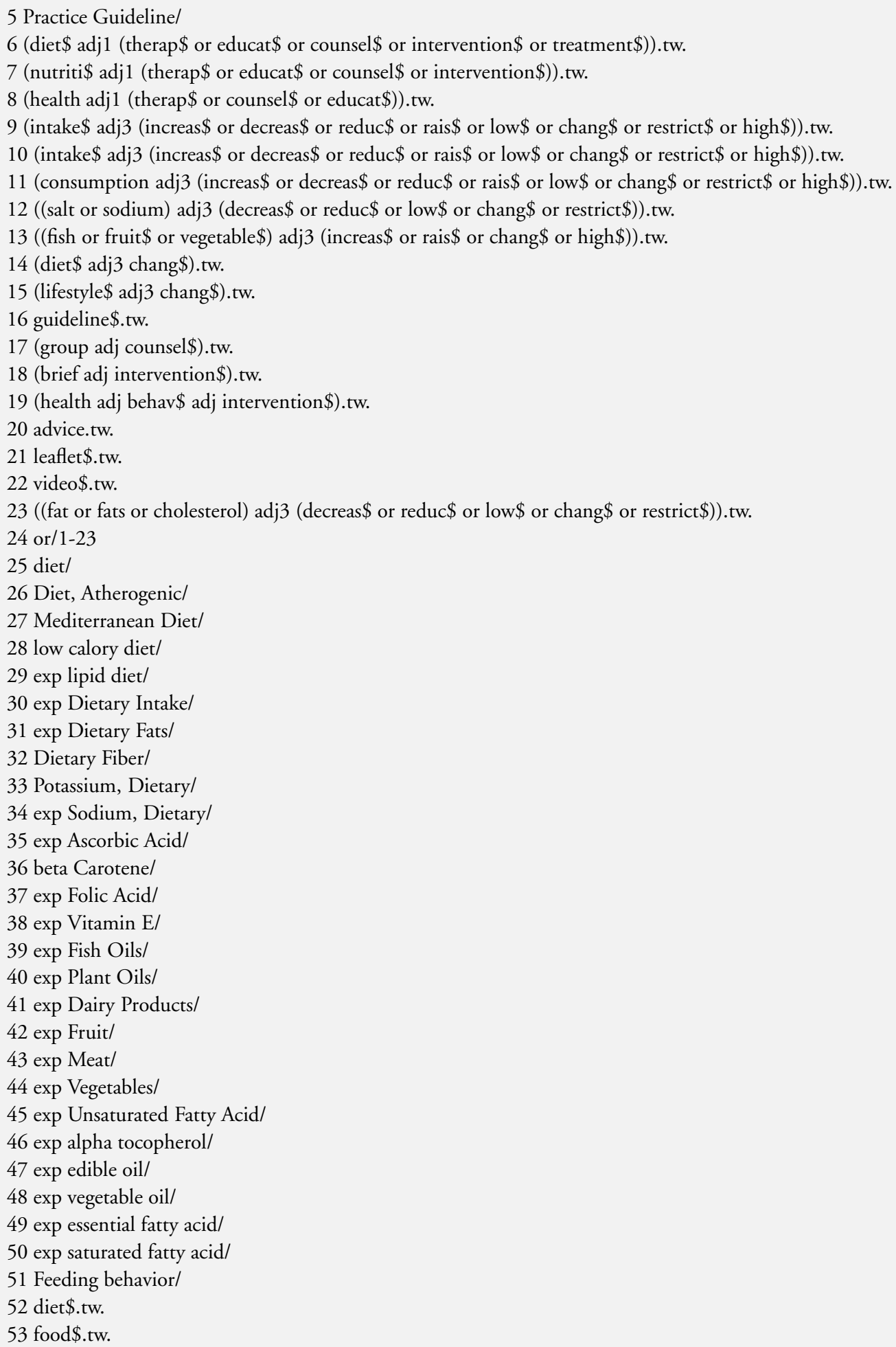




\section{Table 2. EMBASE (Ovid) search strategy (Continued)}

54 (lipid\$ adj3 (low\$ or reduc\$ or modifis)).tw.

55 polyunsaturat $\$$.tw.

56 (polyunsaturat\$ or poly-unsaturat\$).tw.

57 (monunsaturat\$ or mono-unsaturat\$).tw.

58 (omega $\$$ adj 3 fat $\$$ ).tw.

59 (omega3 or omega-3).tw.

60 marg? rine $\$$.tw.

61 butter\$.tw.

62 (meat or meats).tw.

63 fish.tw.

64 vegetable\$.tw.

65 fruit\$.tw.

66 legum\$.tw.

67 soy\$.tw.

68 bean\$.tw.

69 oat\$.tw.

70 grain\$.tw.

71 starch\$.tw.

72 exp Dietary Carbohydrates/

73 carbohydrate\$.tw.

74 roughage.tw.

75 ((non-starch or nonstarch) adj (poly-saccharhide\$ or polysaccharide\$)).tw.

76 (nut or nuts).tw.

77 lard\$.tw.

78 salt.tw.

79 (antioxidant\$ or anti-oxidant\$).tw.

80 folic.tw.

81 folate $\$ . t w$.

82 ascorb\$.tw.

83 tocopherol\$.tw.

84 alphatocopherol\$.tw.

85 vitamin c.tw.

86 vitamin e.tw.

87 (betacarotene or beta-carotene or crotenoid\$).tw.

88 (betacarotene or beta-carotene or carotenoid\$).tw.

89 (sodium adj2 intake\$).tw.

90 (potassium adj2 intake\$).tw.

91 (fat $\$$ adj3 (low $\$$ or modifi $\$$ or animal $\$$ or vegetable $\$$ or acid $\$$ or saturat $\$$ or unsaturat $\$$ )).tw.

92 (oil $\$$ adj3 (vegetable $\$$ or olive $\$$ or rape $\$$ or sunflow\$ or linseed $\$$ or saturat $\$$ or unsaturat $\$$ )).tw.

93 or/25-92

94 exp diet therapy/

9524 and 93

9694 or 95

97 exp child/ not Adult/

9896 not 97

Dietary advice for reducing cardiovascular risk (Review) 
Table 3. Methodological quality of included studies

\begin{tabular}{|c|c|c|c|c|}
\hline Study ID & Randomisation & Alloc. concealment & Blinding? & Loss to follow-up \\
\hline Anderson & $\begin{array}{l}\text { Stratified systematic ran- } \\
\text { dom procedure }\end{array}$ & Unclear & Unclear & $\begin{array}{l}17.5 \% \text { loss to follow-up } \\
\text { over } 12 \text { months }\end{array}$ \\
\hline Baron & Unclear & Unclear & Unclear & $\begin{array}{l}18 \% \text { loss to follow-up at } \\
3 \text { months }\end{array}$ \\
\hline Beresford & Random numbers & Unclear. & $\begin{array}{l}\text { Interviewer and partici- } \\
\text { pants blind to group allo- } \\
\text { cation }\end{array}$ & $\begin{array}{l}14 \% \text { of individuals lost to } \\
\text { follow-up over } 12 \text { months }\end{array}$ \\
\hline Bloemberg & Unclear & Unclear & Outcome assessors & $\begin{array}{l}1 \% \text { loss to follow-up over } \\
6 \text { months }\end{array}$ \\
\hline Brekke & $\begin{array}{l}\text { Minimisation method for } \\
\text { small clinical trials (Alt- } \\
\text { man) to balance a large } \\
\text { number of strata }\end{array}$ & Unclear & Unclear & $\begin{array}{l}8.5 \% \text { of individuals lost } \\
\text { to follow-up over } 12 \\
\text { months }\end{array}$ \\
\hline Buller & Unclear & $\begin{array}{l}\text { Adequate. Project statisti- } \\
\text { cian }\end{array}$ & Unclear & $\begin{array}{l}\text { Clusters analysed, but re- } \\
\text { sponse rate to follow- } \\
\text { up surveys for individuals } \\
\text { only } 64 \% \text { at } 6 \text { months }\end{array}$ \\
\hline Cheng & Random number table & Unclear & Unclear & $\begin{array}{l}16 \% \text { of individuals lost to } \\
\text { follow-up at } 4 \text { months }\end{array}$ \\
\hline Coates WHR MP & Unclear & Unclear & Unclear & $\begin{array}{l}19 \% \text { of the interven- } \\
\text { tion group lost to follow- } \\
\text { up at } 6 \text { months, at } 12 \\
\text { months loss to follow-up } \\
\text { was } 33 \% \text {, at } 2 \text { years } 76 \%\end{array}$ \\
\hline Cox & Lottery method & Unclear & Unclear & $\begin{array}{l}\text { None reported from the } \\
\text { CVD arm of the trial }\end{array}$ \\
\hline Djuric & Unclear & Unclear & Unclear & $\begin{array}{l}16.3 \% \text { of individuals lost } \\
\text { to follow-up over } 12 \\
\text { months, } 37 \% \text { at } 2 \text { years. } \\
\text { Data were analysed at } 12 \\
\text { months }\end{array}$ \\
\hline Elder & Unclear & Unclear & Unclear & $\begin{array}{l}12.3 \% \text { loss to follow-up } \\
\text { at } 12 \text { weeks, } 21.5 \% \text { at } 12 \\
\text { months. Data have been } \\
\text { analysed at } 12 \text { weeks }\end{array}$ \\
\hline
\end{tabular}

Dietary advice for reducing cardiovascular risk (Review) 
Table 3. Methodological quality of included studies (Continued)

\begin{tabular}{|c|c|c|c|c|}
\hline Fuemmeler & Unclear & Unclear & Unclear & $\begin{array}{l}\text { Clusters analysed, no loss } \\
\text { of clusters, } 16 \% \text { of indi- } \\
\text { viduals lost to follow-up } \\
\text { over } 12 \text { months }\end{array}$ \\
\hline Gann & Random number table & Unclear & Unclear & $\begin{array}{l}16.9 \% \text { of individuals lost } \\
\text { to follow-up over } 12 \\
\text { months }\end{array}$ \\
\hline Havas & Unclear & Unclear & Unclear & $\begin{array}{l}\text { I of } 16 \text { sites excluded - } 6 \text {. } \\
25 \%\end{array}$ \\
\hline Hellenius & Unclear & Unclear & Unclear & $\begin{array}{l}2 \% \text { loss to follow-up over } \\
6 \text { months }\end{array}$ \\
\hline Henderson WHT V & Unclear & Unclear & Unclear & $\begin{array}{l}5.3 \% \text { loss to follow-up } \\
\text { over } 24 \text { months }\end{array}$ \\
\hline John & $\begin{array}{l}\text { Computer generated ran- } \\
\text { domisation list }\end{array}$ & Unclear & Unclear & $\begin{array}{l}7.7 \% \text { of } \\
\text { individuals lost to follow- } \\
\text { up over } 6 \text { months }\end{array}$ \\
\hline Keyserling & Unclear & Unclear & Unclear & $\begin{array}{l}8 \% \text { loss to follow-up for } \\
\text { blood analyses }\end{array}$ \\
\hline Koopman & Unclear & Unclear & Unclear & $\begin{array}{l}14 \% \text { loss to follow-up } \\
\text { over } 3 \text { months }\end{array}$ \\
\hline Kristal & Unclear & Unclear & Unclear & $\begin{array}{l}13.5 \% \text { loss to follow-up } \\
\text { over } 12 \text { months }\end{array}$ \\
\hline Little & Random number table & $\begin{array}{l}\text { Adequate - opaque sealed } \\
\text { envelopes }\end{array}$ & Unclear & $\begin{array}{l}14 \% \text { lost to follow-up for } \\
\text { prompt plus salt and con- } \\
\text { trol group at } 6 \text { months. } \\
27 \% \text { loss to follow-up in } \\
\text { the prompt group - these } \\
\text { data were excluded }\end{array}$ \\
\hline Lutz & Unclear & Unclear & Unclear & $\begin{array}{l}19 \% \text { loss to follow-up at } \\
6 \text { months }\end{array}$ \\
\hline Maskarinec & Unclear & Unclear & Unclear & $\begin{array}{l}12 \% \text { loss to follow-up } \\
\text { over } 6 \text { months }\end{array}$ \\
\hline Moy & Unclear & Unclear & Unclear & $\begin{array}{l}23 \% \text { lost to follow-up } \\
\text { over } 12 \text { months but au- } \\
\text { thors used ITT analysis }\end{array}$ \\
\hline
\end{tabular}

Dietary advice for reducing cardiovascular risk (Review) 
Table 3. Methodological quality of included studies (Continued)

\begin{tabular}{|c|c|c|c|c|}
\hline Neil & $\begin{array}{l}\text { List of consecutive ran- } \\
\text { dom treatment assign- } \\
\text { ments }\end{array}$ & Unclear & Outcome assessors & $9.7 \%$ loss to follow-up \\
\hline Riddell & Unclear & Unclear & Unclear & $\begin{array}{l}4.5 \% \text { loss to follow-up at } \\
12 \text { weeks }\end{array}$ \\
\hline Rock & Unclear & Unclear & Unclear & $\begin{array}{l}5.4 \% \text { of } \\
\text { individuals lost to follow- } \\
\text { up over } 6 \text { months }\end{array}$ \\
\hline Sacerdote & $\begin{array}{l}\text { Random numbers gener- } \\
\text { ated by computer }\end{array}$ & Unclear & Outcome assessors & $\begin{array}{l}6.4 \% \text { lost to follow-up } \\
\text { over } 12 \text { months }\end{array}$ \\
\hline Schatzkin & $\begin{array}{l}\text { Computer program of } \\
\text { random numbers }\end{array}$ & $\begin{array}{l}\text { Adequate. Telephone co- } \\
\text { ordinating centre }\end{array}$ & Unclear & $\begin{array}{l}8.4 \% \text { loss to follow-up } \\
\text { over } 4 \text { years }\end{array}$ \\
\hline Smith-Warner & Unclear & Unclear & Unclear & $\begin{array}{l}8 \% \text { loss to follow-up at } 12 \\
\text { months }\end{array}$ \\
\hline Sorensen & Unclear & Unclear & Unclear & $\begin{array}{l}3.9 \% \text { individuals lost to } \\
\text { follow-up at } 19.5 \text { months }\end{array}$ \\
\hline Stevens & Unclear & Unclear & Unclear & $\begin{array}{l}13 \% \text { lost to follow-up } \\
\text { over } 12 \text { months }\end{array}$ \\
\hline Takahashi & Unclear & Unclear & Unclear & $\begin{array}{l}2.9 \% \text { loss to follow-up for } \\
\text { questionnaire based out- } \\
\text { comes, } 17.2 \% \text { for blood } \\
\text { pressure outcomes over } \\
12 \text { months }\end{array}$ \\
\hline Tilley & Random number table & Unclear & Unclear & $\begin{array}{l}1.6 \% \text { individuals lost to } \\
\text { follow-up at } 12 \text { months, } \\
3.5 \% \text { at } 24 \text { months }\end{array}$ \\
\hline TOHP I & Unclear & Unclear & Outcome assessors & $\begin{array}{l}20 \% \text { loss to follow-up } \\
\text { over } 12 \text { months }\end{array}$ \\
\hline TOHP II & Unclear & $\begin{array}{l}\text { Adequate. Telephone co- } \\
\text { ordinating centre or } \\
\text { opaque envelopes }\end{array}$ & Outcome assessors & $\begin{array}{l}7.5 \% \text { loss to follow-up at } \\
18 \text { months }\end{array}$ \\
\hline van der Veen & Unclear & Unclear & Unclear & $\begin{array}{l}\text { Clusters analysed, no loss } \\
\text { of clusters but } 9 \% \text { of indi- } \\
\text { viduals lost to follow-up } \\
\text { over } 12 \text { months }\end{array}$ \\
\hline
\end{tabular}

Dietary advice for reducing cardiovascular risk (Review) 
Table 4. Initial mean level of risk factors in control group of included studies

\begin{tabular}{|c|c|c|}
\hline Study ID & Cholesterol mmol/l & Blood pressure mmHg \\
\hline Anderson 1992 & 5.9 & not available \\
\hline Baron 1990 men & 4.8 & not available \\
\hline Baron 1990 women & 4.9 & not available \\
\hline Bloemberg 1991 & 7.0 & not available \\
\hline Brekke 2005 & 4.95 & not available \\
\hline Coates 1999 HT MP & 5.7 & not available \\
\hline Cheng 2004 & 6.0 & not available \\
\hline Djuric 2006 & 4.43 & not available \\
\hline Hellenius 1993 & 6.0 & $130 / 82$ \\
\hline John 2002 & 5.12 & $129 / 80$ \\
\hline Keyserling 1997 & 6.5 & not available \\
\hline Koopman 1990 & not available & $144 / 95$ \\
\hline Little 2004 & not available & $154 / 93$ \\
\hline Moy 2001 & not available & not available \\
\hline Neil 1995 & 7.4 & not available \\
\hline Sacerdote 2006 & not available & $129 / 79$ \\
\hline Stevens 2003 & 6.01 & not available \\
\hline Takahashi 2006 & not available & $128 / 76$ \\
\hline TOHP I & not available & $125 / 84$ \\
\hline TOHP II 1997 & not available & $127 / 86$ \\
\hline van der Veen 2002 & 6.6 & not available \\
\hline
\end{tabular}




\section{WHAT'S NEW}

Last assessed as up-to-date: 29 July 2007.

\begin{tabular}{l|l|l}
\hline Date & Event & Description \\
\hline 8 September 2008 & Amended & Converted to new review format. \\
\hline
\end{tabular}

\section{H I S T O R Y}

Protocol first published: Issue 2, 2000

Review first published: Issue 4, 2005

\begin{tabular}{lll}
\hline Date & Event & Description \\
\hline 30 July 2007 & New citation required and conclusions have changed & Substantive amendment \\
\hline
\end{tabular}

\section{CONTRIBUTIONSOFAUTHORS}

Eric Brunner, Margaret Thorogood and Karen Rees wrote the original review.

For the update:

Karen Rees selected studies, abstracted data, analysed the data and co-wrote the review

Kirsten Ward selected studies and abstracted data

Margaret Burke ran the searches

Eric Brunner selected studies, gave advice and co-wrote the review

\section{DECLARATIONSOF INTEREST}

None known.

\section{SOURCESOFS UPPORT}




\section{Internal sources}

- Department of Epidemiology and Public Health, University College London, UK.

- University of Warwick Medical School, UK.

- Department of Epidemiology and Population Health, London School of Hygiene and Tropical Medicine, UK.

\section{External sources}

- Coronary Prevention Group, UK.

- Department of Health Cochrane Review Incentive Scheme 2006, UK.

\section{INDEX TERMS}

\section{Medical Subject Headings (MeSH)}

*Diet; Cardiovascular Diseases [*prevention \& control]; Cholesterol [blood]; Diet, Fat-Restricted; Dietetics [*methods]; Randomized Controlled Trials as Topic

\section{MeSH check words}

Humans 